\title{
SUBDUCTION DYNAMICS AT THE MIDDLE AMERICA TRENCH: NEW CONSTRAINTS FROM SWATH BATHYMETRY, MULTICHANNEL SEISMIC DATA, AND ${ }^{10} \mathrm{BE}$
}

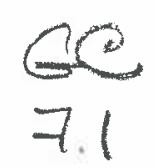

By

Robyn K. Kelly

B.S., Geology/Chemistry, University of South Carolina, 1997

Submitted in partial fulfillment of the requirements for the degree of

Doctor of Philosophy

at the

Massachusetts Institute of Technology

and the

and the

September 2003

(C) 2003 Robyn K. Kelly

All rights reserved.

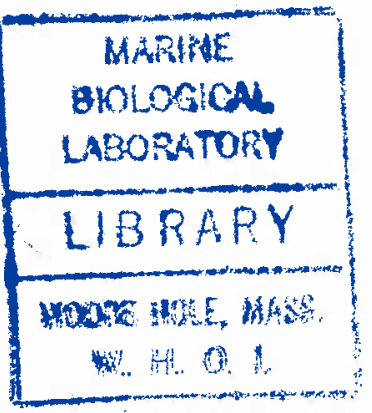

The author hereby grants to MIT and WHOI permission to reproduce paper and electronic copies of this thesis in whole or in part and to distribute them publicly.

Signature of Author

Joint Prograrb in Qceanography, Mas $\$ a c h u s e t t s$ Institute of Technology and Woods Hofle Oqeano raphic Institution,

September 2003

Certified by

Peter Clift, Associate Scientist

Thesis Advisor

Accepted by

Dan C. McCorkle

Chair, Joint Committee for Marine Geology and Geophysics

Woods Hole Oceanographic Institution 
This thesis is dedicated to my parents 


\section{Acknowledgements}

It's hard to believe that this has all come to a close. I'm sure it will sink in eventually, but in the meantime I find it difficult to anticipate what life will be like without the Joint Program, and without the many people who have made my experience here so enjoyable. First of course, I owe a huge debt of gratitude to my advisor for the last six years, Neal Driscoll. He has been incredibly supportive and encouraging throughout my graduate tenure, and he is one of the primary reasons that I successfully made it through to the end. I must also thank my advisor Peter Clift, who came into the middle of my project but really made the effort to be a great source of advice, a patient sounding board, and a fabulous field trip leader. My committee members Stan Hart, Peter Kelemen, Mark Kurz, and Wiki Royden have also provided me with a diverse array of scientific input. Stan was always around for whatever questions I had, Peter K. generously shared his time in working with me on getting my first paper published, and Mark was an ideal defense chair. Thanks also to the WHOI scientists as a whole, who always have an open door policy for grad students.

I would also like to thank the many colleagues who have made my thesis possible by sharing data, their time, and their lab space. My eternal gratitude to Julie Morris, Kirk McIntosh, Eli Silver, John Goff, Robbie Valentine, Cesar Ranero, Roland von Huene, Geoff Wheat, Andy Fisher, and all the fellow participants on my many cruises who have been crucial to the success of my research.

The G\&G staff and the Academic Programs Office have been invaluable to helping me get through the day to day tasks. Pam, Diane, and Maryanne have always answered even my silliest questions, and they haven't hesitated to help me with all things large and small. John, Judy, Julia, and Marsha are without compare. There is no other graduate program anywhere that has such a strong foundation. The incredible consideration shown to graduate students here is all because of them. They truly spoil us.

Finally, friends and family, about whom there just isn't enough space to gush. My parents and brothers are the most loving family anyone could ask for. My extended 
family, Grandma, aunts, uncles, and cousins, made family get-togethers always something to look forward to. Grandma, thank you so much for taking care of me these last six years. Home cooked meals were the perfect antidote to homesickness. Uncle Mike, you'll probably never read this, but you have been a second dad. I'll miss you lots. You and Maureen were the coolest parents at my dance recitals. Carolyn, thank you for being the best friend that I could have imagined. If I'll miss anything about grad school, it will be you. Steph, thanks for being such a great housemate. Tracy, we never got to go out dancing enough, but when we did it was a trip. Fernanda and Amy D., what would Norway have been without you guys? I will miss all of you. Thanks to all the G\&G students past and present who have made the last six years so much fun.

And, most importantly, Ian. Though I thankfully won't have to miss you any longer since we will now finally be in the same state (yay me!), you have been the best part of the last two years, and, well, pretty much the last twenty-seven as well. Loofah.

Funding for this work was provided by the National Science Foundation Graduate Research Fellowship, the WHOI Ocean Ventures Fund, the WHOI Deep Ocean Institute Graduate Fellowship, and Geological Society of America Graduate Research Grant \#7179-02. 


\section{Table of Contents}

ABSTRACT

Chapter I. Subduction dynamics at the Middle America Trench:

New Constraints from Swath Bathymetry, Multichannel Seismic

Data, and ${ }^{10} \mathrm{Be}$

13

Background and Motivation $\quad 13$

$\begin{array}{ll}\text { Thesis Organization } & 17\end{array}$

$\begin{array}{ll}\text { Figure } & 20\end{array}$

$\begin{array}{ll}\text { References } & 22\end{array}$

Chapter II. New ${ }^{10}$ Be and Bathymetric Constraints on

Sediment Recycling in Central America $\quad 25$

$\begin{array}{ll}\text { Abstract } & 25\end{array}$

Introduction $\quad 26$

Geologic Setting $\quad 27$

Data and Methods $\quad 29$

$\begin{array}{ll}\text { Results } & 30\end{array}$

Discussion $\quad 31$

Conclusions 33

Acknowledgements $\quad 34$

Table 35

$\begin{array}{ll}\text { Figures } & 36\end{array}$

References $\quad 44$

Chapter III. Cocos Plate Morphology at the Middle

America Trench: Implications for ${ }^{10}$ Be Recycling 47

$\begin{array}{ll}\text { Abstract } & 47\end{array}$ 
$\begin{array}{ll}\text { Introduction } & 48\end{array}$

Distribution of ${ }^{10} \mathrm{Be}$ in Arc Volcanic Rocks $\quad 50$

Geologic Setting $\quad 52$

${ }^{10} \mathrm{Be}$ Input to the Trench

Cocos and Caribbean Plate Characteristics $\quad 53$

Crustal Faulting in the Cocos Plate at the Middle America

$\begin{array}{ll}\text { Trench } & 56\end{array}$

Methods $\quad 57$

Middle America Trench Morphology 61

RMS Height, Azimuth, and Characteristic Width 0-25 km from the Trench

Bathymetric Deflection of the Plate at the Trench 64

Shoaling of the Trench as a Lateral Response to Buoyancy 66

Fault Morphology with Distance from the Trench 68

Deformation in the Lower Forearc Slope 69

$\begin{array}{ll}\text { The Central American Volcanic Arc } & 71\end{array}$

$\begin{array}{ll}\text { Elements from the Slab } & 72\end{array}$

Regional Variations in Arc Geochemistry 73

${ }^{10}$ Be Mobility in Fluids $\quad 75$

${ }^{10}$ Be Transfer to the Central American Volcanic Arc:

Fluid vs. Melt

${ }^{10}$ Be: Implications for Sediment Recycling $\quad 79$

Transitions in ${ }^{10} \mathrm{Be}$ and Fault Relief $\quad 79$

Shallow Sediment ${ }^{10}$ Be Removal Via Underplating 84

Underplating vs. Tectonic Erosion 86

$\begin{array}{ll}\text { Conclusions } & 90\end{array}$

$\begin{array}{ll}\text { Tables } & 93\end{array}$

$\begin{array}{ll}\text { Figures } & 100\end{array}$

$\begin{array}{ll}\text { References } & 166\end{array}$ 


\section{Chapter IV. ${ }^{10}$ Be Variability in Surficial Sediments at the}

\section{Middle America Trench 181}

$\begin{array}{ll}\text { Abstract } & 181\end{array}$

Introduction 182

Methods 183

Sample Selection 183

Isotopic, Major, and Trace Element Analysis $\quad 184$

Contamination in Vema Cores 186

Middle America Trench/Central American Volcanic Arc System 188

Middle America Trench Sediment 188

${ }^{10}$ Be Concentrations Along the Middle America Trench 189

Implications for Arc Volcanic ${ }^{10}$ Be 195

Proximity to Trench 196

Summary 197

Local Influences on ${ }^{10} \mathrm{Be}$ in Surficial Middle America Trench Sediment 198

${ }^{10}$ Be Depositional Systematics 198

Geochemical Characteristics of Surficial Middle America Trench

Sediments 200

${ }^{10}$ Be Associations in the Middle America Trench Region

Grain Size and ${ }^{10} B e \quad 201$

Conclusions 206

Tables 208

Figures 220

$\begin{array}{ll}\text { References } & 276\end{array}$

$\begin{array}{ll}\text { Chapter V. Summary } & 281\end{array}$

${ }^{10} \mathrm{Be}$ in the Central American Volcanic Arc $\quad 281$

$\begin{array}{ll}\text { Future Work } & 284\end{array}$ 
References

Appendix 1. Core Descriptions

Appendix 2. Buoyancy Of The Continental Upper Mantle 


\title{
Subduction Dynamics at the Middle America Trench: New Constraints from Swath Bathymetry, Multichannel Seismic Data, and ${ }^{10} \mathrm{Be}$
}

\author{
Robyn Kelly
}

\begin{abstract}
The cosmogenic radionuclide ${ }^{10} \mathrm{Be}$ is a unique tracer of shallow sediment subduction in volcanic arcs. The range in ${ }^{10} \mathrm{Be}$ enrichment in the Central American Volcanic Arc between Guatemala and Costa Rica is not controlled by variations in ${ }^{10} \mathrm{Be}$ concentrations in subducting sediment seaward of the Middle America Trench. Sedimentary ${ }^{10} \mathrm{Be}$ is correlated negatively with ${ }^{143} \mathrm{Nd} /{ }^{144} \mathrm{Nd}$, illustrating that ${ }^{10} \mathrm{Be}$ concentrations varied both between and within cores due to mixing between terrigenous clay and volcanic ash endmember components. This mixing behavior was determined to be a function of grain size controls on ${ }^{10} \mathrm{Be}$ concentrations. A negative correlation of bulk sedimentary ${ }^{10} \mathrm{Be}$ concentrations with median grain size and a positive correlation with the proportion of the sediment grains that were $<32 \mu \mathrm{m}$ in diameter demonstrated that high concentrations of ${ }^{10} \mathrm{Be}$ in fine-grained, terrigenous sediments were diluted by larger grained volcanogenic material.

The sharp decrease in ${ }^{10} \mathrm{Be}$ enrichment in the Central American Volcanic Arc between southeastern Nicaragua and northwestern Costa Rica correlates with changes in fault structure in the subducting Cocos plate. Offshore of Nicaragua, extensional faults associated with plate bending have throw equal to or greater than the overlying subducting sediment thickness. These faults enable efficient subduction of the entire sediment package by preventing relocation of the décollement within the downgoing sediments. Offshore of Costa Rica, the reduction of fault relief results in basement faults that do not penetrate the overlying sediment. A conceptual model is proposed in which the absence of significant basement roughness allows the décollement to descend into the subducting sediment column, leading to subsequent underplating and therefore removal of the bulk of the sediment layer that contains ${ }^{10} \mathrm{Be}$.

Basement fault relief was linearly related to plate curvature and trench depth. The systematic shoaling of the plate from southeastern Nicaragua to northwestern Costa Rica is not explained by changes in plate age for this region. Instead, it is hypothesized that the flexural shape of the plate offshore of southeastern Nicaragua and northwestern Costa Rica represents a lateral response to a buoyant load caused by the thick crust and elevated thermal regime in the Cocos plate offshore of southeastern Costa Rica.
\end{abstract}




\section{Chapter I}

\section{Subduction Dynamics at the Middle America Trench: New Constraints from Swath Bathymetry, Multichannel Seismic Data, and ${ }^{10} \mathrm{Be}$}

\section{Background and Motivation}

Subduction zones control geochemical recycling between different earth reservoirs. The complex relationships between slab and sediment geochemistry, fault structure, and their secondary effects such as volatile input, dehydration reactions, and sediment dynamics (accretion, tectonic erosion, or subduction) play a crucial role in the global distribution of geochemical constituents. These interconnected mechanisms of recycling in turn influence the behavior of the seismogenic zone and arc magma genesis and evolution, making the study of subduction zones socially relevant to assess potential catastrophic hazards such as earthquakes, tsunamis, and volcanism. The goal of this thesis research was to focus on the processes governing recycling of an integral tracer of sediment subduction at convergent margins, providing a building block that will contribute to our broader comprehension of these important tectonic systems.

${ }^{10} \mathrm{Be}$ is a cosmogenic radionuclide generated from cosmic ray spallation reactions on oxygen and nitrogen in the atmosphere. As ${ }^{10} \mathrm{Be}$ has a relatively short half-life of $1.5 \mathrm{x}$ $10^{6}$ yrs (Yiou and Raisbeck, 1972), it is only found in significant concentrations in the upper tens of meters of marine sediment. Enriched concentrations of ${ }^{10} \mathrm{Be}$ have been detected in arc volcanic lavas, but not in other mantle-derived rocks such as MORB, OIB, and continental flood basalts (Brown et al., 1982; Tera et al., 1986; Ryan and Langmuir, 1988; Monaghan et al., 1988; Morris and Tera, 1989; Morris et al., 1990). ${ }^{10} \mathrm{Be}$ was therefore recognized as an important tracer of sediment subduction in arc petrogenesis because its presence in arc lavas implies subduction of surficial sediments to the roots of the arc system (e.g., Tera et al., 1986; Morris et al., 1990).

The use of arc volcanic ${ }^{10} \mathrm{Be}$ as a tracer of sediment subduction is predicated upon the assumption that the sole source of the ${ }^{10} \mathrm{Be}$ is marine sediments that have been incorporated into arc lavas during subduction. Therefore, systematic examinations of the 
mechanisms by which ${ }^{10} \mathrm{Be}$ could be concentrated in these rocks were conducted to determine that variations in young, subducting sediment were the likely source of arc volcanic ${ }^{10} \mathrm{Be}$ variability (e.g., Tera et al., 1986; Monaghan et al., 1988; Ryan and Langmuir, 1988; Morris and Tera, 1989). By normalizing ${ }^{10} \mathrm{Be}$ to its stable isotope ${ }^{9} \mathrm{Be}$, effects from partial melting and fractional crystallization could be eliminated. Whole rock and mineral separate studies of ${ }^{10} \mathrm{Be} /{ }^{9} \mathrm{Be}$ ratios revealed constant ratios between phases within the same arc lava sample, implying that the ratio was imparted prior to crystallization, inconsistent with contamination of ${ }^{10} \mathrm{Be}$ by post-eruptive surface alteration (Monaghan et al., 1988; Ryan and Langmuir, 1988; Morris and Tera, 1989). Nor did ${ }^{10} \mathrm{Be}$ concentrations in arc lavas vary with degree of alteration (Tera et al., 1986). Additionally, the low concentrations of ${ }^{10} \mathrm{Be}$ in rain water and groundwater $\left(\leq 1 \times 10^{4}\right.$ atom/g; e.g., Pavich et al., 1985; Monaghan et al., 1983) relative to arc rocks would necessitate high water:rock ratios $(\sim 100)$, unrealistic for these environments, to produce the $>10^{6}$ atom $/ \mathrm{g}$ concentrations of arc lavas (Tera et al., 1986).

Arc lavas measured for ${ }^{10} \mathrm{Be}$ analysis are also too young to have built up large amounts of ${ }^{10} \mathrm{Be}$ via cosmic ray bombardment or alteration processes (Tera et al., 1986; Morris and Tera, 1989). Old, moderately altered lavas unassociated with subduction do not contain ${ }^{10} \mathrm{Be}$ in measurable quantities. Even for highly weathered samples in which the rinds did have ${ }^{10} \mathrm{Be}$ enrichment, the ${ }^{10} \mathrm{Be}$ disappeared when the weathered portion of the sample was removed, which is part of the established analytical procedure for volcanic rocks (Tera et al., 1986). The possibility that ${ }^{10} \mathrm{Be}$ came from near-surface assimilation of sediments was also considered and dismissed in these studies. High ${ }^{10} \mathrm{Be}$ concentrations were found in arcs that do not have young sediments in their edifices (i.e., S. Chile), and Loihi seamount lavas had no ${ }^{10} \mathrm{Be}$ enrichment despite erupting through young, marine sediments (Morris and Tera, 1989). The low to zero ${ }^{10} \mathrm{Be}$ concentrations recorded in arc lavas such as the Cascades, in which the recycling time from trench to volcano is long enough for the subducted sedimentary ${ }^{10} \mathrm{Be}$ signal to have decayed away, is also consistent with a lack of near-surface sediment assimilation (Morris and Tera, 1989). The 
geochemical evidence therefore strongly supports the interpretation that the source of

${ }^{10} \mathrm{Be}$ in arc lavas is subducted marine sediment.

The variations in, and occurrences of, sediment-derived ${ }^{10} \mathrm{Be}$ in volcanic arcs are not well understood in the context of the various competing factors that could influence ${ }^{10} \mathrm{Be}$ subduction recycling. There are four main processes that control ${ }^{10} \mathrm{Be}$ enrichment in arc volcanics: (1) ${ }^{10} \mathrm{Be}$ concentration in the downgoing sediments, (2) convergence rates, (3) geophysical and structural characteristics related to subduction style of the trench system (e.g., offscraping, underplating, tectonic erosion, or complete sediment subduction), and (4) geochemical processes during incorporation of sedimentary ${ }^{10} \mathrm{Be}$ into arc magmas. In the Central American Volcanic Arc (CAVA), major changes in the magnitude of ${ }^{10} \mathrm{Be}$ enrichment are observed along strike of the arc (Figure 1). The wide span of ${ }^{10} \mathrm{Be}$ values from background to highly enriched encompasses almost the entire global range of ${ }^{10} \mathrm{Be}$ concentrations observed in arc volcanics (Tera et al., 1986; Morris and Tera, 1989; Morris et al., 1990). The pattern of enrichment progresses from moderate in Guatemala to high in Nicaragua and then rapidly diminishes toward Costa Rica, which shows little to no enrichment. The abundant geochemical and geophysical data characterizing the arc also serve to make the Middle America Trench/Central American Volcanic Arc system an ideal locale to evaluate the primary processes affecting arc volcanic ${ }^{10} \mathrm{Be}$ enrichment.

The variability of CAVA ${ }^{10} \mathrm{Be}$ enrichment does not appear to relate in a simple fashion to any of the main subduction parameters, such as the thickness of the young trench sediments, the age of the subducting slab, seismicity, dip angle of the slab, and convergence rate (e.g., Carr, 1984; Tera et al., 1986; DeMets et al., 1990; Morris et al., 1990; Protti et al., 1995; Barckhausen et al., 2001). Even other geochemical tracers of the slab contribution to the arc do not uniformly vary with the arc volcanic ${ }^{10} \mathrm{Be}$ (e.g., Morris et al., 1990). Prior to this work, the sharp decrease in ${ }^{10} \mathrm{Be}$ between southeastern Nicaragua and northwestern Costa Rica had not been explained by previous investigations.

The motivation for this work originated in the observation that, in contrast to other subduction parameters, the topography and deformation of the downgoing plate change 
markedly between Nicaragua and Costa Rica (Aubouin et al., 1982; Kimura et al., 1997). Hilde (1983) proposed that normal faulting in a subducting plate leads to graben and horst structures that can protect sediment from erosional processes during subduction. Basement roughness with relief the same size as the overlying subducting sediment thickness can potentially act to inhibit relocation of the décollement within the sediment column, preserving shallow sediment layers for incorporation into arc magmas (Schweller and Kulm, 1978; Hilde, 1983; von Huene and Scholl, 1991).

Large half-grabens were imaged in a multichannel seismic (MCS) line of the downgoing slab offshore of Nicaragua (Crowe and Buffler, 1985). The throws on these extensional faults are equal to or greater than the thickness of the sediment column $(\sim 400$ m) (Ranero et al., 2000). Offshore of Costa Rica, normal faulting in the subducting plate is not as pronounced (Shipley and Moore, 1986; Hinz et al., 1996; Ye et al., 1996; Kimura et al., 1997; Christeson et al., 1999; von Huene et al., 2000). It was therefore thought possible that beneath Nicaragua, large basement faults facilitated efficient subduction of the shallow, ${ }^{10} \mathrm{Be}$-bearing sediment layer to the arc volcanic roots, whereas this absence of fault relief offshore of Costa Rica could lead to removal of the uppermost sediment layer through underplating (Kelly and Driscoll, 1998). High-resolution swath bathymetry and MCS data acquired during R/V Ewing cruise EW0005 (May-June 2000) allowed us to define the relationship between crustal structure and shallow sediment subduction between Nicaragua and Costa Rica.

In addition to comparing the geophysical characteristics of the Cocos plate to the arc volcanic geochemistry, the hypothesis that the variation in ${ }^{10} \mathrm{Be}$ along the arc was not controlled by the initial concentrations of ${ }^{10} \mathrm{Be}$ in the subducting sediment along the trench also needed to be confirmed. The two drill sites seaward of the trench in the region, DSDP Site 495 offshore of Guatemala and ODP Site 1039 offshore of Costa Rica, differ in their ${ }^{10} \mathrm{Be}$ budgets by $\sim 30 \%$ (Valentine et al., 1997). However, the upper sedimentary succession was not recovered at DSDP site 495 ( 19 m; Aubouin et al., 1982), and the top $20 \mathrm{~m}$ at ODP Site 1039 contained a turbidite flow that diluted the ${ }^{10} \mathrm{Be}$ concentrations. 
This variability highlighted the need to conduct further studies of ${ }^{10} \mathrm{Be}$ concentrations in surficial sediments. The surficial sediment composition along the Middle America Trench does not vary significantly immediately seaward of the trench, but other depositional processes may influence the accumulation of ${ }^{10} \mathrm{Be}$. The shallowest sections of the drill cores (the top ten meters) contain $20-30 \%$ of the ${ }^{10} \mathrm{Be}$ budget (Zheng et al., 1994); moreover, the surficial sediments contain the zero-age ${ }^{10} \mathrm{Be}$ concentration, which is a critical value to integrating ${ }^{10} \mathrm{Be}$ over the total sediment column. Therefore, in order to assess the impact of sedimentary variability on the arc volcanic ${ }^{10} \mathrm{Be},{ }^{10} \mathrm{Be}$ concentrations in the uppermost sediments are required to quantify the ${ }^{10} \mathrm{Be}$ budget in the subducting sediments. It is essential to establish the distribution of ${ }^{10} \mathrm{Be}$ in the youngest sediments throughout the region in order to place rigorous constraints on the mass balance of sediment subduction in the region (Tera et al., 1986; Morris and Tera, 1989; Morris et al., 1990).

In April-May 2001, R/V Ewing cruise EW0104, provided the opportunity to sample piston core sediments seaward of the Middle America Trench offshore of the Nicoya Peninsula, Costa Rica. These samples were combined with piston core samples stored at the Lamont-Doherty Earth Observatory Core Repository to examine the geographical and down-core distribution of ${ }^{10} \mathrm{Be}$ concentrations in surficial sediments offshore of Guatemala, El Salvador, Nicaragua, and Costa Rica. Measuring surficial sediment ${ }^{10} \mathrm{Be}$ concentrations along the trench represents a key part of the cooperative effort to constrain the ${ }^{10} \mathrm{Be}$ flux from trench input to volcanic output.

\section{Thesis Organization}

This thesis is divided into three data chapters, all of which were made possible by the collaborative efforts of many scientists at a number of institutions (see Acknowledgements). Throughout, "ka" and "Ma" represent ages or dates, while "yr", "kyr", and "Myr" denote duration of time. Chapter II, for submission to the journal Geology, describes the first-order results of the comparison of a detailed statistical analysis (Goff and Jordan, 1988) of fault relief in the subducting plate offshore of 
Nicaragua and Costa Rica with new and old arc volcanic ${ }^{10} \mathrm{Be}$ data. Chapter III reviews and synthesizes the geophysical and geochemical characteristics of the Middle America Trench/CAVA system in the context of the processes that govern ${ }^{10} \mathrm{Be}$ recycling and enrichment in the arc. The geodynamic causes of the change in fault relief along strike of the trench are also explored by considering the flexural behavior of the subducting plate, with specific emphasis on plate curvature and trench depth and the mechanisms that affect both. The final data chapter, Chapter IV, compares the ${ }^{10} \mathrm{Be}$ variability in the surficial piston core sediments seaward of the Middle America Trench with the variability in the arc. Additionally, the ${ }^{10} \mathrm{Be}$ concentrations are viewed in conjunction with $\mathrm{Sr}$ and $\mathrm{Nd}$ isotopic data, major and trace element concentrations, and grain size measurements, in order to determine potential controls on ${ }^{10} \mathrm{Be}$ variability between and within cores. Chapter V briefly summarizes the broad conclusions that can be drawn from the results of all three data chapters, linking them into the larger picture of how the geochemical and geophysical characteristics of the Middle America Trench/CAVA system affect ${ }^{10} \mathrm{Be}$ recycling from trench to volcano.

The use of both geochemistry and geophysics to understand complicated tectonic environments can allow the multi-disciplinary scientist to investigate geological questions pertinent to a variety of earth systems. Therefore, a paper published in the journal Geochemistry, Geophysics, Geosystems is also included as an appendix (Kelly et al., 2003), in which mantle peridotite xenoliths from the Kaapvaal craton in South Africa were used to study chemical buoyancy at the base of the thermal boundary layer as a possible source of long-term stability for the upper mantle in Archean continents. 
Figure 1. The Central American Volcanic Arc shows a wide range in enrichment, from moderate ${ }^{10} \mathrm{Be} /{ }^{9} \mathrm{Be}$ values in Guatemala to a global high in southeastern Nicaragua. Between Nicaragua and Costa Rica, ${ }^{10} \mathrm{Be} /{ }^{9} \mathrm{Be}$ drops to minimal but measurable enrichment in the northwestern portion before decreasing to values indistinguishable from background. ${ }^{10} \mathrm{Be} /{ }^{9} \mathrm{Be}$ data from Tera et al. (1986), Morris et al. (1990), Reagan et al. (1994), Morris et al. (2002), and Table 1, Chap. II. 


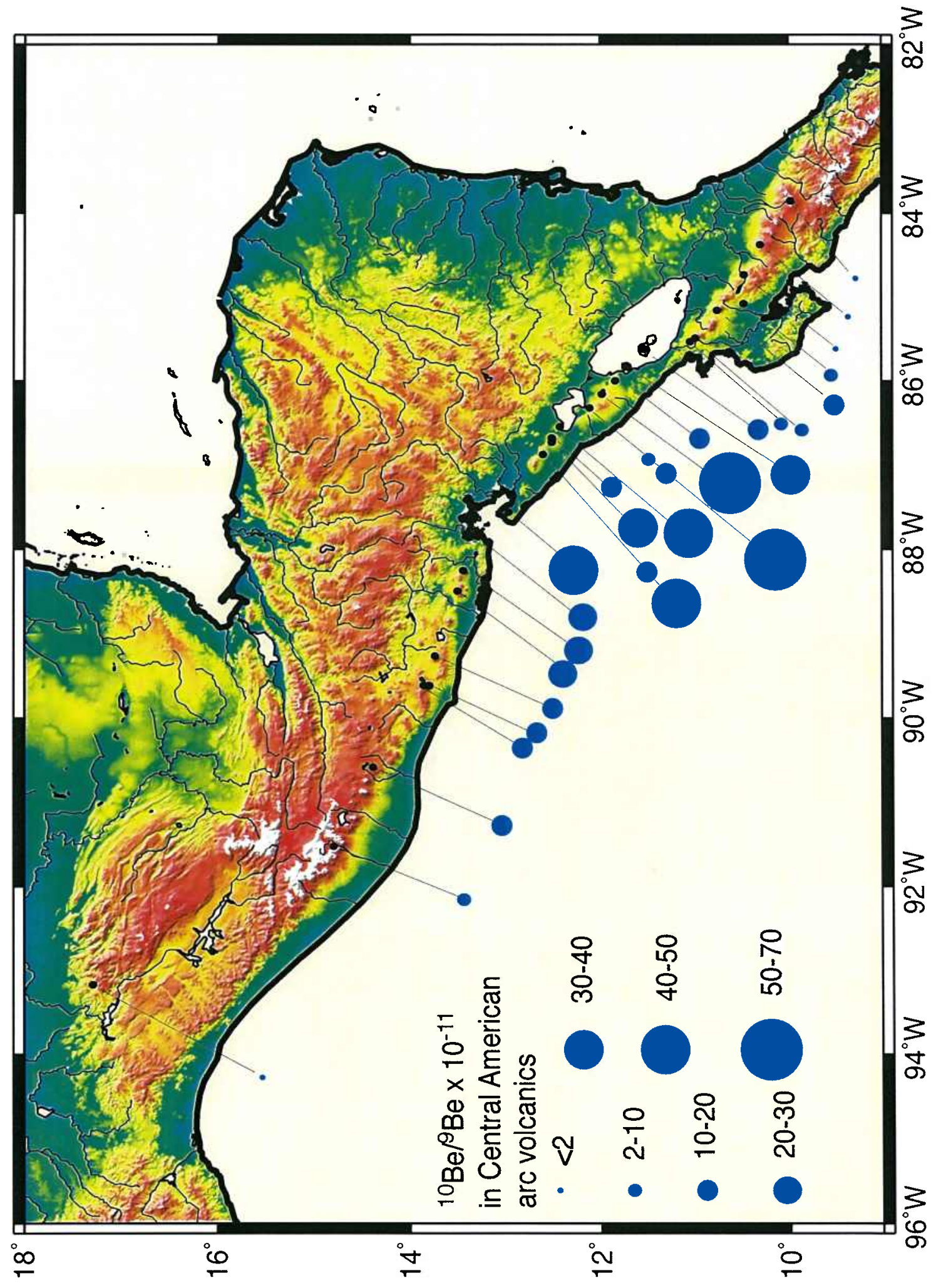




\section{References}

Aubouin, J., R. von Huene, et al., Init. Repts. DSDP, 67, US Govt. Printing Office, Washington, DC, 1982.

Barckhausen, U., C.R., Ranero, R. von Huene, S.C. Cande, and H.A. Roeser, Revised tectonic boundaries in the Cocos Plate off Costa Rica; implications for the segmentation of the convergent margin and for plate tectonic models, J. Geophys. Res., 106, 19,207-19,220, 2001.

Brown, L., J. Klein, R. Middleton, I. Selwyn Sacks, and F. Tera, ${ }^{10}$ Be in island-arc volcanoes and implications for subduction, Nature, 299, 718-720, 1982.

Carr, M.J., Symmetrical and segmented variation of physical and geochemical characteristics of the Central America volcanic front, J. Volcan. Geotherm. Res., 20, 231-252, 1984.

Christeson, G.L., K.D. McIntosh, T.H. Shipley, E. Flueh, H. Goedde, and G. Leandro, Structure of Costa Rica convergent margin, offshore Nicoya Peninsula, J. Geophys. Res., 104, 25,442-25,468, 1999.

Crowe, J.C., and R.T. Buffler, Multichannel seismic records across the Middle America Trench and Costa Rica-Nicaragua convergent margin, NCY-7 and NIC-1, in Middle America Trench off Western Central America, Ocean Drilling Program, Reg. Data Syn. Ser., Atlas 7, J.W. Ladd and R.T. Buffler, eds. 11 pp., Mar. Sci. Int., Woods Hole, Mass., 1985.

DeMets, C., R.G. Gordon, D.F. Argus, and S. Stein, Current plate motions. Geophys. Jour. Int., 101, 425-478, 1990.

Goff, J. A., and T.H. Jordan, Stochastic modeling of seafloor morphology: Inversion of Seabeam data for second-order statistics, J. Geophys. Res., 93, 13,589-13,608, 1988. Hilde, T.W.C., Sediment subduction versus accretion around the Pacific, Tectonophysics, 99, 381-397, 1983. 
Hinz, K., R. von Huene, C.R. Ranero, and PACOMAR Working Group, Tectonic structure of the convergent Pacific offshore Costa Rica from multichannel seismic reflection data, Tectonics, 15, 54-66, 1996.

Kelly, R. and N. Driscoll, Structural controls on beryllium-10 occurrences in arc lavas, EOS Trans. AGU, 79, 396, 1998.

Kelly, R.K., P. Kelemen, and M. Jull, Buoyancy of the Continental Upper Mantle. Geochem. Geophys. Geosys., 4, DOI10.1029/2002GC000399, 2003.

Kimura, G., E. Silver, P. Blum, et al., Proc. ODP. Init. Repts., 170, College Station, TX (Ocean Drilling Program), 1997.

Monaghan, M.C., S. Krishnaswami, and K.K. Turekian, Be-10 flux to the earth's surface based on yearly integrated precipitation collections, EOS Trans. AGU, 64, 283, 1983.

Monaghan, M.C., J. Klein, and C.I. Measures, The origin of ${ }^{10} \mathrm{Be}$ in island-arc volcanic rocks, Earth Planet. Sci. Lett., 89, 288-298, 1988.

Morris, J., and F. Tera, ${ }^{10} \mathrm{Be}$ and ${ }^{9} \mathrm{Be}$ in mineral separates and whole rocks from volcanic arcs: Implications for sediment subduction, Geochim. Cosmochim. Acta, 53, 3197-3206, 1989.

Morris, J.D., W.P. Leeman, and F. Tera, The subducted component in island arc lavas: constraints from Be isotopes and B-Be systematics, Nature, 344, 31-36, 1990.

Morris, J.D., J. Gosse, S. Brachfeld, and F. Tera, Cosmogenic Be-10 and the Solid Earth: Studies in Geomagnetism, Subduction Zone Processes, and Active Tectonics, in Beryllium: Mineralogy, Petrology, and Geochemistry, Reviews in Mineralogy and Geochemistry, 50, edited by E.S. Grew, pp. 207-270, Mineralogical Society of America, Washington, D.C., 2002.

Pavich, M.J., L. Brown, J.N. Valette-Silver, J. Klein, and R. Middleton, ${ }^{10}$ Be analysis of a Quaternary weathering profile in the Virginia Piedmont, Geology, 13, 39-41, 1985.

Protti, M., F. Guendel, and K. McNally, Correlation between the age of the subducting Cocos plate and the geometry of the Wadati-Benioff zone under Nicaragua and Costa Rica, in: Geologic and Tectonic Development of the Caribbean Plate Boundary in Southern Central America, P. Mann, ed., GSA Spec. Pap., 295, 309-326, 1995. 
Reagan, M.K., J.D. Morris, E.A. Herrstrom, and M.T. Murrell, Uranium series and beryllium isotope evidence for an extended history of subduction modification of the mantle below Nicaragua, Geochim. Cosmochim. Acta, 58, 4199-4212, 1994.

Ryan, J.G., and C.H. Langmuir, Beryllium systematics in young volcanic rocks: Implications for ${ }^{10} \mathrm{Be}$, Geochim. Cosmochim. Acta, 52, 237-244, 1988.

Schweller, W.J., and L.D. Kulm, Extensional rupture of oceanic crust in the Chile Trench, Mar. Geol., 28, 271-291, 1978.

Shipley, T.H. and G.F. Moore, Sediment accretion, subduction, and dewatering at the base of the trench slope off Costa Rica: A seismic reflection view of the decollement, $J$. Geophys. Res., 91, 2019-2028, 1986.

Tera, F., L. Brown, J. Morris, I. Selwyn Sacks, J. Klein, R. and Middleton, Sediment incorporation in island-arc magmas: Inferences from ${ }^{10} \mathrm{Be}$, Geochim. Cosmochim. Acta, 50, 535-550, 1986.

Valentine, R.B., J.D. Morris, and J. Duncan, D., Sediment subduction, accretion, underplating, and arc volcanism along the margin of Costa Rica: Constraints from $\mathrm{Ba}$, $\mathrm{Zn}, \mathrm{Ni}$, and ${ }^{10} \mathrm{Be}$ concentrations, EOS Trans. AGU, 78, 46, 1997.

von Huene, R., C.R. Ranero, W. Weinrebe, and K. Hinz, Quaternary convergent margin tectonics of Costa Rica, segmentation of the Cocos plate, and Central American volcanism, Tectonics, 19, 314-334, 2000.

Ye, S., J. Bialas, E.R. Flueh, A. Stavenhagen, R. von Huene, G. Leandro, and K. Hinz, Crustal structure of the Middle American Trench off Costa Rica from wide-angle seismic data, Tectonics, 15, 1006-1021, 1996.

Yiou, F., and G.M. Raisbeck, Half-life of ${ }^{10}$ Be, Phys. Rev. Lett., 29, 372-375, 1972.

Zheng, S.H., J.D. Morris, F. Tera, J. Klein, and R. Middleton, Beryllium isotopic investigation of sedimentary columns outboard of subduction zones, ICOG, 8, 1994. 


\title{
Chapter II
}

\section{New ${ }^{10}$ Be and Bathymetric Constraints on Sediment Recycling in Central America*}

Robyn K. Kelly ${ }^{1}$, Julie D. Morris ${ }^{2}$, Kirk D. McIntosh ${ }^{3}$, Eli A. Silver ${ }^{4}$, Neal W. Driscoll ${ }^{5}$, Jeffrey G. Ryan ${ }^{6}$, John A. Goff ${ }^{3}$, Imtiaz Ahmed ${ }^{3}$, Roland von Huene ${ }^{7}$

\footnotetext{
${ }^{1}$ Woods Hole Oceanographic Institution, Woods Hole, MA 02543

${ }^{2}$ Washington University, St. Louis, MO 63130

${ }^{3}$ University of Texas Institute of Geophysics, Austin, TX 78759

${ }^{4}$ University of California, Santa Cruz, California 95064

${ }^{5}$ Scripps Institution of Oceanography, La Jolla, CA 92093

${ }^{6}$ University of South Florida, Tampa FL 33620

${ }^{7}$ GEOMAR Research Center, Kiel 24148, Germany
}

\begin{abstract}
${ }^{10} \mathrm{Be}$ enrichment in arc volcanoes reflects deep subduction of young marine sediments. New geophysical and geochemical data is presented that demonstrate a correlation between fault structure of the incoming plate and variation of ${ }^{10} \mathrm{Be}$ in the Central American Volcanic Arc. Hydrosweep bathymetric data and multichannel seismic reflection data acquired across the downgoing Cocos plate seaward of the Middle America Trench reveal a marked transition in the size of bending-related extensional faults. This transition in fault size, as illustrated by a sharp decrease in the height of the surface relief, is spatially coincident with new arc volcanic ${ }^{10} \mathrm{Be} /{ }^{9} \mathrm{Be}$ data that confirm a sharp boundary in the amount of sedimentary ${ }^{10} \mathrm{Be}$ reaching arc volcanoes between southeast Nicaragua and northwest Costa Rica. These results indicate that the style of faulting on the subducting plate acts as a first order control on sediment recycling through the arc in this region.
\end{abstract}

*For submission to Geology 


\section{Introduction}

${ }^{10} \mathrm{Be}$ is a radionuclide produced by cosmic ray spallation in the atmosphere. Reaching the oceans via precipitation, ${ }^{10} \mathrm{Be}$ is rapidly adsorbed on settling sediment particles. Because ${ }^{10} \mathrm{Be}$ has a relatively short half-life $\left(1.5 \times 10^{6} \mathrm{yrs}\right)$, it is only found in significant concentrations in the youngest marine sediments $(<10 \mathrm{Ma})$. Given average sedimentation rates, this corresponds to the upper tens to (rarely) hundreds of meters. The presence of high ${ }^{10} \mathrm{Be}$ in arc volcanics requires that the youngest sediment be subducted to the arc volcanic roots.

Globally, ${ }^{10} \mathrm{Be}$ in arc lavas shows a wide range of variation with many arcs having no enrichment and others with concentrations varying from high to low (Morris et al., 2002a). This distribution is not explained through simple relationships between $\operatorname{arc}{ }^{10} \mathrm{Be}$ and a single subduction parameter such as convergence rate, plate age, or slab dip angle. There is also no clear-cut relationship between sediment thickness on the incoming plate or recent sedimentation rates and $\operatorname{arc}{ }^{10} \mathrm{Be}$ (Tera et al., 1986). Rather, the level of ${ }^{10} \mathrm{Be}$ enrichment in an arc appears to reflect the interplay between sediment dynamics (sediment subduction, accretion and erosion), subduction time, and geochemical processes in the mantle and slab-mantle interface.

The Central America arc-trench system provides an exceptional opportunity to explore the relationships between geodynamics, sediment dynamics, and ${ }^{10} \mathrm{Be}$ recycling to the arc because the arc exhibits a wide range of ${ }^{10} \mathrm{Be}$ from background levels to highly enriched (Tera et al., 1986; Morris et al., 1990). Incoming sediments are lithologically and chemically similar along the length of the margin (e.g., Aubouin et al., 1982; Kimura et al., 1997; Patino et al., 2000) and have similar amounts of ${ }^{10} \mathrm{Be}$ (Valentine et al., 1997). Parameters such as plate age, slab dip angle and convergence rate change only gradationally from Guatemala to Costa Rica (Carr, 1984; DeMets et al., 1990; Protti et al., 1995; von Huene et al., 2000; Barckhausen et al., 2001). There is little if any frontal accretion of incoming sediments along the margin (Aubouin et al., 1982; Kimura et al., 1997; Morris et al., 2002b). Despite these similarities, volcanoes in SE Nicaragua have some of the highest ${ }^{10} \mathrm{Be}$ enrichments ever measured, while lavas from NW Costa Rica 
have very low, but not zero, concentrations (Fig. 1). The abrupt change in ${ }^{10} \mathrm{Be}$ concentrations along the arc suggests an abrupt transition from nearly complete sediment subduction beneath Nicaragua to significant underplating $(\sim 80 \mathrm{~m})$ of the surficial sediments beneath Costa Rica (Tera et al., 1986; Morris et al., 1990; Reagan et al., 1994; Valentine et al., 1997), or this change reflects tectonic erosion of the forearc basement and dilution of the ${ }^{10} \mathrm{Be}$ signal beneath Costa Rica (von Huene et al., 2000; Vannucchi et al., 2001).

The dynamics of sediment subduction have important implications for chemical recycling on a global scale. If some of the possible variables in the subduction process can be constrained by ${ }^{10} \mathrm{Be}$, we can evaluate the relative influence of the different tectonic or sedimentary factors that can control the flux of sediment to the arc. Here we use new ${ }^{10} \mathrm{Be}$ measurements combined with geophysical data to investigate the potential relationship between the change in Cocos plate crustal morphology and arc volcanic ${ }^{10} \mathrm{Be}$ from Nicaragua to Costa Rica (e.g., Kelly and Driscoll, 1998).

\section{Geologic Setting}

Moderate ${ }^{10} \mathrm{Be}$ enrichment in Guatemala progresses to a peak in Nicaragua, abruptly plummeting to values slightly above background in Costa Rica (Fig. 1; Electronic Data Supplement Table 1). These recent and new ${ }^{10} \mathrm{Be}$ measurements (with a detection limit of $0.1 \mathrm{million}$ atom $/ \mathrm{g}$ ) delineate the change from Nicaragua to Costa Rica. Low-Ti lavas from SE Nicaragua have ${ }^{10} \mathrm{Be} /{ }^{9} \mathrm{Be}$ atom ratios in the range $18-70 \times 10^{-11}$, contrasting sharply with lavas from NW Costa Rica, which have ${ }^{10} \mathrm{Be} /{ }^{9} \mathrm{Be}$ ratios of $1-6 \times 10^{-11}$ (with one outlier; Morris et al., 2002a). High-Ti Nicaraguan arc lavas have lower ${ }^{10} \mathrm{Be}$ concentrations relative to the low-Ti lavas within the same volcanic center (Morris et al., 1990; Reagan et al., 1994). However, the Th-isotope excesses in the high-Ti lavas (Reagan et al., 1994) indicate probable melting in the presence of garnet, and therefore a potentially deeper melting source with a lower slab signal than the low-Ti arc front lavas. As such, the high-Ti lavas are not considered representative of the dominant trend of arc 
magma genesis in Nicaragua and are not used for further comparison with Costa Rican lavas (e.g., review in Carr et al., 2003).

Incoming sediment heterogeneity is unlikely to produce this large range in the arc volcanic ${ }^{10} \mathrm{Be}$ observed in Central America, as the two drill cores in this region contain comparable ${ }^{10} \mathrm{Be}$ budgets (Valentine et al., 1997). The change in the observed ${ }^{10} \mathrm{Be}$ pattern in the Central American Volcanic Arc between SE Nicaragua and NW Costa Rica (Fig. 1 ) is not well correlated with the other elements used to constrain geochemical recycling of slab constituents (e.g., Patino et al., 2000). Arc lava enrichment of $\mathrm{Ba} / \mathrm{La}$, a ratio that is constant through the sediment column, has been used as a proxy for variations in ${ }^{10} \mathrm{Be}$ via different amounts of fluid flux (e.g., Rupke et al., 2002). However, between SE Nicaragua and NW Costa Rica the Ba/La ratio remains constant (Carr et al., 2003), whereas the ${ }^{10} \mathrm{Be}$ enrichment significantly decreases across this boundary.

The transition to very low ${ }^{10} \mathrm{Be}$ concentrations coincides with an offset of the volcanic front (Fig. 2), in an area where (NW to SE) convergence rate ( $85-86 \mathrm{~mm} / \mathrm{yr}$ ), plate age (23-22 Ma), and slab dip $\left(84-80^{\circ}\right)$ change only moderately and in a gradational rather than abrupt manner (Protti et al., 1995; Barckhausen et al., 2001; DeMets, 2001). There is, however, a marked transition in the bathymetric features of the subducting plate close to the trench between Nicaragua to Costa Rica, as revealed by our newly acquired geophysical data (Fig. 2). Multichannel seismic (MCS) data image similar sediment thicknesses along the Cocos plate as it enters the trench $(400-500 \mathrm{~m})$, but there is less basement fault throw offshore of Costa Rica $(<250-300 \mathrm{~m})$ compared to Nicaragua ( $<500-700$ m) (Fig. 3; von Huene et al., 2000; Ranero et al., 2000).

During subduction, bending of the downgoing slab can result in large scale extensional faulting that generates basement relief in the oceanic crust at the trench. If the thickness of the subducting sediment column is comparable to fault throw and does not change along strike, then fault relief could enhance subduction of the downgoing sediment; offscraping or underplating may be more prevalent when basement faults in the downgoing plate are small in comparison with the overlying sediment thickness (Schweller and Kulm, 1978; Hilde, 1983). We examined swath bathymetry data together 
with new and existing MCS data to constrain the variation in Cocos plate basement fault structure along strike of the margin and its possible impact on surface sediment subduction and ${ }^{10} \mathrm{Be}$ recycling.

\section{Data and Methods}

The swath bathymetry data set is a largely a compilation acquired from R/V Sonne cruises by researchers at GEOMAR and from our recent R/V Ewing cruise in May 2000. The MCS data offshore of Nicaragua are from R/V Ewing and data offshore of Costa Rica are from R/V Ida Green (CR-2B and CR-7A) and R/V Fred H. Moore (CR-001; lines located in Fig. 2).

Seismic data illustrate the difference in fault throw entering the trench between Nicaragua and Costa Rica (Fig. 3). Fault throw was converted to meters from two-way travel time using a constant sediment velocity of $1650 \mathrm{~m} / \mathrm{s}$ based on stacking velocities. MCS line NIC-80 (Fig. 3a) shows a succession of high-relief (up to $700 \mathrm{~m}$ ), back tilted normal faults in the basement as the Cocos plate subducts into the Middle America Trench. MCS line CR-7A (Fig. 3b) offshore of the northwestern part of the Nicoya Peninsula (Costa Rica) has non-tilted fault blocks with basement fault throws less than $200 \mathrm{~m}$.

Although the seismic data provide a measure of changes in fault throw along the trench, the lines are irregularly spaced, especially offshore of Costa Rica, and do not provide sufficient spatial coverage to accurately map the transition between the different Cocos plate deformation regimes. However, because basement faulting in the Cocos plate also affects the seafloor morphology (e.g., Fig. 3), a stochastic statistical analysis (method in Goff and Jordan, 1988) of the extensive swath bathymetric data set can serve as a proxy for basement structure within the entire study area. To identify significant changes in Cocos plate fault structure along strike of the Middle America Trench, we calculated the average root mean squared (RMS) height of the bathymetric data for grids with dimensions of $10 \mathrm{~km}$ along the trench and $25 \mathrm{~km}$ perpendicular to the trench. RMS 
height is defined as the square root of the variance of the bathymetric relief from the large-scale curvature of the subducting plate (Goff and Jordan, 1988).

\section{Results}

RMS height and basement roughness show a peak in fault relief between about 670 $\mathrm{km}$ and $720 \mathrm{~km}$ in distance along-strike of the trench (Fig. 4). All distances are referenced to an orthogonal projection of the bathymetry and MCS data across the trench to the along-strike distance of the volcanic arc (distances from Carr et al., 2003). Between $875 \mathrm{~km}$ and $975 \mathrm{~km}$, the RMS height changes from moderate or high relief in the northwest to consistently low surface relief in the southeast, corresponding to trends in basement fault throw along strike (Fig. 4). The decreases in RMS height occur on either side of the boundary between East Pacific Rise (EPR)-derived crust with trench-parallel magnetic anomalies and Cocos-Nazca Spreading Center (CNS) crust with trenchperpendicular magnetic anomalies (Figs. 2 and 4; von Huene et al., 2000; Barckhausen et al., 2001).

The pattern of ${ }^{10} \mathrm{Be}$ enrichment along strike was compared to the fault relief in the subducting plate, assuming an orthogonal projection of the subducting plate across the trench to the facing volcanoes (Figs. 2 and 4). This does not take into account plate motions over time or divergence of the bending axis from the azimuth of the trench, but the overall correlation between basement fault structure and geochemical variation can be clearly observed. The RMS height transition zone is spatially coincident with the ${ }^{10} \mathrm{Be}$ transition region in which there is minimal but measurable enrichment. The northwesternmost Costa Rican volcanoes, which display the sharp decrease in ${ }^{10} \mathrm{Be}$ enrichment, are located at $852 \mathrm{~km}$ and $862 \mathrm{~km}$ along strike. The first significant decrease in RMS height, as projected across the trench, is slightly to the southeast of these volcanoes (Figs. 2 and 4). Southeast of the RMS height drop at $975 \mathrm{~km}$, the volcanic ${ }^{10} \mathrm{Be}$ enrichment is indistinguishable from background. 


\section{Discussion}

The presence of minimal ${ }^{10} \mathrm{Be}$ enrichment in the Costa Rican volcanoes requires either large amounts of tectonic erosion to dilute the incoming sediment package, a small amount of underplating to remove most of the shallow ${ }^{10} \mathrm{Be}$-bearing sediments, or a change in geochemical processes, from efficient recycling of subducting ${ }^{10} \mathrm{Be}$ in the north to inefficient recycling in the south. The constant $\mathrm{Ba} / \mathrm{La}$ between SE Nicaragua and NW Costa Rica (Carr et al., 2003) indicates that geochemical processes are unlikely to be significantly different within this region. Therefore, mechanical processes are examined.

Underplating of the upper $80 \mathrm{~m}$ (or less) of the sediment column subducting offshore of Costa Rica would account for the ${ }^{10} \mathrm{Be}$ signature in the NW Costa Rican arc (Valentine et al., 1997). As an alternative model, the low ${ }^{10} \mathrm{Be}$ of the Costa Rican volcanoes could be produced by dilution of the sedimentary ${ }^{10} \mathrm{Be}$ with very large amounts of forearc basement removed by subduction erosion, comparable to the proposed $\sim 36 \mathrm{~km}^{3}$ per $\mathrm{km}$ of arc length per my, averaged since 16-17 Ma (Vannucchi et al., 2001).

Within a region where other subduction parameters remain constant (i.e., SE Nicaragua to NW Costa Rica), the onset of tectonic erosion would reduce the ${ }^{10} \mathrm{Be}$ signal by adding mass with no ${ }^{10} \mathrm{Be}$. Because material eroded from the overriding plate is thought to be igneous basement rather than wedge sediment based on seismic velocities (e.g., von Huene et al., 2000), other geochemical tracers would be expected to vary systematically with ${ }^{10} \mathrm{Be}$. Yet decreases in sediment proxies such as $\mathrm{Ba} / \mathrm{La}$ or $\mathrm{Ba} / \mathrm{Th}$ do not occur at the same location as the sharp change in ${ }^{10} \mathrm{Be}$ (e.g., Patino et al., 2000; Carr et al., 2003). Additionally, interpretation of the Costa Rican volcano geochemistry (e.g., Fischer et al., 2002) suggests a significant contribution from carbonate but not hemipelagic sediment, more consistent with a model where the majority of the incoming hemipelagic sediments are underplated, allowing the carbonate section to subduct to depth. It is therefore possible that tectonic erosion is temporally and spatially episodic and may not dominate subduction systematics on the time scale of ${ }^{10} \mathrm{Be}$ recycling beneath NW Costa Rica. 
Underplating of the youngest sediments beneath the forearc, which may also be an episodic process, would be a simple way to reduce the ${ }^{10} \mathrm{Be}$ signal without significantly affecting other slab-derived trace element ratios. Relocation of the décollement could occur within the subducting sediment section along a horizon below which elevated pore pressures serve to create a slip surface within the incoming section (e.g., von Huene and Scholl, 1991). At $\sim 80$ m below the top of the compacted lower plate sediment column sampled at ODP Site 1040 in the toe of the Costa Rica prism, excess pore pressures increase from values indicating partial fluid escape nearly to those expected from undrained loading beneath the forearc (Saffer et al., 2000). Furthermore, detailed analysis of seven seismic profiles offshore of the Nicoya Peninsula by McIntosh and Sen (2000) shows that after initial rapid thinning, the upper part of the underthrust sedimentary section is structurally thickened as it moves $3-5 \mathrm{~km}$ landward from the trench. This thickening requires slip on fault surfaces below the original décollement. Even though the entire sediment column is initially underthrust offshore of the Nicoya Peninsula area of Costa Rica (e.g., Kimura et al., 1997), subsequent relocation of the décollement within the subducting sediment column could cause underplating of the youngest, shallowest sediments.

We propose that the absence of large basement fault relief in the subducting plate offshore of Costa Rica allows for the eventual formation of a décollement within the subducting sediment. When fault throw is small compared to the thickness of the overlying sediments, the position of the décollement is not influenced by the fault structure of the downgoing plate (Schweller and Kulm, 1978; Hilde, 1983; von Huene and Scholl, 1991). Offshore of Nicaragua, the large basement faults minimize or inhibit the development of a décollement within the subducting sediment package. The high ${ }^{10} \mathrm{Be}$ signature of the Nicaraguan arc volcanoes illustrates that, in the region with high-relief basement faults, the surficial sediment appears to be efficiently subducted, allowing for components derived from this sediment to be incorporated into arc magmas.

One important caveat is that sediment underplating would require an isostatic response of uplift. According to Vannucchi et al. (2001), the lower slope of the Costa 
Rica margin wedge has been in subsidence since $\sim 16-17 \mathrm{Ma}$. Farther landward, though a Holocene terrace has a measured rate of uplift of $1.6 \pm 2.0 \mathrm{~m} / \mathrm{kyr}$ (Gardner et al., 1992), there are no calculated rates for either uplift or subsidence in the northwestern portion of the Nicoya Peninsula region since the Plio-Pleistocene (the period of time relevant to ${ }^{10} \mathrm{Be}$ recycling). In order to conclusively distinguish whether tectonic erosion or underplating is the likely mechanism controlling ${ }^{10} \mathrm{Be}$ recycling in this region, it would be necessary to determine if uplift had been occurring landward of the trench since the Pleistocene, or demonstrate that tectonic erosion of upper plate material would be consistent with the observed arc volcanic concentrations of other geochemical tracers, not just ${ }^{10} \mathrm{Be}$.

Currently, we believe that it is probable that an underplating model explains the sediment dynamics and chemical systematics of the Costa Rica segment since $2 \mathrm{Ma}$, while subduction erosion has played an important role over longer times (e.g., Vannucchi et al., 2001).

\section{Conclusions}

Arc volcanic ${ }^{10} \mathrm{Be}$ concentrations indicate a transition in the sediment subduction signature between Nicaragua and Costa Rica volcanoes. In Nicaragua, there is almost complete subduction of the entire sediment column, including the young, ${ }^{10} \mathrm{Be}$-bearing sediments. In contrast, the Costa Rican arc lavas have very small amounts of ${ }^{10} \mathrm{Be}$. MCS and high-resolution swath bathymetry data show a correlation between basement structure and $\operatorname{arc}{ }^{10} \mathrm{Be}$ variation, delineating a boundary in the extensional fault relief of the subducting Cocos plate that is spatially consistent with the arc volcanic ${ }^{10} \mathrm{Be}$ boundary. Sediment mass balance estimates imply either large amounts of tectonic erosion, or accretion of the upper $80 \mathrm{~m}$ of the sediment column. We suggest that offshore of Nicaragua, where the basement fault throws are comparable to the subducting sediment thickness, the fault blocks interfere with the formation of the décollement within the subducting sedimentary section, allowing for subduction of the entire sediment package. In contrast, offshore of Costa Rica, where the fault size is significantly less than the overlying sediment thickness, the formation of a décollement at $\sim 80 \mathrm{~m}$ depth in the 
sediment column and consequent underplating causes the removal of the uppermost sediments, explaining the observed ${ }^{10} \mathrm{Be}$ concentrations.

\section{Acknowledgements}

We thank T. Plank, M. Carr, and E. Malavassi for collecting and sharing their volcanic samples. This work has greatly benefited from discussions with $\mathrm{R}$. Valentine. We also thank C. Ranero for his generosity in sharing data as well as his constructive review. This work was supported by MARGINS grants 9905355, 9909859, the NSF Graduate Research Fellowship, and the WHOI Deep Ocean Institute Graduate Fellowship. We gratefully acknowledge ODP for providing sediment core samples for analysis. 
Electronic Data Supplement: Table 1: ${ }^{10} \mathrm{Be}$ analyses

\begin{tabular}{|c|c|c|c|c|c|}
\hline Volcano & Sample & Age & $\begin{array}{l}{ }^{10} \mathbf{B e} \\
\left(10^{6} \mathrm{a} / \mathrm{g}\right)\end{array}$ & $\begin{array}{l}{ }^{9} \mathbf{B e} \\
(\mathrm{ppm})\end{array}$ & $\begin{array}{c}{ }^{{ }^{10}} \mathbf{B e} /{ }^{9} \mathbf{B e} \\
\left(\times 10^{-11}\right)\end{array}$ \\
\hline \multicolumn{6}{|l|}{ Nicaragua } \\
\hline Cosiguina & $\mathrm{Ni}-\operatorname{Cos} 9 \mathrm{a}$ & 1835 & 14.5 & 0.46 & 47.2 \\
\hline \multirow[t]{2}{*}{ Telica } & $\mathrm{Ni}-\mathrm{Te} 1$ & Historic & 10.7 & 0.39 & 41.1 \\
\hline & Ni-Te6 & $200 \mathrm{a}$ & 5.8 & 0.61 & 14.4 \\
\hline \multirow[t]{3}{*}{ Cerro Negro } & Rubin 1 & 1957 & 4.9 & & \\
\hline & Rubin2 & 1850 & 4.4 & & \\
\hline & $\mathrm{CN} 1$ & 1957 & 7.2 & 0.33 & 32.7 \\
\hline Asosoca & $\mathrm{AS}-2$ & Pre-historic & 6.2 & 0.73 & 12.7 \\
\hline Momotombo & Ni-Mt1-1 & 1905 & 10.8 & 0.39 & 41.5 \\
\hline \multirow[t]{4}{*}{ Nejapa } & $\mathrm{Ne} 202$ & unknown & 2.8 & 0.33 & 12.7 \\
\hline & $\mathrm{Ne} 203$ & unknown & 1.9 & 0.38 & 7.5 \\
\hline & $\mathrm{Ne} 92-2$ & $<600 \mathrm{a}$ & 15.5 & & \\
\hline & NE-13 & unknown & 11.4 & 0.25 & 68.8 \\
\hline \multirow[t]{2}{*}{ Masaya } & Ni-Ms4 & 1772 & 24 & 0.6 & 59.9 \\
\hline & Ni-Ms11 & 1670 & 27.4 & 0.62 & 66.2 \\
\hline Mombacho & Mo97 & Holocene & 7.9 & 0.62 & 19.1 \\
\hline Zapatera & Atr96 & Holocene & 14.4 & 0.63 & 34.2 \\
\hline Concepcion & C-92-2 & $1957 ?$ & 18.8 & 1.59 & 17.7 \\
\hline \multicolumn{6}{|l|}{ Costa Rica } \\
\hline Hacha & Hacha704 & $5-15 \mathrm{ka}$ & 1.25 & 0.58 & 3.2 \\
\hline Orosi & 672 Orosi & Quaternary & 1.47 & 0.35 & 6.3 \\
\hline Miravalles & 665 & Holocene? & 8.4 & 0.87 & 14.5 \\
\hline Cerro Chopo & 600 & Holocene? & 1.78 & 0.76 & 3.5 \\
\hline \multirow[t]{6}{*}{ Arenal } & Cr-Ar82 & 1982 & 0.6 & 0.63 & 1.4 \\
\hline & USNM 112151 & 1968 & 1.1 & & \\
\hline & USNM 112152 & 1970 & 0.7 & & \\
\hline & USNM 113634 & 1970 & 0.6 & & \\
\hline & $\operatorname{Ar} 8 / 89$ & 1989 & 0.86 & 0.66 & 1.95 \\
\hline & $\operatorname{Ar} 12 / 95$ & 1995 & 0.76 & 0.61 & 1.87 \\
\hline Platanar & CRPP7 & & 0.8 & 0.54 & 2.2 \\
\hline Irazu & CR-I63g & 1964 & 1.3 & 1.4 & 1.4 \\
\hline
\end{tabular}

Table 1. Old and new volcano data for Nicaragua and Costa Rica illustrate a transition in ${ }^{10}$ Be enrichment across the Nicaragua/Costa Rica border. Samples Ni-Te6, AS-2, Ne202, and $\mathrm{Ne} 203$ are designated as high-Ti relative to other lavas within the same volcanic center (Morris et al., 1990; Reagan et al., 1994). All pre-historic lavas leached prior to analysis; all samples for which data is reported had no leachable ${ }^{10} \mathrm{Be}$. New data with detection limits of 0.1 million atoms/gram, $1 \sigma$ uncertainties of $5 \%$; all others with detection limits of 1 million atoms/gram, $1 \sigma$ uncertainty of $15 \%$. References: $\mathrm{N}$ indicates new results, this study; 1) Morris et al., 1990; 2) Reagan et al., 1994; 3) Tera et al., 1986. 
Figure 1. The pattern of ${ }^{10} \mathrm{Be}$ enrichment in the Central American Volcanic Arc progresses from moderate in Guatemala to high in Nicaragua and then rapidly diminishes toward Costa Rica, where small but measurable ${ }^{10} \mathrm{Be}$ concentrations occur only in the most northwestern volcanoes (Morris et al., 1990; Morris et al., 2002a). 


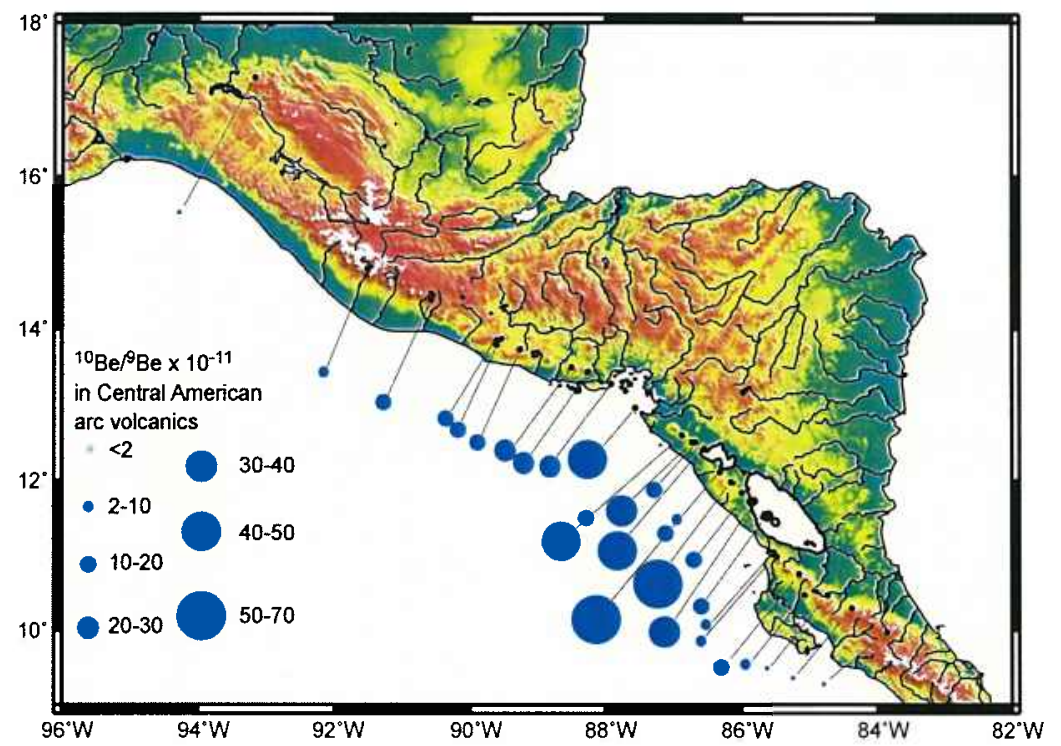


Figure 2. Regional map shows location of seismic lines, bathymetry, volcanoes, and data boundaries. Box with color contains region of new hydrosweep bathymetry collected during EW0005. ${ }^{10} \mathrm{Be}$ transition region (black rectangle) indicates the NW Costa Rica volcanoes with small but measurable ${ }^{10} \mathrm{Be}$ concentrations. To the northwest in Nicaragua, ${ }^{10} \mathrm{Be}$ concentrations are moderate to highly enriched. To the southeast in central Costa Rica, ${ }^{10} \mathrm{Be}$ concentrations are indistinguishable from background detection levels. 

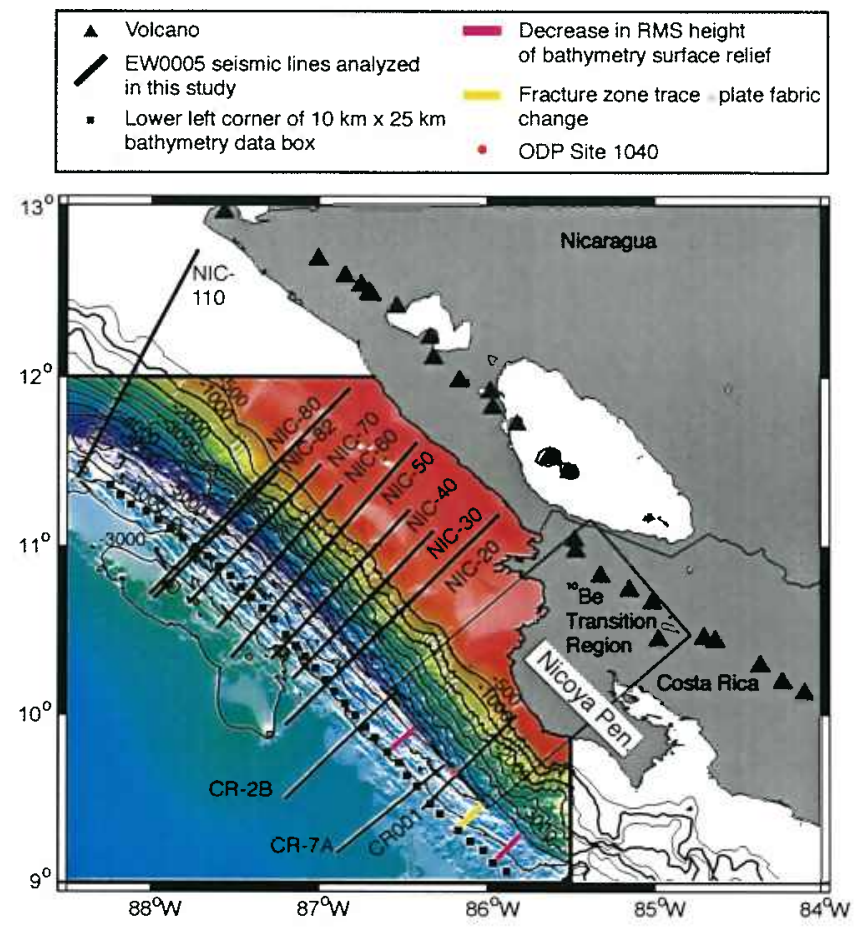
Figure 3. A: MCS line NIC- 80 offshore of central Nicaragua shows a succession of highrelief (up to $700 \mathrm{~m}$ ), back-tilted normal faults in the basement as the Cocos plate subducts into the Middle America Trench. B: MCS line CR-7A offshore of northwestern Costa Rica has basement fault throws that are less than $200 \mathrm{~m}$. See Figure 2 for seismic line locations. 

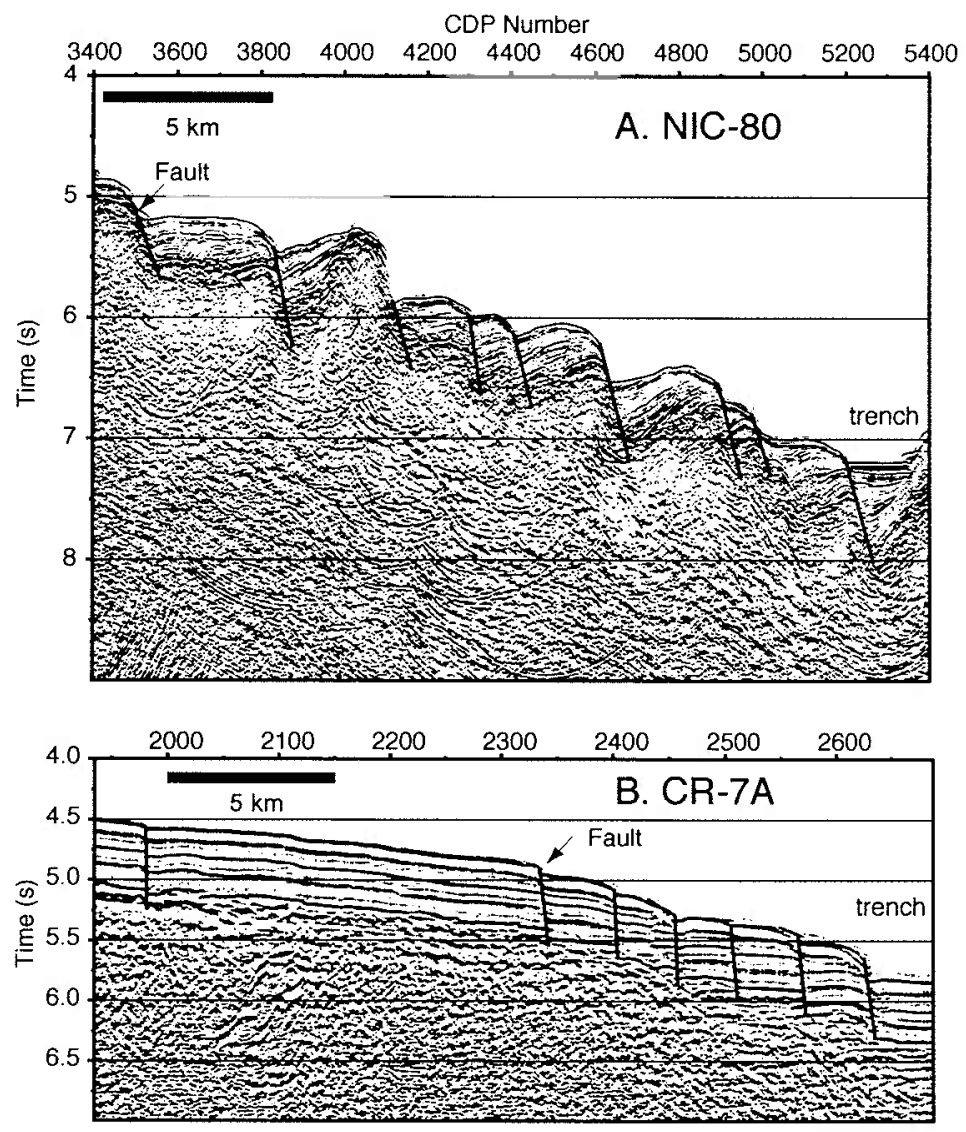
Figure 4. A: ${ }^{10} \mathrm{Be} /{ }^{9} \mathrm{Be}$ enrichment in the Central American Volcanic Arc is shown with distance along strike of the arc (origin and projection for arc volcano distance reference frame is given in Carr et al. (2003), www-rci.rutgers.edu/ carr/index.html). Solid black lines bracket ${ }^{10} \mathrm{Be} /{ }^{9} \mathrm{Be}$ transition region. Solid squares are low-Ti arc lavas. Open squares represent high-Ti Nicaraguan arc lavas, which have lower ${ }^{10} \mathrm{Be}$ concentrations (and lower $\mathrm{Ba} / \mathrm{La}$ ) relative to the low-Ti lavas within the same volcanic center (Morris et al., 1990; Reagan et al., 1994). The high-Ti lavas were most likely subject to different magmatic processes than the low-Ti arc front lavas (e.g., review in Carr et al., 2003). B: The average RMS heights for data boxes $10 \mathrm{~km}$ wide extending $25 \mathrm{~km}$ from the trench are plotted with distance along strike of the arc. Distance is obtained by projecting the left side of the data box orthogonally across the trench to the volcanic arc. Swath bathymetry data does not extend beyond $990 \mathrm{~km}$ (Fig. 2). Vertical error bars represent 1б. C: The average basement fault throws of seismic lines $0-25 \mathrm{~km}$ from the trench are plotted with distance along strike of the arc. Distance is obtained by projecting the seismic line orthogonally across the trench to the volcanic arc. Seismic data does not extend beyond $920 \mathrm{~km}$. Error bars are 1б. A-C: Dashed line indicates Nicaragua/Costa Rica border. B-C: Black lines bracket the transition in fault throw-related bathymetric roughness (located in Fig. 2). 


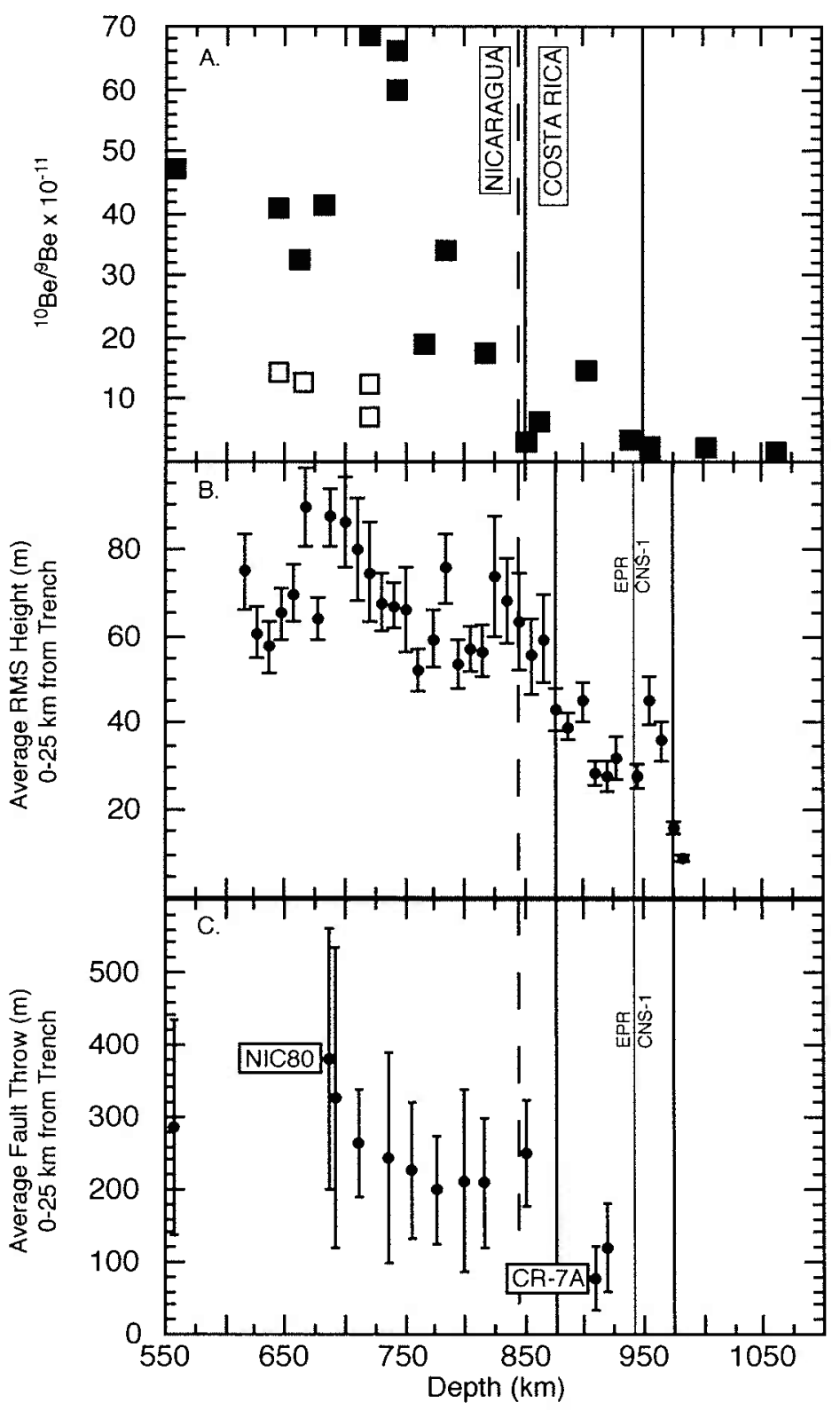




\section{References}

Aubouin, J., von Huene, R., et al., 1982, Init. Repts. DSDP, 67: US Govt. Printing Office, Washington, DC.

Barckhausen, U., Ranero, C.R., von Huene, R., Cande, S.C., and Roeser, H.A., 2001, Revised tectonic boundaries in the Cocos Plate off Costa Rica: Implications for the segmentation of the convergent margin and for plate tectonic models: J. Geophys. Res., v. 106 , p. $19,207-19,220$.

Carr, M.J., 1984, Symmetrical and segmented variation of physical and geochemical characteristics of the Central America volcanic front: J. Volcan. Geotherm. Res., v. 20, p. 231-252.

Carr, M.J., Feigenson, M.D., Patino, L.C., and Walker, J.A., 2003, Volcanism and geochemistry in Central America: Progress and problems, in The Subduction Factory, J.M. Eiler and G. Abers (eds.), AGU Monog. Ser., Washington, D.C., in press, 2003.

DeMets, C., 2001, A new estimate for present day Cocos-Caribbean plate motion: Implications for slip along the Central American volcanic arc, Geophys. Res. Lett., v. 28, p. 4043-4046.

DeMets, C., Gordon, R.G., Argus, D.F., and Stein, S., 1990, Current plate motions: Geophys. J. Int., v. 101, p. 425-478.

Fischer, T.P., Hilton, D.R., Zimmer, M.M., Shaw, A.M., Sharp, Z.D., and Walker, J.A., 2002, Subduction and recycling of nitrogen along the Central American margin:

Science, v. 297, p. 1154-1157.

Gardner, T.W., Verdonck, D., Pinter, N.M., Slingerland, R., Furlong, K.P., Bullard, T.F., and Wells, S.G., 1992, Quaternary uplift astride the aseismic Cocos Ridge, Pacific coast, Costa Rica: Geol. Soc. Amer. Bull., v. 104, p. 219-232.

Goff, J. A. and Jordan, T.H., 1988. Stochastic modeling of seafloor morphology: Inversion of Seabeam data for second-order statistics, J. Geophys. Res., v. 93, p. 13,589-13,608.

Hilde, T.W.C., 1983, Sediment subduction versus accretion around the Pacific: Tectonophysics, v. 99, p. 381-397. 
Kelly, R.K., and Driscoll, N.W., 1998, Structural controls on Be-10 occurrences in arc lavas: Suppl., EOS, AGU v. 79, n. 45, F396.

Kimura, G., Silver, E., Blum, P., et al., 1997, Proc. ODP. Init. Repts., 170: College Station, TX (Ocean Drilling Program).

McIntosh, K.D. and M.K. Sen, Geophysical evidence for dewatering and deformation processes in the ODP Leg 170 area offshore Costa Rica, Earth Planet. Sci. Lett., 178, 125-138, 2000.

Morris, J.D., Leeman, W.P., and Tera, F., 1990, The subducted component in island arc lavas: constraints from Be isotopes and B-Be systematics: Nature, v. 344, p. 31-36.

Morris, J., Gosse, J., and Brachfeld, S., 2002a, Cosmogenic ${ }^{10} \mathrm{Be}$ and the solid earth: studies in active tectonics, geomagnetism and subduction zone processes, in Grew, E., ed., Beryllium: mineralogy, petrology, and geochemistry: Rev. Mineral. Geochem., v. $50,207-270$.

Morris, J., Valentine, R., and Harrison, T., 2002b, ${ }^{10} \mathrm{Be}$ imaging of sediment accretion and subduction along the northeast Japan and Costa Rica convergent margins: Geology, v. 30 , p. 59-62.

Patino, L.C., Carr, M.J., and Feigenson, M.D., 2000, Local and regional variations in Central American arc lavas controlled by variations in subducted sediment input: Contrib. Mineral. Petrol., v. 138, p. 265-283.

Protti, M., Guendel, F., and McNally, K., 1995, Correlation between the age of the subducting Cocos plate and the geometry of the Wadati-Benioff zone under Nicaragua and Costa Rica, in: Geologic and Tectonic Development of the Caribbean Plate Boundary in Southern Central America, P. Mann, ed., GSA Spec. Pap., v. 295, p. 309326.

Ranero, C.R., von Huene, R., Flueh, E., Duarte, M., Baca, D., and McIntosh, K., 2000, A cross section of the convergent Pacific margin of Nicaragua: Tectonics, v. 19, p. $335-357$. 
Reagan, M.K., Morris, J.D., Herrstrom, E.A., and Murrell, M.T., 1994, Uranium series and beryllium isotope evidence for an extended history of subduction modification of the mantle below Nicaragua. Geochim. Cosmochim. Acta, v. 58, p. 4199-4212.

Rupke, L.H., Morgan, J.P., Hort, M., and Connolly, J.A.D., 2002, Are the regional variations in Central American arc lavas due to differing basaltic versus peridotitic slab sources of fluids? Geology, v. 30, p. 1035-1038.

Saffer, D.M., Silver, E.A., Fisher, A.T., Tobin, H., and Moran, K., 2000, Inferred pore pressures at the Costa Rica subduction zone: implications for dewatering processes: Earth and Planet. Sci. Lett., v. 177, p. 193-207.

Schweller, W.J. and Kulm, L.D., 1978, Extensional rupture of oceanic crust in the Chile Trench: Mar. Geol. V. 28, p. 271-291.

Tera, F., Brown, L., Morris, J., Selwyn Sacks, I., Klein, J., and Middleton, R., 1986, Sediment incorporation in island-arc magmas: Inferences from ${ }^{10} \mathrm{Be}$ : Geochim. Cosmochim. Acta, v. 50, p. 535-550.

Valentine, R.B., Morris, J.D., and Duncan, D. Jr., 1997, Sediment subduction, accretion, underplating, and arc volcanism along the margin of Costa Rica: constraints from $\mathrm{Ba}$, $\mathrm{Zn}, \mathrm{Ni}$, and ${ }^{10} \mathrm{Be}$ concentrations: EOS, Trans., AGU, v. 78, p. 673.

Vannucchi, P., Scholl, D.W., Meschede, M., and McDougall-Reid, K., 2001, Tectonic erosion and consequent collapse of the Pacific margin of Costa Rica: Combined implications from ODP Leg 170, seismic offshore data, and regional geology of the Nicoya Peninsula: Tectonics, v. 20, p. 649-668.

von Huene, R., and Scholl, D.W., 1991, Observations at convergent margins concerning sediment subduction, subduction erosion, and the growth of continental crust: Reviews of Geophysics, v. 29, p. 279-316.

von Huene, R., Ranero, C.R., Weinrebe, W., and Hinz, K., 2000, Quaternary convergent margin tectonics of Costa Rica, segmentation of the Cocos plate, and Central American volcanism. Tectonics, v. 19, p. 314-334. 


\title{
Chapter III
}

\section{Cocos Plate Morphology at the Middle America Trench: Implications for ${ }^{10} \mathrm{Be}$ Recycling}

\begin{abstract}
Extensional faulting associated with flexural bending in the Cocos plate offshore of Nicaragua and Costa Rica, seaward of the Middle America Trench, was quantitatively analyzed by correlating a stochastic statistical analysis of Cocos plate hydrosweep bathymetry data with a measurement of basement fault relief in multichannel seismic (MCS) data. Root mean squared (RMS) height, characteristic width, and the azimuth of the hydrosweep bathymetry surface topography are shown to be an accurate indicator of basement fault size and distribution as identified in the MCS data. The MCS data image a fairly constant sediment thickness along strike as the Cocos plate approaches the trench ( $400-500 \mathrm{~m}$ ) but a decrease in basement fault throw from Nicaragua to Costa Rica. High basement fault relief $(\sim 500 \mathrm{~m})$ is present in the Cocos plate offshore of Nicaragua but low-relief basement faults $(<300 \mathrm{~m})$ exist offshore of Costa Rica. The decrease in extensional fault relief is directly correlated with a shallowing trench depth and a decrease in curvature of the plate at the trench. This transition in fault size, as illustrated by a sharp decrease in the RMS height of the surface relief, is also spatially coincident with a transition in arc volcanic ${ }^{10} \mathrm{Be}$ concentrations between Nicaragua and Costa Rica. As ${ }^{10} \mathrm{Be}$ is only found in young surficial sediments, this change in ${ }^{10} \mathrm{Be}$ concentration indicates a change in the delivery of the uppermost sediments to the sources of volcanism. It is proposed that in the subducting plate offshore of Nicaragua, extensional basement faults with relief the same size as the overlying sediment thickness promote efficient subduction of the entire sediment column by maintaining the décollement along the top of the subducting plate. Offshore of Costa Rica, the smaller basement faults allow the décollement to develop within the subducting sediment column, potentially leading to underplating of sediments to a degree consistent with the small but measurable concentrations of arc volcanic ${ }^{10} \mathrm{Be}$ in northwestern Costa Rica.
\end{abstract}




\section{Introduction}

The role of sediment subduction in the petrogenesis of arc magmas can be better understood by combining geochemical and geophysical constraints. The processes that control the recycling of sediment-derived geochemical constituents from input at the trench through the depths of arc magma generation to subsequent eruption remain poorly constrained. The proportion of fluid and/or melt component derived from the subducting sediment, the potential sequestering of this fluid and/or melt prior to magma genesis, mantle wedge dynamics, and arc crustal and lithospheric thicknesses can all affect the signature of sediment involvement in arc petrogenesis. Different studies, even within the same geographical region, have invoked greater or lesser amounts of influence from these subduction zone characteristics to explain arc geochemistry (e.g., review in Carr et al., 2003). This chapter examines in more detail the results of Chapter II, which used highresolution swath bathymetry and multichannel seismic (MCS) reflection data to demonstrate a potential link between sediment subduction systematics at the trench and erupted arc magma ${ }^{10}$ Be geochemistry within one arc-trench segment. By identifying the relative importance of competing factors governing the presence of geochemical tracers within a specific arc volcanic region, while also providing an in depth analysis of one subduction parameter in particular, we can potentially contribute additional insight into subduction systematics on a global level.

Our geochemical focus is specifically on the isotope ${ }^{10} \mathrm{Be}$, a radionuclide generated from cosmic ray spallation reactions on oxygen and nitrogen in the atmosphere. ${ }^{10} \mathrm{Be}$ reaches the ocean via precipitation, where it then adsorbs onto particulate matter settling to the ocean floor. As ${ }^{10} \mathrm{Be}$ has a half-life of $1.5 \times 10^{6} \mathrm{yrs}$ (Yiou and Raisbeck, 1972), it is only found in significant concentrations in the upper tens of meters of marine sediment. Thus it was thus a major advance in the studies of active margin dynamics when enriched concentrations of ${ }^{10} \mathrm{Be}\left(>1 \times 10^{6}\right.$ atoms/g) were detected in arc volcanic lavas (e.g., Brown et al., 1982; Tera et al., 1986; Ryan and Langmuir, 1988; Monaghan et al., 1988; Morris and Tera, 1989; Morris et al., 1990). In contrast, mantle-derived lavas (i.e., midocean ridge basalts, ocean island basalts, and continental rift magmas) have very low ${ }^{10} \mathrm{Be}$ 
concentrations, in the range of detection limits $\left(<0.1 \times 10^{6}\right.$ atoms $\left./ \mathrm{g}\right)$. Therefore, the presence of ${ }^{10} \mathrm{Be}$ in some arc lavas strongly suggests that the youngest sediment was subducted to the arc volcanic roots and incorporated into the magmatic system (Brown et al., 1982; Tera et al., 1986; Ryan and Langmuir, 1988).

Despite the unequivocal nature of the source of ${ }^{10} \mathrm{Be}$ enrichment in volcanic arcs, the variations in, and occurrence of, ${ }^{10} \mathrm{Be}$ in these arcs are still not well understood in light of subduction zone systematics. Because the incorporation of ${ }^{10} \mathrm{Be}$ into arc lavas requires the subduction of the very youngest sediments, its variability in a single active margin can highlight important differences in the dynamics of subduction along strike. This enables ${ }^{10} \mathrm{Be}$ to become a powerful tool to examine the tectonic factors that control the flux of sediment to the arc.

The use of ${ }^{10} \mathrm{Be}$ in comprehending subduction dynamics has historically been informative, yet also frustrating. Beyond the requirement for young sediment to be subducted to great depth below the margin, interpretation of arc ${ }^{10} \mathrm{Be}$ data has been problematic because arc lavas rich in ${ }^{10} \mathrm{Be}$ are found in subduction zones with very different characteristics. There seems to be no definitive global correlation of ${ }^{10} \mathrm{Be}$ enrichment with any of the main subduction parameters, such as convergence rate, age of the subducting slab, dip angle of the slab, or depth of the slab beneath the volcanic arc (Table 1). Nor do sediment thickness or deposition rate necessarily determine whether an arc will have ${ }^{10} \mathrm{Be}$ enrichment (Tera et al., 1986). A significant fraction of young sediments on the incoming plate is definitely a prerequisite, but not a guarantee for ${ }^{10} \mathrm{Be}$ enrichment in the arc (Tera et al., 1986).

There are four main controls on ${ }^{10} \mathrm{Be}$ enrichment in arc volcanic rocks: $(1){ }^{10} \mathrm{Be}$ concentration in the downgoing sediments, (2) convergence rates, (3) sediment subduction dynamics (e.g., tectonic erosion or subduction accretion), and (4) geochemical processes during incorporation of a sediment component into arc magmas (Figure 1). ${ }^{10} \mathrm{Be}$ sediment budgets can be established from drill cores (e.g., Morris et al., 2002a, b), and convergence rates can be calculated from plate motion models (e.g., DeMets et al., 1990, 1994; DeMets, 2001). These two variables are necessary to quantify the first-order input 
of ${ }^{10} \mathrm{Be}$ at the trench. The latter two processes subsequently affect the input of ${ }^{10} \mathrm{Be}$ to the arc magmas. A variety of arc tracers can act as a window into geochemical processes during subduction (e.g., reviews by Tatsumi and Eggins, 1995; Davidson, 1996), while estimates of accretion or erosion typically come from a combination of sources, including seismic data as well as sedimentological and geochemical data derived from drill core samples (e.g., von Huene and Lallemand, 1990; von Huene and Scholl, 1991; Clift and MacLeod, 1999; Vannucchi et al., 2000).

In order to evaluate the degree to which either process determines ${ }^{10} \mathrm{Be}$ enrichment in arc magmas, it is most useful to look at the evidence within a geophysical and geochemical framework, as recent studies comparing geophysical and geochemical trends within an arc system have demonstrated (e.g., von Huene et al., 2000; Carr et al., 2003). In arcs where the initial input is comparable along-strike, the large-scale variability of slab-derived tracers in arc rocks can reflect the complex interplay between numerous controls such as slab dip, tectonic erosion, sediment accretion, thermal regime, fluid flux, and upper plate crustal thickness. Isolating the effect of any one control can be very difficult. Within an arc, ${ }^{10} \mathrm{Be}$ may co-vary with other sediment tracers that display a more constant value through the sediment column (e.g., Ba/La, Patino et al., 2000). However, as ${ }^{10} \mathrm{Be}$ is only found in the uppermost sediments, it is particularly sensitive to processes that impact only the top layer of subducting sediments rather than the bulk sediment column. Thus, deviations of ${ }^{10} \mathrm{Be}$ arc volcanic enrichment patterns from what would be expected given the patterns of other geochemical sediment tracers, or significant geochemical changes across a region where the main subduction parameters appear similar, create an ideal opportunity to narrow the field of possible forcing functions and potentially analyze a direct relationship between a process governing input and its associated output.

\section{Distribution of ${ }^{10} \mathrm{Be}$ in Arc Volcanic Rocks}

Globally there are eleven arcs that are known to have volcanoes with higher than background concentrations of ${ }^{10} \mathrm{Be}$. Volcanic rocks from the Aleutians, Kuriles, Central 
America, South America, Hokkaido, Scotia, Izu, Marianas, Tonga, Kermadec, and Bismarck have arc lava atomic ratios of ${ }^{10} \mathrm{Be} /{ }^{9} \mathrm{Be}$ that range from background (i.e., indistinguishable from blanks) to as high as $81 \times 10^{-11}$ in a Hokkaido volcano (Brown et al., 1982; Tera et al., 1986; Monaghan et al., 1988; Ryan and Langmuir, 1988; Morris and Tera, 1989; Morris et al., 1990; Sigmarsson et al., 1990; Tera et al., 1993; Gill et al., 1993; Reagan et al., 1994; Herrstrom et al., 1995; Morris et al., 2002a). In contrast, the Cascadia, Halmahera, Kamchatka, and Sunda arcs exhibit no enrichment of ${ }^{10} \mathrm{Be}$ in the volcanic rocks (Tera et al., 1986; Morris and Tera, 1989; Edwards et al., 1993; Morris et al., 2002a), despite having a clear indication of some sediment involvement in their petrogenesis based on other geochemical tracers. Reanalysis with a detection limit of 0.1 rather than 1 million a/g might change this interpretation, but the level of enrichment would remain small (Morris et al., 2002a).

In order to determine the relative influence of the processes responsible for ${ }^{10} \mathrm{Be}$ enrichment in arc volcanic rocks, it is advantageous to choose an arc/trench system where dramatic ${ }^{10} \mathrm{Be}$ variations within the entire arc or a specific arc segment are observed. The Middle America Trench from Guatemala to Costa Rica is an ideal location for such a study. The ${ }^{10} \mathrm{Be} /{ }^{9} \mathrm{Be}$ atom ratios range from just slightly above background in Costa Rican volcanoes to $69 \times 10^{-11}$ in the Nejapa volcano in Nicaragua (Tera et al., 1986; Morris and Tera, 1989, Morris et al., 1990; Morris et al., 2002a; see Table 1, Chapter II). Moderate ${ }^{10} \mathrm{Be}$ enrichments in Guatemala increase to a maximum in Nicaragua and then diminish to slightly above background values in Costa Rica (Figure 2).

The most pronounced change in ${ }^{10} \mathrm{Be}$ enrichment occurs across the Nicaragua/Costa Rica border. Low-Ti lavas in southeastern Nicaraguan volcanoes (Nejapa, Masaya, Mombacho, Zapatera, and Concepcion volcanoes) have ${ }^{10} \mathrm{Be}$ concentrations and ${ }^{10} \mathrm{Be} /{ }^{9} \mathrm{Be}$ atom ratios in the ranges of 8-27 million a/g and $\sim 20-70 \times 10^{-11}$, respectively (Morris et al., 1990; Reagan et al., 1994; Morris et al., 2002a; Table 1, Chapter II). Nejapa and Masaya volcanoes have the highest recorded ${ }^{10} \mathrm{Be}$ concentrations in the world (Morris et al., 1990). High-Ti Nicaraguan arc lavas have lower ${ }^{10} \mathrm{Be} /{ }^{9} \mathrm{Be}$ ratios $\left(7.5-14.4 \times 10^{-11}\right)$ relative to the low-Ti lavas within the same volcanic center (Table 1, Chapter II; Morris 
et al., 1990; Reagan et al., 1994). However, Th-isotope excesses in the high-Ti lavas

(Reagan et al., 1994) indicate probable melting in the presence of garnet, and therefore a potentially deeper melting source that may be depleted in slab-derived elements relative to the source of low-Ti arc front lavas. As such, the high-Ti lavas are not considered representative of the dominant processes governing arc magma genesis in Nicaragua and are not used for further comparison with Costa Rican lavas (e.g., review in Carr et al., 2003).

In northwestern Costa Rica volcanoes (Hacha, Orosi, and Cerro Chopo), ${ }^{10} \mathrm{Be}$ concentrations range from $1.3-1.8$ million a/g with ${ }^{10} \mathrm{Be} /{ }^{9} \mathrm{Be}$ ratios $<6.3 \times 10^{-11}$ (with an outlier from Miravalles that has a ${ }^{10} \mathrm{Be}$ concentration of 8.4 million a/g and ${ }^{10} \mathrm{Be} /{ }^{9} \mathrm{Be}$ of $14.5 \times 10^{-11}$ ) (Morris et al., 2002a; Table 1, Chapter II). Farther to the southeast in Costa Rica, Arenal lavas have ${ }^{10} \mathrm{Be}=0.7-1.1$ million a/g with ratios of $<2 \times 10^{-11}$, and central Costa Rican lavas from Platanar and Irazu have ${ }^{10} \mathrm{Be}=0.8-1.3$ million a/g with ratios $<2.2 \times 10^{-11}$ (Morris et al., 1990; Morris et al., 2002a; Table 1, Chapter II).

\section{Geological Setting}

The large contrast in ${ }^{10} \mathrm{Be}$ between the Nicaragua and Costa Rica lavas reveals a significant change in the degree to which a geochemical signature from the surficial sediments is incorporated into the arc lavas. Systematic examination of this variability within the context of the major geophysical and geochemical parameters of this subduction system may highlight comparable and related variations across the Nicaragua/Costa Rica border. Subduction parameters such as convergence rate, dip of the subducting slab, and major tectonic features and boundaries in the subducting plate are well constrained, though variable, along the Middle America Trench (e.g., DeMets, 2001; Protti et al., 1995; Ranero et al., 2000; von Huene et al., 2000; Barckhausen et al., 2001). The general organization of this study will proceed from trench to arc, following the path of the ${ }^{10} \mathrm{Be}$-bearing sediments. 


\section{$3.1{ }^{10}$ Be Input to the Trench}

MCS and drill core data confirm a fairly consistent sediment thickness at the trench from Guatemala to Costa Rica, 400-500 m (e.g., Aubouin et al., 1982; Kimura et al., 1997). There appears to be no frontal offscraping or present-day formation of an accretionary prism along the Middle America Trench from Guatemala to northwest Costa Rica. DSDP Leg 67 drilling and seismic data from the region demonstrate there is no accretionary prism offshore of Guatemala (Aubouin et al., 1982), while in Costa Rica, drilling in the toe of the forearc structure has revealed a complete repetition of the Cocos plate sediment section beneath the décollement, reflecting little if any recent offscraping (Kimura et al., 1997).

Incoming sediment geochemical heterogeneity is minimal; high ${ }^{10} \mathrm{Be}$ concentrations in two drill sites (DSDP Site 495 offshore of Guatemala and ODP Site 1039 offshore of Costa Rica) indicate similar ${ }^{10} \mathrm{Be}$ inventories along the trench, with slightly higher values offshore of Guatemala (Morris et al., 2002a, b). Convergence of the Cocos plate with respect to a fixed Caribbean plate is slightly oblique to the trench, with relatively fast rates increasing from $73 \mathrm{~mm} / \mathrm{yr}$ offshore of Guatemala to $85 \mathrm{~mm} / \mathrm{yr}$ offshore of Costa Rica (DeMets, 2001). The rapid convergence rates and plate geometry (see Section 3.2) result in a subduction time of 2.5-2 $\mathrm{Myr}$ in which sediments travel from the trench to beneath the arc (Morris et al., 2002a). The combination of a large incoming ${ }^{10} \mathrm{Be}$ sediment budget with a recycling period that is short enough to prevent significant decay of sedimentary ${ }^{10} \mathrm{Be}$ fulfills the preliminary requirements for arc magmatic enrichment in ${ }^{10} \mathrm{Be}$ (Morris et al., 2002a).

\subsection{Cocos and Caribbean Plate Characteristics}

The Central American Volcanic Arc formed due to subduction of the Cocos plate beneath the Caribbean at the Middle America Trench (MAT) (Figures 3 and 4). The Cocos plate is composed of conjoined crust from the East Pacific Rise (EPR) and the Cocos-Nazca Spreading Center (CNS) (Hey, 1977). The age of the subducting Cocos plate does not vary significantly along the trench between Guatemala and northern Costa 
Rica ( 25-22 Ma, northwest to southeast, Barckhausen et al., 2001; Figures 3 and 4). Magnetic anomaly data delineate the change from EPR oceanic crust to CNS oceanic crust offshore of northwestern Costa Rica (Figures 3 and 4; Barckhausen et al., 1998; von Huene et al., 2000; Barckhausen et al., 2001). The EPR fabric lies parallel to the trench. The CNS fabric is orthogonal to the trench, but where immediately adjacent to the EPR crust it is only a few million years younger than the oceanic crust subducting beneath Nicaragua.

Offshore of the Nicoya Peninsula of Costa Rica, there is an older wedge of CNS crust (CNS-1, Barckhausen et al., 2001) between EPR fabric to the north and the bulk of the CNS crust (CNS-2) (Figure 4). The EPR/CNS-1 fracture zone trace is marked by an escarpment offshore of the middle of the Nicoya Peninsula (von Huene et al., 2000). The triple-junction trace between EPR and CNS-2 (CNS-1/CNS-2 at the trench) represents the "rough-smooth" boundary (Hey, 1977), with CNS-2 having rougher seafloor morphology due to Galapagos hot spot volcanism and slower spreading at the CNS than the "smooth" EPR fabric (von Huene et al., 2000).

Bathymetric profiles (locations in Figure 5; data from Smith and Sandwell, 1997) spaced every $30 \mathrm{~km}$ along the trench axis were projected $400 \mathrm{~km}$ seaward and $50-75 \mathrm{~km}$ landward from the trench axis (Figure 6). The linear slope of the plate (shown for the profiles from Guatemala to the southeastern edge of the Nicoya Peninsula) calculated both $25 \mathrm{~km}$ and $50 \mathrm{~km}$ from the trench displays a comparable deflection from Guatemala to Nicaragua (Figure 7), with a slightly more pronounced flexural bulge peaking $\sim 75 \mathrm{~km}$ from the trench offshore of central Nicaragua (Figure 6). Though the plate is not strictly linear at the trench, a simple slope calculation was used to illustrate general changes in curvature along strike. Small deviations in the slope from the general trend along strike typically reflect the presence of more localized bathymetric features, such as seamounts or small troughs. Offshore of Costa Rica, the trench shallows significantly, and the deflection of the plate at the trench also decreases. This transition in curvature will be explored in more depth in Section 5. 
In contrast to the curvature of the plate at the trench, the dip angle of the subducting plate imaged from seismicity at $>100 \mathrm{~km}$ depth beneath the volcanic arc steepens from $\sim 60^{\circ}$ beneath Guatemala (Burbach et al., 1984) to a maximum of $84^{\circ}$ under Nicaragua, shallowing slightly to $80^{\circ}$ beneath northwestern Costa Rica (Protti et al., 1995). There is a contortion or tear in the subducting Cocos plate offshore of northwestern Costa Rica called the Quesada Sharp Contortion (QSC), which is approximately coincident with the CNS-1/CNS-2 boundary (Figure 4; Burbach et al., 1984; Protti et al., 1995; Barckhausen et al., 2001). The projection of the QSC to the upper plate is also located where there is a major change in the slab signal of the arc volcanic geochemistry, with a moderate slab enrichment of arc lavas directly northwest of the QSC and a minimal or absent slab signature in arc lavas southeast of the QSC (Carr et al., 1990; Patino et al., 2000; Carr et al., 2003). In the Cocos plate southeast of the QSC, the dip angle of the Cocos plate abruptly shallows to $60^{\circ}$ beneath central Costa Rica, with no apparent Wadati-Benioff Zone (WBZ) at depth under southeastern Costa Rica where the aseismic Cocos Ridge subducts (Protti et al., 1995). Subduction of the Cocos Ridge, which is the trace of the Galapagos hot spot and CNS magmatism, has been linked to shoaling of the subducting plate, uplift in the overriding continent, and the lack of modern active volcanism in the southern Costa Rica Arc (Gardner et al., 1992; Kolarsky et al., 1995; Corrigan et al., 1995; de Boer et al., 1995).

The physical characteristics of the Central American Volcanic Arc are reviewed in depth in Carr (1984) and Carr et al. (2003) and are only briefly summarized here. The crustal thickness of the Caribbean plate decreases from a maximum of $50 \mathrm{~km}$ in Guatemala to $\sim 30 \mathrm{~km}$ in Nicaragua, increasing again to $45 \mathrm{~km}$ in central Costa Rica. Volcanic edifice heights also reach a minimum in Nicaragua, increasing to the northwest and southeast. The largest volcanic centers $\left(>300 \mathrm{~km}^{3}\right)$ are located to the northwest and southeast of the smaller volcanic centers in Nicaragua (generally $<30 \mathrm{~km}^{3}$ with the exception of one volcano that has a volume of $178 \mathrm{~km}^{3}$ ). However, the estimations of volcanic center volumes are not well constrained and there is a large degree of variability, with small volumes $<30 \mathrm{~km}^{3}$ occurring along the length of the entire arc. 
Focal mechanisms (Figure 4) and onland geological fault mapping indicate that deformation in the volcanic arc and back-arc regions of the upper plate is primarily strike-slip and extensional from Guatemala to Nicaragua (e.g., Weyl, 1980; Weinberg, 1992; La Femina et al., 2002), whereas in central and southern Costa Rica, strike-slip motion is accompanied by a more compressional deformation regime (e.g., Marshall et al., 2000). Relative to a hot spot reference frame, the Caribbean plate at the trench is moving south-southeast at $18.8 \mathrm{~mm} / \mathrm{yr}$ (Figure 4; Gripp and Gordon, 1990).

\subsection{Crustal Faulting in the Cocos Plate at the Middle America Trench}

Bending of a downgoing slab can result in large extensional faulting that generates horsts and grabens in the oceanic crust, or half-grabens as in the case of Nicaragua and Costa Rica. Although the "rough-smooth" boundary of Hey (1977) refers to the "rough" seamount topography in the CNS-derived Cocos plate crust offshore of central Costa Rica, MCS data and high-resolution swath bathymetry have imaged pronounced seafloor morphology offshore of Guatemala and Nicaragua due to high-relief extensional faults associated with plate bending. These normal faults have throws $(\sim 500-700 \mathrm{~m})$ that are equal to or greater than sediment column thicknesses $(\sim 400-500 \mathrm{~m})$, creating a washboard-like topography at the trench offshore of Nicaragua (Figures 8 and 9; Aubouin et al., 1982; Ranero et al., 2000; von Huene et al., 2000). Offshore of northwestern Costa Rica, fault relief appears to have a maximum of 250--300 m (Figure 9; Shipley and Moore, 1986; Ye et al., 1996; Hinz et al., 1996; Kimura et al., 1997; von Huene et al., 2000, Ranero et al., 2000). Though the cause of this change in extensional systematics has been debated, a number of studies have hypothesized that the differences in fault relief along strike are related (either by preferential sediment subduction or by a faultenhanced fluid flux) to the changes in arc volcanic geochemistry between Nicaragua and Costa Rica (Kelly and Driscoll, 1998; Patino et al., 2000; von Huene et al., 2000; Rupke et al., 2002).

The motivation for this study was to investigate the Central American arc volcanic ${ }^{10} \mathrm{Be}$ geochemistry in terms of the idea that basement normal faults may act as protective 
barriers for sediments being subducted to depth. During subduction, if the thickness of the subducting sediment column is less than or equal to the size of the fault-generated relief, grabens could preserve the uppermost sediments in the fault-bounded basins, though there could be potential erosion of the sediments overlying intervening highstanding horst blocks (Hilde, 1983). Extensional basement faults with no horst development, such as those imaged offshore of Nicaragua (Figure 9), may inhibit the formation of the décollement within the entire subducting sediment package when fault throws are equal to or greater than the overlying sediment thickness (Hilde, 1983; von Huene and Scholl, 1991). Efficient sediment subduction due to high-relief, bendinginduced faults might account for a high ${ }^{10} \mathrm{Be}$ signature in the Guatemala to Nicaragua volcanic arc lavas. Conversely, the lack of large basement relief in the downgoing plate might explain the lack of ${ }^{10} \mathrm{Be}$ in Costa Rica. Offscraping or underplating may be more prevalent when the extensional fault formation in the downgoing plate is minimal or small in comparison with the overlying sediment thickness (Schweller and Kulm, 1978; Hilde and Sharman, 1978; Hilde, 1983).

\section{Methods}

In order to quantify the change in basement fault relief along the trench between Nicaragua and Costa Rica, we analyzed both swath bathymetry and MCS data sets. The swath bathymetry data set (Figure 8) is a compilation from R/V Sonne cruises SO76, SO81, SO107, and SO144 acquired by researchers at GEOMAR (Kiel, Germany), and from R/V Maurice Ewing cruise EW0005. Offshore of Nicaragua, the MCS data used in this project (Figure 9) was collected on the R/V Maurice Ewing cruise EW0005 using a 6 $\mathrm{km}, 480$ channel streamer and 10-gun array. Shot spacing was $50 \mathrm{~m}$ and the data was binned to $12.5 \mathrm{~m}$ common midpoint groups. Offshore of Costa Rica, three 2D MCS lines were used: CR-001, collected by the R/V Fred H. Moore cruise FM3502 in 1987, and CR-2B and CR-7A from R/V Ida Green cruise IG2402 in March 1977, with 33.3 m CDP spacing. 
The MCS lines provide the first-order means for measuring fault relief as the plate approaches the trench. From the post-stack time migrations, basement fault throws for the individual faults along each line extending seaward from the trench were measured using a sediment velocity of $1650 \mathrm{~m} / \mathrm{s}$ (based on velocity studies of ODP Site 1039; McIntosh and Sen, 2000). In order to average the fault throw for each seismic line within a given distance from the trench, a normal fault within the basement was given a weight of one if it had visible associated morphological relief at the sediment/water interface (typically for fault throws greater than $\sim 50 \mathrm{~m}$ ). Groups of small, closely spaced successive faults that had one singular bathymetric expression were summed together for a total fault relief with a weight of one (Figure 10). If successive faults with small relief had enough horizontal separation that they could be classified as individual (though narrow) fault blocks, they were not summed. Small seamounts have substantial basement relief, but they are not necessarily the locations of faults associated with plate bending. Thus, the difference between the basement high of a seamount and the basement of the adjacent trenchward fault block was treated as equivalent to throw on a normal fault and was included in the averaging. These minor seamounts are included because they have basement relief that presumably can affect the mechanical efficiency of sediment subduction. Large seamounts $>1 \mathrm{~km}$ in relief (e.g., Figure 9c) were not included, as they are localized and not representative of the dominant seafloor morphology (Figure 8).

The principal drawbacks to using seismic lines to characterize changes in faulting along the trench are data density and irregular spacing, especially offshore of Costa Rica where there are few lines extending very far from the trench. The distribution of the seismic data is too limited to accurately locate a transition or boundary in deformation style. Based on the observation that basement faulting in the Cocos plate has an associated response in the surface seafloor morphology (e.g., Figure 9), the hydrosweep swath bathymetry data can be used as a proxy for basement structure continuously along the trench.

Our analysis of the swath bathymetry employed a second-order stochastic statistical method, the construction and theory of which is detailed in Goff and Jordan (1988). This method of statistically quantifying seafloor morphology has been successfully applied in 
a number of studies of abyssal hills (Goff, 1991; Goff et al., 1991; Goff et al., 1995). Abyssal hills are produced in a fairly consistent, process-driven manner and therefore fulfill the necessary assumptions that 1) the morphologic features are statistically homogeneous, and 2) the statistical parameters describing the characteristic morphology are resolvable within a reasonably sized sampling region (Goff and Jordan, 1988). As such, this statistical method is also appropriate for fault morphology induced by plate bending at trenches, especially as the basement faults often reactivate pre-existing abyssal hill fabric. Prominent, localized seafloor features unrelated to the generation of bendingrelated extensional faults negate the assumption of morphological homogeneity and produce overly large standard deviations if included for analysis using the statistical method. Therefore, where large seamounts or tectonic boundaries have bathymetric expressions that are distinguishable from extensional faults, the corresponding region of the swath bathymetric data is removed prior to statistical analysis.

The homogeneous covariance function of the statistical analysis is based on determining the deviation of seafloor relief from a set of mean values. The mean values are identified as the large-scale morphology of the seafloor, in this particular case the overall curvature of the plate bending into the trench. We quantified the following physical parameters to characterize the subducting Cocos plate:

1. The RMS height (in meters) is the square root of the integrated variance of the bathymetry about the mean depth.

2. The azimuth (degrees) is the orientation of the strike of the lineated features (in this case, the faults associated with plate bending).

3. The characteristic width (in $\mathrm{km}$ ) is the average peak-to-peak distance between the major lineations, orthogonal to their strike. The characteristic length (in $\mathrm{km}$ ) is the average distance between the major peaks in the along-strike direction.

In selecting a suitable size for each sample region, we used two basic criteria: 1) a box length in which the slope of the plate with distance from the trench did not significantly change (as the general characteristics of the fault morphology could be affected by the degree of bending of the plate), and 2) a box length over which the fault lineations 
occurred with enough frequency to obtain well-resolved estimations of the statistical parameters of interest. We binned the bathymetry data in boxes $10 \mathrm{~km}$ in width along the trench, with successive lengths perpendicular to the trench: $0-15 \mathrm{~km}, 0-25 \mathrm{~km}$, and $15-40 \mathrm{~km}$. The bulk of the interpretations come from the results of the data boxes extending 0-25 km from the trench (located in Figure 8; Table 2), as those were judged to optimize the aforementioned criteria of box length. The short length of the boxes extending 0-15 $\mathrm{km}$ from the trench limited the ability to effectively resolve parameters and allowed localized anomalous features to have a greater impact on the statistical results than might be appropriate (e.g., Goff, 1991). The $15-40 \mathrm{~km}$ boxes (Table 3) are useful in characterizing basement fault trends with distance from the trench, but as this range extends over a change in the dominant slope of the plate, such that there is some effect due to flattening, it would not be appropriate to bin the data $0-40 \mathrm{~km}$ from the trench.

Rather than use a predicted elastic plate flexural model shape based on seafloor age, we detrended the actual curvature of the plate for each sample region to produce the set of mean depths from which to calculate bathymetric variance. Because the elastic thickness will be affected by plate curvature (e.g., Bodine, 1981; Judge and McNutt, 1991), the strength of the plate will vary away from the trench. Misfits between observed data and flexural models might introduce artifacts. We found that a quadratic fit for the mean depth was more representative of the large-scale shape of the plate than either a linear or higher-order polynomial fit (Figure 11). As the plate is not strictly linear at the trench, using a linear equation for the mean depth had the effect of underfitting the large-scale morphology, creating anomalously high values for RMS height. A higher-order polynomial detrend overfit the smaller-scale features, removing them from the statistical analysis.

As a last step, we also confirmed that the statistical analysis of bathymetric relief was analogous to the relief on basement fault features. While it is qualitatively clear from the seismic profiles that basement relief has an associated bathymetric expression in some places, we tested and quantified the relationship between basement fault throw in the 
seismic profiles and co-located seismic and swath bathymetric relief (Figure 12). Small basement fault throw and the resulting surface relief are linearly correlated and nearly equal, but surface relief is less than the fault throw of large basement faults (Figure 12a). With progressively larger fault throws, bathymetric relief is not equivalent to the basement relief because of subsequent differential erosion of sediments on basement highs, preferential sediment deposition in basement troughs (especially at the trench, where large basement fault relief is obscured in the bathymetry by trench fill), and smallscale sediment failure during extension (e.g., Figure 9).

As RMS height is the deviation of bathymetric relief from a set of mean depths, it does not have the same relationship with fault throw as the bathymetric relief measured directly from the seismic data does (Figure 12). Yet RMS height still shows a strong linear relationship with basement fault relief averaged over the corresponding distance from the trench, despite the large ranges in fault throws within individual seismic lines (Figure 12b). Based on this analysis, it is evident that RMS height as a measure of bathymetric roughness yields a minimum estimate for the larger faults and is a robust proxy for evaluating basement fault relief in this region of the Middle America Trench (Figure 12).

\section{Middle America Trench Morphology}

\subsection{RMS Height, Azimuth, and Characteristic Width 0-25 km from the Trench}

Since we are comparing the variability in the downgoing plate to the geochemical variability of the arc, the along-strike positions of data regions in the subducting plate are referenced to the along-strike distances of the volcanic arc projected orthogonally across the trench, using the CENTAM volcano database (www-rci.rutgers.edu/ carr/index.html; Carr et al., 2003). As an orthogonal projection does not take into account plate motions over time or divergence of the bending axis from the azimuth of the trench, the assumption that the lower plate characteristics at the trench reflect the plate beneath the opposing section of the volcanic arc will be further discussed in Section 7.1. 
The morphology of the subducting Cocos plate from Nicaragua to Costa Rica shows several interesting features (Figure 13). RMS height, which peaks offshore of central Nicaragua, decreases to a region of low bathymetric roughness offshore of Costa Rica. We identify a transition region in RMS height offshore of Costa Rica, between the domains of uniformly high or low fault relief, that begins just southeast of the Nicaragua/Costa Rica border (Figures 8 and 13a). It is immediately apparent that this transition occurs on either side of, rather than at, the fracture zone trace marking the boundary between EPR and CNS-1 crust. In contrast, the azimuths of the fault lineations change at the EPR/CNS-1 boundary (Figure 13b).

A previous study identified a global relationship between bending-induced extensional faulting and previously existing abyssal hill fabric, as determined by the trend of magnetic anomalies (Masson, 1991). Masson (1991) found that inherited ocean spreading fabric controlled the orientation of normal faults in the subducting plate when the magnetic anomalies were less than $25-30^{\circ}$ oblique from the strike of the subducting slab. In this interpretation, the faults reactivate pre-existing planes of weakness in the abyssal hill fabric. At greater than $30^{\circ}$ obliquity, the strike of the subducting slab, or its bending axis (typically sub-parallel or parallel to the strike of the trench), rather than the ridgecrest fabric of the downgoing plate, will determine the orientation of bending-related faulting in the basement of the subducting plate (Masson, 1991).

The azimuth of the extensional faults within EPR crust offshore of Nicaragua and northwestern Costa Rica are consistent with the relationship observed by Masson (1991) (Figure 13b). Offshore of northwest Nicaragua where the trench azimuth angles westnorthwest rather than northwest, the fault azimuths still remain predominantly parallel to the magnetic anomalies. This can be observed qualitatively by noting the truncation of the morphological lineations at the northwest edge of the trench: though the trench changes strike, the fault features in the bathymetry do not change direction to remain parallel to the trench (Figure 8). This would imply that, at least in the EPR-derived Cocos plate crust, the faults may be reactivating an inherited spreading center fabric. 
The range in characteristic widths for this region (1.5-4.2 km, Figure 13c) also is compatible with reactivation of an inherited crustal fabric. Abyssal hills are typically spaced on the order of hundreds of meters to tens of kilometers, with spreading rate being inversely proportional to fault spacing (e.g., Malinverno and Pockalny, 1990; Carbotte and Macdonald, 1994). The characteristic widths for abyssal hill morphology presently forming on the Cocos plate at the EPR range from $1.2 \mathrm{~km}$ to $4.2 \mathrm{~km}$ for latitudes similar to the Middle America Trench (Goff et al., 1991), although Pacific-Cocos spreading rates during formation of the plate subducting at the trench (early Miocene) were more rapid than today (Wilson, 1996). With somewhat faster spreading rates in the Miocene, abyssal hill spacing may have been smaller than that currently observed at the ridge, so it seems likely that bending-induced faults at the trench reactivate many, but not necessarily all, of the pre-existing planes of weakness.

In the CNS- 1 crust, where the magnetic anomalies trend $N 50^{\circ} \mathrm{E}$ (Barckhausen et al., 2001; Figure 3), the orientation of the faults is not parallel to the strike of the magnetic anomalies or to the strike of the trench (Figure 13b). As noted by Masson (1991) for the western Aleutian Trench, this might imply that in this particular region of the Cocos plate, the axis of bending stress on the slab does not parallel the strike of the trench or the strike of the slab (which, based on seismicity, does not change in this region (Protti et al., (1995)). Another possible explanation for the apparent fault orientations is that the statistical results were dominated by a few prominent but possibly anomalous features, such as the large troughs that can be observed in the southeasternmost region of the swath bathymetry (Figure 8 ).

Additionally, in the CNS-2 derived Cocos plate crust farther to the southeast, von Huene et al. (2000) marked faults parallel to the $N 70^{\circ} \mathrm{E}$ magnetic anomaly trend in that area, even more highly oblique to the trench than faults in the CNS-1 region, indicating that the $30^{\circ}$ rule as identified by Masson (1991) may not always be applicable. However, despite the deviation of the fault orientation in the CNS-1 Cocos plate crust from what might be expected following Masson (1991), it is clear that an inherited abyssal hill fabric is not being reactivated during faulting at the trench. The characteristic widths for 
the CNS-1 crust are still comparable to those in the EPR crust, which might indicate that the accommodation of extensional stress as determined by the larger scale bending of the plate is the first control on fault spacing at a trench. Reactivation along abyssal hill fabric may be a secondary effect when the location of preexisting zones of weakness facilitates the bending-related extensional deformation.

Because of the azimuthal delineation between faults compatible with reactivation of fabric originated at the EPR and new faults forming within the crust from the CNS, it seems initially surprising that the change in basement roughness does not occur at this boundary. Though the relief on extensional faults generated at the outer rise bulge should first be a function of the degree of curvature as the plate flexes into the trench (e.g., Masson, 1991), reactivation along pre-existing abyssal hill fabric (as in the EPR crust) might be expected to add the abyssal hill fault relief to the fault throw derived from bending-induced strain. Yet enhanced fault relief due to reactivation of inherited abyssal hill fabric does not seem to be occurring in the EPR crust at the Middle America Trench, as illustrated by the offset between the RMS height transition and the EPR/CNS-1 boundary. Instead, plate curvature may be the sole control on the change in fault relief in this region.

\subsection{Bathymetric Deflection of the Plate at the Trench}

Bathymetric profiles were projected for each of the $10 \mathrm{~km}$ wide swath bathymetry data bins offshore of Nicaragua and the Nicoya Peninsula, with the new hydrosweep swath bathymetry data superposed on the Smith and Sandwell (1997) bathymetry (Figure 14). The broad trend in plate curvature observed in Figures 6 and 7 can be located more precisely using the higher resolution bathymetry data and smaller spacing between projections (Figures 14 and 15). The slope of the plate over distances $25 \mathrm{~km}$ and $50 \mathrm{~km}$ from the trench shows a systematic decrease in the southeastern direction, with minimal deflection offshore of Costa Rica, southeastward of the Nicaragua/Costa Rica border.

This change in deflection is the most likely cause of the change in RMS height averaged over $25 \mathrm{~km}$ from the trench (Figure 16). There is a visible break in the degree of 
plate deflection that is coincident with the start of the RMS height transition region. Only the first three data regions offshore of northwestern Costa Rica have both comparable RMS height and plate deflection to those offshore of southeastern Nicaragua. The two Costa Rican data points that have anomalously high RMS heights for the corresponding slope of the plate are the two bathymetry data bins with the prominent troughs that could potentially be skewing the statistical analysis results, as mentioned above. The offset in the correlation between RMS height and slope for these two data regions raises the possibility that these troughs are not related to faulting associated with plate bending. Though there is some scatter to the linear relationship between plate slope and RMS height, the RMS height is averaged over a data region $10 \mathrm{~km}$ by $25 \mathrm{~km}$ and the slope is only calculated from a single bathymetric profile $25 \mathrm{~km}$ long. The well-defined correlation between slope and RMS height for the Cocos plate region offshore from Nicaragua and Costa Rica indicates that fault relief is dependent on the slope of the plate.

In the Cocos plate offshore of the Nicoya Peninsula, both within the EPR as well as the CNS-1 crust, the deflection of the plate decreases with the shallowing of the trench (Figure 17). The relationship between trench depth and plate slope is less pronounced offshore from Guatemala, El Salvador, and Nicaragua. As the slope of the plate at the trench calculated from Smith and Sandwell (1997) bathymetry for Nicaragua and Costa Rica shows more scatter than the slope when calculated using the new hydrosweep bathymetry data, it is possible that higher resolution bathymetry data for Guatemala and El Salvador would also resolve a stronger correlation between trench depth and plate curvature in these regions. However, the fault throw may not necessarily increase toward Guatemala even with increasing plate curvature. The few seismic lines offshore of Guatemala show basement fault throw at the trench equal to, but not greater than, the maximum throw of faults offshore of Nicaragua (Aubouin et al., 1982). It may be that beyond a certain degree of curvature, an increase in plate deflection will not cause a similar degree of increase in the relief on bending-induced faults.

The obvious breaks that can be observed in the RMS height and plate bending results do not correspond with the change in plate origin. Thus, either the EPR/CNS-1 boundary 
is not a controlling factor in the degree of plate bending and extensional deformation due to subduction in this region, or its effects extend beyond its two-dimensional lineation. If the gradational decreases in trench depth, deflection of the plate, and RMS height are related to the location of the EPR/CNS-1 boundary in the Cocos plate, this transition is in contrast to other Cocos plate characteristics that show an abrupt change across this boundary, such as the azimuth of the fault lineations (Figure 13), heat flow (Langseth and Silver, 1996; Silver et al., 2000; Fisher et al., 2003) and updip seismicity limits (Newman et al., 2002).

\subsection{Shoaling of the Trench as a Lateral Response to Buoyancy}

A possible unifying explanation for the observed changes in trench depth and plate curvature might be found in considering the characteristics of the entire length of the trench from Guatemala to southeastern Costa Rica rather than just the smaller region offshore of southeastern Nicaragua and northwestern Costa Rica. Trench depth and flexure will be primarily a function of two things: 1) the age of the subducting plate, and 2) buoyancy effects due to crustal thickness and temperature. A fracture zone in the EPR crust offshore of Nicaragua offsets the magnetic anomalies such that the plate appears to be slightly older at the trench to the northwest (Figure 3). Correspondingly, the plate depth offshore of Guatemala (southeast of the Tehuantepec Ridge) is also deeper than the

plate toward the southeast offshore of El Salvador and Nicaragua (Figure 3). Offshore of Guatemala, El Salvador, and Nicaragua, the curvature of the plate and the trench depth may be exhibiting a flexural response that is determined solely by the age of the subducting oceanic plate. Yet there is a systematic shoaling of the plate and the trench offshore of northwestern Costa Rica that does not seem coincident with a change in plate age. In the absence of variations in age, changes in crustal thickness and temperature must be examined as a potential cause of the progressive shallowing of the trench and reduction in curvature to the southeast.

Directly southeast of the CNS-1 crust offshore of the Nicoya Peninsula is the CNS-2 crust, which decreases significantly in age toward the southeast and therefore has a hotter 
thermal regime at the trench. Subduction of the rough, crustally thicker seamount morphology in the CNS-2 crust (Figure 3) is thought to cause forearc deformation and uplift of the southeast edge of the Nicoya Peninsula (von Huene et al., 1995; Marshall and Anderson, 1995; Fisher et al., 1998; Gardner et al., 2001). Another prominent source of buoyancy from both crustal thickening (Walther, 2003) and increased temperature (de Boer et al., 1995) is the Cocos Ridge, an aseismic hot spot track that causes the plate and trench depth to shoal offshore of southeastern Costa Rica (e.g., Corrigan et al., 1990;

Figure 3). The Cocos Ridge has been linked to uplift in the corresponding regions of the overriding plate, an absence of deep Wadati-Benioff Zone seismicity beneath the Caribbean plate, and a very flat subduction dip angle at the trench, though these effects are not present as far northwest as the Nicoya Peninsula (Gardner et al., 1992; Protti et al., 1995; Kolarsky et al., 1995; Marshall and Anderson, 1995; von Huene et al., 1995).

Thicker crust and therefore greater buoyancy, due to the dense seamount region and the aseismic Cocos Ridge in the CNS-2 crust (e.g., Figure 3), will create a positive (upward) rather than negative (downward) load on the plate. Compared to the cooler, thinner crust in the plate at the trench to the northwest, the thick crust and the increase in crustal temperature toward the Cocos Ridge crust in the southeast will all act to inhibit subduction-related flexure of the Cocos plate perpendicular to the trench. Additionally, these more buoyant plate characteristics may induce a lateral flexural response in the Cocos plate to the northwest, even though the crust offshore of the Nicoya Peninsula and farther northwest offshore of Nicaragua has normal crustal thickness and temperature for its age (e.g., Walther et al., 2000; Fisher et al., 2003). The elastic strength of the plate could act to buffer the boundary between the different crustal thickness and thermal regimes, creating a transitional effect due to a flexural wavelength that extends beyond the immediate location of the buoyant load. Therefore, we suggest that offshore of Guatemala, El Salvador and the northwestern portion of Nicaragua, trench depth and flexure in the plate are controlled by the elastic thickness associated with the age of the plate. Offshore of northwestern Costa Rica, though the plate is not significantly younger than the plate to the northwest, the progressive decrease in trench depth and plate 
curvature may be an example of lateral flexure due to the increased buoyancy offshore of southeastern Costa Rica.

\subsection{Fault Morphology with Distance from the Trench}

As might be expected, with increasing distance from the trench, as the plate flattens out, the fault relief due to plate bending decreases (Figure 18). This decrease is absent or less pronounced for the regions where the outer rise bulge is well defined in the bathymetry offshore of Nicaragua (e.g., Figures 8 and 14), as can be seen in the comparison of fault relief $0-25 \mathrm{~km}$ from the trench with fault relief $15-40 \mathrm{~km}$ from the trench (Figure 18). The RMS height $15-40 \mathrm{~km}$ from the trench also shows a positive correlation with the slope of the plate $15-40 \mathrm{~km}$ from the trench (Figure 19), although there is a smaller range in slope for the corresponding range in RMS height compared to the results $0-25 \mathrm{~km}$ from the trench (Figure 16). In both regions of the plate, the correlation of RMS height with slope is less defined for Nicaragua than for Costa Rica, where the RMS height is more robust due to the small, homogeneous faults. For the plate offshore of Nicaragua, the small scatter in the data may also be because the linear slope is not an accurate proxy for flexure. It is more likely that the wavelength of curvature would be a better proxy for the dynamic control on bending-induced fault relief.

A weighted average of the estimated parameters for combined adjacent data bins can be useful in comparing general trends of the statistical results by eliminating scatter due to localized features (Figure 20). In this calculation, the values are weighted by the inverse of their standard deviation, so that the less robust results with overly large errors do not have a disproportionate significance in the average. The morphological characteristics of the bathymetry are generally comparable between the data regions binned over successive distances from the trench $(0-15 \mathrm{~km}, 0-25 \mathrm{~km}$, and $15-40 \mathrm{~km})$, such that the differences between these regions can highlight important caveats to broad interpretation from one data region alone (Figure 20). As previously discussed, the RMS height 15-40 $\mathrm{km}$ from the trench is typically smaller than the RMS height $0-25 \mathrm{~km}$ from the trench. Additionally, where we have identified a transition zone offshore of Costa Rica in which 
the 0-25 km RMS height decreases along strike (Figure 13a), the RMS height $15-40 \mathrm{~km}$ from the trench also records this drop, but the difference between the RMS heights 0-25 $\mathrm{km}$ and $15-40 \mathrm{~km}$ from the trench becomes more pronounced (Figure 20). The change in the relative RMS height along strike for the $15-40 \mathrm{~km}$ segment compared to the $0-25 \mathrm{~km}$ segment reflects what can be observed qualitatively in the swath bathymetry (Figure 8). In general, the washboard-like morphology remains present farther to the southeast only in close proximity to the trench, whereas in the northwest, pronounced bathymetric roughness can be observed even with increasing distance from the trench.

In contrast to the abrupt change in RMS height along strike observed in the regions 0-25 km and 15-40 km from the trench, the RMS height 0-15 km from the trench appears to exhibit a more monotonic decrease along strike from Nicaragua to Costa Rica. The RMS height $0-15 \mathrm{~km}$ from the trench offshore of Costa Rica is comparable to the results $0-25 \mathrm{~km}$ from the trench, but the degree of the change in RMS height at the northwestern transition zone boundary is reduced in the $0-15 \mathrm{~km}$ results. As previously discussed in Section 4, the short length of the data bin can reduce the ability to effectively resolve statistical parameters. In the MCS lines offshore of Nicaragua (Figure 9a-d), faults with large amounts of fault throw are not concentrated preferentially near the trench, unlike the area offshore of much of the Nicoya Peninsula (e.g., profile CR-7A, Figure 9f), where fault throw is greatest (but still small) at the trench. These results illustrate the benefits of a greater sampling length over which to average the fault morphology, as variability within a smaller section may be unrepresentative of the larger trend. However, the comparison between the differently sized data bins is still useful in that it demonstrates that the decrease in fault relief along strike of the trench is a robust result.

\subsection{Deformation in the Lower Forearc Slope}

Deformation in the forearc offshore of central Costa Rica is clearly influenced by heterogeneous relief in the subducting plate, such as the forearc deformation that occurs during seamount subduction (von Huene et al., 1995; Fisher et al., 1998; von Huene et 
al., 2000). Though the methodology that we have employed for this study would not be appropriate for measuring morphological changes in the forearc due to subduction of individual, localized features, we can potentially quantify the impact of the more homogeneously varying lower plate relief on the overriding forearc wedge offshore of Nicaragua and the Nicoya Peninsula.

There are two principal drawbacks to using the stochastic statistical method to analyze morphology in the overriding plate. The first is that the minimum data region necessary to effectively resolve the parameters in question may be longer than the length of the forearc section (perpendicular to the trench) that would deform in response to the lower plate morphology. Based on MCS data, the frontal sedimentary prism that might exhibit deformation in response to lower plate morphologies may extend less than $10 \mathrm{~km}$ landward from the trench (von Huene et al., 2000). Accordingly, we have chosen to compare the statistical analysis results of the lower plate $0-15 \mathrm{~km}$ seaward of the trench (Table 4) to corresponding data regions in the upper plate $0-15 \mathrm{~km}$ landward of the trench (approximately the $3500 \mathrm{~m}$ depth contour line in the swath bathymetry of Figure 8; Table 5). The second caution is that the assumption of statistically homogeneous morphology may not be valid in the lower continental margin, where slumps, slides, and small-scale slope failures (e.g., Ranero et al., 2000; von Huene et al., 2000) can create localized deformation that can obscure a more regular morphology imparted by the character of the lower plate.

Using weighted averages, we show that the morphological characteristics in the upper plate seem to mimic the lower plate most obviously in the orientation of the lineations (Figure 21). Though there are also some similarities between the average RMS heights of the regions $0-15 \mathrm{~km}$ seaward of the trench and the regions 0-15 landward of the trench, the characteristic width of the upper plate deformation is consistently larger than that for the lower plate. One scenario that could be interpreted from these results is that where fairly smooth, homogeneously deformed seafloor crust (i.e., no seamounts) is subducting, the strike and possibly the relief of the fault features in the lower plate are generally translated through the toe of the forearc region. However, basement faults often begin to 
flatten out beneath the forearc (e.g., Ranero et al., 2000; von Huene et al., 2000), so it is not clear that the relief would be great enough to impact the overlying material.

The taper mechanics of the steeper forearc wedge slope, which tends toward a stable configuration such that the frontal prism restores itself fairly rapidly even after large seamount subduction (von Huene et al., 2000), may control the spacing of upper plate deformation. Additionally, the deformation of the upper plate, if indeed it is affected by the bending-induced morphology of the lower plate, will be a dynamic rather than static function. As the lower plate continuously moves beneath the forearc, new responses in the frontal prism will be imprinted on the previously existing structures, which might make it improbable that the RMS height and characteristic width of the upper plate would ever be correlated with that of the lower plate. The similar azimuths of the two plate morphologies support the hypothesis that the toe of the upper plate undergoes deformation related to the extensional fault features in the subducting plate, but this is also equivocal as lineations in the frontal prism may simply be a function of the orientation of the trench. As the orientation of the crustal structure in the Cocos plate is sub-parallel to the trench, it is not possible to distinguish between the potential controls on upper plate morphology from these results.

\section{The Central American Volcanic Arc}

After sediment is subducted to the depths of magma genesis, the processes governing its incorporation into arc magma are controlled by the petrological and thermal regimes of the subduction zone system. Detailed discussions of Central American Volcanic Arc (CAVA) geochemical variability and its implications for magmatic processes are presented elsewhere (e.g., Carr et al., 1990; Reagan et al., 1994; Leeman and Carr, 1995; Patino et al., 2000; Carr et al., 2003), but here we review some of the data relevant to interpreting the relationship between Cocos plate fault structure at the trench and the transport of young, surficial, ${ }^{10} \mathrm{Be}$-bearing sediments to the depths of magma genesis. 


\subsection{Elements from the Slab}

Geochemical signatures that trace different source components in the subducting slab vary with one another in a broadly consistent manner through the length of the arc (Figure 22; e.g., Patino et al., 2000). A moderate slab signal in Guatemala progresses to a peak in Nicaragua, decreasing again from Nicaragua to Costa Rica. In central Costa Rica, geochemical constituents, including fluid-mobile elements, that trace slab input to arc magmas fall either close to or within the range of values for mantle-derived lavas (e.g., Patino et al., 2000). However, there are localized discrepancies in the behavior of these tracers that have yet to be effectively explained. By comparing the systematics (i.e., source component in the slab, method of transfer to arc magmas) of some of these tracers, it is possible that unexpected geochemical differences within a given region of the arc will enable the causes of these variations to be identified.

${ }^{10} \mathrm{Be} /{ }^{9} \mathrm{Be}$, tracking the input from shallow (<200 mbsf), young hemipelagic sediments, shows a peak in the Nejapa and Masaya volcanoes in eastern Nicaragua (Figure 22a; Morris et al., 1990; Morris et al., 2002a). This ratio smoothly decreases in southeastern Nicaragua and then abruptly drops in the southeast across the Nicaragua/Costa Rica border (Morris et al., 2002a). In contrast to the other Costa Rican volcanoes landward of the Nicoya Peninsula, which have small but measurable enrichments in ${ }^{10} \mathrm{Be} /{ }^{9} \mathrm{Be}$, concentrations of ${ }^{10} \mathrm{Be}$ indistinguishable from background detection limits are recorded in Arenal, the last volcano northwest of the QSC (Figures 8 and 22a). Enriched ${ }^{10} \mathrm{Be}$ concentrations are also absent in Platanar and Irazu, in central Costa Rica (Figure 22a).

$\mathrm{Ba} / \mathrm{La}$ and $\mathrm{U} / \mathrm{Th}$ in arc lavas are typically used as tracers of input from the bulk sediment column at the Middle America Trench, as these ratios are distinctly lower in the mantle than in sediments, they remain fairly constant through the length of drill core sediments, and they do not show fractionation between the upper hemipelagic and lower carbonate layers (Plank and Langmuir, 1998; Patino et al., 2000; Carr et al., 2003). Ba/La is a slightly more robust tracer than $\mathrm{U} / \mathrm{Th}$, which shows more variation with sediment depth and somewhat higher values in the hemipelagic section (Patino et al., 2000; Carr et al., 2003). Ba/La and U/Th increase from Guatemala to a peak in the Telica volcano in 
western Nicaragua. These ratios decrease again in eastern Nicaragua, with the range in $\mathrm{Ba} / \mathrm{La}$ leveling out between southeastern Nicaragua and northwestern Costa Rica. In contrast, U/Th shows lower values in northwestern Costa Rica than southeastern Nicaragua. Central Costa Rican lavas exhibit minimal degrees of slab enrichment of $\mathrm{Ba} / \mathrm{La}$ and $\mathrm{U} / \mathrm{Th}$ (Figure 22b, c).

$\mathrm{B} / \mathrm{Be}$ is also used as a slab tracer, though the boron is more likely derived from the altered oceanic crust than the sediments, based on boron isotope studies in other arcs (e.g., Ishikawa and Nakamura, 1993; Ishikawa and Nakamura, 1994; Ishikawa and Tera, 1997; Clift et al., 2001). In the Central American Volcanic Arc, B/Be also peaks in western Nicaragua, decreasing in eastern Nicaragua and remaining constant across the Nicaragua/Costa Rica border (Figure 22d; Morris et al., 1990). The variability of B/Be within the entire arc appears more scattered compared to the consistent chevron pattern of the sediment tracers, perhaps because input from the sediments may not always change identically with input derived from the subducting oceanic crust.

\subsection{Regional Variations in Arc Geochemistry}

From Guatemala to Nicaragua, the smoothly increasing slab dip has been invoked as the cause of an increasingly concentrated slab flux that produces smaller volumes of higher degree melts, explaining the variable magnitude of the slab signal in this region (Carr et al., 1990; Carr et al., 2003). This model is supported by the pattern of $\mathrm{La} / \mathrm{Yb}$ (lower degrees of melting produces higher $\mathrm{La} / \mathrm{Yb}$ ), which is inversely correlated with the slab signal as traced by Ba/La and U/Th (Carr et al., 2003). Between southeastern Nicaragua and northwestern Costa $\mathrm{Rica}, \mathrm{La} / \mathrm{Yb}$ remains constant, consistent with the similar dip angle of the Wadati-Benioff zone at depth between these two regions (Protti et al., 1995). Though central Costa Rican lavas are often interpreted as distinct from the general trends of the rest of the arc based on the $\mathrm{Pb}$ and $\mathrm{Nd}$ isotope characteristics of the mantle source region (Feigenson and Carr, 1993; Feigenson et al., 1996; Abratis and Wörner, 2001; Carr et al., 2003), the shallower dip and very small slab signal in this region also fit with the Carr et al. (1990) model of slab flux as related to slab dip. 
As the dip angle of the subducting slab beneath the overriding plate steepens from Guatemala to Nicaragua and then shallows beneath central Costa Rica (Table 1; Figure 2 ), the depth of the slab beneath the arc increases and decreases accordingly. Some Nicaraguan arc volcanoes are over $150 \mathrm{~km}$ above the Cocos plate, while northwestern Costa Rican volcanoes are $\sim 100 \mathrm{~km}$ above the plate (Protti et al., 1995). Small offsets between arc segments along strike also affect the distance between the arc and the subducting plate. A significant trenchward jump in the arc is located at the Nicaragua/Costa Rica border (Figure 8), even though Wadati-Benioff Zone seismicity does not record a change in the dip angle of the plate beneath the arc (Protti et al., 1995).

Along strike of the CAVA volcanic front from Guatemala to Nicaragua, as the depth to the slab beneath the arc increases due to an increasing dip angle, the slab signal in the arc lavas also generally increases (Carr et al., 1990). This is in contrast to back-arc volcanoes in Guatemala and Honduras, where large ion lithophile element (LILE)/light rare earth element (LREE) enrichments (i.e., $\mathrm{Ba} / \mathrm{La}$ ) decrease steadily with increasing distance from the front (and increasing depth to the Wadati-Benioff zone), signifying a continuous decline in the slab contribution across the arc (Walker et al., 1995; Patino et al., 1997). However, the principal geochemical trends in the behind-the-front volcanoes are most likely produced by decompression melting (Walker et al., 1995; Patino et al., 1997; Walker et al., 2000), as opposed to the flux melting that dominates the volcanic front (e.g., Reagan et al., 1994; Patino et al., 2000; Thomas et al., 2002; Carr et al., 2003).

An unexplained phenomenon in the arc is the constant range in the $\mathrm{Ba} / \mathrm{La}$ ratio between southeastern Nicaragua and northwestern Costa Rica, where the largest offset in the volcanic front occurs and the depth to the slab from the volcanic front shallows from 150$200 \mathrm{~km}$ beneath Nicaragua to $100 \mathrm{~km}$ beneath Costa Rica. As the inactive Santa Elena Suture bounds the Costa Rican segment of the volcanic arc to the north, it has been suggested that the offset in the arc between Nicaragua and Costa Rica is potentially related to overriding plate crustal structure, as opposed to a boundary in the lower plate (von Huene et al., 2000). Perhaps the magmatic pathways in the upper plate allow for a slab flux beneath Costa Rica to be generated in a thermo-chemical environment similar to 
that for southeastern Nicaragua (consistent with the comparable plate age and slab dip between the two regions), but the melt then migrates trenchward to the current location of the Costa Rican arc.

One complication to this idea is that radiometric dating of ancient arc lavas indicates that the Nicaraguan arc has been moving progressively seaward since $\sim 25 \mathrm{Ma}$ (Ehrenborg, 1996; Plank et al., 2002). The Costa Rican arc was coincident with the Nicaraguan arc until $\sim 10.5 \mathrm{Ma}$, at which time the Costa Rican arc rotated to the modernday forearc area, only migrating landward to its present position after $6.5 \mathrm{Ma}$ (Gans et al., 2002). Therefore, the current gap between the southeastern Nicaragua and northwestern Costa Rican arc segments was larger in the past. The Nicaraguan arc is thought to have been in geochemical steady state since the early Miocene, despite its trenchward migration (Plank et al., 2002). In contrast, northern Costa Rica was subject to a complicated plate tectonic subduction history during the period corresponding to the large seaward rotation and separation of the Costa Rican arc from the Nicaraguan arc (e.g., Hey, 1977; MacMillan et al., 2003). With the southeastward passage of the major heterogeneous features in the subducting plate (e.g., Hey, 1977) and the subsequently more homogeneous tectonic configuration currently beneath southeastern Nicaragua and northwestern Costa Rica, it is possible that the northwestern Costa Rica arc is now reestablishing itself in response to the renewed similarities in the subducting plate regimes. As such, the landward progression of the arc may be a function of melt generation at depths deeper than the location of the plate directly below the current arc.

\section{$6.3{ }^{10}$ Be Mobility in Fluids}

$\mathrm{B} / \mathrm{Be}, \mathrm{U} / \mathrm{Th}$, and $\mathrm{Ba} / \mathrm{La}$ are all ratios coupling a fluid-mobile element to an element that is incompatible in melt but not in hydrous fluids (e.g., Brenan et al., 1995; Brenan et al., 1998b). Subduction-related metamorphic rocks in terranes such as the Catalina Schist have boron concentrations that decrease proportionally with $\mathrm{H}_{2} \mathrm{O}$ concentrations in rocks of increasing metamorphic grade (Leeman et al., 1992; Moran et al., 1992; Domanik et al., 1993; Bebout et al., 1993, 1999). However, the Be concentrations in these rocks 
remained relatively constant even with increasing levels of devolatilization; average $\mathrm{Be}$ concentrations were constant within one or two standard deviations across metamorphic grades (Domanik et al., 1993; Bebout et al., 1993). Solid-fluid partition coefficients for beryllium are consistently at least two orders of magnitude larger than partition coefficients for boron at $900^{\circ} \mathrm{C}$ and $2.0 \mathrm{GPa}$ (Brenan et al., 1998b). Experiments on serpentinite at $850^{\circ} \mathrm{C}$ and $1.5 \mathrm{GPa}$ showed that only small amounts of beryllium were liberated with $\mathrm{H}_{2} \mathrm{O}$ during dehydration (Tatsumi and Isoyama, 1988).

White mica is thought to be the dominant mineral host of $\mathrm{Be}, \mathrm{B}$, and $\mathrm{Ba}$ in subducting sediments and oceanic crust (Domanik et al., 1993; Bebout et al., 1993, 1999). Within white mica, Be concentrations do not show significant decrease with increasing metamorphic grade (Domanik et al., 1993). Stability experiments on phengitic muscovite have shown that in hydrous sediments and warm subduction zone P-T conditions the phase persists until 180--240 km depth (Domanik and Holloway, 1996). Pore water and sediment distributions of ${ }^{9} \mathrm{Be}$ and ${ }^{10} \mathrm{Be}$ show only small degrees of Be mobilization from sediments during pore fluid expulsion (e.g., particulate Be $10^{5}$ times greater than seawater $\mathrm{Be})$. At higher pressures and temperatures and lower $\mathrm{pH}, \mathrm{Be}_{\text {solid }} / \mathrm{Be}_{\text {fluid }}$ between sediment and pore water decreased by an order of magnitude but was still large (You et al., 1994, 1996). In laboratory melting experiments, Johnson and Plank (1999) found that below the solidus at $750^{\circ} \mathrm{C}$, less than $10 \%$ of the Be was lost from sediments.

\section{$6.4^{10}$ Be Transfer to the Central American Volcanic Arc: Fluid vs. Melt}

Though the general covariation of ${ }^{10} \mathrm{Be} /{ }^{9} \mathrm{Be}$ with tracers such as $\mathrm{Ba} / \mathrm{La}$ or $\mathrm{B} / \mathrm{Be}$ (Figure 23) has led to the use of $\mathrm{Ba} / \mathrm{La}$ and $\mathrm{B} / \mathrm{Be}$ as proxies for ${ }^{10} \mathrm{Be} /{ }^{9} \mathrm{Be}$, there are two notable exceptions in these correlations for Central American Volcanic Arc lavas. These different ratios are not correlated where they peak in Nicaragua and where they decrease in Costa Rica. These disparities illustrate the likelihood that either ${ }^{10} \mathrm{Be}$, or the surficial sediment package carrying ${ }^{10} \mathrm{Be}$, is not uniformly subject to the same processes as tracers of bulk sediment recycling or altered oceanic crust recycling throughout the arc. Discerning why the surficial sediments are decoupled from the sources of other signals of slab component 
recycling is complicated by the controversy surrounding how ${ }^{10} \mathrm{Be}$ is incorporated into arc magmas. In arc magmas, ${ }^{10} \mathrm{Be}$ has been demonstrated to correlate well with element and isotope ratios (e.g., $\left.{ }^{238} \mathrm{U}\right) /\left({ }^{232} \mathrm{Th}\right)$ ) that are thought to reflect hydrous fluid mobility (e.g., Morris et al., 1990; Sigmarsson et al., 1990; McDermott and Hawkesworth, 1991; Sigmarsson et al., 2002). However, as discussed in Section $6.3,{ }^{10} \mathrm{Be}$ is highly incompatible in melts (e.g., Brenan et al., 1998a; Johnson and Plank, 1999; Ryan, 2002) but does not appear fluid-mobile, implying ${ }^{10} \mathrm{Be}$ transfer in some arcs may require sediment melting (e.g., review in Ryan, 2002).

Recycling efficiencies for ${ }^{10} \mathrm{Be}$ in Nicaragua (i.e., the fraction of ${ }^{10} \mathrm{Be}$ input to the arc magmas that erupts in the arc lavas) are calculated to be at least 30\% (Morris et al., 2002a). The large solid/fluid distribution coefficients for Be seem to require at least some amount of partial melting of the sediments carrying the ${ }^{10} \mathrm{Be}$ to produce the high concentrations of ${ }^{10} \mathrm{Be}$ in Nicaraguan lavas, a scenario that is also supported by studies of Th fluid mobility and recycling in arcs (Ryan and Langmuir, 1988; Morris et al., 1990; Plank and Langmuir, 1993; Gill et al., 1993; Reagan et al., 1994; Elliott et al., 1997; Hawkesworth et al., 1997; Johnson and Plank, 1999; Morris et al., 2002a). The additional observation of the co-variation of ${ }^{10} \mathrm{Be}$ with ${ }^{230} \mathrm{Th}$ rather than ${ }^{238} \mathrm{U}$ in Nicaragua (Reagan et al., 1994) and the Bismarck arc (Gill et al., 1993) is also difficult to explain if the only mode of transfer from the slab is via a hydrous fluid.

For back arc volcanoes where the slab might reach depths great enough to allow sediment melting, the sediment component may well be a partial melt enriched in both mobile and immobile elements, as suggested by Morris et al. (2002a) and supported by back arc studies in the Kuriles, Aleutians, and Bismarck Arcs that measured high ${ }^{10} \mathrm{Be}$ and $\mathrm{Ba}$ (sometimes higher than the volcanic front) (Tera et al., 1993; Ryan et al., 1995; Morris and Tera, 2000; Morris et al., 2002a). However, thermal models have not unequivocally demonstrated that sediments achieve temperatures high enough to undergo partial melting at the depths beneath volcanic fronts (e.g., Peacock, 1996).

Isotope studies in some arcs indicate hydrous geochemical transfer of geochemical constituents is a dominant process in magma genesis. For example, Clift et al. (2001) 
argue that $\mathrm{B}$ isotopes in Tonga are too $\delta^{11} \mathrm{~B}$ positive unless most of the boron is carried by hydrous fluids, i.e., boron is not transported from the slab in a melt. Studies of uranium series isotopes in arcs have led to models that support the idea of a slab-derived aqueous fluid that fluxes partial melting in the mantle (e.g., Reagan et al., 1994; Stolper and Newman, 1994; Elliott et al., 1997; Thomas et al., 2002). To explain the correlation of

${ }^{10} \mathrm{Be}$ with elements such as boron and barium, it would seem to be necessary for an aqueous fluid to also flux sediment melting in a degree proportional to the amount of fluid. Johnson and Plank (1999) suggested that it is possible that geodynamic model constraints on the thermal conditions of sediments in subduction zones might need to be revised.

We would also like to suggest an unexpected potential source of higher slab temperatures than would be assumed in a normal subduction zone model, at least beneath Central America. A recent tomographic study of Central America has imaged slab detachment below $\sim 200 \mathrm{~km}$ depth, which has resulted in a $300 \mathrm{~km}$ wide gap in the subducted slab extending parallel to the Middle America Trench from the Tehuantepec Ridge (Figure 3) in the northwest to the Cocos-Nazca-Pacific triple junction trace (CNS1/CNS-2 boundary in Figure 4)) at the southeastern edge of the Nicoya Peninsula (Rogers et al., 2002). Hot, upwelling asthenosphere following slab detachment may cause heating of the overlying material for several million years after the event, resulting in a temperature increase of $>500^{\circ} \mathrm{C}$ (van de Zedde and Wortel, 2001). The inflowing asthenosphere, which can be observed in the tomographic images of Rogers et al. (2002) beneath the undetached portion of the subducting slab, may potentially elevate the temperature of the subducting slab beneath the arc as far southeast as the QSC, such that the sediments might achieve partial melting under Nicaragua and northwestern Costa Rica. However, this hypothesis is speculative and would require new thermal models that incorporate heating of the slab at $200 \mathrm{~km}$ depth to determine if this is a viable scenario. 


\section{7. ${ }^{10}$ Be: Implications for Sediment Recycling}

\subsection{Transitions in ${ }^{10}$ Be and Fault Relief}

Regardless of how ${ }^{10} \mathrm{Be}$ is transferred from the slab into the arc magmas, the presence of small but real ${ }^{10} \mathrm{Be}$ enrichments in the northern Costa Rican lavas imposes stronger constraints on models of Be recycling than did the absence of ${ }^{10} \mathrm{Be}$ in earlier measurements (e.g., Morris et al., 1990). As ${ }^{10} \mathrm{Be}$ will vary far more drastically from processes affecting only the uppermost sediments than $\mathrm{Ba} / \mathrm{La}$ or $\mathrm{B} / \mathrm{Be}$, its reduction or absence in a region where the other tracers remain constant, such as in northwestern Costa Rica, reflects an important change in the delivery of the surface sediment component that does not affect the rest of the slab.

In an area where most tectonic parameters appear constant but the degree of bendingrelated faulting in the crust subsides, the dramatically higher slab signal in Nicaragua compared to Costa Rica has resulted in the hypothesis of a link between faulting in the Cocos plate and subduction recycling of sediment tracers (Kelly and Driscoll, 1998; Patino et al., 2000; von Huene et al., 2000; Rupke et al., 2002). Kelly and Driscoll (1998) suggested that high-relief basement faults offshore of Nicaragua would preferentially preserve the uppermost sediment column carrying ${ }^{10} \mathrm{Be}$ to the depths of magma genesis, whereas the smaller faults to the southeast with relief less than the sediment thickness would potentially allow for the loss of the surficial sediments, possibly through underplating.

Our results demonstrate that the transition in the degree of basement fault relief appears to be spatially coincident with the transition zone in ${ }^{10} \mathrm{Be}$ enrichment. The shift from high fault relief to low fault relief occurs through a region 875 to $975 \mathrm{~km}$ along the trench, with distances referenced orthogonally across the trench to the volcanic arc (Figure 24; see figure caption for explanation of distances). The first northwestern Costa Rica volcanoes, El Hacha and Orosi, which display the sharp decrease in ${ }^{10} \mathrm{Be}$ compared to the southeastern Nicaragua volcano Concepcion, are located 852 and $862 \mathrm{~km}$ along the volcanic arc. Arenal, the first volcano to record no measurable ${ }^{10} \mathrm{Be}$ enrichment, is 958 $\mathrm{km}$ along the volcanic front. 
Comparing the change in fault relief to the ${ }^{10} \mathrm{Be}$ in the corresponding volcanoes orthogonally across the trench requires a relatively short elapsed time (less than a few hundred kyr) between loss of ${ }^{10} \mathrm{Be}$ from the sediments and subsequent eruption. This allows us to make the assumption that the plate currently subducting at the trench can be projected directly across the trench beneath the arc. The only constraints on mantle residence times for ${ }^{10} \mathrm{Be}$ in Nicaragua come from a study of Nicaraguan arc volcanic rocks in which ${ }^{10} \mathrm{Be}$ was shown to be correlated with Th isotopes but not $\mathrm{U}$-excesses, leading to the conclusion that ${ }^{10} \mathrm{Be}$ had been added to the arc volcanic magma source between $300 \mathrm{ka}$ and $2 \mathrm{Ma}$ (Reagan et al., 1994). However, new work incorporating the results from Reagan et al. (1994) finds that the linear relationships observed between ${ }^{10} \mathrm{Be}$ and other isotopes could have been generated through the effects of flux-ingrowth melting, rather than a specific isochronous relationship (Thomas et al., 2002).

${ }^{10} \mathrm{Be}$ flux balances in Nicaragua justify the expectation of short mantle residence times for ${ }^{10} \mathrm{Be}$. In calculating the recycling efficiency of ${ }^{10} \mathrm{Be}$ through the subduction zone, the shortest path is assumed, i.e., subduction time is calculated based on convergence rates, dip angle, and distance of the plate from the trench to beneath the arc, with the time of transfer from slab to volcano regarded as comparatively inconsequential (e.g., Morris et al., 2002a; Valentine et al., 1997; Valentine et al., submitted). For a subduction time of 2.5 Myr in Nicaragua, the calculated recycling efficiency is $\sim 30 \%$, which is the highest for arcs globally (Morris et al., 2002a). If an increased mantle residence time for the ${ }^{10} \mathrm{Be}$ were added to the subduction time, recycling efficiency would have to increase to account for the additional decay of ${ }^{10} \mathrm{Be}$. In Costa Rica, the calculated recycling efficiency decreases to $2 \%$, despite a slightly faster convergence rate, higher ${ }^{10} \mathrm{Be}$ sediment input at the trench, and shorter distance from the trench to beneath the arc compared to Nicaragua (Morris et al., 2002a). It is possible that this reduction could simply be a function of longer mantle residence times, but it is unclear why this would occur beneath northwestern Costa Rica. Nor is it evident why the mode of geochemical transfer from the slab would abruptly transition from partial melting of sediments beneath southeastern Nicaragua to fluid transport beneath northwestern Costa Rica. As such, we 
favor an explanation that invokes a physical change in the delivery of the amount of ${ }^{10} \mathrm{Be}$ bearing sediments to the depths of arc magma genesis along strike.

In the event that the elapsed time between the release of ${ }^{10} \mathrm{Be}$ (through dehydration or partial melting) and its eventual volcanic expulsion was longer than what is currently indicated, plate motions through time would have to be taken into account. If the boundary demarcating the transition zone into lower fault relief could be approximated as a lineation exactly parallel to the strike of the plate convergence direction, it would remain stationary relative to the overriding plate. In contrast, the slight acute obliquity between the strike of the EPR/CNS-1 boundary and the strike of the convergence direction $\left(\sim 12^{\circ}\right)$ has resulted in northwestern migration of the EPR/CNS-1 boundary relative to the trench by $\sim 20 \mathrm{~km} / \mathrm{Myr}$ (Barckhausen et al., 2001). Therefore, if the location of the RMS height boundary were subparallel to the convergence direction to depths beneath the arc, the RMS height transition zone would also have migrated through time. However, as discussed above, mantle residence times long enough ( $>1 \mathrm{Myr})$ to allow significant movement of the plate beneath the arc after ${ }^{10} \mathrm{Be}$ was incorporated into the arc magmas seem unlikely based on Th isotope systematics (Reagan et al., 1994) and calculated recycling efficiencies for Nicaragua (Morris et al., 2002a).

The along strike offset between the beginning of the ${ }^{10} \mathrm{Be}$ transition zone at $852 \mathrm{~km}$ and the RMS height transition zone beginning at $875 \mathrm{~km}$ may even be reduced if projections across the bending axis are considered. For illustrative purposes, we assume a bending axis parallel to the strike of the dipping plate. In northwestern Costa Rica, the trend of the $100 \mathrm{~km}$ depth isobath is $\sim \mathrm{N} 42^{\circ} \mathrm{W}$ in map view (Protti et al., 1995). Bending a lineation less than perpendicular to the bending axis (i.e., more northerly than $\mathrm{N} 48^{\circ} \mathrm{E}$ ) would subsequently deflect it by some amount to the north, depending on trend of lineation and dip. For example, the EPR/CNS-1 boundary trends $N 43^{\circ} \mathrm{E}$ (Barckhausen et al., 2001). Bending the EPR/CNS- 1 boundary across an axis of $\mathrm{N} 42^{\circ} \mathrm{W}$ by $80^{\circ}$ (the plate dip at $>100$ $\mathrm{km}$ depth; Protti et al., 1995) yields a new trend of $\mathrm{N} 21^{\circ} \mathrm{E}$ (plunging $78^{\circ}$ ) (Figure 25). Therefore, depending on the orientation of the RMS height boundary with respect to the 
bending axis for that region of the plate, the region of low RMS height could possibly be located beneath the El Hacha and Orosi volcanoes (locations shown in Figure 8).

In contrast to our model for a relationship between basement fault relief and arc volcanic ${ }^{10} \mathrm{Be}$ between Nicaragua and Costa Rica, a scenario has also been proposed in which the high-relief faults offshore of Nicaragua result in preferential fluid transport of ${ }^{10}$ Be beneath the Nicaraguan but not the Costa Rican arc (e.g., Rupke et al., 2002). Outer rise faults in the Cocos plate offshore of Nicaragua, which extend $>20 \mathrm{~km}$ into the slab (Ranero et al., 2001), could allow for increased hydration and serpentinization in the subducting plate offshore from Nicaragua compared to the oceanic crust offshore of Costa Rica (Patino et al., 2000; von Huene et al., 2000; Ranero et al., 2001). During subduction, this hydration would result in additional fluid release, and perhaps fluidfluxed sediment melting, that would enhance transport of slab components such as $\mathrm{Ba} / \mathrm{La}$ to the Nicaraguan arc (e.g., Patino et al., 2000; von Huene et al., 2000; Rupke et al., 2002). As ${ }^{10} \mathrm{Be}$ and $\mathrm{Ba} / \mathrm{La}$ co-vary in much of the arc, Rupke et al. (2002) also invoked this mechanism to explain ${ }^{10} \mathrm{Be}$ variations.

Fluid transfer model parameters that use basement faults to completely hydrate a $10 \mathrm{~km}$ upper layer prior to subduction offshore of Nicaragua (e.g., Rupke et al., 2002) may be unrealistic, as serpentinization of this amount of peridotite would cause considerable isostatic uplift due to the lower density of serpentinite compared to peridotite. Yet a new seismic velocity study of the Nicaraguan slab concludes that the Nicaraguan slab is twice as hydrous as other slabs at the 2.5 GPa conditions of the study (Abers et al., 2003). Abers et al. (2003) hypothesize instead that the extensive hydration of the slab may be caused by updip flow of fluids produced by dehydration reactions at $>75 \mathrm{~km}$ slab depth (e.g., Hacker et al., 2003), possibly augmented by only partial hydration via the outer rise extensional faults, which are spaced several $\mathrm{km}$ apart.

Though differential fluid flux would likely result in variable transport and therefore enrichment of fluid-mobile element signatures (i.e., $\mathrm{Ba} / \mathrm{La}$ ), this increased hydration of the Nicaraguan slab is unlikely to affect the relatively fluid immobile ${ }^{10} \mathrm{Be}$ (see Section 6.3). It should also be noted that Rupke et al. (2002) were comparing northwestern 
Nicaragua with central Costa Rica, as opposed to the contrast between southeastern Nicaragua and northwestern Costa Rica considered here. Unlike ${ }^{10} \mathrm{Be}$, the range in $\mathrm{Ba} / \mathrm{La}$ remains constant from southeastern Nicaragua through the volcanoes opposite the transition region in RMS height. The $\mathrm{Ba} / \mathrm{La}$ ratios only consistently decrease again southeast of the Quesada Sharp Contortion, where major tectonic parameters such as plate age, dip angle, and plate roughness also change (Figure 24). Lavas from the Arenal volcano in northwestern Costa Rica have ${ }^{10} \mathrm{Be} /{ }^{9} \mathrm{Be}$ values indistinguishable from mantlederived lavas, but they have $\mathrm{Ba} / \mathrm{La}$ ratios that are comparable to the $\mathrm{Ba} / \mathrm{La}$ ratio of the Concepcion lava in southeastern Nicaragua that has enriched ${ }^{10} \mathrm{Be} /{ }^{9} \mathrm{Be}$ (Figure 23a). Though $\mathrm{Ba} / \mathrm{La}$ can be highly variable within one volcanic center, the absence of a significant decrease in the maximum $\mathrm{Ba} / \mathrm{La}$ ratios between southeastern Nicaragua and northwestern Costa Rica does not support a change in the sediment-derived, aqueous fluid component as the source of the change in ${ }^{10} \mathrm{Be}$ enrichment.

If the $\mathrm{Ba} / \mathrm{La}$ signal is controlled by increased fluid flux as a result of higher degrees of hydration in the Nicaraguan crust compared to Costa Rica (e.g., von Huene et al., 2000; Rupke et al., 2002), it seems likely that a change in slab hydration is not present between southeastern Nicaragua and northwestern Costa Rica. Though larger fault relief may contribute to hydration and therefore higher fluid release from the crust subducting beneath Nicaragua (e.g., Ranero et al., 2001; Rupke et al., 2002), differences in fault relief between the regions of the plate offshore of southeastern Nicaragua and northwestern Costa Rica may not be large enough to substantially affect fault-induced hydration of the oceanic crust prior to subduction. However, as the RMS height along strike does have a peak fairly close to the peak in $\mathrm{Ba} / \mathrm{La}$, perhaps the larger contrast between the faults offshore of northwestern Nicaragua and the faults southeast of the RMS height transition zone could still be a factor in generating the pronounced change in the $\mathrm{Ba} / \mathrm{La}$ signature between Nicaragua and central Costa Rica (e.g., von Huene et al., 2000; Rupke et al., 2002). 


\subsection{Shallow Sediment ${ }^{10}$ Be Removal Via Underplating}

In order to link the transition in basement fault relief to the transition in ${ }^{10} \mathrm{Be}$ in northwestern Costa Rica, we must find a mechanism that affects ${ }^{10} \mathrm{Be}$ but not $\mathrm{Ba} / \mathrm{La}$ or $\mathrm{B} / \mathrm{Be}$, since $\mathrm{Ba} / \mathrm{La}$ and $\mathrm{B} / \mathrm{Be}$ remain constant through southeastern Nicaragua and northwestern Costa Rica. Also, fault relief is not linearly related to ${ }^{10} \mathrm{Be}$ within the entire region of Nicaragua and Costa Rica region, even when contiguous RMS height data regions are averaged together to smooth out scatter (Figure 26). Therefore, we offer a hypothesis in which bending-induced faulting is not the dominant control on the overall variation in ${ }^{10} \mathrm{Be}$ between Nicaragua and Costa Rica, but it does play a role in reducing the ${ }^{10} \mathrm{Be}$ recycling between southeastern Nicaragua and northwestern Costa Rica without affecting other slab tracers.

Mass balance calculations by Valentine et al. (1997, submitted) indicate that $\sim 80 \mathrm{~m}$ of underplating of the sediment column being subducted offshore of Costa Rica, or a maximum of $2 \mathrm{~km}^{3} / \mathrm{km}$ arc length per Myr, would account for the low ${ }^{10} \mathrm{Be}$ concentrations observed in northwestern Costa Rican arc lavas. Initiation of a décollement within a subducting sediment section can be promoted by material properties of the sediment such as a weak stratigraphic layer (e.g., Pickering, 1993), or the presence of a horizon below which elevated pore pressures serve to create a slip surface within the incoming section (e.g., von Huene and Scholl, 1991).

Consolidation tests of the underthrust sediments of ODP Site 1040 (located in Figure 8) in the toe of the Costa Rica prism show a transition in excess pore pressures within the hemipelagic Cocos plate sediments (Saffer et al., 2000). Approximately $80 \mathrm{~m}$ below the top of the compacted lower plate sediment column, excess pore pressures increase from pressures consistent with partial fluid escape to values almost as high as those expected from undrained loading beneath the forearc (Saffer et al., 2000). Furthermore, detailed analysis of seven seismic profiles offshore of the Nicoya Peninsula by McIntosh and Sen (2000) shows that after initial rapid thinning, the upper part of the underthrust sedimentary section is structurally thickened as it moves $3-5 \mathrm{~km}$ landward from the trench. This thickening requires slip on fault surfaces below the original décollement. 
Even though the entire sediment column is initially underthrust along the ODP Leg 170 transect offshore of Costa Rica, relocation of the décollement deeper within the subducting sediment column may account for the underplating of the youngest, shallowest sediments.

It has been suggested that large horst and graben structures, with relief equal to the thickness of the sediment layer mantling the subducting plate, cause the décollement to form at the top of the basement fault blocks (Schweller and Kulm, 1978; Hilde, 1983; von Huene and Scholl, 1991). Conversely, when basement relief is small compared to the thickness of the overlying sediments, the position of the décollement is not influenced by the basement fault structure of the downgoing plate (Schweller and Kulm, 1978; Hilde, 1983; von Huene and Scholl, 1991). As the Cocos plate flexes into the Middle America Trench northwest of the Nicaragua/Costa Rica border, it forms fault blocks with throws equal to or greater than the overlying sediment thickness ( 400-500 m), creating corresponding surface relief. Offshore of Costa Rica, the fault relief abruptly decreases such that it is barely visible in the bathymetric roughness. We propose that it is this absence of large fault throws in the subducting plate offshore of Costa Rica that allows for the eventual formation of a décollement within the subducting sediment.

The consequence of establishing a décollement within the down-going sediments is that the uppermost, ${ }^{10} \mathrm{Be}$-bearing sediments are underplated, which results in the small enrichment of ${ }^{10} \mathrm{Be}$ in the northwestern Costa Rican volcanoes compared to the southeastern Nicaraguan volcanoes. Offshore of Nicaragua, the large basement fault relief would minimize or inhibit the development of a décollement within the subducting sediment package. The high ${ }^{10} \mathrm{Be}$ signature of the Nicaraguan arc volcanoes illustrates that geochemical components from surficial sediment are recycled into the arc magmas. Therefore, in these regions where bending-induced extensional faults have throws that are equal to or greater than the overlying sediment thickness, the surficial sediment appears to be efficiently subducted to the depths of magma genesis.

This mechanism of underplating does not produce a linear relationship between fault relief and arc ${ }^{10} \mathrm{Be}$ enrichment (Figure 26), because the fault relief would have a threshold 
effect rather than acting as a constant control (Figure 24). Below a certain amount of fault relief, the décollement may relocate, but the depth of the new décollement would be determined by material properties in the sediments as discussed above. Above a certain amount of fault relief, the sediment package may be subducted in its entirety to the region of magma genesis. At that point, the transfer of geochemical constituents out of the slab (i.e., the recycling efficiency) will be a function of processes governed by the thermal regime, fluid flux, and/or degree of partial melting. Where the plate is either consistently highly flexed or completely lacking in significant faulting, models explaining regional geochemical variations via the changes in focused slab flux (e.g., Carr et al., 1990; Carr et al., 2003) or differential fluid release (e.g., Patino et al., 2000; von Huene et al., 2000; Rupke et al., 2002) seem to provide good explanations for variation of $\mathrm{Ba} / \mathrm{La}, \mathrm{B} / \mathrm{Be}$, and even ${ }^{10} \mathrm{Be} /{ }^{9} \mathrm{Be}$ on a larger scale.

\subsection{Underplating vs. Tectonic Erosion}

Though the underplating scenario seems a relatively simple means by which most of the ${ }^{10} \mathrm{Be}$ subducting beneath Costa Rica can be removed without affecting any other tracers, there are two major caveats to this hypothesis. The first is that tectonic erosion (e.g., Ranero and von Huene, 2000; von Huene et al., 2000) can not be conclusively dismissed as a viable alternative explanation for low ${ }^{10} \mathrm{Be}$, in which erosion of material from the overlying plate dilutes the incoming ${ }^{10} \mathrm{Be}$ signal. From subsidence rates based on benthic foraminifera and sedimentology data from ODP Site 1042 located within the Nicoya Peninsula forearc, Vannucchi et al. (2001) calculated $\sim 36 \mathrm{~km}^{3}$ of erosion per $\mathrm{km}$ of arc length per Myr, over a time frame since 16-17 Ma. This volume of added material, if it had no ${ }^{10} \mathrm{Be}$, could potentially reduce the ${ }^{10} \mathrm{Be}$ flux to the arc to the level calculated for the northwestern Costa Rican volcanoes.

However, this amount of erosion might also affect the other slab tracers, such as $\mathrm{Ba} / \mathrm{La}$, in some way. If the eroded material were accretionary prism sediment, the sediment subducted to depth would have geochemical characteristics dominated by hemipelagic or terrigenous sediments. This seems inconsistent with interpretations of Costa Rican arc 
geochemistry that suggest the Ba/Th ratios (e.g., Patino et al., 2000; Plank et al., 2002) and nitrogen isotope data (e.g., Fisher et al., 2002) indicate a significant contribution from carbonate sediments beneath Costa Rica with no detectable hemipelagic component. The geochemistry seems more easily explained by underplating of the majority of the incoming hemipelagic sediments, allowing the carbonate section to subduct to depth (e.g., Patino et al., 2000; Fischer et al., 2002).

Seismic velocities of $4-6 \mathrm{~km} / \mathrm{s}$ beneath the lower and middle slope of the Nicoya Peninsula forearc are interpreted as igneous rock, presumably the ophiolitic Nicoya Complex (Christeson et al., 1999; Sallares et al., 2001). Therefore, Ranero and von Huene (2000) concluded that the eroded material transported into the subduction zone is igneous basement from the forearc. While this would have the effect of reducing the proportion of hemipelagic sediment contribution from the slab, it does not seem likely that the low, MORB-like concentrations of slab tracers present in Nicoya Complex material (Sinton et al., 1997) would result in nearly constant flux of elements such as barium while diluting ${ }^{10} \mathrm{Be}$. A mass balance model that invoked tectonic erosion of Nicoya Complex material to explain the ${ }^{10} \mathrm{Be}$ decrease across the Nicaragua/Costa Rica border would also have to account for slab tracer ratios that remain elevated and relatively constant across the Nicaragua/Costa Rica border, such as $\mathrm{Ba} / \mathrm{La}$ and $\mathrm{Ba} / \mathrm{Th}$ (e.g., Patino et al., 2000; Carr et al., 2003).

It may be possible that erosion of igneous rock can account for both the constant range of ratios such as $\mathrm{Ba} / \mathrm{La}$ as well as low ${ }^{10} \mathrm{Be}$ concentrations in Costa Rican arc volcanics, even given the additional complication of the transition from depleted mantle characteristics beneath Nicaragua to a more enriched, OIB-like mantle for Costa Rica (e.g., Feigenson and Carr, 1993; Herrstrom et al., 1995; Carr et al., 2003). As velocities in the Cascadia forearc comparable to those in the Costa Rican margin wedge were interpreted as highly dewatered, compacted sediments (Flueh et al., 1998), it may also be possible that there is erosion of an older, compacted wedge sediment component that would contain high $\mathrm{Ba} / \mathrm{La}$ ratios but no ${ }^{10} \mathrm{Be}$. However, constructing an appropriate mass balance model is beyond the scope of this study. 
The other major caveat to the underplating model is that it is unlikely that underplating would be operating in an area of subsidence. Vannucchi et al. (2001) suggest that the region of the forearc within $10 \mathrm{~km}$ of the trench is subsiding. Thus, if underplating is occurring, it must be farther inland. Using layer thicknesses and velocities for the Nicoya Peninsula in Sallares et al. (2001) to construct a simple 1-D isostatic column at an arbitrary distance $40 \mathrm{~km}$ landward of the trench, we calculate that $2 \mathrm{~km}$ of underplated sediments (e.g., the upper limit per Myr from Valentine et al., submitted) of $1.6 \mathrm{~g} / \mathrm{cm}^{3}$ density (e.g., McIntosh and Sen, 2000) would require a maximum of $\sim 1.5 \mathrm{~km}$ of uplift. This prediction of uplift is a maximum because sediment density increases during subduction due to compaction and dehydration of minerals. While Plio-Pleistocene uplift rates of slightly less than $1 \mathrm{~m} / \mathrm{kyr}$ were estimated from an exposure along the southeastern edge of the Nicoya Peninsula, the only data for the northwestern edge of the Nicoya Peninsula is from a Holocene terrace with a measured rate of uplift of $1.6 \pm 2.0$ $\mathrm{m} / \mathrm{kyr}$ (Gardner et al., 1992). In order to evaluate whether underplating has occurred over the past $2 \mathrm{Myr}$, subsidence or uplift rates farther inland from the trench would have to be determined.

As $2 \mathrm{~km}$ of underplated sediments per Myr assumes constant underplating to balance the lowest Costa Rican arc ${ }^{10} \mathrm{Be}$ concentrations (Valentine et al., submitted), the necessary uplift response would be lessened if underplating were episodic. A periodic underplating mechanism might account for the higher ${ }^{10} \mathrm{Be}$ concentration in Miravalles volcano compared to the other northwestern Costa Rican volcanoes. Episodic underplating would also be consistent with basement fault heterogeneities in the subducting plate, such as infrequent seamount subduction or variability in fault throw at the trench. If basement relief were close to the underplating threshold, small changes in extensional basement faulting could even have allowed for temporarily underplated sediments to later erode, after ${ }^{10} \mathrm{Be}$ concentrations significantly decayed.

Though still equivocal, the onset of episodic underplating related to the absence of significant basement fault relief in the subducting plate is a probable mechanism for explaining the ${ }^{10} \mathrm{Be}$ systematics of the northwestern Costa Rica segment from $2 \mathrm{Ma}$ to the 
present. Subduction erosion may have played an important role in sediment dynamics and geochemical characteristics over the longer time frames ( $16 \mathrm{Myr}+)$ addressed by Vannucchi et al. (2001). The small amounts of sediment removal that would be required to reduce ${ }^{10} \mathrm{Be}$ arc volcanic concentrations to the levels measured in northwestern Costa Rica would have little effect on the concentrations of other elements commonly fluxed out of the subducting slab (e.g., Valentine et al., 1997, submitted). The enrichment of ${ }^{10} \mathrm{Be}$ in only the youngest, shallowest sediments gives an underplating model the advantage of a simple way to account for the decrease in ${ }^{10} \mathrm{Be}$ concentrations between southeastern Nicaragua and northwestern Costa Rica, without necessitating changes in recycling of the other myriad geochemical components that are present through the bulk of the sediment column, the altered oceanic crust, and the mantle wedge.

The initiation of underplating, within a subduction erosion regime that has been present over longer time scales, may indicate that the subduction systematics of the Costa Rican arc have not been in steady state, perhaps even since the Miocene when the arc began its trenchward rotation (e.g., Gans et al., 2002). Though the geochemical consistency of the Nicaraguan volcanic rocks from the Miocene to the present-day supports the idea of steady state subduction in this region (e.g., Plank et al., 2002), it seems that the position and geochemistry of the Costa Rican arc has been constantly evolving on short time scales (e.g., MacMillan et al., 2003). If the current geochemistry of the northwestern portion of the Costa Rican arc has been influenced by structural changes in the subducting Cocos plate (i.e., the northwestern migration of the EPR/CNS-1 boundary along the trench to its present location), the geochemical signatures of older ( $>3 \mathrm{Ma}$ ) Costa Rican arc volcanic rocks would provide for a useful comparison. Unfortunately, any ${ }^{10} \mathrm{Be}$ enrichment would have decayed away, but the other trace element characteristics may still shed light on the temporal development of Costa Rican subduction systematics, such as the impact of tectonic erosion on sediment recycling. 


\section{Conclusions}

Extensional faulting in the Cocos plate at the Middle America Trench exhibits marked differences along strike from Nicaragua to Costa Rica. Basement fault relief peaks offshore of northwest/central Nicaragua, consistent with the more pronounced degree of plate curvature to the northwest. Offshore of Nicaragua, fault throw is comparable to or greater than the thickness of the subducting sediment column at the trench. Offshore of Costa Rica, the fault relief is always smaller than the overlying sediment thickness. This decrease in bending-related faulting between Nicaragua and northwestern Costa Rica is caused by a reduction in Cocos plate curvature as it bends into the Middle America Trench. The change in curvature and the progressive shoaling of the trench offshore of southeastern Nicaragua and northwestern Costa Rica appear unrelated to local variations in plate age. Instead, the thicker, younger, and hotter CNS-2 and Cocos Ridge crust subducting offshore of southeastern Costa Rica creates a buoyant load that may induce a lateral flexural response to the northwest. Thus, while Cocos plate flexure offshore of Guatemala, El Salvador, and Nicaragua is likely to be a function of elastic thickness as controlled by plate age, flexural curvature in the plate offshore of northwestern Costa Rica may be inhibited due to lateral flexure caused by other buoyancy effects.

${ }^{10} \mathrm{Be}$ concentrations in the Central American Volcanic Arc abruptly decrease between southeastern Nicaragua and northwestern Costa Rica, falling from a maximum recycling efficiency in Nicaragua to a greatly reduced efficiency in northwestern Costa Rica (Morris et al., 2002a). Farther southeast in the volcanic chain, arc volcanoes contain no measurable ${ }^{10} \mathrm{Be}$ concentrations (Morris et al., 1990). The transition zone in ${ }^{10} \mathrm{Be}$ is nearly coincident in distance along the arc-trench system with the transition zone in basement fault relief associated with plate bending. We propose that when basement fault throw is equal to or greater than the overlying sediment thickness, as offshore from Nicaragua, the rough basement morphology of the subducting plate inhibits the formation of a décollement within the subducting sediment column. Establishing the décollement above the shallow sediments of the lower plate enhances subduction of the entire sediment 
package to depths of magmatic incorporation into the arc, consistent with enriched ${ }^{10} \mathrm{Be}$ arc volcanic concentrations.

The absence of high-relief faults, as offshore of Costa Rica, could allow for the décollement to eventually develop within the lower plate sediments. The depth of the relocated décollement will be a function of material properties within the sediment column, and thus the reduction in ${ }^{10} \mathrm{Be}$ recycling will be abrupt, and not linearly related to the basement fault relief. Subsequent underplating of the surficial sediments would remove a large enough portion of the young, surficial, ${ }^{10} \mathrm{Be}$-bearing hemipelagic sediment layer to significantly decrease the flux of ${ }^{10} \mathrm{Be}$ to the depths of arc magma genesis, without necessarily affecting other slab tracers such as $\mathrm{Ba} / \mathrm{La}$ that are more constant within the entire sediment column.

It is unlikely that underplating beneath northwestern Costa Rica began operating prior to the last few million years. Subduction erosion, consistent with measured rates of subsidence in the Nicoya Peninsula forearc since the Miocene, was probably the dominant control on subduction systematics on longer time scales. However, the PlioPleistocene migration of the EPR/CNS-1 boundary northwest along the trench may have been accompanied by comparable northwest advancement of the region of low extensional fault relief, producing a change from an erosional regime to one of underplating and accretion, especially landward of the area of subsidence. This underplating may occur episodically, controlled by heterogeneous basement relief at the top of the subducting plates. Measurement of uplift rates for the Nicoya Peninsula region since the Pleistocene would be required to constrain maximum allowable amounts of underplating.

Based on the evidence of evolving subduction systematics, we conclude that, unlike Nicaragua, the northwestern Costa Rican arc is unlikely to have been in geochemical steady state since the Miocene. This hypothesis could be confirmed by a broader study of the temporal development of Costa Rican arc geochemistry within the context of changing tectonic parameters within the subducting and overriding plates. 
Table 1 Global subduction parameters for arcs with ${ }^{10} \mathrm{Be}$ enrichment

\begin{tabular}{|l|r|r|r|r|r|r|}
\hline Arc & $\begin{array}{l}\text { 10 Be million } \\
\text { atoms/g }\end{array}$ & $\begin{array}{l}\text { Dip angle } \\
60-100 \\
\mathrm{~km}\end{array}$ & $\begin{array}{l}\text { Dip angle } \\
>100 \mathrm{~km}\end{array}$ & $\begin{array}{l}\text { Slab age } \\
\text { at trench } \\
(\mathrm{Ma})\end{array}$ & $\begin{array}{l}\text { Depth to } \\
\text { WBZ } \\
\text { (km) }\end{array}$ & \begin{tabular}{l}
$\begin{array}{l}\text { Convergence } \\
\text { rate (mm/yr) }\end{array}$ \\
\hline Aleutians
\end{tabular}$\quad 15.3$ \\
Guatemala & 3.5 & 53 & 65 & $\sim 55$ & $\sim 100$ & 75 \\
El Salvador & 14.4 & 55 & 60 & $25 ?$ & 120 & 73 \\
Nicaragua & 27.1 & 65 & $75-84$ & $25 ?$ & $120-150$ & 75 \\
& & 23 & $150-200$ & 80 \\
Costa Rica & $1.8,8.4 *$ & $30(\mathrm{SE})$ & $60(\mathrm{C})$ & $22-<20$ & $100-80$ & 85 \\
Peru & 8 & $\sim 20$ & $\sim 10$ & $\sim 45$ & $<100 ?$ & 82 \\
Chile & 2.1 & $25-30$ & $25-30$ & $\sim 40$ & $<\sim 100$ & 85 \\
Scotia & 4.1 & $\sim 20-25$ & $\sim 25-30$ & $<10$ & $100-120$ & 77 \\
Kurile & 8 & 33 & 45 & $\sim 140$ & 120 & 85 \\
Hokkaido & 13.5 & & & $\sim 135$ & $\sim 110$ & 87 \\
Izu & 1.4 & 50 & $55-65$ & $\sim 140$ & 125 & 100 \\
Mariana & 1 & 35 & 70 & $\sim 180$ & 100 & 90 \\
Bismarck & 8.4 & $70-75$ & $70-75$ & $<10 ?$ & $100-200$ & 110 \\
Tonga & 2.2 & 50 & 55 & $83-120$ & 100 & $<170$ \\
Kermadec & 2.3 & 50 & 50 & $83-120$ & 100 & 60 \\
\hline
\end{tabular}

* Indicates one outlier of Miravalles volcano.

Dip angle refers to the dip of the subducting plate in degrees.

References: ${ }^{10} \mathrm{Be}$ (Morris et al., 2002a); dip angle 60-100 km and $>100 \mathrm{~km}$ depth (angles from seismicity profiles in: Isacks and Barazanghi, 1977; Burbach et al., 1984; Carr, 1984; Cooper and Taylor, 1987; Protti et al., 1995; Tatsumi and Eggins, 1996; Marotta and Mongelli, 1998); slab age at trench (Mueller et al., 1997); depth to Wadati-Benioff Zone (WBZ; Tatsumi and Eggins, 1996); convergence rate of lower plate (Jarrard, 1986; DeMets et al., 1990, 1994, 2001; Zhang and Schwartz, 1992). 


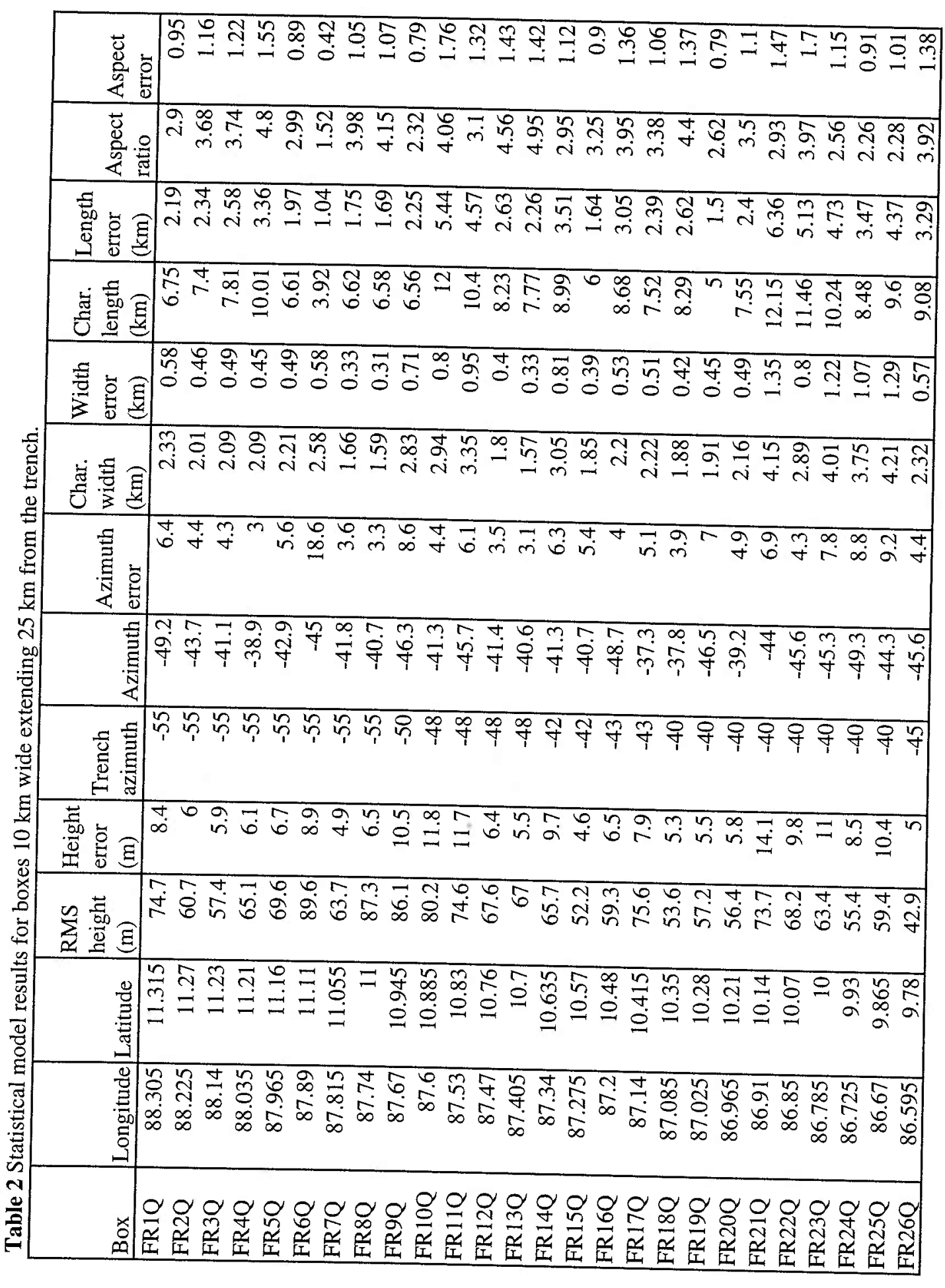




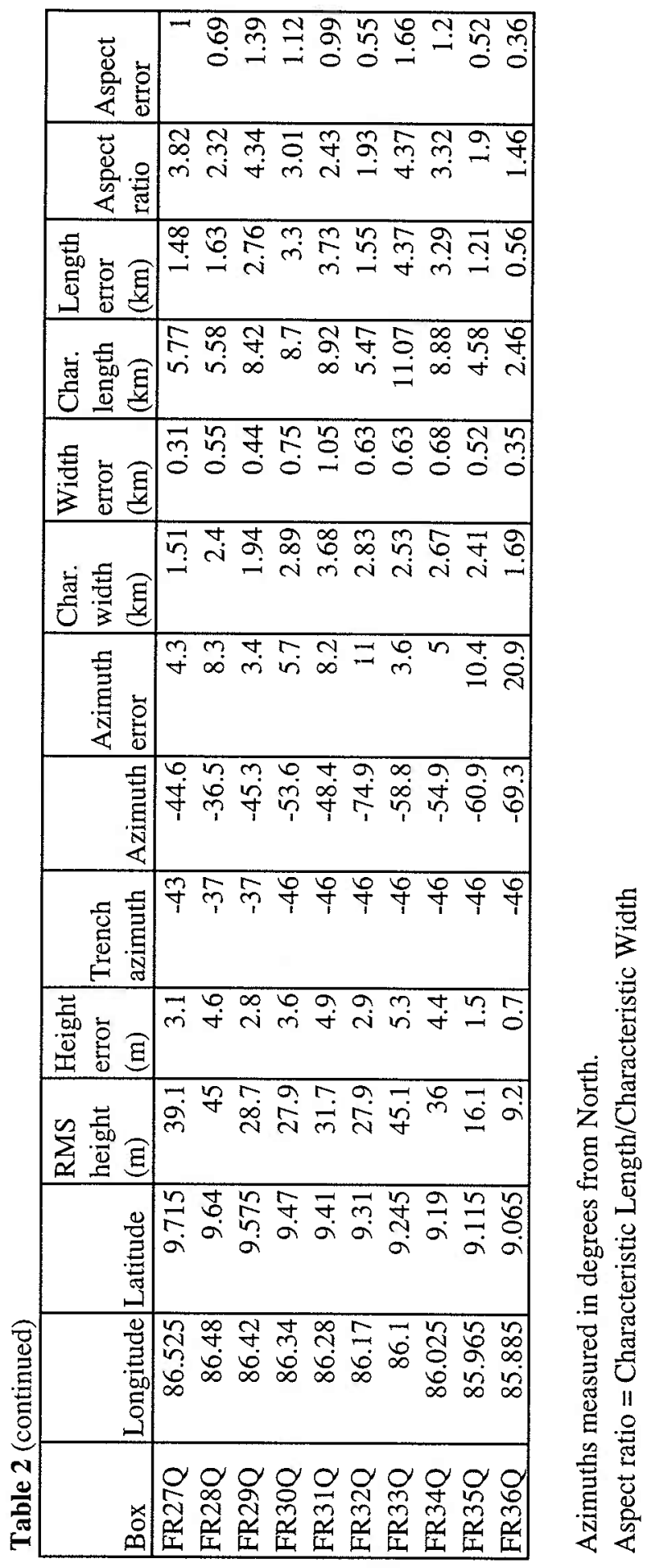


Table 3 Model parameter outputs for data boxes $10 \mathrm{~km}$ by $25 \mathrm{~km}$ extending $15-40 \mathrm{~km}$ from trench on the lower plate.

\begin{tabular}{|l|r|r|r|r|r|r|}
\hline Box & $\begin{array}{l}\text { RMS } \\
\text { height }(\mathrm{m})\end{array}$ & $\begin{array}{l}\text { Height } \\
\text { error }(\mathrm{m})\end{array}$ & $\begin{array}{l}\text { Azimuth } \\
\text { Azimuth } \\
\text { error }\end{array}$ & $\begin{array}{l}\text { Char. width } \\
(\mathrm{km})\end{array}$ & $\begin{array}{l}\text { Width error } \\
(\mathrm{km})\end{array}$ \\
\hline MR4 & 46.6 & 4.8 & -40.7 & 3.2 & 2.01 & 0.46 \\
MR5 & 65.9 & 6.8 & -50 & 12 & 2.24 & 0.53 \\
MR6 & 92.8 & 13.2 & -52.6 & 9.3 & 2.82 & 0.82 \\
MR7 & 54.5 & 4.2 & -45.7 & 3.5 & 1.53 & 0.31 \\
MR8 & 85.8 & 9.4 & -40.9 & 5 & 2.56 & 0.6 \\
MR9 & 91.4 & 12.9 & -45.5 & 9.9 & 3.36 & 0.94 \\
MR10 & 61.2 & 8.3 & -43 & 5 & 2.81 & 0.73 \\
MR11 & 63 & 7.4 & -42.2 & 4.3 & 2.4 & 0.58 \\
MR12 & 56.3 & 5.2 & -40.6 & 4.6 & 1.85 & 0.4 \\
MR13 & 62.2 & 6.6 & -44 & 4.1 & 2.02 & 0.48 \\
MR14 & 46.8 & 5.5 & -45.1 & 5.5 & 2.58 & 0.65 \\
MR15 & 41.8 & 4.9 & -38.5 & 4.9 & 2.42 & 0.6 \\
MR16 & seamount in & majority & of box & & & \\
MR17 & 59.7 & 6.4 & -34.3 & 5.4 & 2.14 & 0.51 \\
MR18 & 34.9 & 3.2 & -46.3 & 3.9 & 1.86 & 0.41 \\
MR19 & 54.5 & 7.4 & -53.3 & 5.8 & 3.16 & 0.85 \\
MR20 & 45 & 6.2 & -40.6 & 6.7 & 3.08 & 0.82 \\
MR21 & 58.8 & 9.1 & -46.9 & 4.6 & 3.2 & 0.92 \\
MR22 & 60.1 & 9.2 & -48.3 & 5.1 & 3.29 & 0.94 \\
MR23 & 51.6 & 9.6 & -40.3 & 8 & 4.24 & 1.34 \\
MR24 & 50.9 & 8.8 & -56.3 & 11.8 & 4.42 & 1.34 \\
MR25 & 39.7 & 4.8 & -45 & 5.5 & 2.49 & 0.63 \\
MR26 & 29.9 & 3.6 & -45 & 4.4 & 2.13 & 0.54 \\
MR27 & 25.3 & 4.1 & -43.8 & 8.8 & 3.32 & 0.98 \\
MR28 & 24.8 & 3.5 & -46.7 & 17.9 & 3.98 & 1.09 \\
MR29 & 13.8 & 1.7 & -43.2 & 6.8 & 2.7 & 0.7 \\
MR30 & 9 & 0.8 & -44.6 & 6.5 & 1.78 & 0.38 \\
MR31 & 14.5 & 2.1 & -55.5 & 11.8 & 3.65 & 1.01 \\
MR32 & 15.5 & 1.6 & bad model data & & 3.25 & 0.8 \\
MR33 & 16.8 & 1.6 & -57.9 & 6.5 & 2.27 & 0.51 \\
MR34 & 12.3 & 1 & -63.8 & 5 & 1.81 & 0.37 \\
\hline
\end{tabular}

Azimuths measured in degrees from North. 
Table 4 Model parameter outputs for data boxes $10 \mathrm{~km}$ by $15 \mathrm{~km}$ extending $0-15 \mathrm{~km}$ from trench on the lower plate.

\begin{tabular}{|c|c|c|c|c|c|c|}
\hline Box & \begin{tabular}{|l|} 
RMS \\
height (m) \\
\end{tabular} & $\begin{array}{l}\text { Height } \\
\text { error }(\mathrm{m})\end{array}$ & Azimuth & $\begin{array}{l}\text { Azimuth } \\
\text { error }\end{array}$ & $\begin{array}{l}\text { Char. width } \\
(\mathrm{km})\end{array}$ & $\begin{array}{l}\text { Width error } \\
(\mathrm{km})\end{array}$ \\
\hline OR1 & 78.4 & 8.8 & -52.4 & 6.3 & 1.92 & 0.46 \\
\hline OR2 & 58 & 5.1 & -40.9 & 3.2 & 1.45 & 0.31 \\
\hline OR3 & 54.6 & 5 & -36.5 & 2.4 & 1.58 & 0.34 \\
\hline OR4 & 74.1 & 11.5 & -40 & 4 & 2.48 & 0.71 \\
\hline OR5 & 50.6 & 5.7 & -39.5 & 3.9 & 1.82 & 0.44 \\
\hline OR6 & 64.6 & 6.8 & -39.9 & 6.5 & 1.82 & 0.43 \\
\hline OR7 & 63.1 & 7.1 & -38 & 4.4 & 1.88 & 0.45 \\
\hline OR8 & 78.9 & 8.1 & -42 & 3.2 & 1.54 & 0.36 \\
\hline OR9 & 73.8 & 12.5 & -46 & 5.9 & 2.5 & 0.76 \\
\hline OR10 & 69.3 & 10.4 & -41.7 & 3.7 & 2.01 & 0.57 \\
\hline OR11 & 69.8 & 14.3 & -44.9 & 7.3 & 3.11 & 1.04 \\
\hline OR12 & 63.8 & 9.4 & -42.4 & 3.7 & 1.9 & 0.54 \\
\hline OR13 & 66.7 & 7.7 & -39.2 & 3.7 & 1.66 & 0.42 \\
\hline OR14 & 66.6 & 12.1 & -41.2 & 6 & 2.67 & 0.84 \\
\hline OR15 & 57.1 & 6.8 & -40.9 & 5.4 & 1.75 & 0.45 \\
\hline OR16 & 31.9 & 1 & -45.1 & 2.3 & 0.92 & 0.12 \\
\hline OR17 & 53.2 & 1.9 & -39.1 & 1.8 & 1.28 & 1.16 \\
\hline OR18 & 56.4 & 7.9 & -36.2 & 3.6 & 1.8 & 0.5 \\
\hline OR19 & 54.2 & 7.9 & -43.5 & 4.4 & 1.51 & 0.47 \\
\hline OR20 & 49.6 & 1.3 & -41.6 & 1.9 & 1.07 & 0.12 \\
\hline OR21 & 58.2 & 11.1 & -42.4 & 4.5 & 2.54 & 0.84 \\
\hline OR22 & 42.4 & 5.8 & -41.9 & 4.1 & 1.82 & 0.51 \\
\hline OR23 & 55.2 & 11.2 & -43.9 & 5.7 & 2.89 & 0.98 \\
\hline OR24 & 34.6 & 4.6 & -41.5 & 4.4 & 1.81 & 0.49 \\
\hline OR25 & 39.5 & 5.4 & -42.6 & 4.7 & 1.91 & 0.53 \\
\hline OR26 & 40.3 & 5.3 & -43.6 & 4.2 & 1.76 & 0.48 \\
\hline OR27 & 41.6 & 1.3 & -44.1 & 2 & 1.05 & 0.17 \\
\hline OR28 & 42.6 & 4.7 & -38 & 6.8 & 1.77 & 0.43 \\
\hline OR29 & 31.4 & 4 & -46.3 & 3.3 & 1.82 & 0.49 \\
\hline OR30 & 28.9 & 3.9 & -54 & 5.4 & 2.12 & 0.59 \\
\hline OR31 & 35 & 6.3 & -46.4 & 5.2 & 2.51 & 0.8 \\
\hline OR32 & 30.2 & 3.9 & -70.5 & 10.7 & 2.48 & 0.63 \\
\hline OR33 & 55.4 & 9.7 & -59.4 & 4.4 & 2.68 & 0.83 \\
\hline OR34 & 34.7 & 4.5 & -54.7 & 4.9 & 2 & 0.53 \\
\hline OR35 & 18.7 & 2 & -59.6 & 8.3 & 1.85 & 0.47 \\
\hline OR36 & 8.4 & 0.4 & -59.5 & 5.1 & 1.02 & 0.18 \\
\hline
\end{tabular}

Azimuths measured in degrees from North. 
Table 5 Model parameter outputs for data boxes $10 \mathrm{~km}$ by $15 \mathrm{~km}$ extending $0-15 \mathrm{~km}$ from trench on the upper plate.

\begin{tabular}{|c|c|c|c|c|c|c|}
\hline Box & $\begin{array}{l}\text { RMS } \\
\text { height (m) }\end{array}$ & \begin{tabular}{|l|} 
Height \\
error $(\mathrm{m})$
\end{tabular} & Azimuth & $\begin{array}{l}\text { Azimuth } \\
\text { error }\end{array}$ & $\begin{array}{l}\text { Char. width } \\
(\mathrm{km})\end{array}$ & $\begin{array}{l}\text { Width error } \\
(\mathrm{km})\end{array}$ \\
\hline UP4Q & 75 & 10.6 & -49 & 23.2 & 3.37 & 0.99 \\
\hline UP5Q & 67.3 & 12.6 & -37.4 & 9.7 & 3.38 & 1.08 \\
\hline UP6Q & 96.4 & 18.7 & -61 & 13.6 & 3.62 & 1,19 \\
\hline UP7Q & 56.1 & 6.2 & -48 & 18.5 & 2.25 & 0.53 \\
\hline UP8Q & 63.3 & 8.4 & -63 & 13.9 & 2.59 & 0.69 \\
\hline UP9Q & 63.1 & 7.4 & -46.4 & 8.7 & 2.03 & 0.5 \\
\hline UP10Q & 65.4 & 12.9 & -41.7 & 7.1 & 2.96 & 0.96 \\
\hline UP11Q & 73.6 & 12.2 & -35.7 & 10.1 & 3.01 & 0.89 \\
\hline UP12Q & 66.8 & 12.8 & -45.7 & 7.5 & 2.98 & 0.97 \\
\hline UP13Q & 82.5 & 18 & -47.3 & 13.7 & 3.95 & 1.39 \\
\hline UP14Q & 64.9 & 15.4 & -43 & 10.2 & 3.92 & 1.44 \\
\hline UP15Q & 58.4 & 8.68 & -71.7 & 14.8 & 3 & 0.83 \\
\hline UP16Q & 66.7 & 16.7 & -37.7 & 11.5 & 4.23 & 1.62 \\
\hline UP17Q & 52.6 & 7.3 & -46.1 & 15.8 & 2.75 & 0.75 \\
\hline UP18Q & 83.6 & 20.7 & -39.6 & 7.5 & 3.66 & 1.39 \\
\hline UP19Q & 69.7 & 12.9 & -46.5 & 9 & 3.14 & 1.01 \\
\hline UP20Q & 77.7 & 12.5 & -29.6 & 20.8 & 3.34 & 0.97 \\
\hline UP21Q & 56 & 9.4 & -47.3 & 11.6 & 3.1 & 0.94 \\
\hline UP22Q & 53 & 8.1 & -45.8 & 8.3 & 2.61 & 0.76 \\
\hline UP23Q & 65.1 & 11.2 & -39.3 & 8 & 2.77 & 0.86 \\
\hline UP24Q & 44.2 & 6 & -90.8 & 45.2 & 3 & 0.83 \\
\hline UP25Q & 45.6 & 6 & -45.5 & 16.9 & 2.65 & 0.71 \\
\hline UP26Q & 61.6 & 6.4 & -70.7 & 30.2 & 2.06 & 0.49 \\
\hline UP27Q & 49.7 & 8.6 & -47.6 & 6.5 & 2.68 & 0.83 \\
\hline UP28Q & 41.5 & 4.7 & -26.6 & 10.7 & 2.1 & 0.51 \\
\hline UP29Q & 36.8 & 5.4 & -41.9 & 6 & 2.26 & 0.65 \\
\hline UP30Q & 34.3 & 4.7 & -29.8 & 24.3 & 2.94 & 0.8 \\
\hline UP31Q & 43.2 & 6.8 & -51.8 & 15.8 & 3.13 & 0.91 \\
\hline UP32Q & 49.7 & 8.8 & -38.9 & 11 & 3.18 & 0.99 \\
\hline UP33Q & 41.6 & 4.9 & -62 & 8.6 & 2.16 & 0.54 \\
\hline UP34Q & 59.7 & 11.6 & -57 & 6.8 & 3.13 & 1.04 \\
\hline UP35Q & 45.6 & 5.1 & -15.5 & 23.7 & 2.34 & 0.57 \\
\hline UP36Q & 46.6 & 4.8 & -40.2 & 26 & 2.09 & 0.47 \\
\hline
\end{tabular}

Azimuths measured in degrees from North. 
Figure 1. The principal subduction controls on ${ }^{10} \mathrm{Be}$ enrichment in arc volcanic rocks are (1) variations in sedimentary ${ }^{10} \mathrm{Be}$ on the downgoing plate (2) convergence rates (3) subduction style (offscraping, underplating, or tectonic erosion), and (4) geochemical processes during magmatic sediment incorporation. 


\section{Processes that Affect ${ }^{10}$ Be Enrichment in Arc Volcanics}

(1) Variations in ${ }^{10} \mathrm{Be}$ concentrations in subducted sediment

(2) Convergence

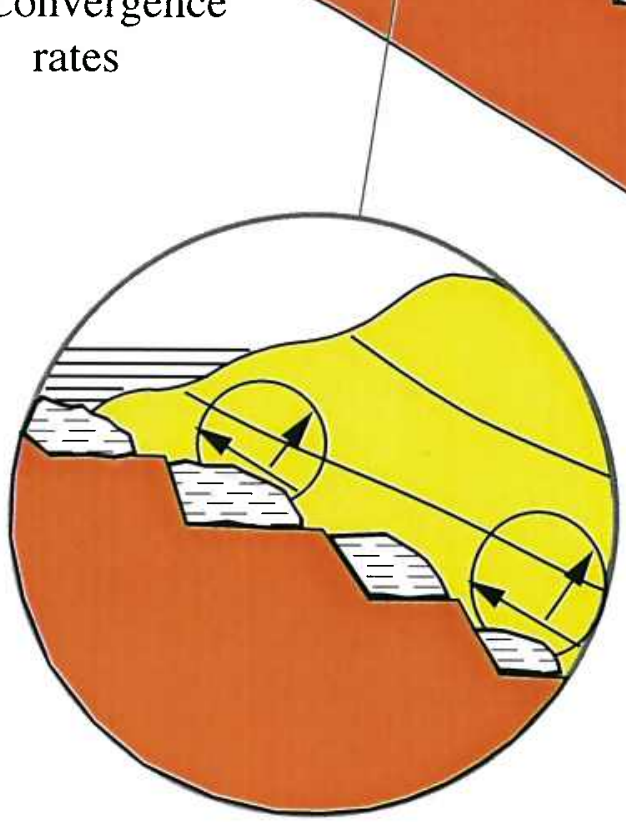

(3) Offscraping, underplating, or tectonic erosion

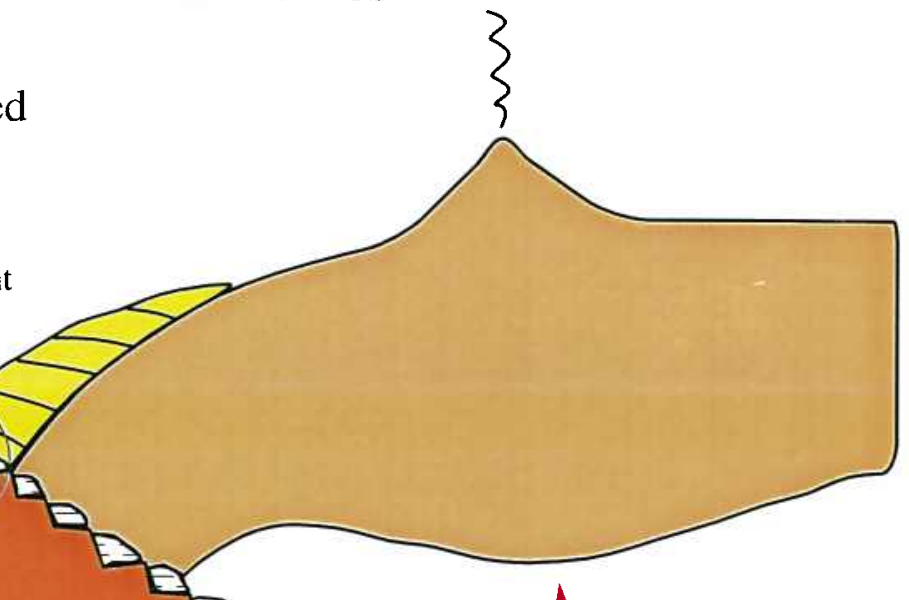


Figure 2. ${ }^{10} \mathrm{Be}$ has been measured on 41 samples from 28 volcanoes along the length of the Central America Volcanic Arc (Brown et al., 1982; Tera et al., 1986; Morris and Tera, 1989; Morris et al., 1990; Reagan et al., 1994; Morris et al., 2002a; Table 1, Chapter II). Sample number, ${ }^{10} \mathrm{Be}$ million atom $/ \mathrm{g}$, and ${ }^{10} \mathrm{Be} /{ }^{9} \mathrm{Be}$ (atom ratio, $\times 10^{-11}$ ) are as follows: Mexico: $\mathrm{n}=4,{ }^{10} \mathrm{Be}=0.3-0.9$ million atom $/ \mathrm{g},{ }^{10} \mathrm{Be} /{ }^{9} \mathrm{Be}<2$; Guatemala: $\mathrm{n}=3$, ${ }^{10} \mathrm{Be}=2.1-3.5$ million atom $/ \mathrm{g},{ }^{10} \mathrm{Be} /{ }^{9} \mathrm{Be}<10.5$; El Salvador: $\mathrm{n}=6,{ }^{10} \mathrm{~B}=7-14$ million atom $/ \mathrm{g},{ }^{10} \mathrm{Be} /{ }^{9} \mathrm{Be}=12-23$; Nicaragua low Ti suite: $\mathrm{n}=12,{ }^{10} \mathrm{Be}=5-27$ million atom/g, ${ }^{10} \mathrm{Be} /{ }^{9} \mathrm{Be}=18-69$; Costa Rica: $\mathrm{n}=12,{ }^{10} \mathrm{Be}=0.8-1.8$ million atom $/ \mathrm{g},{ }^{10} \mathrm{Be} /{ }^{9} \mathrm{Be}=2-6$. Unusual high-Ti lavas from Nicaragua, lacking the high field strength (HFSE) depletion typical of arc lavas, have low ${ }^{10} \mathrm{Be} /{ }^{\rho} \mathrm{Be}$ ratios (8-15) relative to the low-Ti lavas erupted within the same volcanic centers (Morris et al., 1990; Reagan et al., 1994). The high-Ti lavas were most likely subject to different magmatic processes than the low-Ti arc front lavas (e.g., review in Carr et al., 2003). Also shown is dip angle at $100 \mathrm{~km}$ depth. Dip angles for Guatemala, El Salvador, and northwestern Nicaragua are calculated from seismicity profiles in Burbach et al. (1984). Dip angles for Nicaragua and Costa Rica are from Protti et al. (1995). 


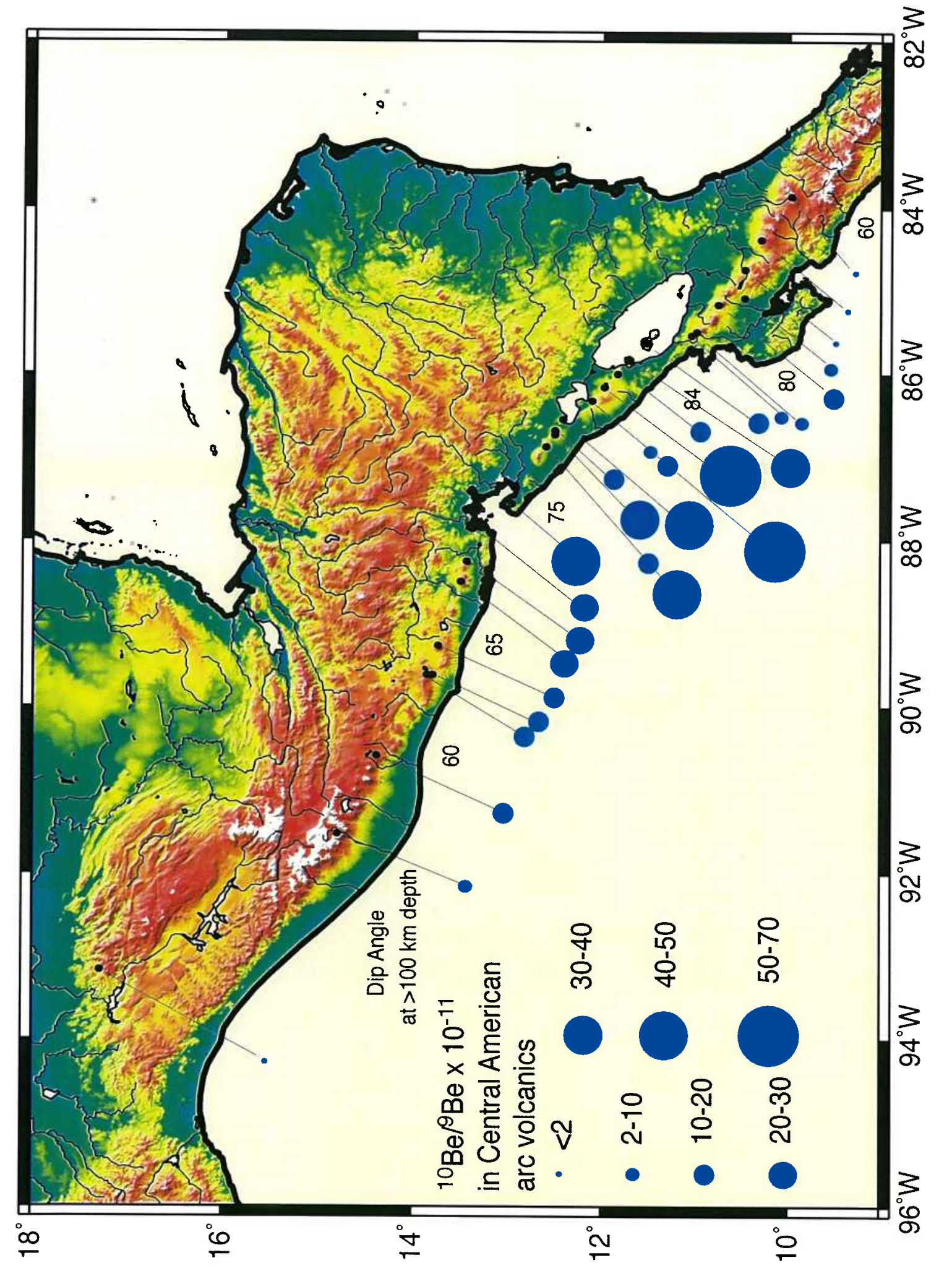


Figure 3. A regional tectonic map of Central America reveals a complicated tectonic history. The Cocos plate subducts beneath the Caribbean plate at the Middle America Trench, creating the Central American Volcanic Arc (CAVA) from Guatemala to Costa Rica. The magnetic anomaly data are compiled after Barckhausen et al. (2001), Wilson (1996), Wilson and Hey (1995), Hardy (1991), and Lonsdale and Klitgord (1978). Chron time scale from Cande and Kent (1995). Numbers on anomalies refer to chrons. GR = Galapagos Rift, ER = Ecuador Rift, CR = Costa Rica Rift, MR = Malpelo Rift, PFZ = Panama Fracture Zone, $\mathrm{CFZ}=$ Coiba Fracture Zone. A triple junction trace separates East Pacific Rise (EPR) derived crust in the northwest from Cocos-Nazca Spreading Center (CNS) crust to the southeast. A small wedge of older CNS crust (CNS-1) is subducting offshore of northwestern Costa Rica; CNS-1 was isolated after a ridge jump began forming the younger CNS crust (CNS-2). The PFZ separates the Cocos plate from Nazca plate. 


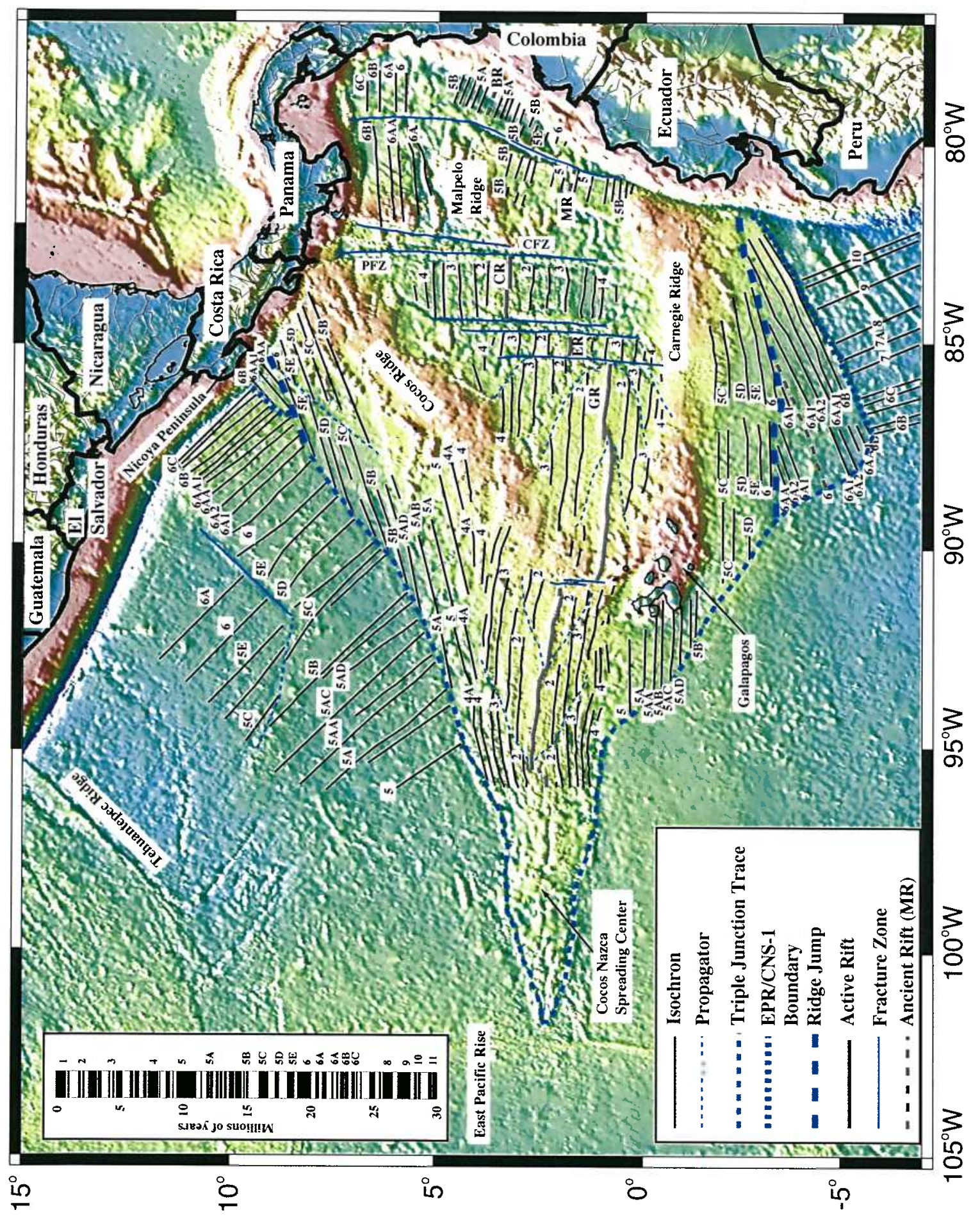


Figure 4. A regional tectonic map of the Middle America Trench (MAT) region offshore from Nicaragua and Costa Rica shows that there are two main crustal regions in the subducting Cocos plate. East Pacific Rise fabric with trench-parallel magnetic anomalies (EPR crust) is conjoined with the crust derived from the Cocos-Nazca Ridge spreading center (CNS-1 and CNS-2 crust), in which magnetic anomalies are approximately perpendicular to the trench. The gray region marks the older wedge of CNS crust termed CNS-1, separated from CNS-2 by a ridge jump (Barckhausen et al., 2001). Legend for dashed lines in the lower plate is the same as in Figure 3. The magnetic anomaly data are compiled after Barckhausen et al. (2001), Wilson (1996), Wilson and Hey (1995), Hardy (1991), and Lonsdale and Klitgord (1978). Numbers on anomalies refer to chrons.

Dashed line in the upper plate marks the projection of the Quesada Sharp Contortion (QSC) to the upper plate. The QSC is a contortion in the lower plate at which WadatiBenioff Zone seismicity abruptly shallows from a dip of $80^{\circ}$ beneath the arc northwest of the QSC to a dip of $60^{\circ}$ beneath the arc southeast of the QSC (Protti et al., 1995). The convergence rate and direction $(85 \mathrm{~mm} / \mathrm{yr})$ for the Cocos plate is relative to a fixed Caribbean plate (DeMets, 2001). Convergence directions for both plates are shown relative to a hot spot reference frame, where Caribbean plate motion is $18.8 \mathrm{~mm} / \mathrm{yr}$ and Cocos plate motion is $67 \mathrm{~mm} / \mathrm{yr}$ for the latitudes and longitudes at the arrow points (Gripp and Gordon, 1990). Caribbean crustal focal mechanisms ( $<30 \mathrm{~km}$ depth in Nicaragua and $<40 \mathrm{~km}$ depth in El Salvador and Costa Rica) are from the Harvard centroid moment tensor catalog. 


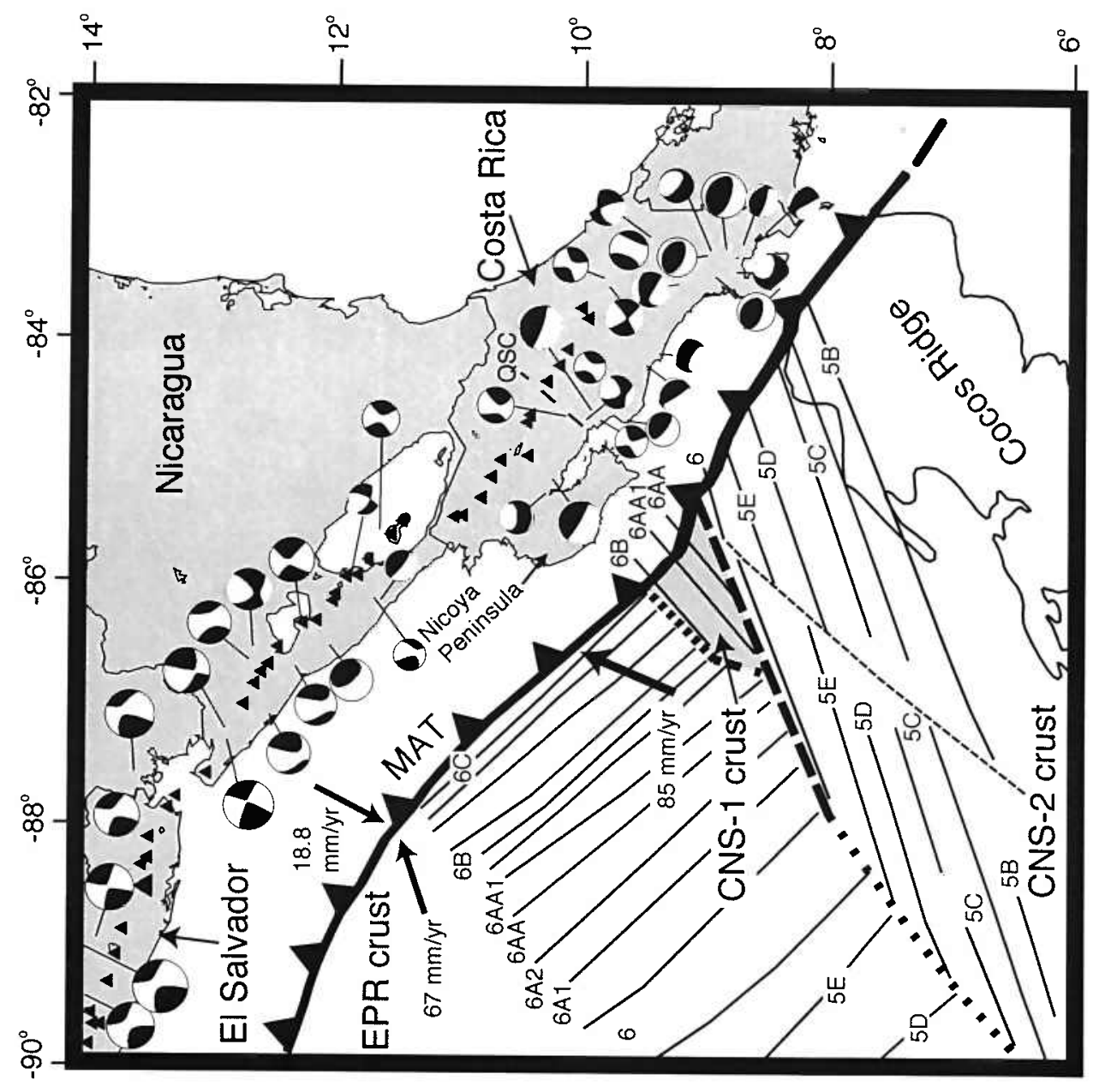


Figure 5. Bathymetric profiles (plotted in Figure 6) were projected $400 \mathrm{~km}$ seaward and $\sim 75-100 \mathrm{~km}$ landward, and spaced at $30 \mathrm{~km}$ intervals along the trench from Guatemala to southern Costa Rica. 


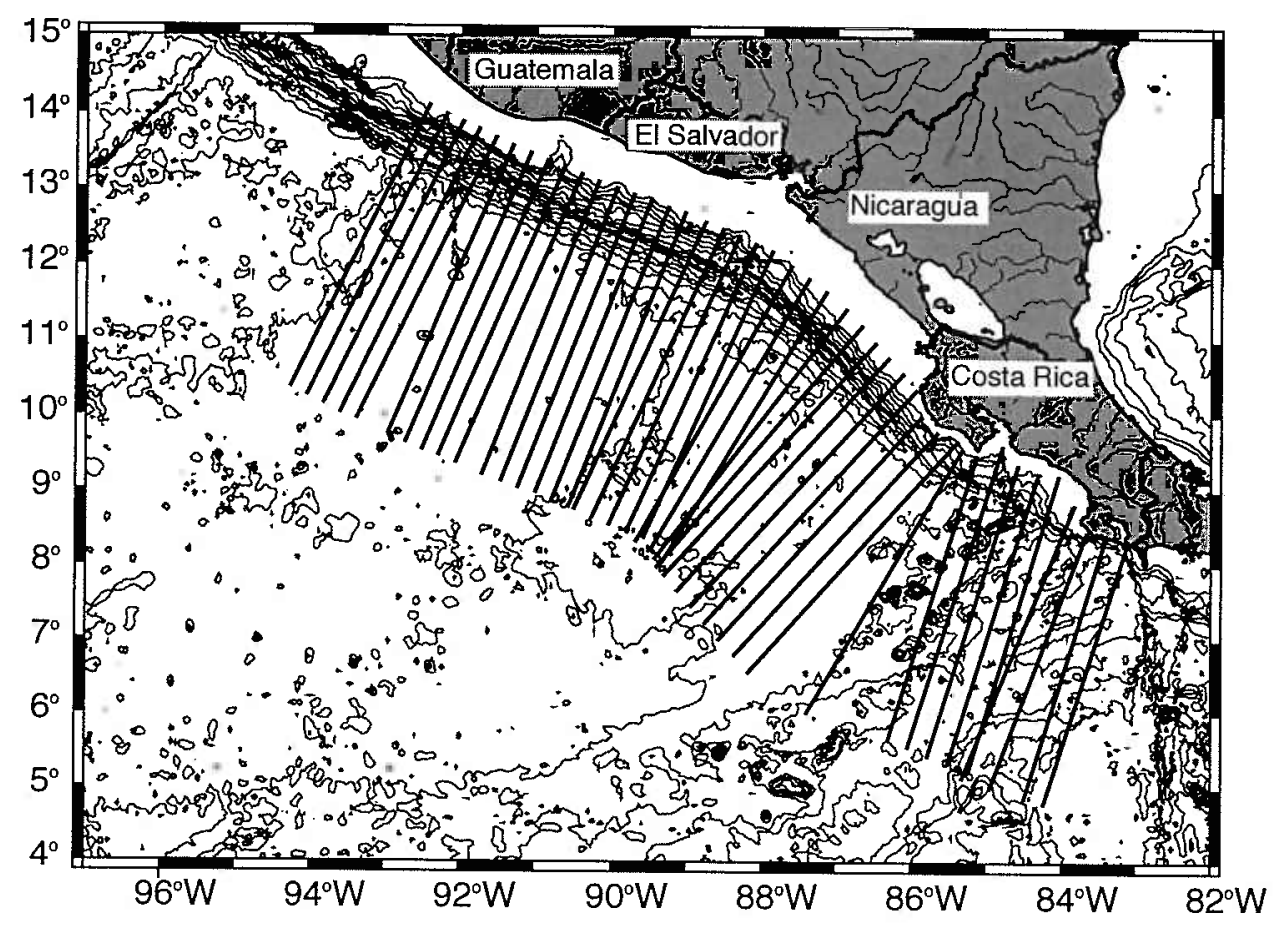


Figure 6. Bathymetric projections (lines located in Figure 5) using Smith and Sandwell (1997) bathymetry data show variations in depth perpendicular to the trench. Despite a consistent shallowing of the trench depth from Guatemala to Costa Rica, the flexural bulge shows a peak in amplitude of northwest/central Nicaragua. Along strike spacing between projections is $30 \mathrm{~km}$. 


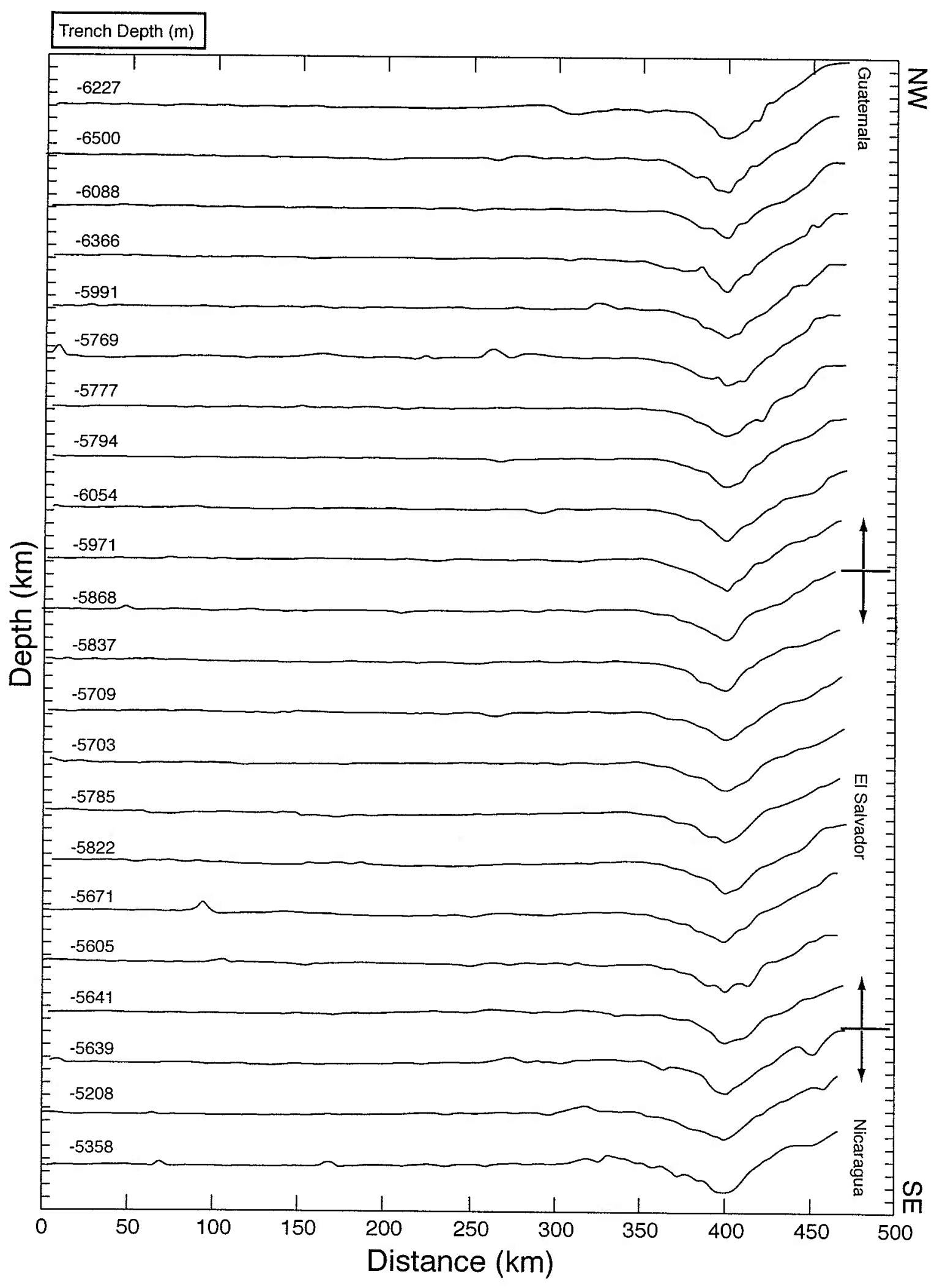


Figure 6 continued. 


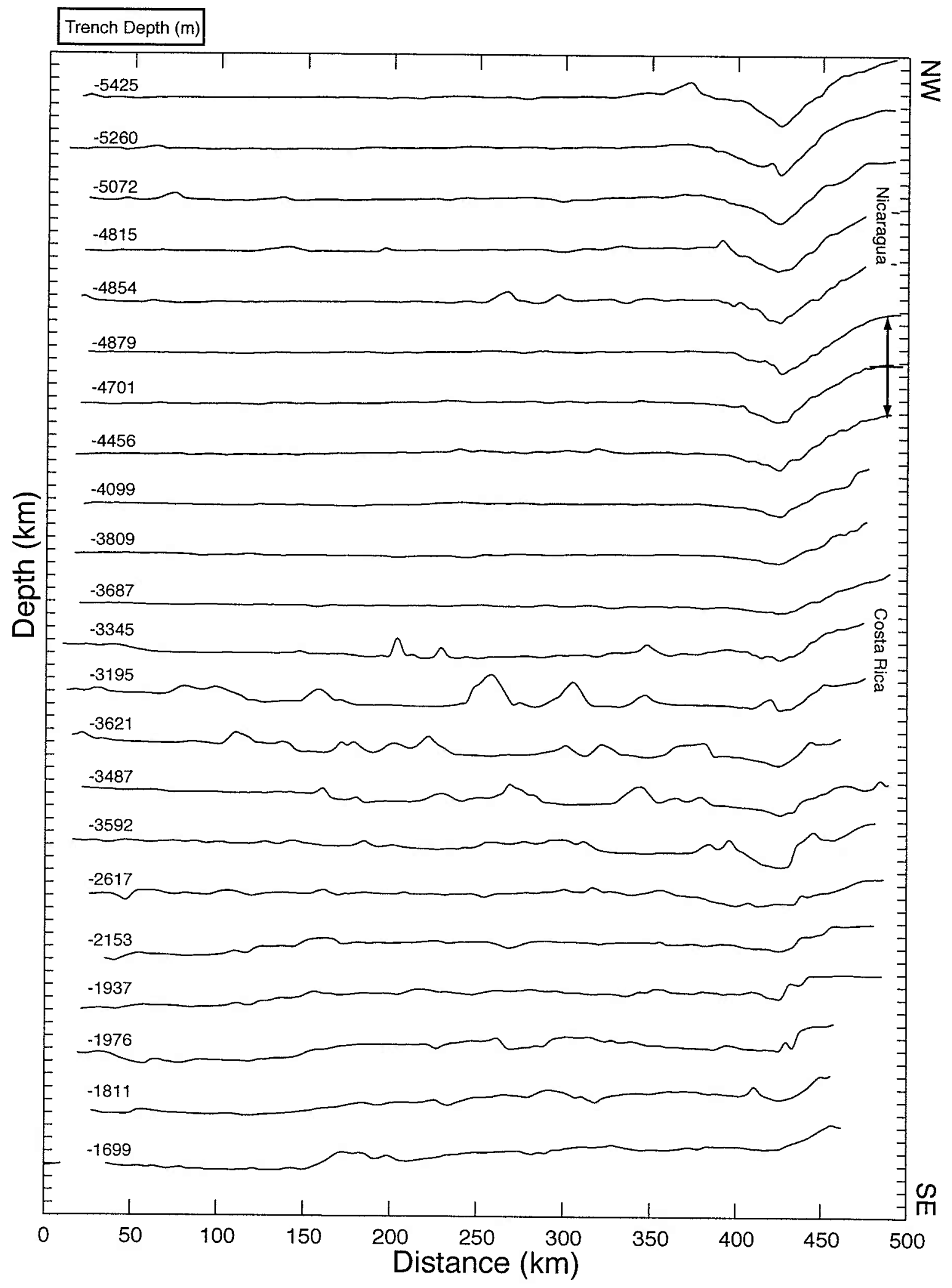


Figure 7. The slope $(\delta y / \delta x)$ of the plate bending at the trench was calculated 25 and 50 $\mathrm{km}$ seaward of the trench for each of the bathymetric projections shown in Figure 6 (except for southern Costa Rica). $\delta y=$ seafloor depth (at 25 or $50 \mathrm{~km}$ from the trench) trench depth, where $\delta x=25$ and $50 \mathrm{~km}$ respectively. The trench depth consistently shoals from Guatemala to Costa Rica, while the slope does not start to decrease until southeastern Nicaragua and northwestern Costa Rica. Dashed lines are country borders. 


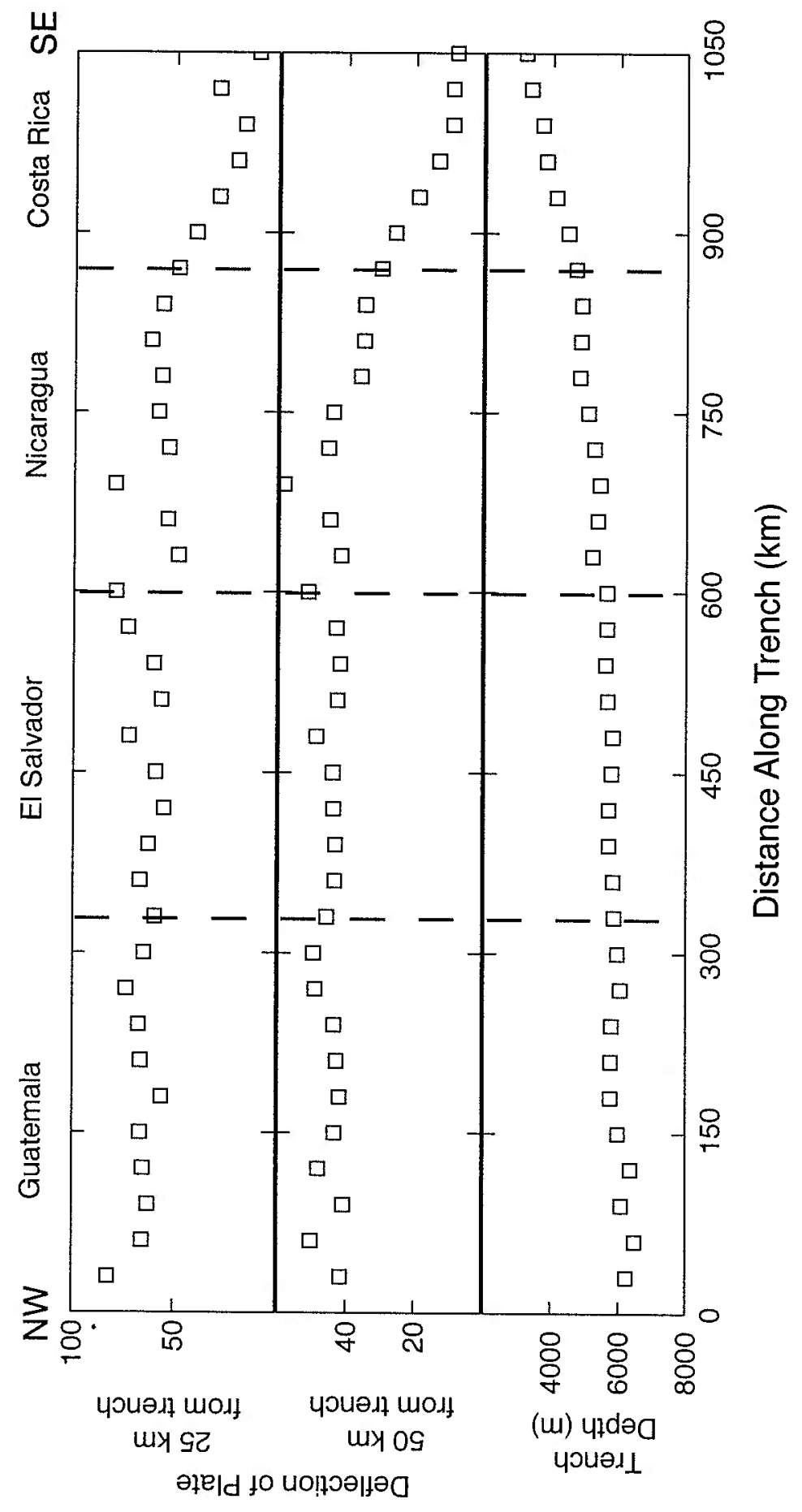


Figure 8. A regional bathymetric map of Nicaragua and Costa Rica shows the location of the new seismic lines and hydrosweep bathymetry data used in this study. Contour intervals are $500 \mathrm{~m}$. Depths shallower than $500 \mathrm{~m}$ are not contoured. Box with color contains region of new hydrosweep bathymetry collected on EW0005. The swath bathymetry data was binned into data regions $10 \mathrm{~km}$ wide and $25 \mathrm{~km}$ from the trench, the lower left corners of which are marked by black boxes (Table 2). ${ }^{10} \mathrm{Be}$ transition region (black rectangle) indicates the northwestern Costa Rica volcanoes with small but measurable ${ }^{10} \mathrm{Be}$ concentrations. To the northwest in Nicaragua, ${ }^{10} \mathrm{Be}$ concentrations are moderate to highly enriched. To the southeast in central Costa Rica, ${ }^{10} \mathrm{Be}$ concentrations are indistinguishable from background detection levels. The RMS height transition region (bracketed by pink lines) indicates the area between consistently high bathymetric relief to the northwest and low bathymetric relief to the southeast. Dashed line indicates the projection of the Quesada Sharp Contortion (QSC) to the upper plate. The QSC marks a contortion in the lower plate and is also coincident with a change in the slab signal of the arc volcanic geochemistry along strike. Volcanoes for which arc lavas have been measured for ${ }^{10} \mathrm{Be}$ are labeled on map, with the exception of Irazu, which is off the map to the southeast. Nicoya Peninsula labeled on map. 

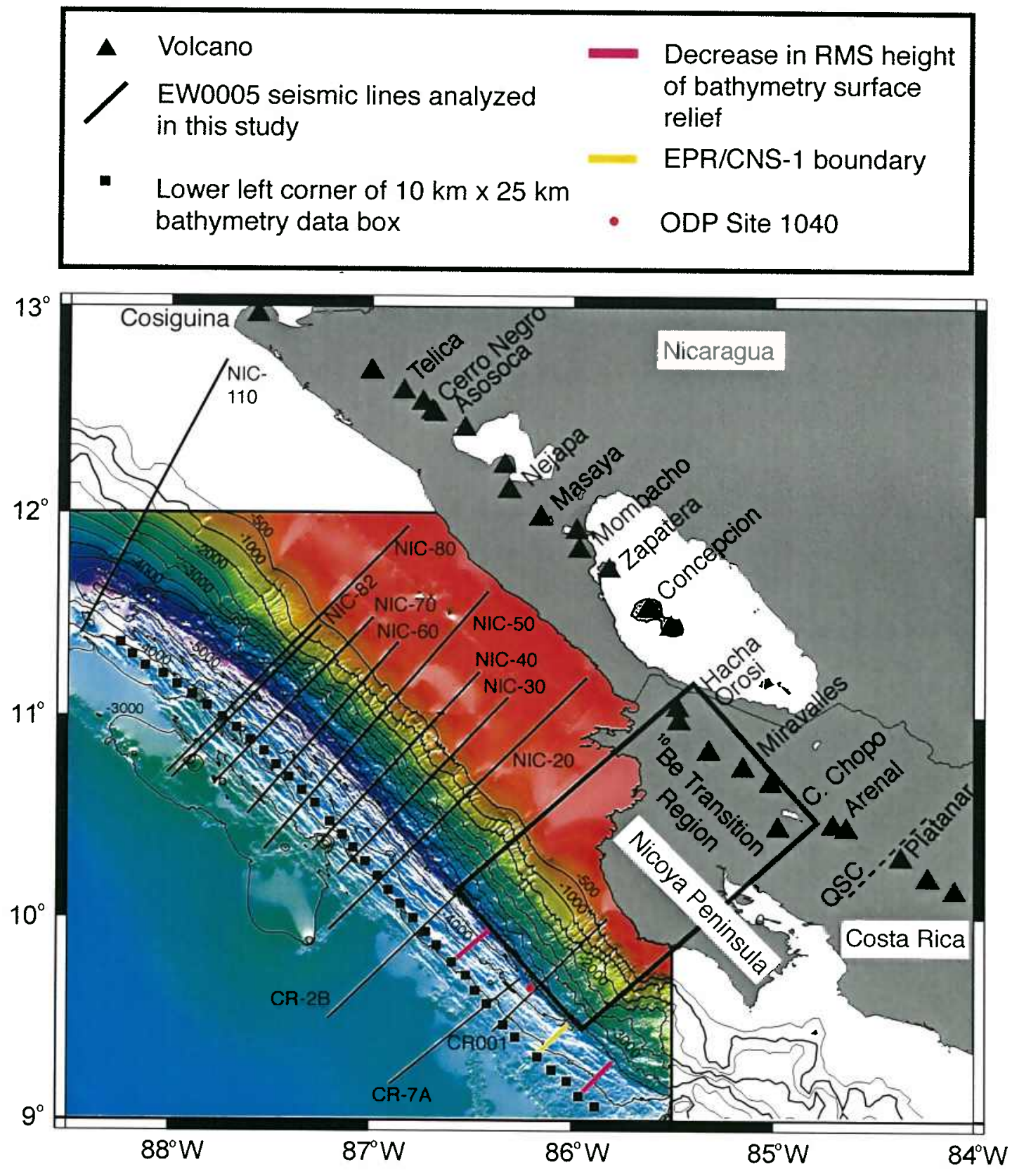
Figure 9. Seismic lines (A) NIC-80, (B) NIC-60b, (C) NIC-40, and (D) NIC-20 (from EW0005) offshore of Nicaragua show extensional basement faults comparable to or greater than the overlying sediment thickness as the plate curves into the trench. (E) CR2B at the Nicaragua/Costa Rica border also has moderately high fault throws, but (F) CR$7 \mathrm{~A}, 50 \mathrm{~km}$ southeast, does not have basement fault relief that penetrates the entire sediment column. $\mathrm{X}$-axis is CDP number (12.5 m spacing for $\mathrm{A}-\mathrm{D}, 33.3 \mathrm{~m}$ spacing for $\mathrm{E}$ and F). Y-axis is two-way travel time (s). Seismic lines are located in Figure 8. Black boxes on (A) NIC-80 locate the sections shown in Figure 10. 


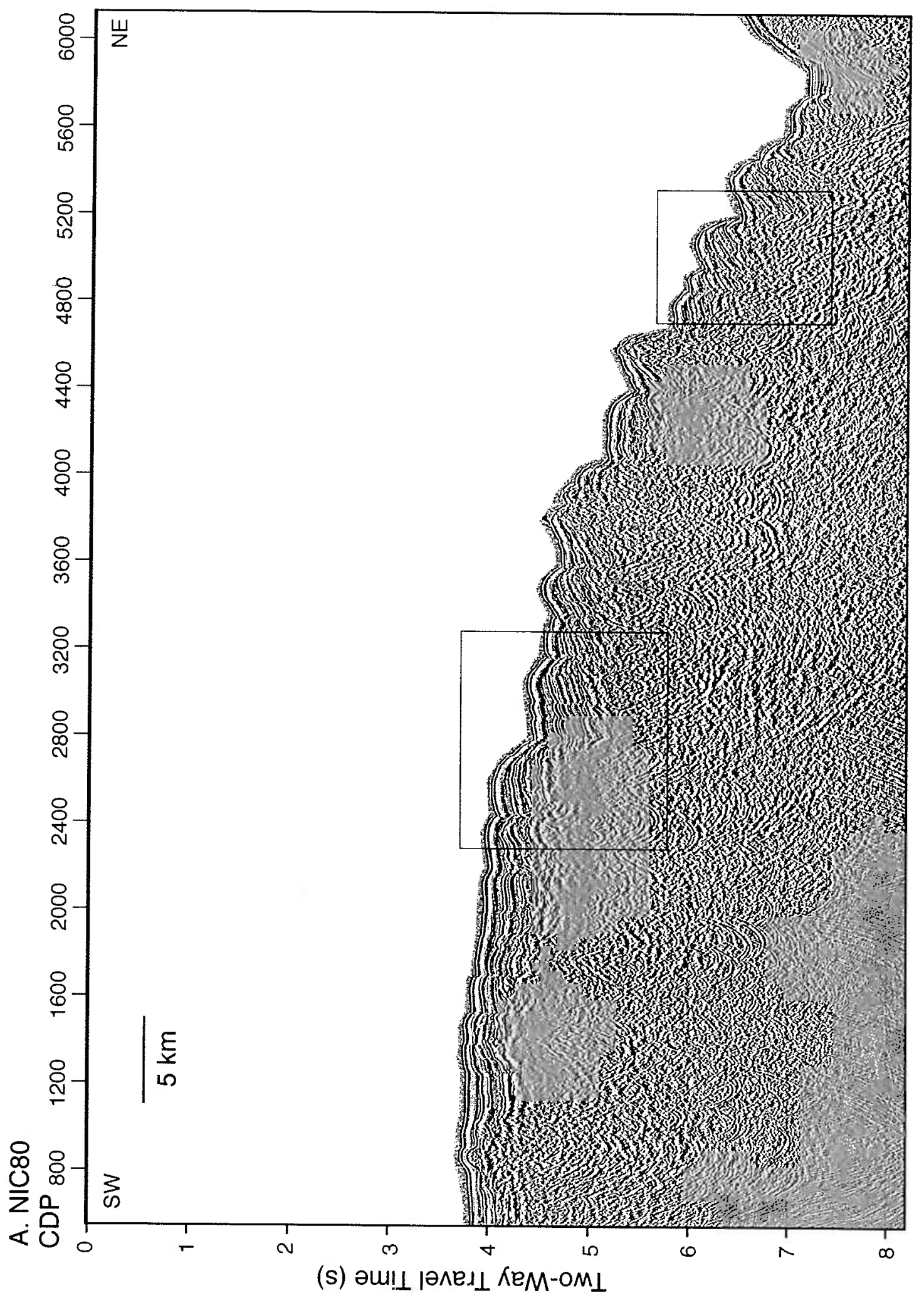


Figure 9b. 


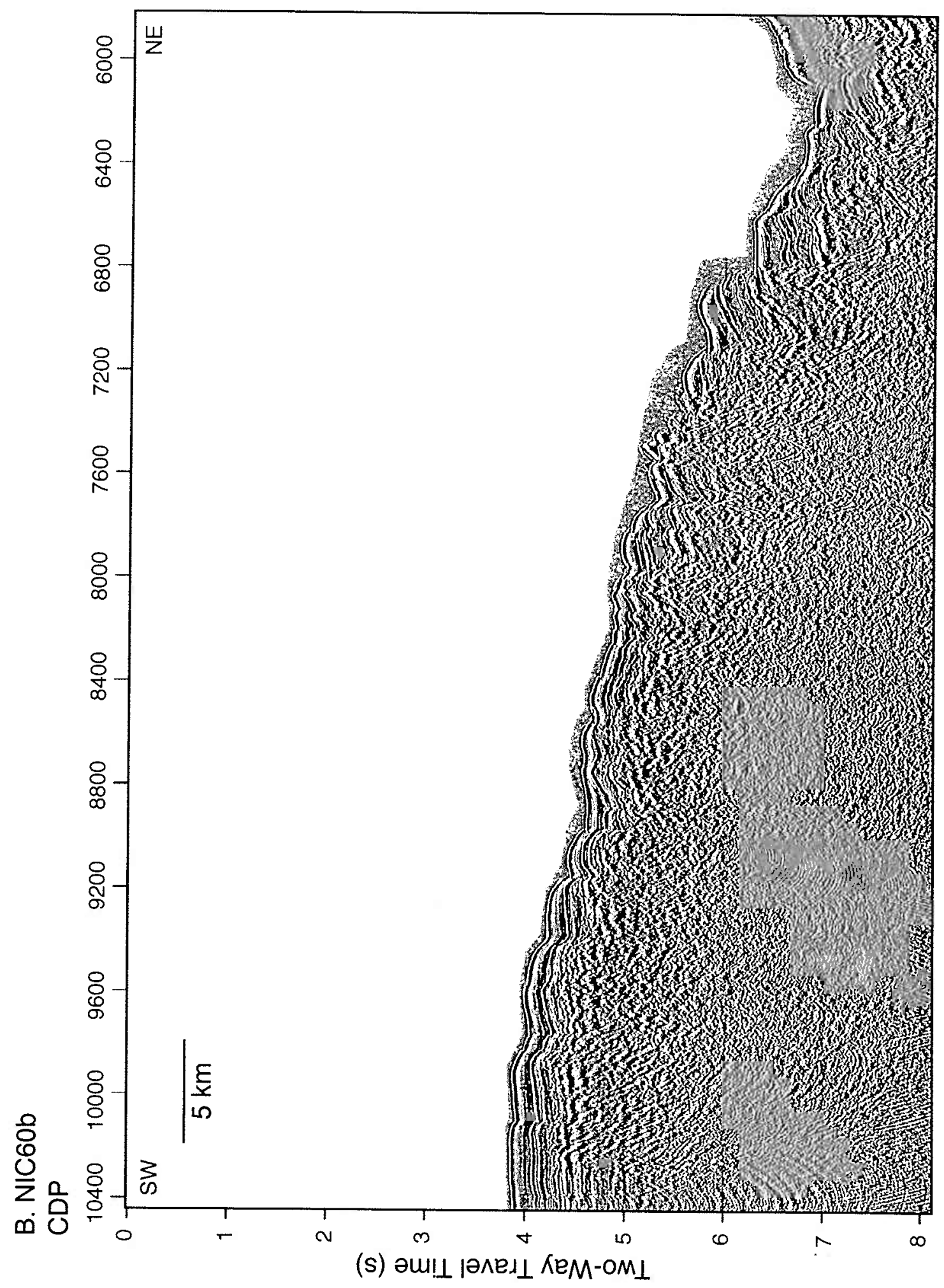


Figure 9c. 


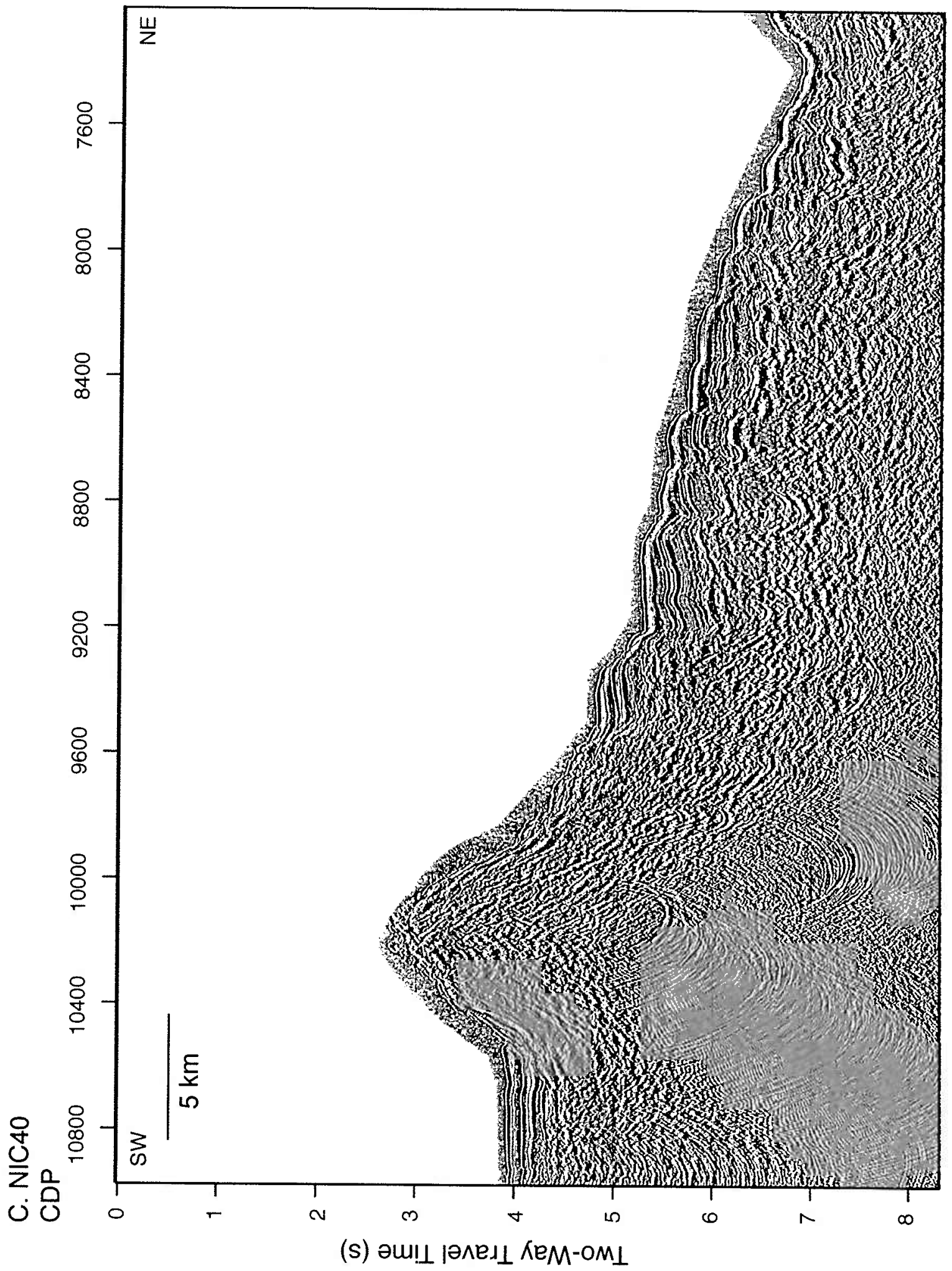


Figure 9d. 


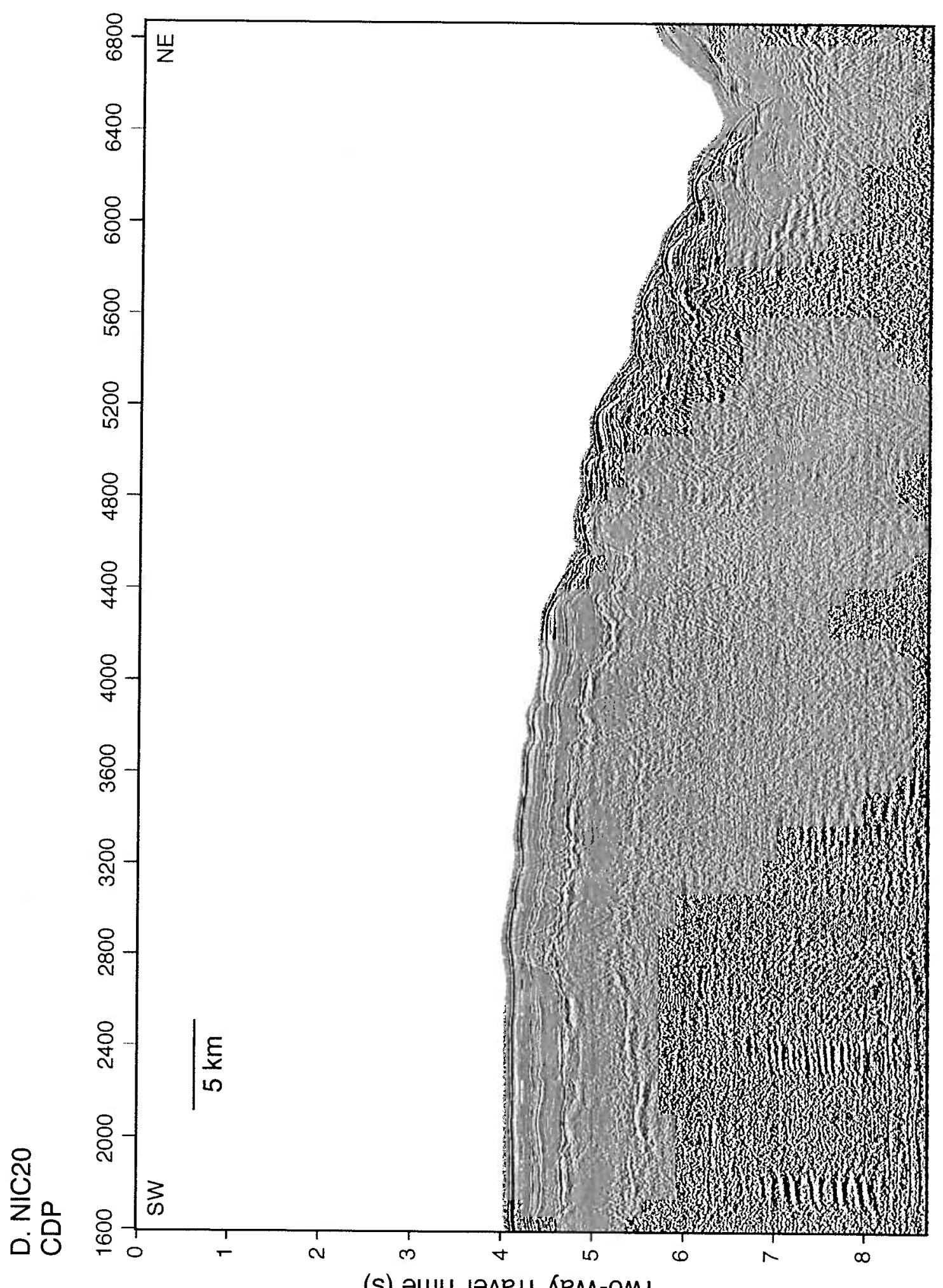

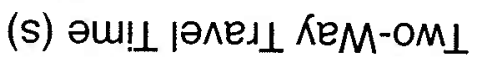


Figure 9e. 


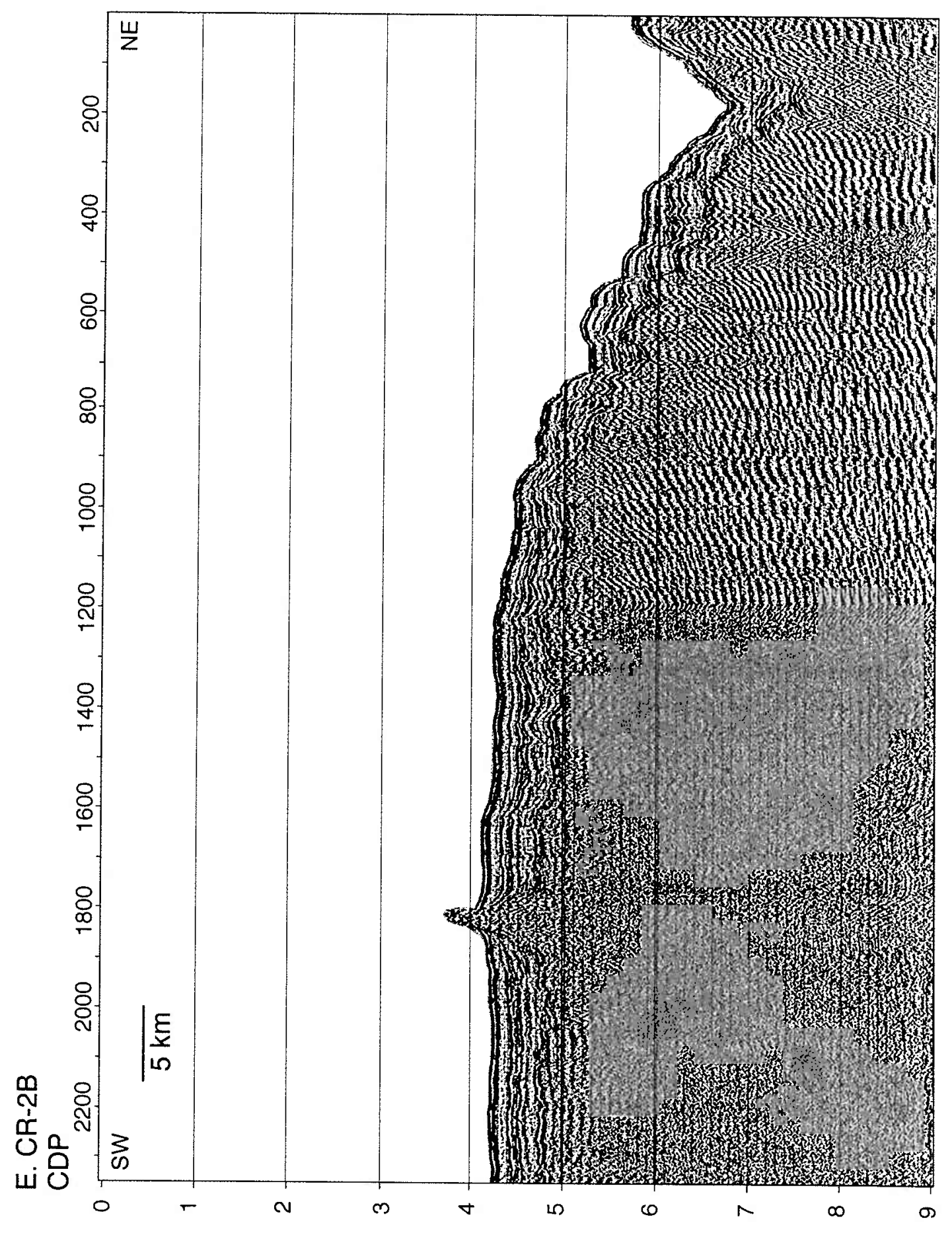

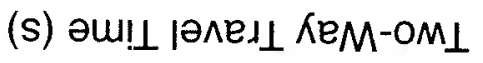


Figure 9f. 


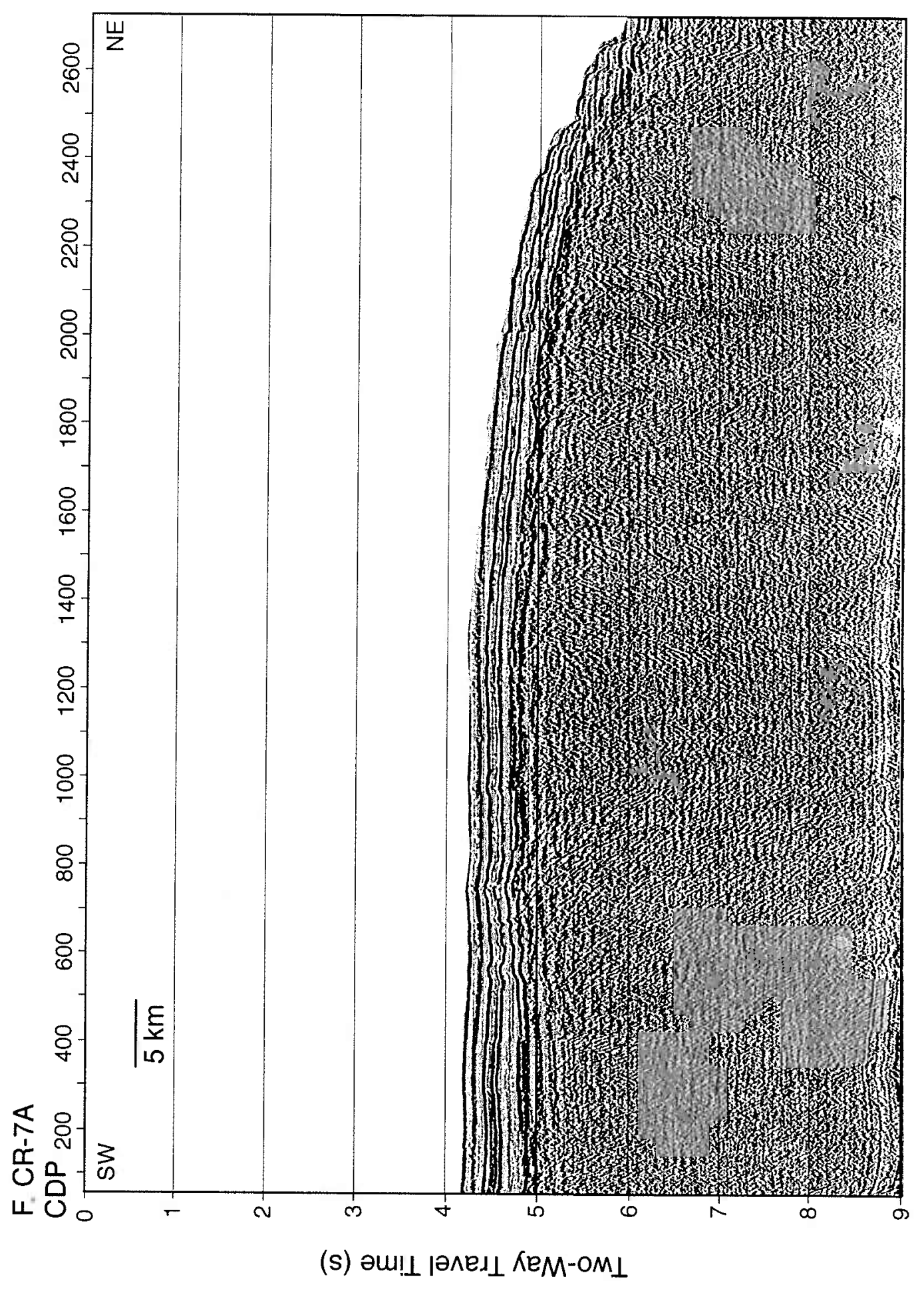


Figure 10. Basement fault throws were measured using a constant two-way travel time conversion of $1650 \mathrm{~m} / \mathrm{s}$ sediment velocity. (A) In averaging basement fault relief within a seismic line, if an extensional fault produced a corresponding bathymetric expression in the overlying sediment layer, it was given a weight of one. (B) If two or more closely spaced basement faults resulted in only one overlying bathymetric expression, these faults were summed together to equal a single basement fault throw with a weight of one. The two examples selected here are located by black boxes on NIC-80 (Figure 9a). Not shown: If a small seamount $(<1 \mathrm{~km})$ produced relief in the basement that also generated bathymetric relief, the vertical offset from the peak of the seamount to the base of the adjacent trenchward fault block was counted as equivalent to the throw on an extensional fault. 


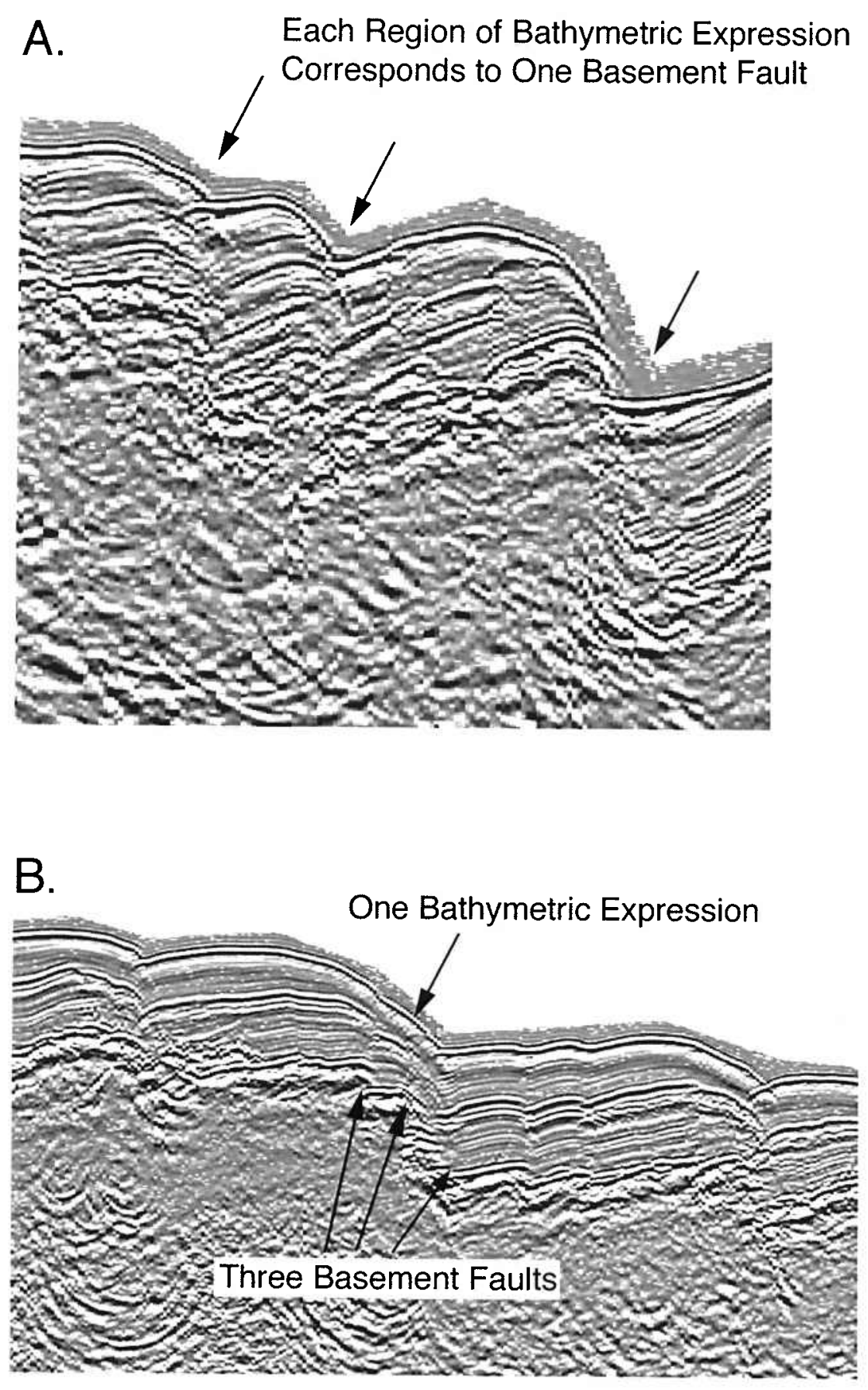


Figure 11. The second-order stochastic statistical method (Goff and Jordan, 1988) used to analyze the bathymetric data calculates the average variation of the bathymetry about a set of mean depths. In this case, the mean depths are based on the deflection of the plate as it bends at the trench. The large-scale curvature of the plate was calculated using both a linear trend and a quadratic polynomial trend. The RMS height results using the quadratic polynomial were selected as representative of the trend of the seafloor morphology. The linear trend underfits the curvature of the plate, resulting in a higher bathymetric variance as well as larger standard deviations. Higher order polynomials overfit the smaller scale bathymetric features of the plate, minimizing the calculated relief. Error bars are 1б. A 1:1 line is shown for comparison. 


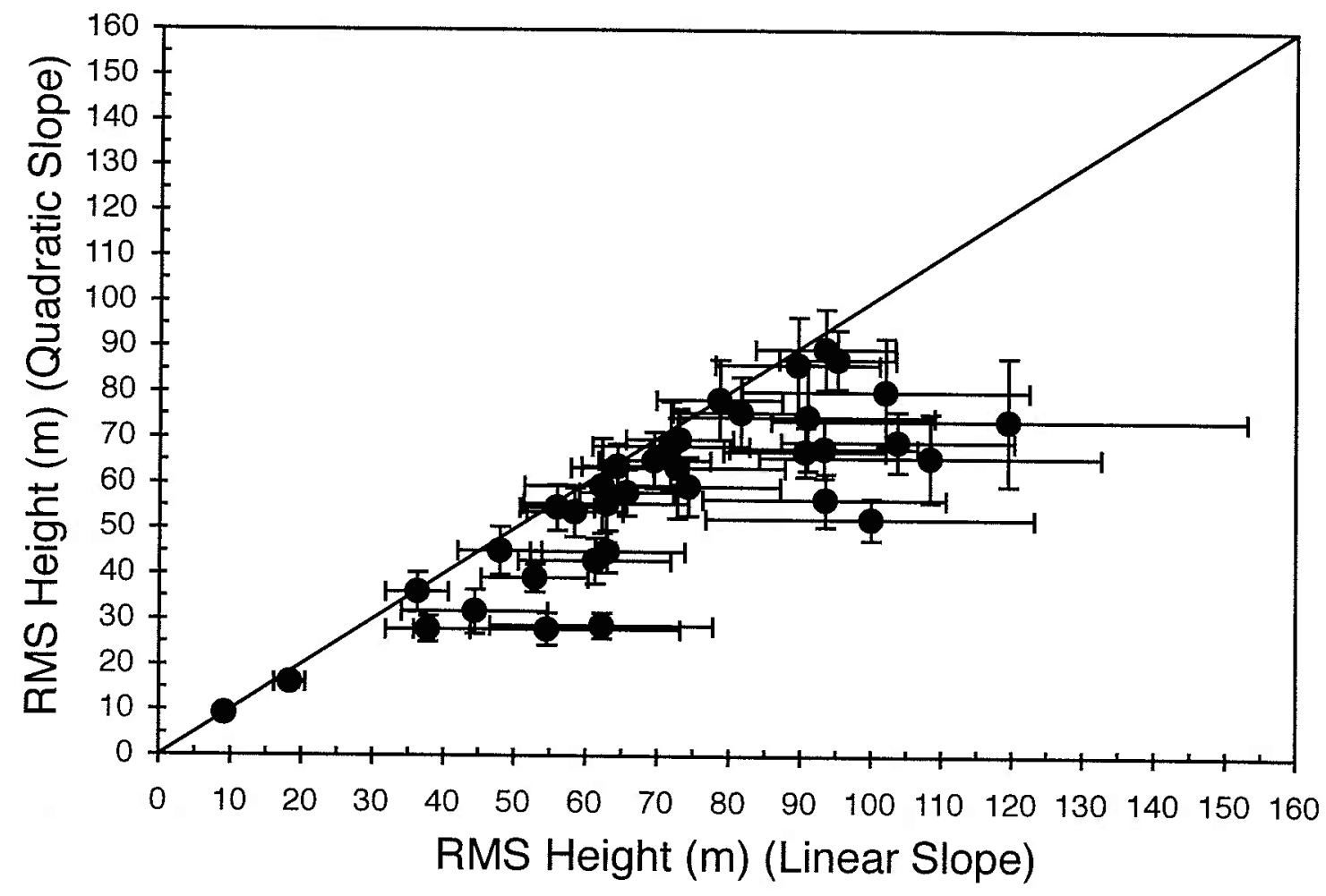


Figure 12. (A) For two seismic lines, NIC-80 offshore of Nicaragua and CR-001 offshore of Costa Rica, the navigational data from the seismic line was projected through the hydrosweep bathymetry data collected on cruise EW0005. The fault throw measured for each basement fault observed in the seismic line was compared to the corresponding bathymetric relief in the extracted bathymetry data. A 1:1 line is shown for comparison. (B) The average fault relief for each seismic line extending $25 \mathrm{~km}$ from the trench was compared to the average RMS height for the $10 \mathrm{~km}$ wide bathymetry data box, also extending $25 \mathrm{~km}$ from the trench, within which the seismic line was located. Error bars are $1 \sigma$. The relatively large standard deviations for the seismic lines offshore of Nicaragua indicate the wide range in individual measurements of fault relief within the seismic section. 

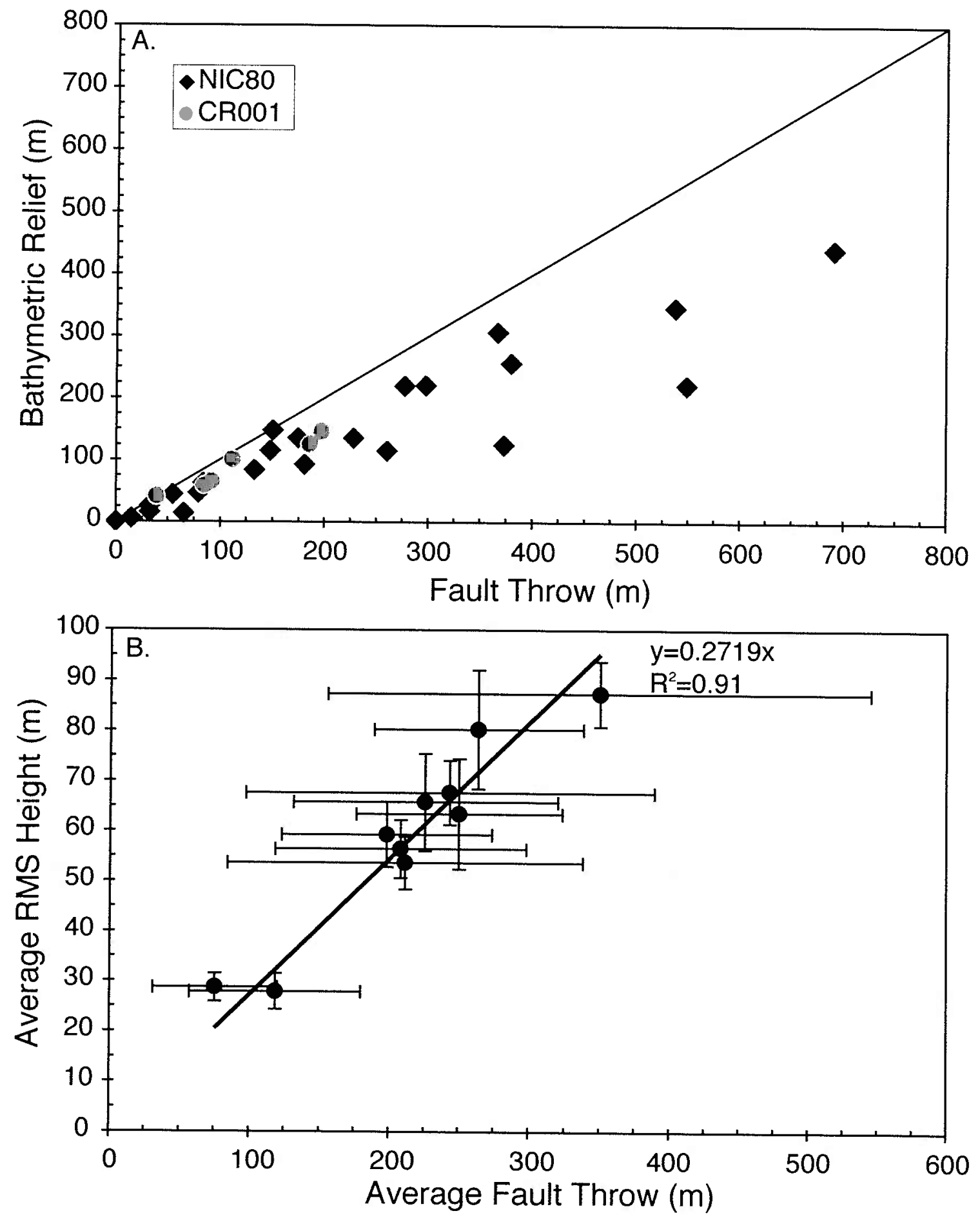
Figure 13. Statistical parameters calculated for the bathymetry data boxes $10 \mathrm{~km}$ wide extending $25 \mathrm{~km}$ from the trench include RMS height, azimuth, characteristic width, and characteristic length. Error bars are 1б. Along strike distances are referenced by projecting each data box orthogonally across the trench to the corresponding distance along the strike of the volcanic arc. The origin and projection for the arc volcano distance reference frame is given in Carr et al. (2003). The location of the EPR/CNS-1 boundary is shown in gray. (A) The RMS height peaks offshore of Nicaragua, levels out, and then decreases offshore of Costa Rica. The solid black lines bracket a transition in bathymetric relief, corresponding to a shift in the subducting plate, from consistently high basement fault relief in which fault throws are equal to or greater than the overlying sediment thickness, to a region in which minimal faulting is observed. (B) The azimuths of the fault lineations in the EPR crust are consistent with reactivation of the inherited abyssal hill fabric, which is parallel or subparallel to the azimuth of the trench, during bending of the Cocos plate at the trench. In the CNS-1 crust, the fault lineations parallel neither the trench nor the pre-existing abyssal hill fabric, which is orthogonal to the trench. (C) The characteristic widths of the bathymetric morphology are also consistent with reactivation of abyssal hills generated at the fast spreading EPR. In the CNS-1 crust, there is no change in characteristic width compared to the EPR-derived crust, which may indicate that inherited abyssal hill fabric can be compatible with, but not a control on, bendingrelated fault spacing. (D) The characteristic lengths of the fault lineations exhibit a wide range but do not follow a specific trend along strike. 


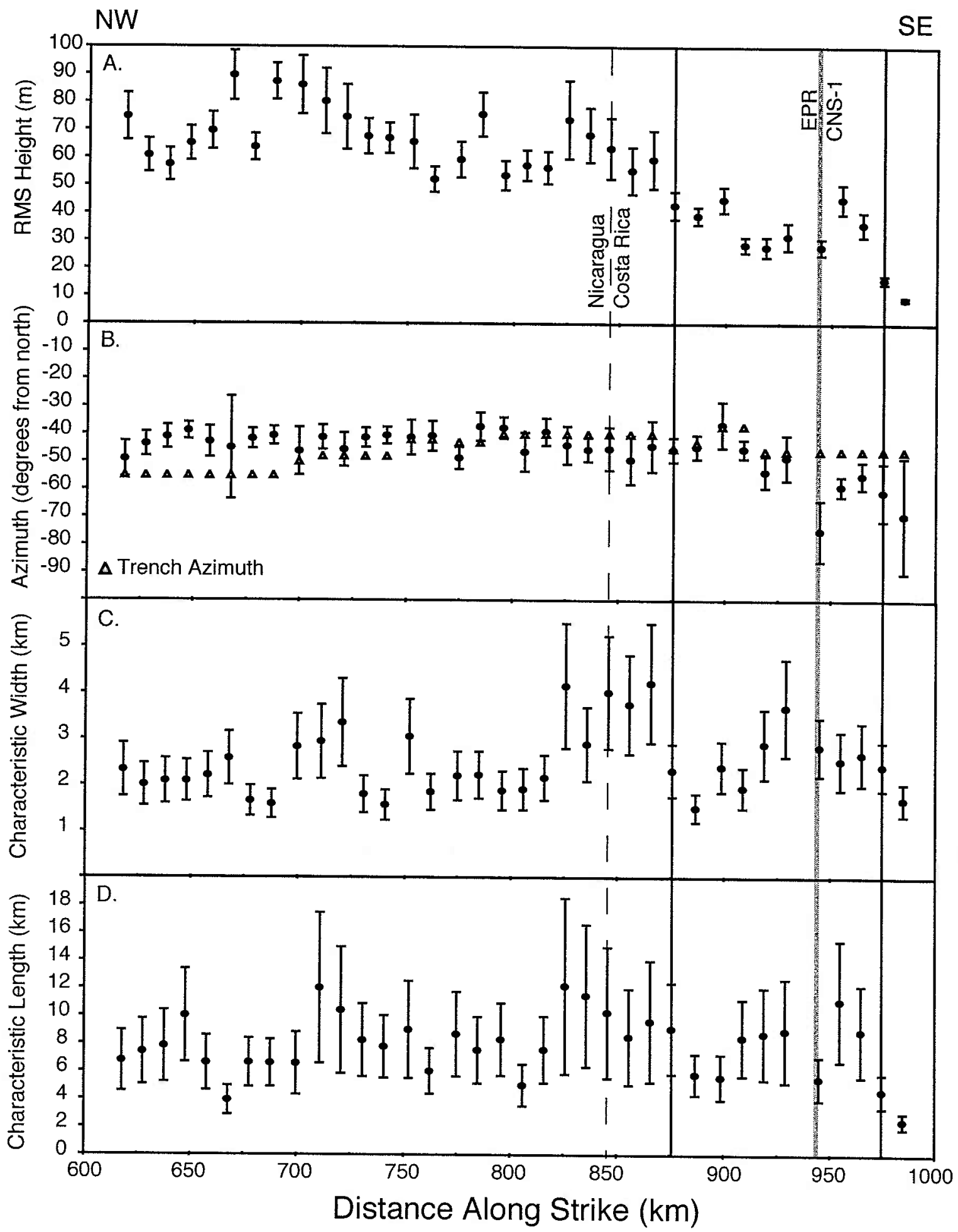


Figure 14. Single bathymetric projections for each of the $10 \mathrm{~km}$ wide bathymetry data regions from Nicaragua to Costa Rica, plotted using the new hydrosweep swath bathymetry data (200 m grid spacing) where available and the Smith and Sandwell (1997) bathymetry ( 2 minute grid spacing) otherwise. RMS Height and EPR/CNS-1 labels are placed above the bathymetric profiles that correspond to those boundaries (as shown in Figure 8). Along strike spacing between projections is $10 \mathrm{~km}$ (see Figure 15). 


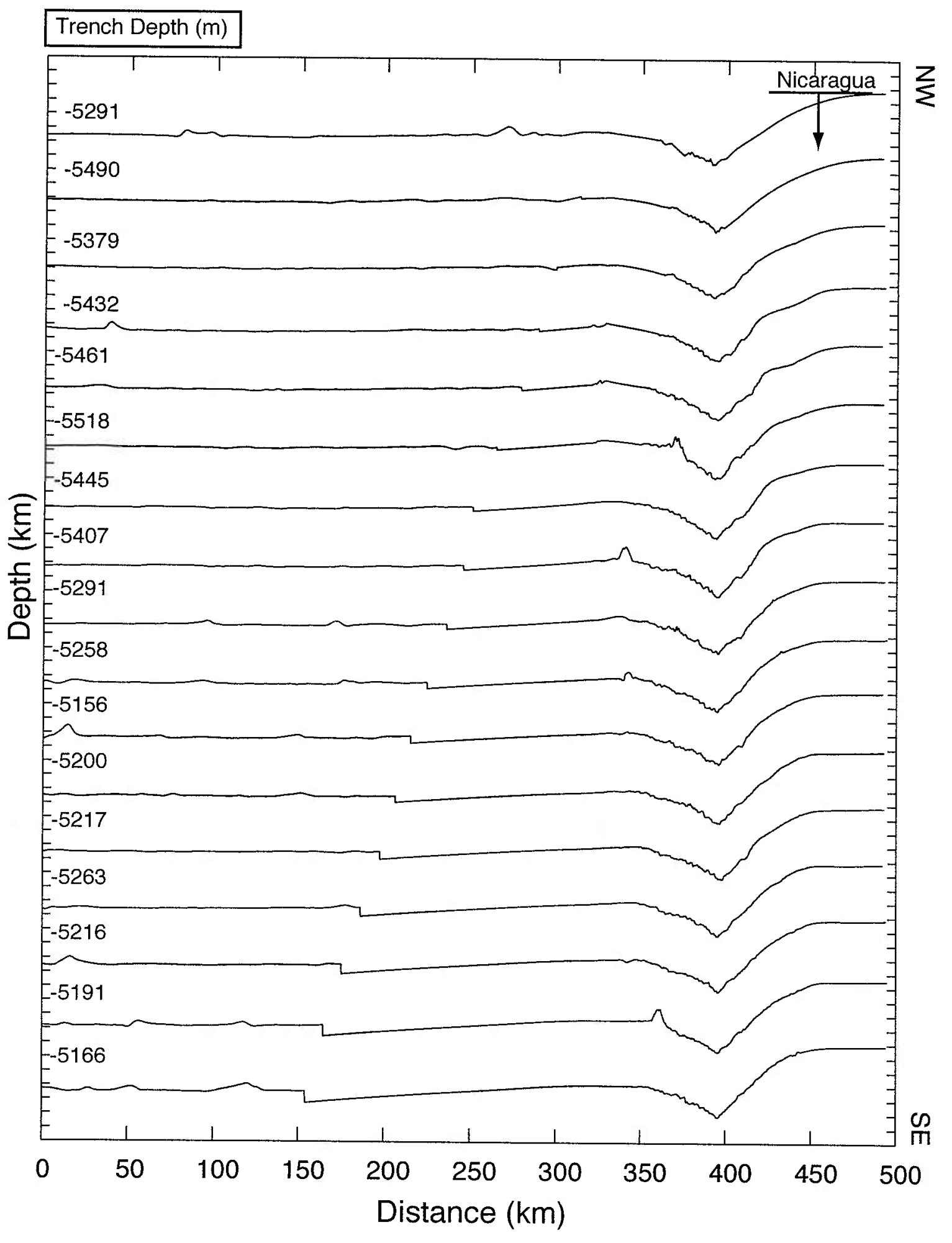


Figure 14 continued. 


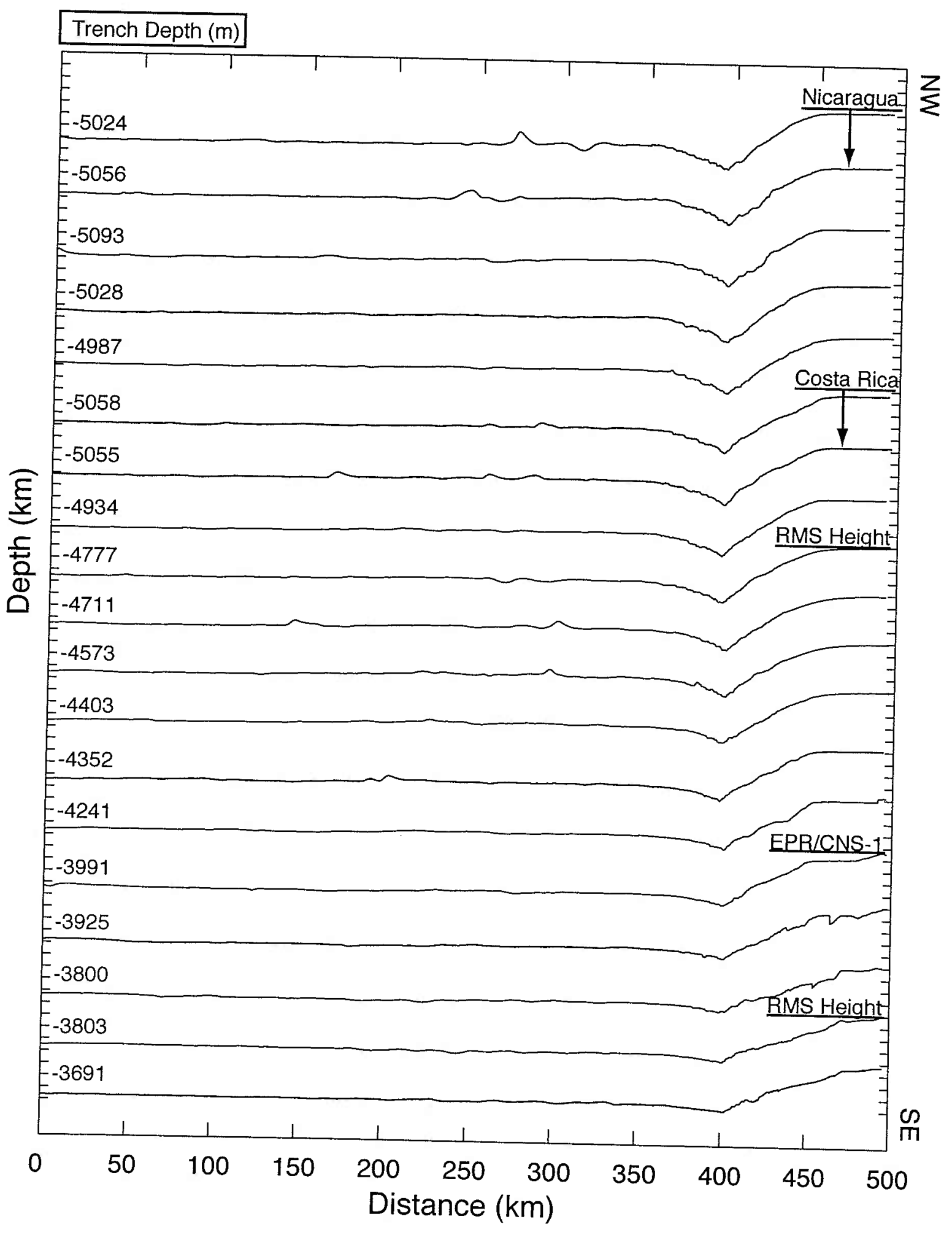


Figure 15. The slope $(\partial y / \partial x)$ of the plate bending at the trench was measured 25 and 50 $\mathrm{km}$ from the trench for each of the bathymetric projections shown in Figure 14. $\partial \mathrm{y}$ and $\partial \mathrm{x}$ are calculated as in Figure 7. The decrease in the deflection of the plate offshore of Costa Rica corresponds to the shallowing of the trench depth. Dashed line is the Nicaragua/Costa Rica border. Solid black lines bound the transition zone in RMS height. The solid gray line is the EPR/CNS-1 boundary. 


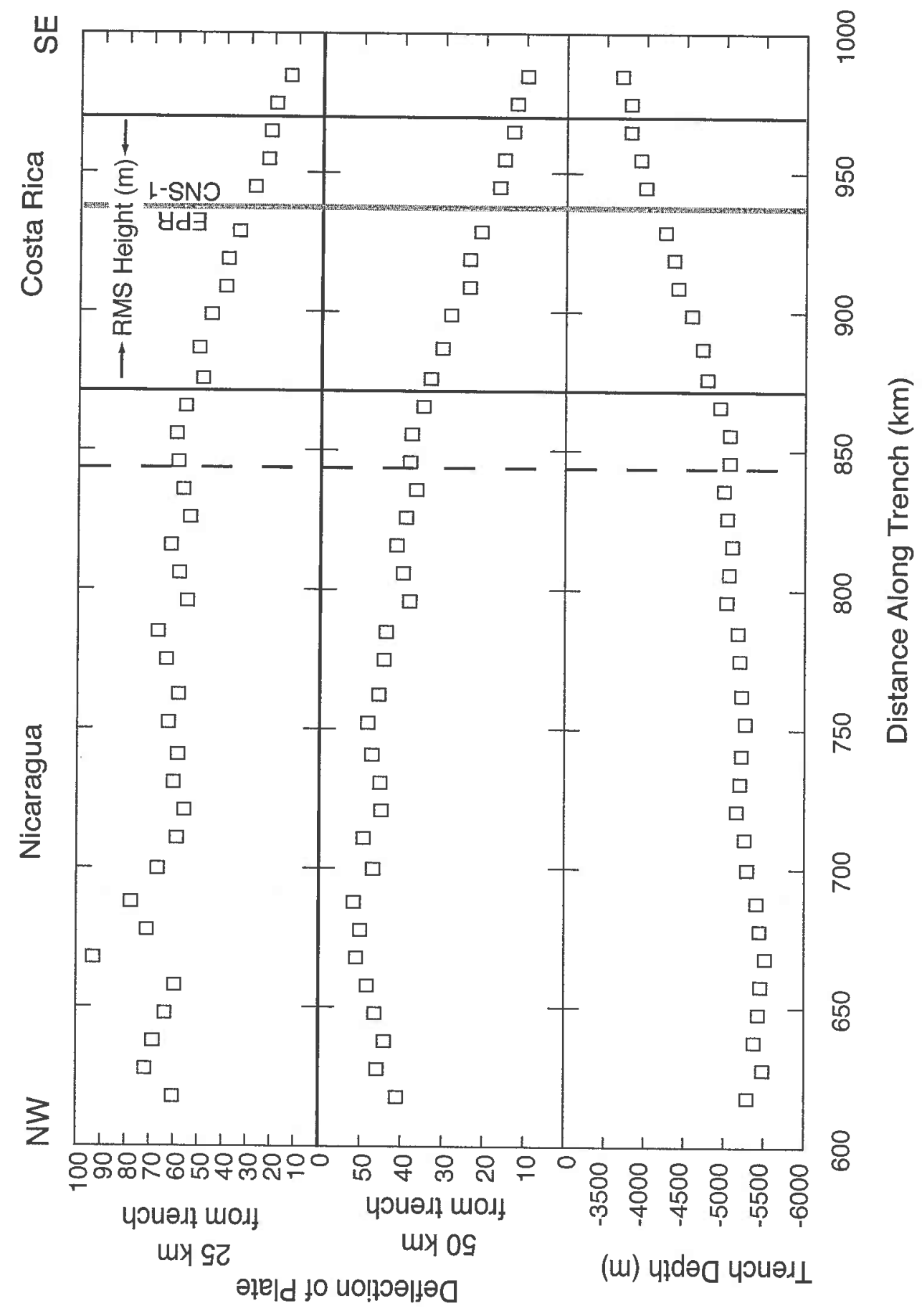


Figure 16. The average RMS height $25 \mathrm{~km}$ from the trench is linearly related to the slope of the plate $25 \mathrm{~km}$ from the trench. This relationship is more clearly defined for the region of the plate offshore of Costa Rica. The Nicaraguan data shows more scatter, which may be a function of two things: 1) Increased curvature should also increase extensional fault relief associated with plate bending, but RMS height does not increase equivalently with basement fault relief (i.e., Figure 12). 2) The method for quantifying the slope may be too simplistic to represent the degree of curvature where a pronounced flexural bulge is present, as offshore of Nicaragua, as the plate is not planar. Instead, the wavelength of curvature may provide a better correlation with bending-induced fault relief for this region. 


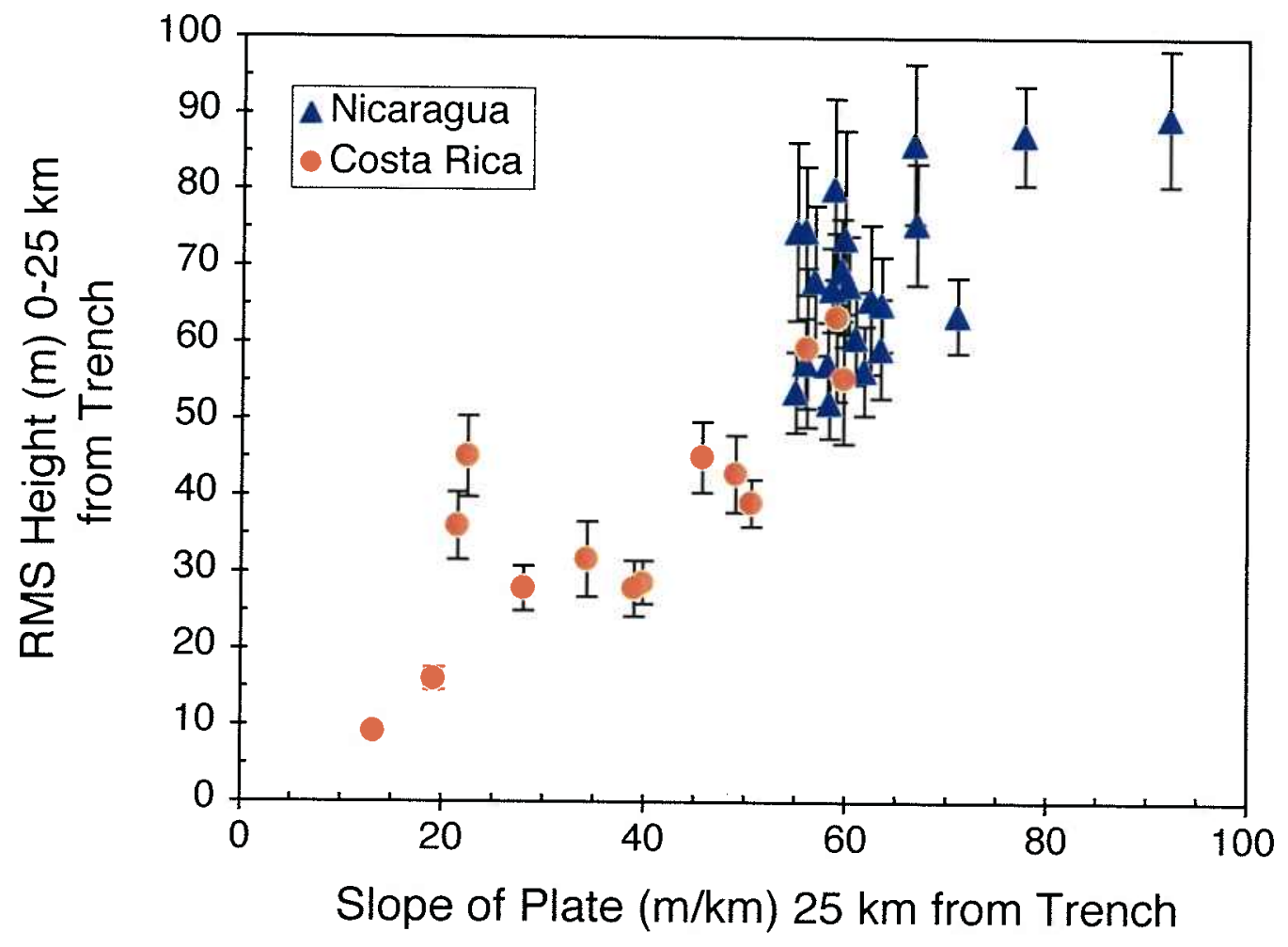


Figure 17. For the Cocos plate subducting offshore of Costa Rica, the slope of the plate $25 \mathrm{~km}$ from the trench decreases as the depth of trench decreases. However, this relationship is less defined from Guatemala to Nicaragua, where the trench shallows along strike but the curvature (as indicated by the slope) remains more constant, though there is considerable scatter. The black and white data points were calculated using Smith and Sandwell (1997) bathymetry (denoted SS in the legend). The blue triangles (Nicaragua) and pink circles (northwestern Costa Rica) were calculated from the EW0005 hydrosweep swath bathymetry data. High-resolution swath bathymetry data for the Cocos plate offshore of Guatemala and El Salvador might resolve whether there is a correlation between trench depth and slope for these regions. 


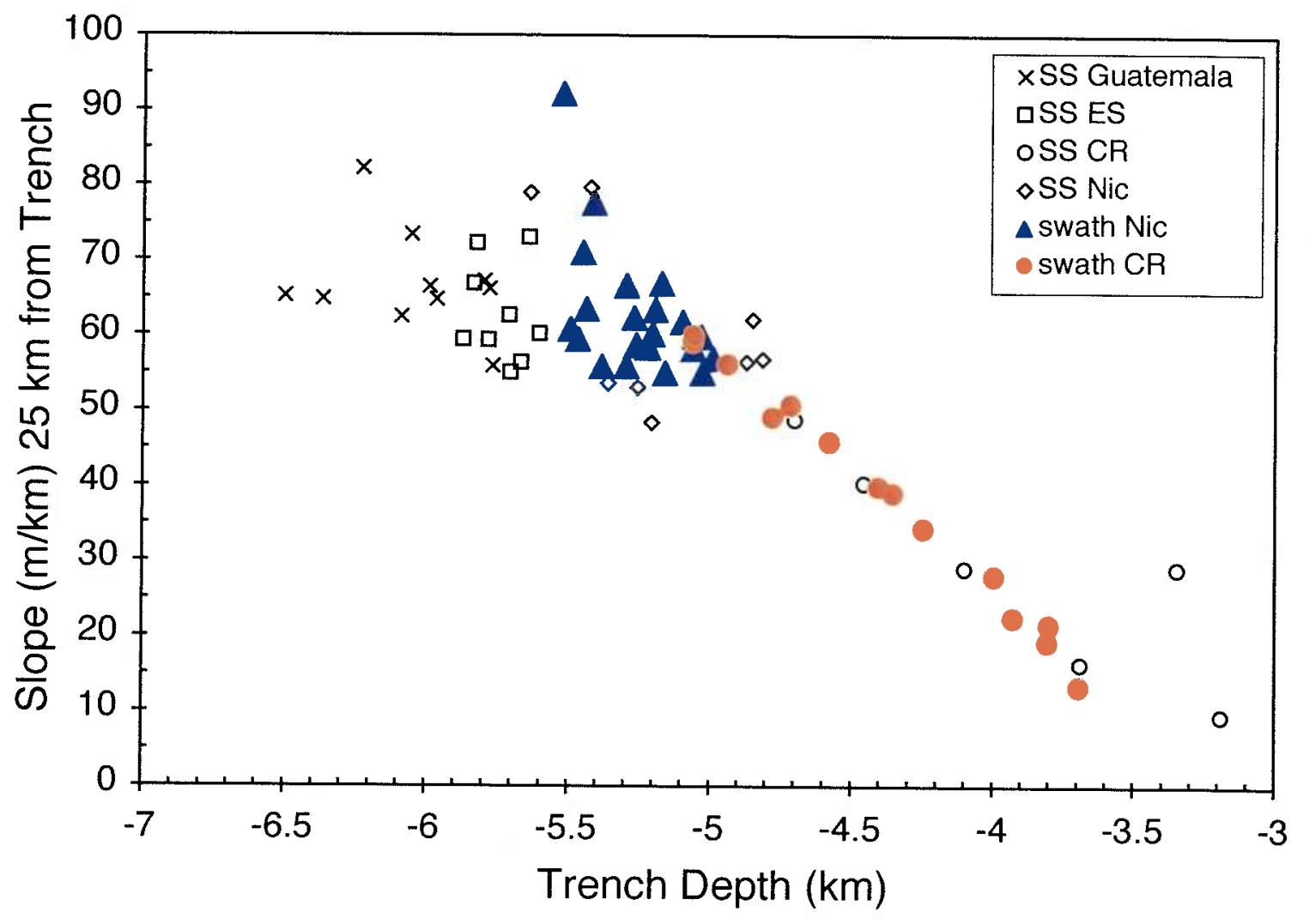


Figure 18. Average RMS heights for bathymetry data regions $0-25 \mathrm{~km}$ from the trench compared to average RMS heights for data regions $15-40 \mathrm{~km}$ from the trench. If fault relief remained constant extending from 0 to $40 \mathrm{~km}$ from the trench, it would be expected that the RMS heights for these regions would be equivalent $(1: 1$ line shown for comparison). A 1:1 relationship is observed only for the regions of high surface relief, which correspond to the region of the Cocos plate offshore of Nicaragua where the highamplitude flexural bulge peaks $\sim 50-75 \mathrm{~km}$ from the trench (e.g., Figure 14). Offshore of Costa Rica, where the RMS height $15-40 \mathrm{~km}$ from the trench is significantly smaller than the RMS height $0-25 \mathrm{~km}$ from the trench, the outer-rise flexural bulge is less pronounced and closer to the trench than in the Cocos plate to the northwest. As the wavelength and degree of curvature due to bending of the subducting plate decrease, the distance from the trench over which consistently rough bathymetric morphology occurs will also be reduced. 


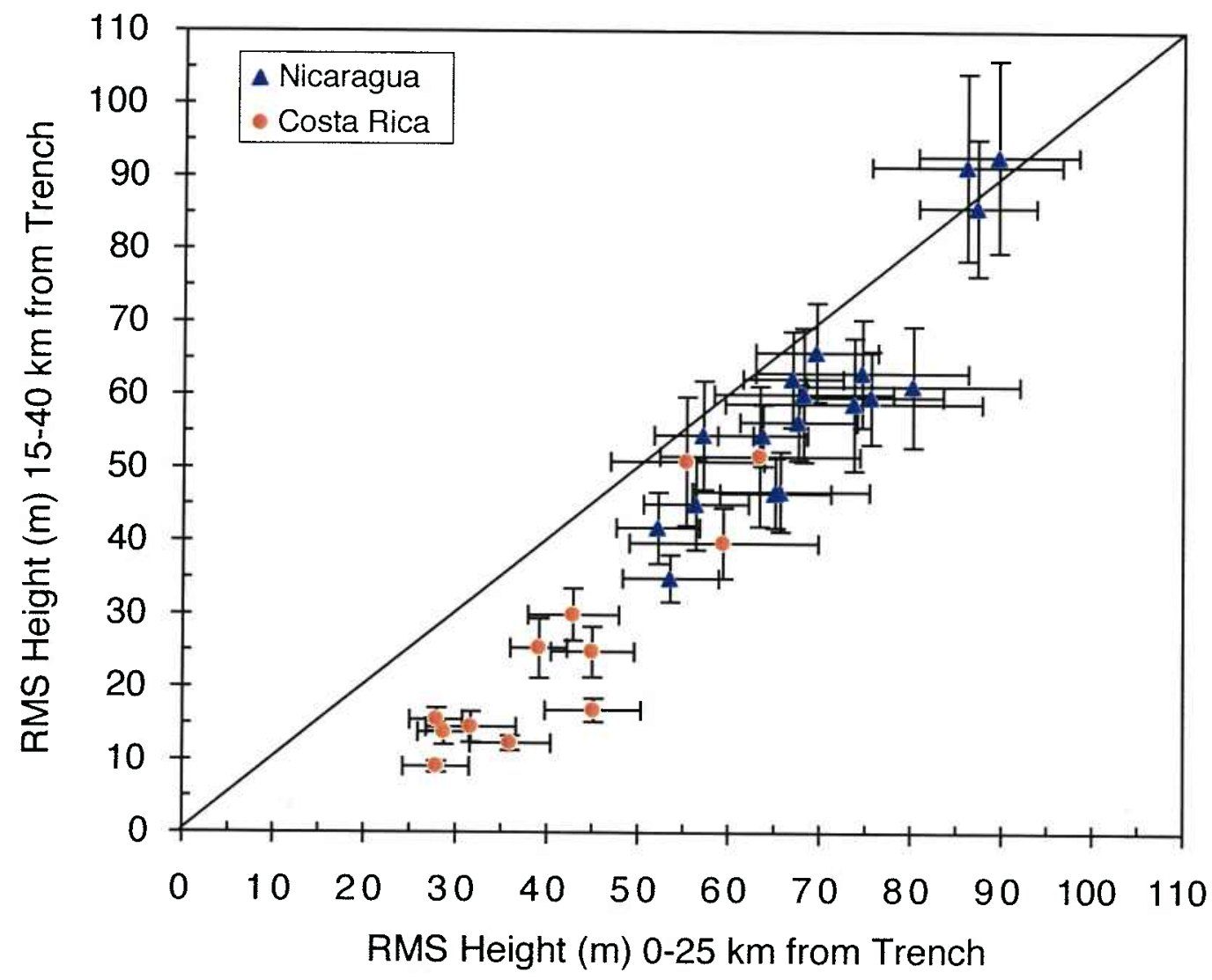


Figure 19. The RMS height $15-40 \mathrm{~km}$ from the trench shows a linear dependence on slope. However, this relationship has more scatter for the Cocos plate offshore of Nicaragua. The use of a linear slope may be too simplistic a measurement to track flexure in this region, as the flattening of the plate with distance from the trench will probably create a change in the slope from a steeper one closer to the trench to a shallower one farther away. This is consistent with our findings that a quadratic fit better approximated the shape of the plate than a linear fit (Figure 11). 


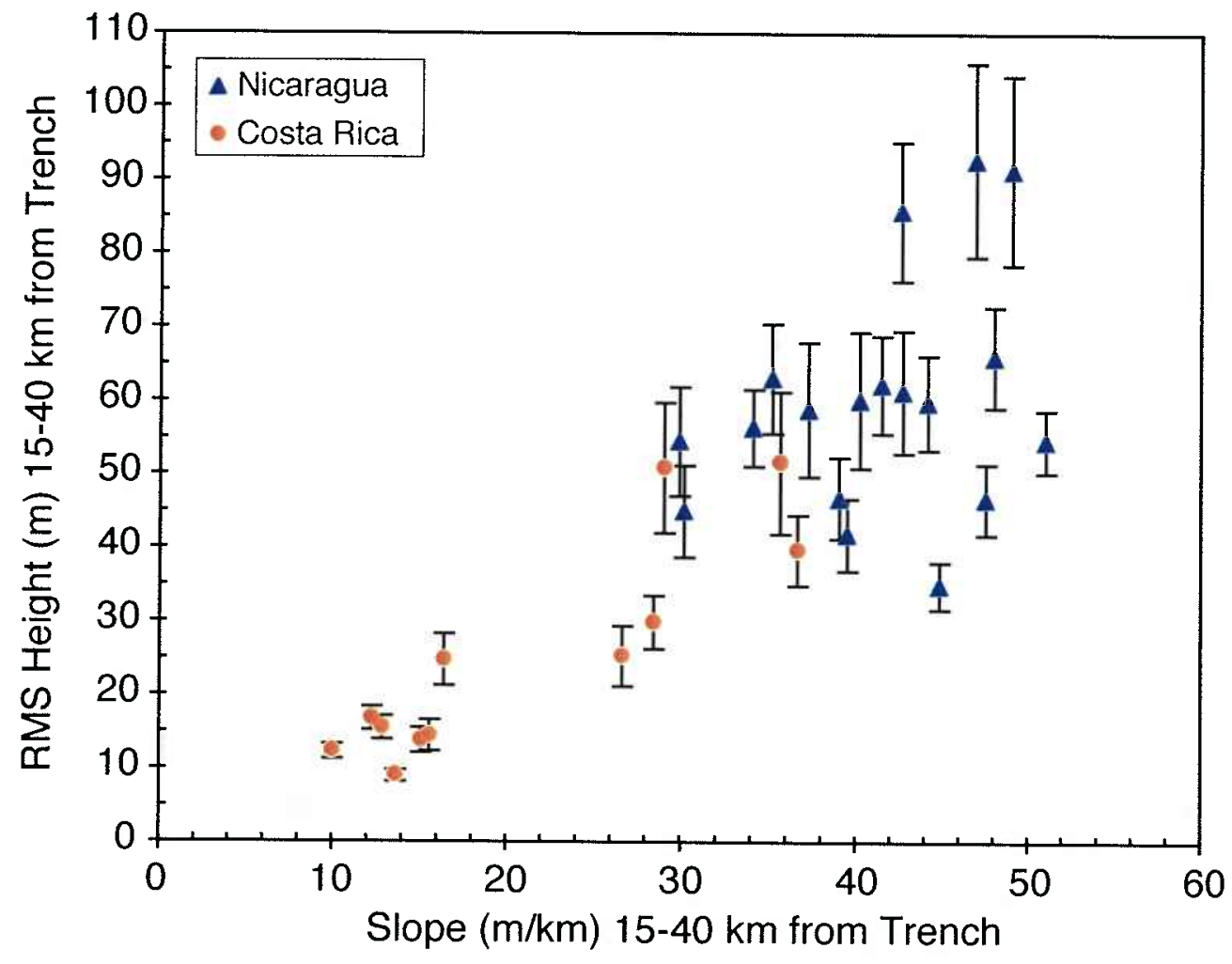


Figure 20. (A) RMS height, (B) azimuth, and (C) characteristic width are shown along strike of the trench for bathymetry regions extending 0-25 km, 15-40 km, and 0-25 km perpendicular to the trench. The statistical parameters exhibit some deviation in RMS height and characteristic width between the different regions of distance from the trench, but the azimuthal orientations of the fault lineations remain constant with distance from the trench. Each data point represents a weighted average (see text for explanation) for contiguous regions of five data boxes $10 \mathrm{~km}$ wide each, except for the boundaries of the swath bathymetry region, in which case the width of the weighted average is for a region $20 \mathrm{~km}$ wide. 


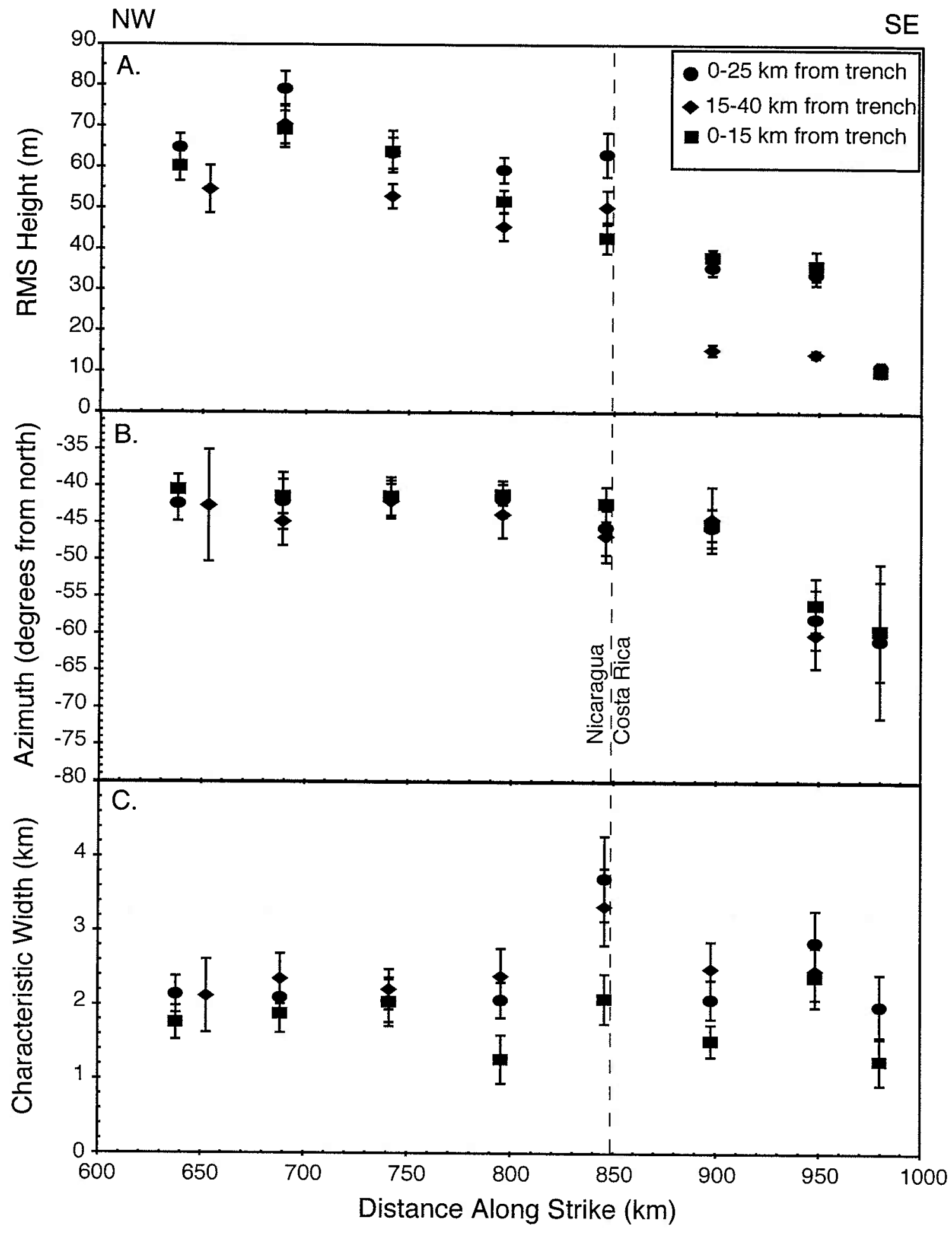


Figure 21. (A) RMS height, (B) azimuth, and (C) characteristic width of $50 \mathrm{~km}$ weighted averages for the data boxes $0-15 \mathrm{~km}$ from the trench were compared to $50 \mathrm{~km}$ weighted averages for bathymetry data boxes located on the upper plate, $0-15 \mathrm{~km}$ from the trench and directly opposite the data regions for the Cocos plate. The RMS height appears to be consistent across the trench, but this may not be causally related, as the characteristic widths do not co-vary. The azimuthal lineations of the morphologies appear similar, which might indicate that deformation due to basement faulting in the lower plate is being translated through the forearc toe of the upper plate. However, this is equivocal, because the orientation of deformation in the upper plate could simply be a function of the trend of the trench. 


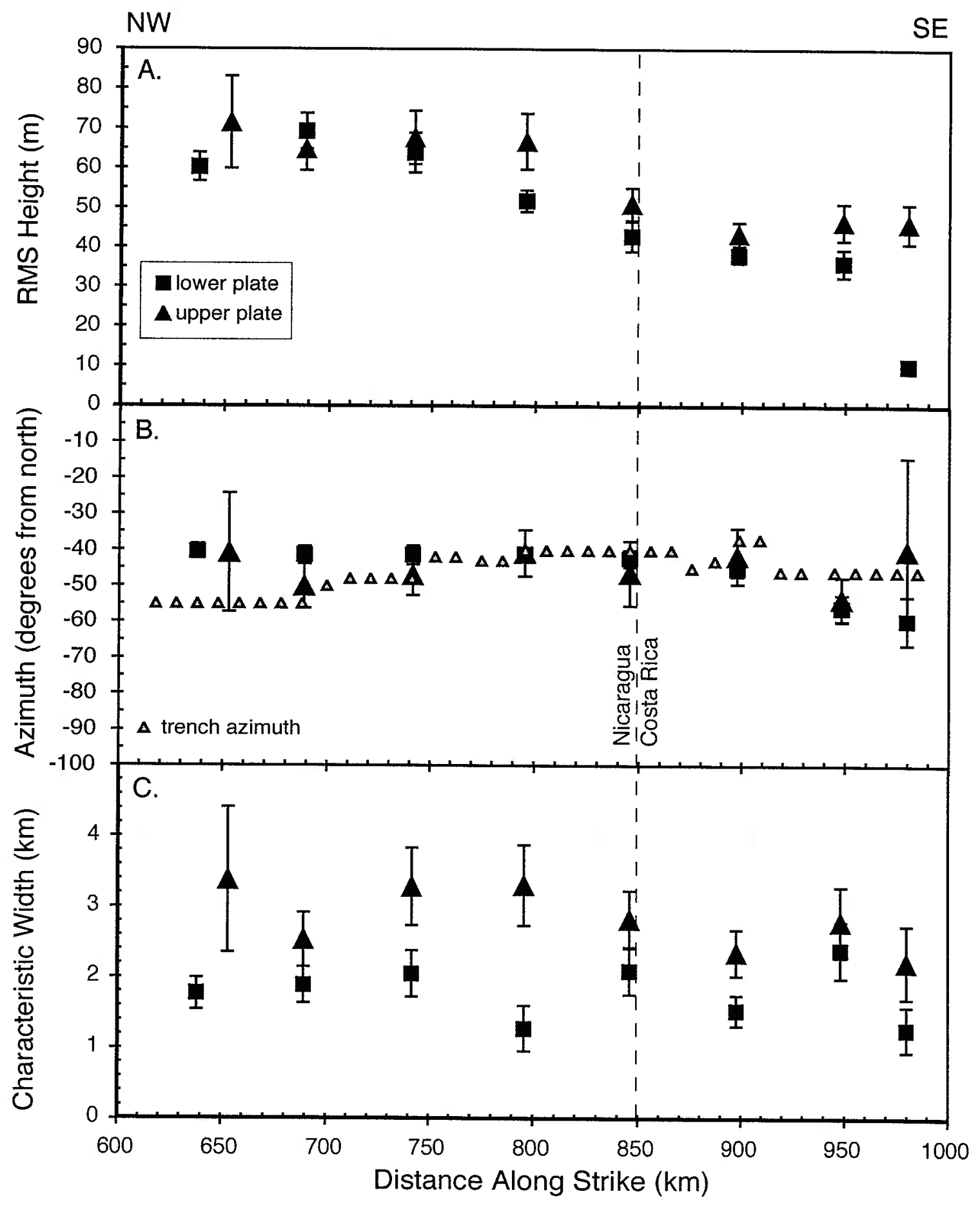


Figure 22. Central American Volcanic Arc geochemistry has signatures indicative of slab enrichment that progress from moderate slab input in Guatemala to a maximum in Nicaragua, decreasing again in Costa Rica. In central Costa Rica, slab enrichment is minimal or absent. (A) ${ }^{10} \mathrm{Be} /{ }^{9} \mathrm{Be}$, a tracer of the shallow hemipelagic sediment section on the subducting plate, peaks slightly to the southeast of the maxima in (B) $\mathrm{Ba} / \mathrm{La},(\mathrm{C})$ $\mathrm{U} / \mathrm{Th}$, and (D) B/Be. ${ }^{10} \mathrm{Be} /{ }^{9} \mathrm{Be}$ sharply decreases across the Nicaragua/Costa Rica border, a region across which the range in $\mathrm{Ba} / \mathrm{La}$ and $\mathrm{B} / \mathrm{Be}$ remain constant. Geochemistry data (except for ${ }^{10} \mathrm{Be} /{ }^{9} \mathrm{Be}$ data: Tera et al., 1986; Morris et al., 1990; Morris et al., 2002a; Table 1, Chapter II) is from the CENTAM database (www-rci.rutgers.edu/ carr/ index.html; Carr et al., 2003 and references therein). Samples plotted have $\mathrm{SiO}_{2}<60 \%$. High-Ti samples, thought to form either in a different melting source region or via different slab element transfer processes than the low-Ti Nicaraguan lavas (e.g., review in Carr et al., 2003) are shown as open symbols. Legend abbreviations are: $\mathrm{W} . \mathrm{Nic}=$ Western Nicaragua, E. Nic $=$ Eastern Nicaragua, $\mathrm{NW} \mathrm{CR}=$ Northwestern Costa Rica, $\mathrm{C}$ $\mathrm{CR}=$ Central Costa Rica. $\mathrm{QSC}=$ Quesada Sharp Contortion. Black dashed lines indicate country boundaries. N-MORB and OIB values from Sun and McDonough (1989). 


\begin{tabular}{|ll|}
\hline$\times$ Guatemala & AE. Nic \\
EI Salvador & NW CR \\
$\bullet$ W. Nic & + C CR \\
\hline
\end{tabular}
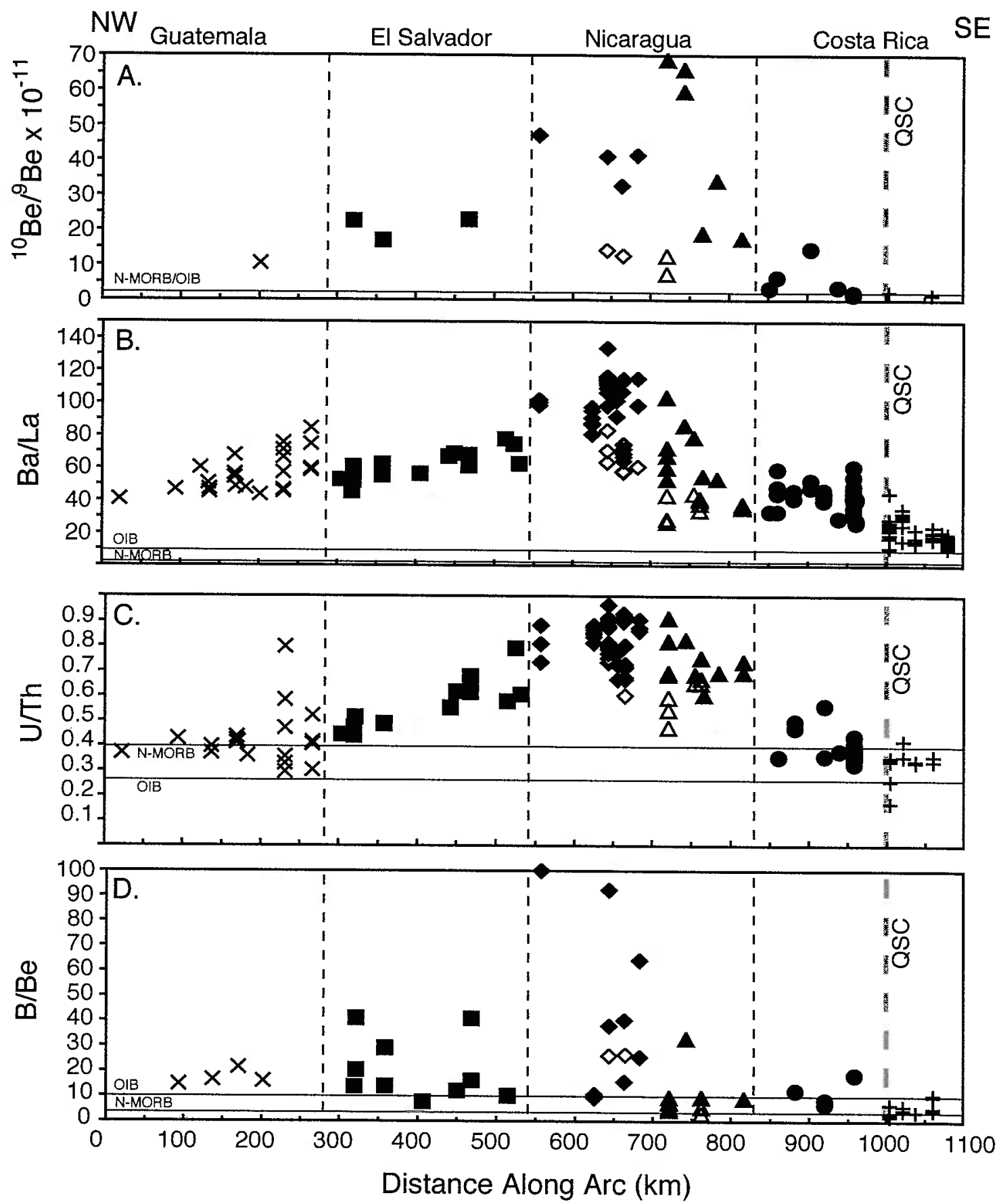
Figure 23. ${ }^{10} \mathrm{Be} /{ }^{9} \mathrm{Be}$ is correlated with (A) $\mathrm{Ba} / \mathrm{La}$ and (B) $\mathrm{B} / \mathrm{Be}$ from Guatemala through Nicaragua. In Costa Rica, $\mathrm{Ba} / \mathrm{La}$ and $\mathrm{B} / \mathrm{Be}$ remain elevated while ${ }^{10} \mathrm{Be} /{ }^{9} \mathrm{Be}$ decreases to minimal enrichment. Nicaraguan high-Ti lavas, which have a smaller slab signal than low-Ti samples from the same volcanic center (e.g., Carr et al., 1990; Reagan et al., 1994; Patino et al., 2000) still fall along the general trend. A logarithmic scale for ${ }^{10} \mathrm{Be} /{ }^{9} \mathrm{Be}$ is used to illustrate that the difference between atomic ratios of 10 and 1 for ${ }^{10} \mathrm{Be} /{ }^{\rho} \mathrm{Be}$ signals a change from moderate enrichment (high, globally) to a value that is indistinguishable from background detection limits. Trace element data corresponding to the most recent ${ }^{10} \mathrm{Be} /{ }^{\rho} \mathrm{Be}$ data for northwestern Costa Rica (e.g., Morris et al., 2002a; Table 1, Chapter II) are not available, but $\mathrm{Ba} / \mathrm{La}$ and $\mathrm{B} / \mathrm{Be}$ are not observed to decrease across the Nicaragua/Costa Rica border (Figure 22). Legend abbreviations are the same as in Figure 22. 

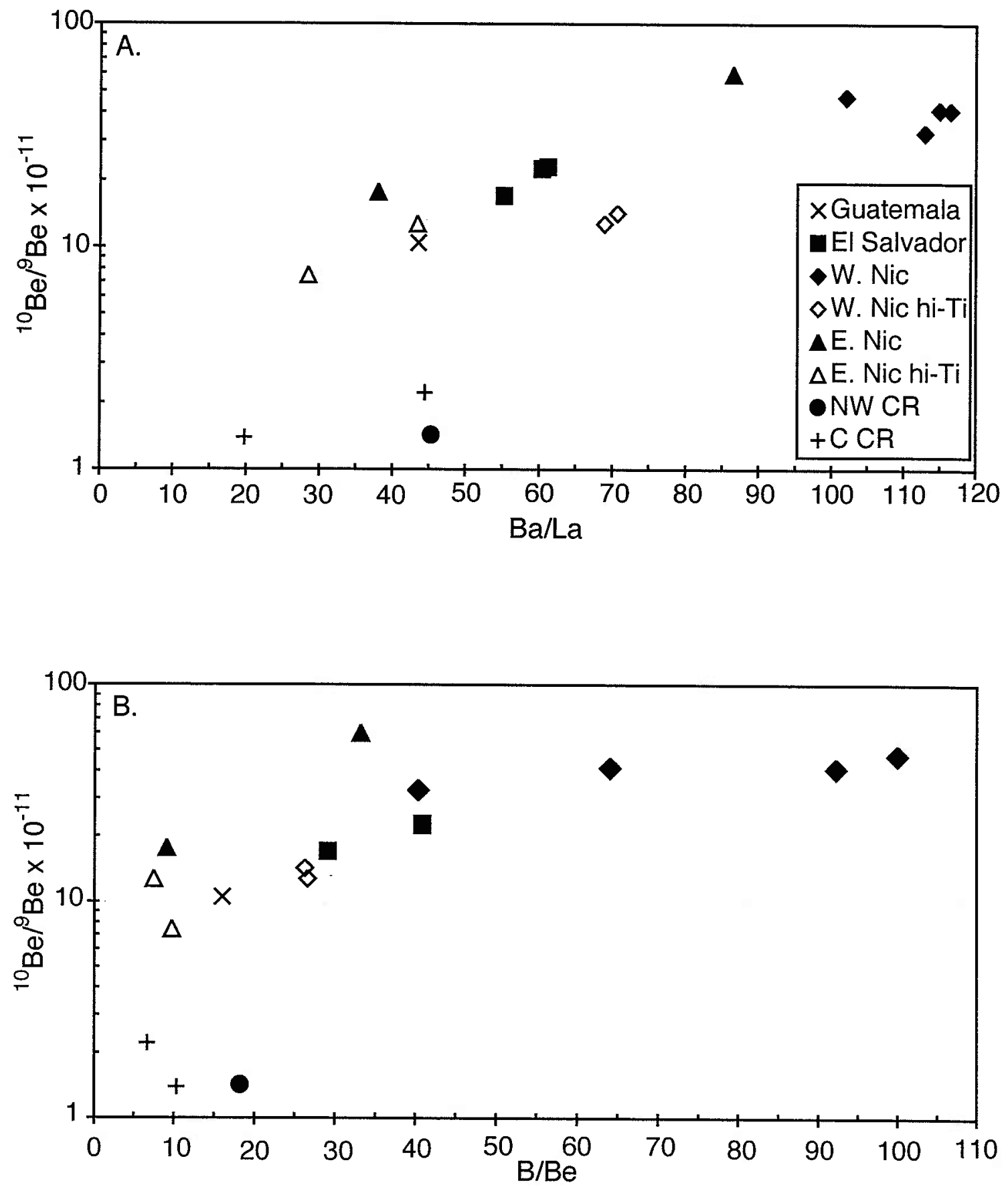
Figure 24. (A) and (B): $\mathrm{Ba} / \mathrm{La}$ and ${ }^{10} \mathrm{Be} /{ }^{9} \mathrm{Be}$ enrichments in the Central American Volcanic Arc are shown with distance along strike of the arc (arc volcano distances: Carr et al., 2003; www-rci.rutgers.edu/ carr/index.html). Symbols are the same as in Figure 22. Solid green lines bracket ${ }^{10} \mathrm{Be} /{ }^{9} \mathrm{Be}$ transition region. N-MORB and OIB values from Sun and McDonough, (1989). (C): The average RMS heights for data boxes $10 \mathrm{~km}$ wide extending $25 \mathrm{~km}$ from the trench are plotted with distance along strike of the arc.

Distance is obtained by projecting the left side of the data box orthogonally across the trench to the corresponding distance along the volcanic arc. Vertical error bars represent 1б. D: The average basement fault throws of seismic lines $0-25 \mathrm{~km}$ from the trench are plotted with distance along strike of the arc. Distance is obtained by projecting the seismic line orthogonally across the trench to the corresponding distance along the volcanic arc. Error bars are 1б. (A-D): Dashed line indicates Nicaragua/Costa Rica border. QSC = Quesada Sharp Contortion, where Wadati-Benioff Zone seismicity shows a sharp decrease in slab dip at $>100 \mathrm{~km}$ depth (Protti et al., 1995). (C-D): Pink lines bracket the transition in bathymetric roughness related to basement fault relief (located in Figure 8). Yellow line indicates the fracture zone trace where the Cocos plate fabric changes from trench-parallel EPR magnetic anomalies to trench-perpendicular CNS magnetic anomalies (see Figure 8). Black horizontal dashed lines mark a proposed threshold for underplating. When fault relief is below this threshold, basement fault structure will not prevent the décollement from relocating within the subducting sediment column, allowing for potential underplating of shallow sediments beneath the forearc. Above this threshold, fault throws that are greater than or equal to the thickness of the overlying sediments promote subduction of the entire sediment column to the depths of magma genesis. 


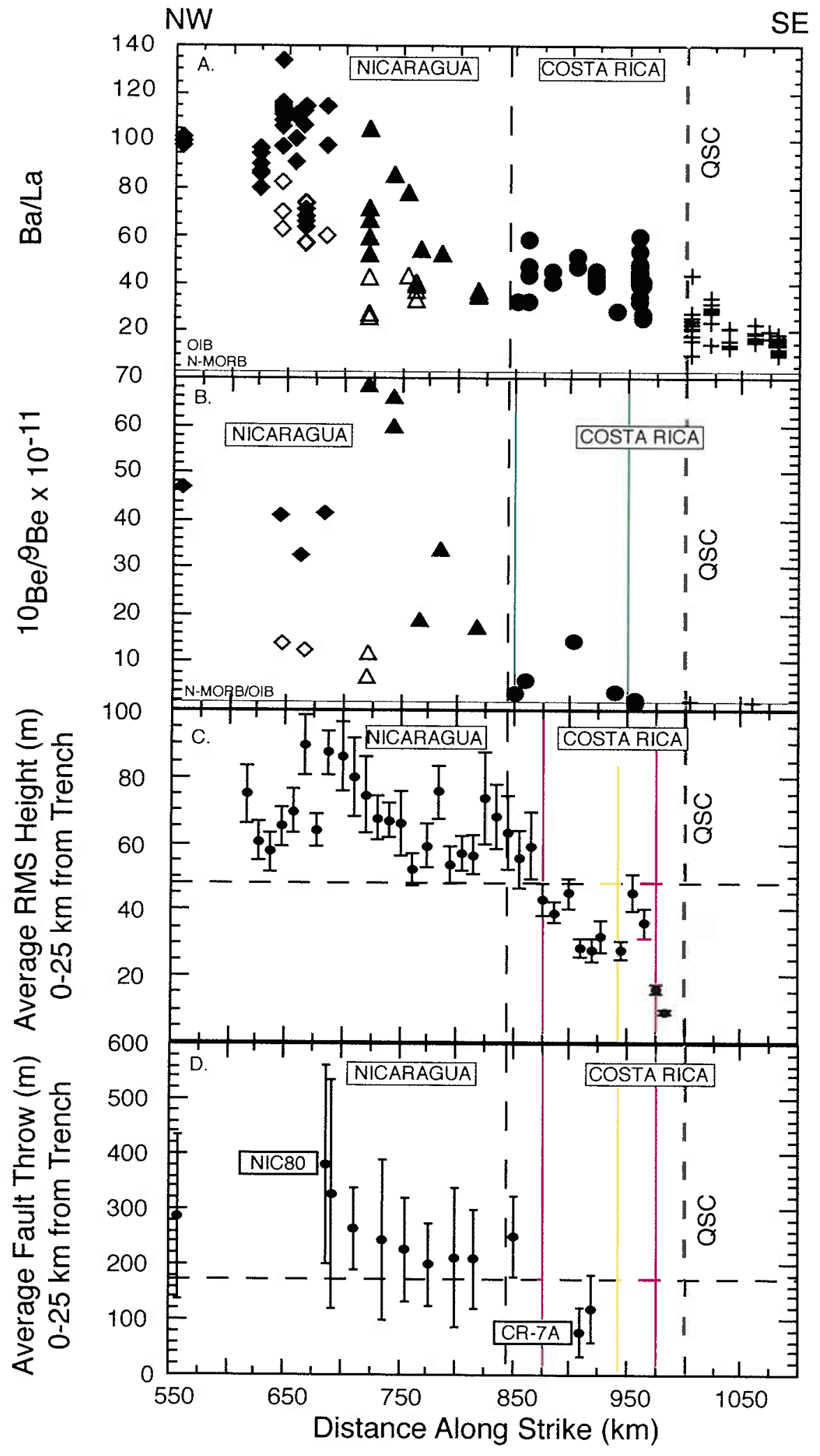


Figure 25. A stereonet diagram illustrates the effect of bending a lineation with the same trend as the EPR/CNS-1 boundary (N43E) across a bending axis of N42W (the trend of the $100 \mathrm{~km}$ depth isobath in the Cocos plate) by a dip of $80^{\circ}$ (the plate dip at $>100 \mathrm{~km}$ depth; Protti et al., 1995). The new trend for this lineation would be N21E plunging $78^{\circ}$. Depending on the trend of the northwestern edge of the RMS height transition zone with respect to the bending axis, at depths beneath the arc the region of low RMS height may actually be located beneath the El Hacha and Orosi volcanoes (labeled in Figure 8). 


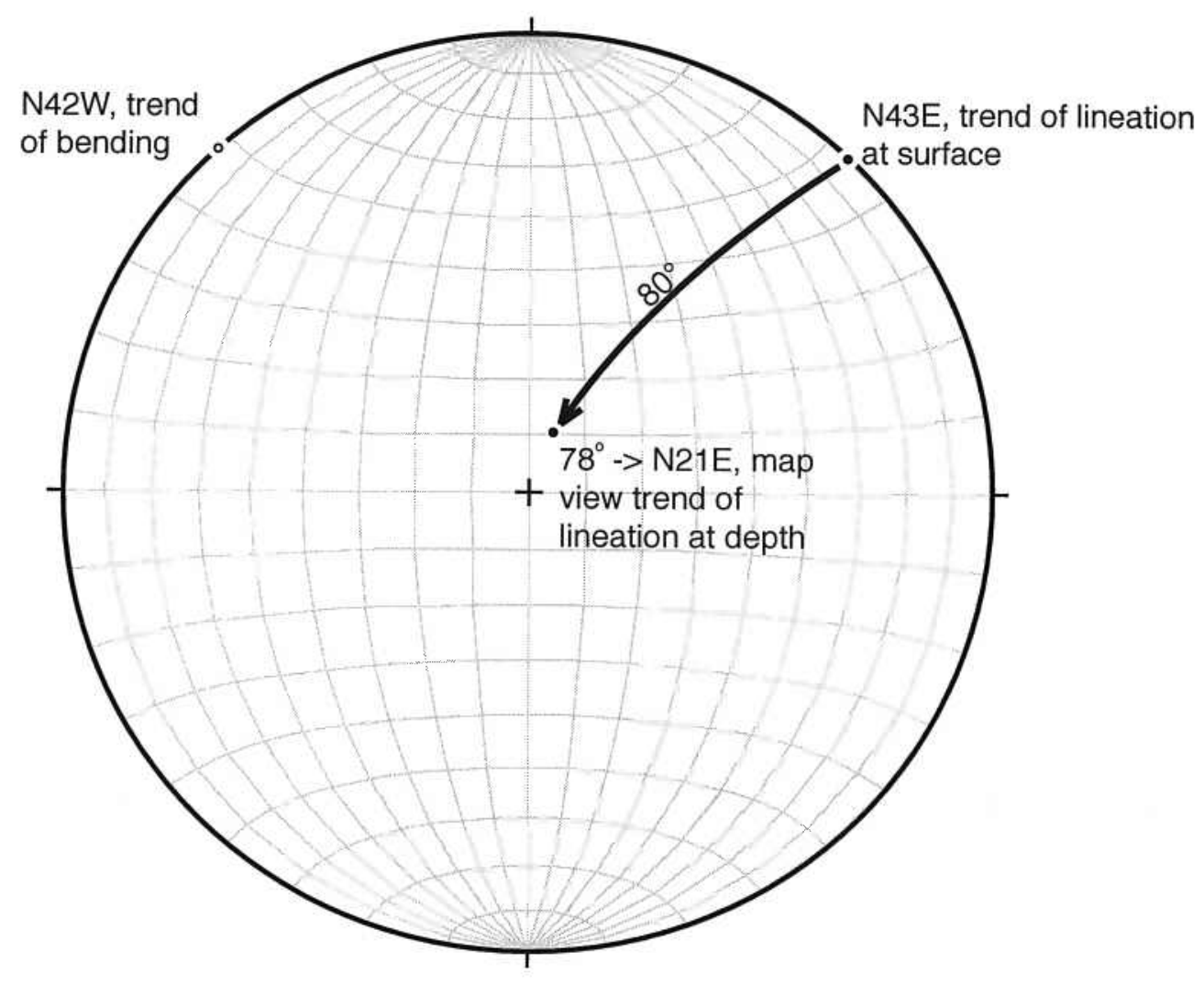


Figure 26. ${ }^{10} \mathrm{Be} /{ }^{9} \mathrm{Be}$ does not show a strong linear dependence on RMS height. RMS height is compared to each volcano using a $30 \mathrm{~km}$ weighted average, in which the bathymetry data that projects orthogonally across the trench from each volcano is averaged with the two adjacent boxes on either side. The open diamond in the western Nicaraguan samples, Cosiguina volcano, is opposite a region that does not have swath bathymetry data; instead, the RMS height was calculated from the average fault throw in seismic line NIC-100 (located in Figure 8), using the mathematical relationship shown in Figure $12 .{ }^{10} \mathrm{Be} /{ }^{9} \mathrm{Be}$ is plotted on a logarithmic scale to illustrate that small changes in value can actually equal large changes in enrichment and recycling efficiency (i.e., the difference between 1 and 10). We propose that the change in basement fault relief from Nicaragua to Costa Rica functions more as a threshold effect (e.g., Figure 24). Large fault throws will allow the entire sediment column to subduct to depths of magma genesis, after which recycling efficiency will be controlled by magmatic processes. Fault throws that are smaller than the overlying sediment thickness could allow the décollement to relocate within the subducting sediment column, based on physical properties within the sediments. Subsequent underplating could remove a significant portion of the shallow, ${ }^{10} \mathrm{Be}$-bearing sediment layer. The onset of underplating would be a function of the fault relief, but it would not thereafter increase as fault relief decreased. The two northwestern Costa Rica volcanoes, El Hacha and Orosi, record low ${ }^{10} \mathrm{Be} /{ }^{9} \mathrm{Be}$ enrichment but have high RMS height. However, if bending axis effects are taken into account (see text for further explanation), these volcanoes may be sampling a plate that actually has low fault relief. Miravalles, farther southeast in Costa Rica, has high ${ }^{10} \mathrm{Be} /{ }^{9} \mathrm{Be}$ enrichment but low RMS height. If underplating were episodic, such that it could be affected by small-scale heterogeneities in the crust (such as seamounts) that would no longer be observed in the plate currently at the trench, this might explain the higher recycling efficiency of ${ }^{10} \mathrm{Be}$ for this volcano. 


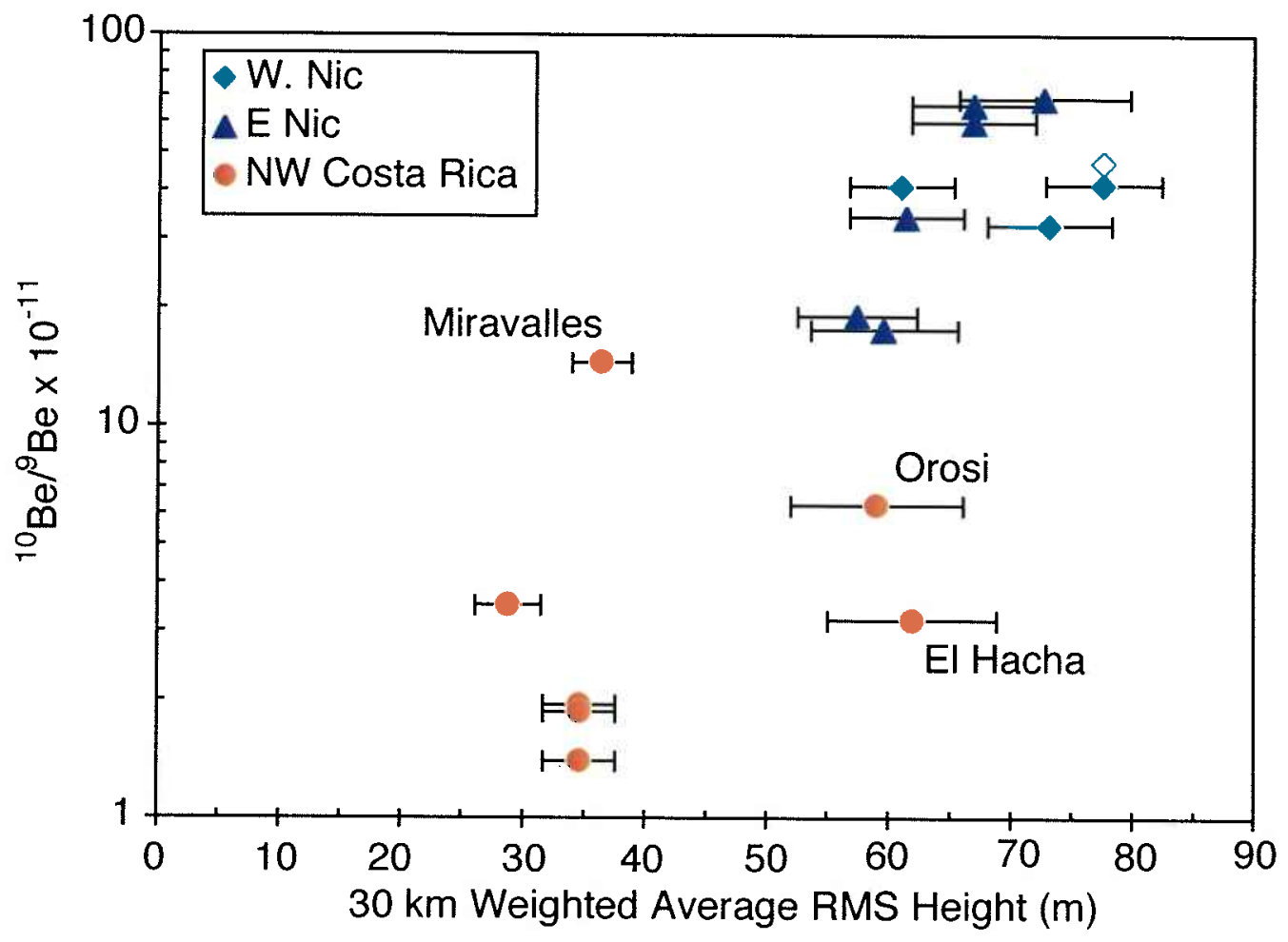




\section{References}

Abers, G.A., T. Plank, and B.R. Hacker, The wet Nicaraguan slab, Geophys. Res. Lett., 30, doi:10.1029/2002GL015649, 2003.

Abratis, M., and G. Wörner, Ridge collision, slab-window formation, and the flux of Pacific asthenosphere into the Caribbean realm, Geology, 29, 127-130, 2001.

Aubouin, J., R. von Huene, et al., Init. Repts. DSDP, 67, US Govt. Printing Office, Washington, DC, 1982.

Barckhausen, U., H.A. Roeser, and R. von Huene, R., Magnetic signature of upper plate structures and subducting seamounts at the convergent margin off Costa Rica, $J$. Geophys. Res., 103, 7079-7093, 1998.

Barckhausen, U., C.R., Ranero, R. von Huene, S.C. Cande, and H.A. Roeser, Revised tectonic boundaries in the Cocos Plate off Costa Rica; implications for the segmentation of the convergent margin and for plate tectonic models, J. Geophys. Res., 106, 19,207-19,220, 2001.

Bebout, G.E., J.G. Ryan, and W.P. Leeman, B-Be systematics in subduction-related metamorphic rocks: characterization of the subducted component, Geochim. Cosmochim. Acta, 57, 2227-2237, 1993.

Bebout, G.E., J.G. Ryan, W.P. Leeman, and A.E. Bebout, Fractionation of trace elements by subduction zone metamorphism: significance for models of crust-mantle mixing, Earth Planet. Sci. Lett., 177, 69-83, 1999.

Bodine, J.H., M.S. Steckler, and A.B. Watts, Observations of flexure and the rheology of the oceanic lithosphere, J. Geophys. Res., 86, 3695-3707, 1981.

Brenan, J.M., H.F. Shaw, F.J. Ryerson, and D.L. Phinney, Mineral-aqueous fluid partitioning of trace elements at $900 \mathrm{oC}$ and $2.0 \mathrm{GPa}$ : Constraints on the trace element geochemistry of mantle and deep crustal fluids, Geochim. Cosmochim. Acta, 59, 3331$3350,1995$.

Brenan, J.M., E. Neroda, C.C. Lindstrom, H.F. Shaw, F.J. Ryerson, and D.L. Phinney, Behavior of boron, beryllium, and lithium during melting and crystallization: 
constraints from mineral-melt partitioning experiments, Geochim. Cosmochim. Acta, 62, 2129-2141, 1998a.

Brenan, J.M., F.J. Ryerson, and H.F. Shaw, The role of aqueous fluids in the slab-tomantle transfer of boron, beryllium, and lithium during subduction: Experiments and models, Geochim. Cosmochim. Acta, 62, 3337-3347, 1998b.

Brown, L., J. Klein, R. Middleton, I. Selwyn Sacks, and F. Tera, ${ }^{10} \mathrm{Be}$ in island-arc volcanoes and implications for subduction, Nature, 299, 718-720, 1982.

Burbach, G.V., C. Frohlich, W.D. Pennington, and T. Matamoto, Seismicity and tectonics of the subducted Cocos plate, J. Geophys. Res., 89, 7719-7735, 1984.

Cande, S.C., and D.V. Kent, Revised calibration of the geomagnetic polarity timescale for the Late Cretaceous and Cenozoic, J. Geophys. Res., 100, 6093-6095, 1995.

Carbotte, S.M., and K.C. Macdonald, Comparison of seafloor tectonic fabric at intermediate, fast, and super fast spreading ridges: Influence of spreading rate, plate motions, and ridge segmentation on fault patterns, J. Geophys. Res., 99, 13,609-13,631, 1994.

Carr, M.J., Symmetrical and segmented variation of physical and geochemical characteristics of the Central America volcanic front, J. Volcan. Geotherm. Res., 20, 231-252, 1984.

Carr, M.J., M.D. Feigenson, and E.A. Bennett, Incompatible element and isotopic evidence for tectonic control of source mixing and melt extraction along the Central American arc, Contrib. Mineral. Petrol., 105, 369-380, 1990.

Carr, M.J., M.D. Feigenson, L.C. Patino, and J.A. Walker, Volcanism and geochemistry in Central America: Progress and problems, in The Subduction Factory, edited by J.M. Eiler and G. Abers, AGU Monog. Ser., Washington, D.C., in press, 2003.

Christeson, G.L., K.D. McIntosh, T.H. Shipley, E. Flueh, H. Goedde, and G. Leandro, Structure of Costa Rica convergent margin, offshore Nicoya Peninsula, J. Geophys. Res., 104, 25,442-25,468, 1999.

Clift, P.D. and C.J. MacLeod, Slow rates of subduction erosion estimated from subsidence and tilting of the Tonga forearc, Geology, 27, 411-414, 1999. 
Clift, P.D., E.F. Rose, N. Shimizu, G.D. Layne, A.E. Draut, and M. Regelous, Tracing the evolving flux from the subducting plate in the Tonga-Kermadec arc system using boron in volcanic glass, Geochim. Cosmochim. Acta, 65, 3347-3364, 2001.

Cooper, P., and B. Taylor, Seismotectonics of New Guinea: A model for arc reversal following arc-continent collision, Tectonics, 6, 53-67, 1987.

Corrigan, J., P. Mann, and J.C. Ingle, Forearc response to subduction of the Cocos Ridge, Panama-Costa Rica, Geol. Soc. Amer. Bull., 102, 628-652, 1990.

Davidson, J.P., Deciphering mantle and crustal signatures in subduction zone magmatism, in: Subduction, Top to Bottom, edited by G. Bebout et al., Amer. Geophys. Union Geophys. Monogr. Ser., 96, 251-262, 1996.

de Boer, J.Z., M.S. Drummond, M.J. Bordelon, M.J. Defant, H. Bellon, and R.C. Maury, Cenozoic magmatic phases of the Costa Rican island arc (Cordillera de Talamanca), in: Geologic and tectonic development of the Caribbean plate boundary in southern Central America, edited by P. Mann, Geol. Soc. Am. Spec. Pap. 295, 35-55, 1995.

DeMets, C., A new estimate for present day Cocos-Caribbean plate motion: Implications for slip along the Central American volcanic arc, Geophys. Res. Lett., 28, 4043-4046, 2001.

DeMets, C., R.G. Gordon, D.F. Argus, and S. Stein, Current plate motions. Geophys. Jour. Int., 101, 425-478, 1990.

DeMets, C., R.G. Gordon, D.F. Argus, and S. Stein, Effect of recent revisions to the geomagnetic reversal time scale on estimates of current plate motions, Geophy. Res. Lett., 21, 2191-2194, 1994.

Domanik, K.J., and J.R. Holloway, The stability and composition of phengitic muscovite and associated phases from 5.5 to $11 \mathrm{GPa}$ : Implications for deeply subducted sediments, Geochim. Cosmochim. Acta, 60, 4133-4150, 1996.

Domanik, K.J., R.L. Hervig, and S.L. Peacock, Beryllium and boron in subduction zone minerals: An ion microprobe study, Geochim. Cosmochim. Acta, 57, 4997-5010, 1993. 
Edwards, C.M.H., J.D. Morris, and M.F. Thirlwall, Separating mantle from slab signatures in arc lavas using $\mathrm{B} / \mathrm{Be}$ and radiogenic isotope systematics, Nature, 362, 530-533, 1993.

Ehrenborg, J., A new stratigraphy for the Tertiary volcanic rocks of the Nicaragua Highland, Geol. Soc. Am. Bull., 108, 830-842, 1996.

Elliott, T., T. Plank, A. Zindler, W. White, and B. Bourdon, Element transport from slab to volcanic front at the Mariana arc, J. Geophys. Res., 102, 14,991-15,019, 1997.

Feigenson, M.D., and M.J. Carr, The source of Central American lavas: inferences from geochemical inverse modeling, Contrib. Mineral. Petrol., 113, 226-235, 1993.

Feigenson, M.D., M.J. Carr, L.C. Patino, S. Maharaj, and S. Juliano, Isotopic identification of distinct mantle domains beneath Central America, Geol. Soc. Amer., Abstracts with Programs, 28, 380, 1996.

Fischer, T.P., D.R. Hilton, M.M. Zimmer, A.M. Shaw, Z.D. Sharp, and J.A. Walker, Subduction and recycling of nitrogen along the Central American margin, Science, 297, 1154-1157, 2002.

Fisher, A.T., C.A. Stein, R.N. Harris, K. Wang, E.A. Silver, M. Pfender, M. Hutnak, A. Cherkaoui, R. Bodzin, and H. Villinger, Abrupt thermal transition reveals hydrothermal boundary and role of seamounts within the Cocos Plate, Geophys. Res. Lett., 30, 2002GL016766, 2003.

Fisher, D. M., T. W. Gardner, J.S. Marshall, P.B. Sak, and M. Protti, Effect of subducting sea-floor roughness on fore-arc kinematics, Pacific coast, Costa Rica, Geology, 26, 467-470, 1998.

Flueh, E.R., M.A. Fisher, J. Bialas, J.R. Childs, D. Klaeschen, N. Kukowski, T. Parsons, D.W. Scholl, U. ten Brink, A.M. Tréhu, and N. Vidal, New seismic images of the Cascadia subduction zone from cruise SO108-ORWELL, Tectonophysics, 293, 69-84, 1998.

Gans, P., I. MacMillan, G. Alvarado, W. Perez, and C. Sigaran, Neogene evolution of the Costa Rican arc, Geol. Soc. Amer., Abstracts with Programs, Fall 2002. 
Gardner, T.W., D. Verdonck, N.M. Pinter, R. Slingerland, K.P. Furlong, T.F. Bullard, and S.G. Wells, Quaternary uplift astride the aseismic Cocos Ridge, Pacific coast, Costa Rica, Geol. Soc. Amer. Bull., 104, 219-232, 1992.

Gardner, T.W., J. Marshall, D. Merritts, B. Bee, R. Burgette, E. Burton, J. Cooke, N.

Kehrwald, M. Protti, D. Fisher, and P. Sak, Holocene forearc block rotation in response to seamount subduction, southeastern Peninsula de Nicoya, Costa Rica, Geology, 29, 151-154, 2001.

Gill, J.B., J.D. Morris, and R.W. Johnson, Timescale for producing the geochemical signature of island arc magmas: U-Th-Po and Be-B systematics in recent Papua New Guinea lavas. Geochim. Cosmochim. Acta, 57, 4269-4283, 1993.

Goff, J.A., A global and regional stochastic analysis of near-ridge abyssal hill morphology, J. Geophys. Res., 96, 21,713-21,737, 1991.

Goff, J. A., and T.H. Jordan, Stochastic modeling of seafloor morphology: Inversion of Seabeam data for second-order statistics, J. Geophys. Res., 93, 13,589-13,608, 1988.

Goff, J.A., T.H. Jordan, M.G. Edwards, and D.J. Fornari, Comparison of a stochastic seafloor model with SeaMARC II bathymetry and sea beam data near the East Pacific Rise $13^{\circ}-15^{\circ} \mathrm{N}$, J. Geophys. Res., 96, 3867-3885, 1991.

Goff, J.A., A. Malinverno, D.J. Fornari, and J.R. Cochran, Abyssal hill segmentation: Quantitative analysis of abyssal hills in the Atlantic Ocean: A correlation between inferred crustal thickness and extensional faulting, J. Geophys. Res., 100, 22,50922,522, 1995.

Gripp, A. E., and R. G. Gordon, Current plate velocities relative to the hotspots incorporating the NUVEL-1 global plate motion model, Geophys. Res. Lett., 17, 1109$1112,1990$.

Hacker, B.R., S.M. Peacock, G.A. Abers, and S.D. Holloway, Subduction Factory 2. Are intermediate-depth earthquakes in subducting slabs linked to metamorphic dehydration reactions? J. Geophys. Res., 108, doi:10.1029/2001JB001129, 2003.

Hardy, N.C., Tectonic evolution of the easternmonst Panama Basin: Some new data and insights, J. So. Amer. Earth Sci., 4, 261-269, 1991. 
Hawkesworth, C.J., S.P. Turner, F. McDermott, D.W. Peate, and P. van Calsteren, U-Th isotopes in Arc Magmas: Implications for element transfer from the subducted crust. Science, 276, 551-555, 1997.

Herrstrom, E.A., M.K. Reagan, and J.D. Morris, Variations in lava composition associated with flow of asthenosphere beneath southern Central America, Geology, 23, $617-620,1995$.

Hey, R., Tectonic evolution of the Cocos-Nazca spreading center, Geol. Soc. Am. Bull., 88, 1404-1420, 1977.

Hilde, T.W.C., Sediment subduction versus accretion around the Pacific, Tectonophysics, 99, 381-397, 1983.

Hilde, T.W.C., and G.F. Sharman, G.F., Fault structure of the descending plate and its influence on the subduction process, EOS Trans. Amer. Geophys. Union, 59, 1182 , 1978.

Hinz, K., R. von Huene, C.R. Ranero, and PACOMAR Working Group, Tectonic structure of the convergent Pacific offshore Costa Rica from multichannel seismic reflection data, Tectonics, 15, 54-66, 1996.

Isacks, B.L., and M. Barazangi, Geometry of Benioff zones: Lateral segmentation and downwards bending of the subducted lithosphere, in: Island arcs, deep sea trenches, and back-arc basins, edited by M. Talwani and W.C. Pitman, III, Amer. Geophys. Union, Wash., D.C., 99-114, 1977.

Ishikawa, T., and E. Nakamura, Boron isotope systematics of marine sediments, Earth Planet Sci. Lett., 117, 567-580, 1993.

Ishikawa, T., and E. Nakamura, Origin of the slab component in arc lavas from across-arc variation of $\mathrm{B}$ and $\mathrm{Pb}$ isotopes, Nature, 370, 205-208, 1994.

Ishikawa, T., and F. Tera, Source, composition, and distribution of the fluid in the Kurile mantle wedge: Constraints from across-arc variations of $\mathrm{B} / \mathrm{Nb}$ and $\mathrm{B}$ isotopes, Earth Planet Sci. Lett., 152, 123-138, 1997.

Jarrard, R.D., Relations among subduction parameters, Rev. Geophys., 24, 217-284, 1986. 
Johnson, M.C., and T. Plank, Dehydration and melting experiments constrain the fate of subducted sediments, Geochem. Geophys. Geosys., l, 1999GC000014, 1999.

Judge, A.V., and M.K. McNutt, The relationship between plate curvature and elastic plate thickness: a study of the Peru-Chile Trench, J. Geophys. Res., 96, 16,625-16,639, 1991.

Kelly, R. and N. Driscoll, Structural controls on beryllium-10 occurrences in arc lavas, EOS Trans. AGU, 79, 396, 1998.

Kimura, G., E. Silver, P. Blum, et al., Proc. ODP. Init. Repts., 170, College Station, TX (Ocean Drilling Program), 1997.

Kolarsky, R.A., P. Mann, and W. Montero, Island arc response to shallow subduction of the Cocos Ridge, Costa Rica, in: Geologic and Tectonic Development of the Caribbean Plate Boundary in Southern Central America, edited by P. Mann, GSA Spec. Pap. 295, 235-262, 1995.

La Femina, P.C., T.H. Dixon, and W. Strauch, Bookshelf faulting in Nicaragua, Geology, $30,751-754,2002$.

Langseth, M.G., and E.A. Silver, The Nicoya convergent margin - a region of exceptionally low heat flow, Geophys. Res. Lett., 23, 891-894, 1996.

Leeman, W.P., V.B. Sisson, and M.R. Reid, Boron geochemistry of the lower crust: Evidence from granulite terranes and deep crustal xenoliths, Geochim. Cosmochim. Acta, 56, 775-788, 1992.

Leeman, W.P., and M.J. Carr, Geochemical constraints on subduction processes in the Central American Volcanic Arc: implications of boron geochemistry, in: Geologic and Tectonic Development of the Caribbean Plate Boundary in Southern Central America, P. Mann, ed., GSA Spec. Pap., 295, 57-73, 1995.

Lonsdale, P. and K.D. Klitgord, Structure and tectonic history of the eastern Panama Basin, Geol. Soc. Am. Bull. 89, 981-999, 1978.

MacMillan, I., P.G. Gans, and G. Alvarado, Middle Miocene to present plate tectonic history of the southern Central America Volcanic Arc, in: Ophiolites and Pacific Margins, Tectonophysics Spec. Paper, in press, 2003. 
Malinverno, A., and R.A. Pockalny, Abyssal hill topography as an indicator of episodicity in crustal accretion and deformation, Earth Planet Sci. Lett., 99, 154-169, 1990.

Marotta, A.M., and F. Mongelli, Flexure of subducted slabs, Geophys. J. Int., 132, 701$711,1998$.

Marshall, J.S., and R.S. Anderson, Quaternary uplift and seismic cycle deformation, Peninsula de Nicoya, Costa Rica, Geol. Soc. Amer. Bull., 107, 463-473, 1995.

Marshall, J.S., D.M. Fisher, and T.W. Gardner, Central Costa Rica deformed belt: Kinematics of diffuse faulting across the western Panama block, Tectonics, 19, 468492, 2000.

Masson, D.G., Fault patterns at outer trench walls, Mar. Geophys. Res., 13, 209-225, 1991.

McDermott, F., and C.J. Hawkesworth, Th, $\mathrm{Pb}$, and $\mathrm{Sr}$ isotope variations in young island arc volcanics and oceanic sediments, Earth Planet Sci. Lett., 104, 1-15, 1991.

McIntosh, K.D. and M.K. Sen, Geophysical evidence for dewatering and deformation processes in the ODP Leg 170 area offshore Costa Rica, Earth Planet. Sci. Lett., 178, $125-138,2000$.

Monaghan, M.C., J. Klein, and C.I. Measures, The origin of ${ }^{10} \mathrm{Be}$ in island-arc volcanic rocks, Earth Planet. Sci. Lett., 89, 288-298, 1988.

Moran, A.E., V.B. Sisson, and W.P. Leeman, Boron depletion during progressive metamorphism: Implications for subduction processes, Earth Planet Sci. Lett., 111, 331-349, 1992.

Morris, J., and F. Tera, ${ }^{10} \mathrm{Be}$ and ${ }^{9} \mathrm{Be}$ in mineral separates and whole rocks from volcanic arcs: Implications for sediment subduction, Geochim. Cosmochim. Acta, 53, 3197-3206, 1989.

Morris, J.D., and F. Tera, Beryllium isotope systematics of volcanic arc cross-chains, V.M. Goldschmidt Conf., Abstr., 5, 720, 2000.

Morris, J.D., W.P. Leeman, and F. Tera, The subducted component in island arc lavas: constraints from Be isotopes and B-Be systematics, Nature, 344, 31-36, 1990. 
Morris, J., J. Gosse, S. Brachfeld, and F. Tera, Cosmogenic ${ }^{10} \mathrm{Be}$ and the Solid Earth:

Studies in Geomagnetism, Subduction Zone Processes, and Active Tectonics, in Beryllium: Mineralogy, Petrology, and Geochemistry, edited by E.S. Grew, Rev. Mineral. Geochem., 50, 207-270, 2002a.

Morris, J., R. Valentine, and T. Harrison, ${ }^{10} \mathrm{Be}$ imaging of sediment accretion and subduction along the northeast Japan and Costa Rica convergent margins, Geology, 30, 59-62, $2002 b$.

Mueller, R.D., W.R. Roest, J. Royer, L.M. Gahagan, J.G. Sclater, Digital isochrons of the world's ocean floor, J. Geophys. Res., 102, 3211-3214, 1997.

Newman, A.V., S.Y. Schwartz, V. Gonzalez, H.R. DeShon, J.M. Protti, and L.M. Dorman, Along-strike variability in the seismogenic zone below Nicoya Peninsula, Costa Rica, Geophys. Res. Lett., 29, 38-1 - 38-3, 2002.

Patino, L.C., M.J. Carr, and M.D. Feigenson, Cross-arc geochemical variations in volcanic fields in Honduras C.A.: progressive changes in source with distance from the volcanic front, Contrib. Mineral. Petrol., 129, 341-351, 1997.

Patino, L.C., M.J. Carr, and M.D. Feigenson, Local and regional variations in Central American arc lavas controlled by variations in subducted sediment input, Contrib. Mineral. Petrol., 138, 265-283, 2000.

Peacock, S.M. Thermal and Petrologic structure of subduction zones, in: Subduction Top to Bottom, edited by G.E. Bebout et al., Amer. Geophys. Union Geophys. Monogr. Ser., 96, 119-133, 1996.

Pickering, K.T., Is the décollement in Nankai accretionary prism localized at a lithological change? New evidence from rare earth elements, and other geochemical data, Terra Abstracts, 5, 345, 1993.

Plank, T., and C.H. Langmuir, Tracing trace elements from sediment input to volcanic output at subduction zones, Nature, 362, 739-743, 1993.

Plank, T., and C.H. Langmuir, The chemical composition of subducting sediment and its consequences for the crust and mantle, Chem. Geol., 145, 325-394, 1998. 
Plank, T., V. Balzer, and M. Carr, Nicaraguan volcanoes record paleoceanographic changes accompanying closure of the Panama gateway, Geology, 30, 1087-1090, 2002.

Protti, M., F. Guendel, and K. McNally, Correlation between the age of the subducting Cocos plate and the geometry of the Wadati-Benioff zone under Nicaragua and Costa Rica, in: Geologic and Tectonic Development of the Caribbean Plate Boundary in Southern Central America, edited by P. Mann, Geol. Soc. Amer. Spec. Pap., 295, 309-326, 1995.

Ranero, C.R., and R. von Huene, Subduction erosion along the Middle America convergent margin, Nature, 404, 748-752, 2000.

Ranero, C.R., R. von Huene, E. Flueh, M. Duarte, D. Baca, and K. McIntosh, A cross section of the convergent Pacific margin of Nicaragua, Tectonics, 19, 335-357, 2000.

Ranero, C.R., J.P. Morgan, K.D. McIntosh, and C. Reichert, Flexural faulting and mantle serpentinization at the Middle America Trench, EOS Trans. AGU, 82, 2001.

Reagan, M.K., J.D. Morris, E.A. Herrstrom, and M.T. Murrell, Uranium series and beryllium isotope evidence for an extended history of subduction modification of the mantle below Nicaragua, Geochim. Cosmochim. Acta, 58, 4199-4212, 1994.

Rogers, R.D., H. Karason, and R.D. van der Hilst, Epeirogenic uplift above a detached slab in northern Central America, Geology, 30, 1031-1034, 2002.

Rupke, L.H., J.P. Morgan, M. Hort, and J.A.D. Connolly, Are the regional variations in Central American arc lavas due to differing basaltic versus peridotitic slab sources of fluids? Geology, 30, 1035-1038, 2002.

Ryan, J.G., and C.H. Langmuir, Beryllium systematics in young volcanic rocks: Implications for ${ }^{10} \mathrm{Be}$, Geochim. Cosmochim. Acta, 52, 237-244, 1988.

Ryan, J.G., J.D. Morris, F. Tera, W.P. Leeman, and A. Tsvetkov, Cross-arc geochemical variations in the Kurile Arc as a function of slab depth, Science, 270, 625-627, 1995.

Ryan, J.G., Trace element systematics of beryllium in terrestrial materials, in Beryllium: mineralogy, petrology, and geochemistry, Grew, E. ed., Rev. Mineral. Geochem., 50, 121-145, 2002. 
Saffer, D.M., E.A. Silver, A.T. Fisher, H. Tobin, and K. Moran, Inferred pore pressures at the Costa Rica subduction zone: implications for dewatering processes, Earth Planet. Sci. Lett., 177, 193-207, 2000.

Sallares, V., J.J. Danobeitia, and E.R. Flueh, Lithospheric structure of the Costa Rican Isthmus: Effects of subduction zone magamtism on an oceanic plateau, J. Geophys. Res., 106, 621-643, 2001.

Schweller, W.J., and L.D. Kulm, Extensional rupture of oceanic crust in the Chile Trench, Mar. Geol., 28, 271-291, 1978.

Shipley, T.H. and G.F. Moore, Sediment accretion, subduction, and dewatering at the base of the trench slope off Costa Rica: A seismic reflection view of the decollement, J. Geophys. Res., 91, 2019-2028, 1986.

Sigmarsson, O., M. Condomines, J.D. Morris, and R.S. Harmon, Uranium and ${ }^{10} \mathrm{Be}$ enrichments by fluids in Andean arc magmas, Nature, 346, 163-165, 1990.

Sigmarsson, O., J. Chmeleff, J.D. Morris, L. Lopez-Escobar, Rapid magma transfer from slab derived ${ }^{226} \mathrm{Ra}^{230} \mathrm{Th}$ disequilibria in lavas from southern Chile, Earth Planet. Sci. Lett., 196, 189-196, 2002.

Silver, E., M. Kastner, A. Fisher, J. Morris, K. McIntosh, and D. Saffer, Fluid flow paths in the Middle America Trench and Costa Rica margin, Geology, 28, 679-682, 2000.

Sinton, C.W., R.A. Duncan, and P. Denyer, Nicoya Peninsula, Costa Rica: A single suite of Caribbean oceanic plateau magmas, J. Geophys. Res., 102, 15,507-15,520, 1997.

Smith, W.H.F and D.T. Sandwell, Global seafloor topography from satellite altimetry and ship depth soundings, Science, 277, 1957-1962, 1997.

Stolper, E., and S. Newman, The role of water in the petrogenesis of Mariana Trough magmas, Earth Planet. Sci. Lett., 121, 293-325, 1994.

Sun, S.S., and W.F. McDonough, Magmatism in the Ocean Basins, Geol. Soc. Amer. Spec. Pap., 42, edited by A.D. Saunders, and M.J. Norry, pp. 313-345, 1989.

Tatsumi, Y., and $\mathrm{H}$. Isoyama, Transportation of beryllium with $\mathrm{H}_{2} \mathrm{O}$ at high pressures: Implication for magma genesis in subduction zones, Geophys. Res. Lett., 15, 180-183, 1988. 
Tatsumi, Y., and S. Eggins, Subduction Zone Magmatism, Blackwell Science, Oxford, 211 pp., 1995.

Tera, F., L. Brown, J. Morris, I. Selwyn Sacks, J. Klein, R. and Middleton, Sediment incorporation in island-arc magmas: Inferences from ${ }^{10} \mathrm{Be}$, Geochim. Cosmochim. Acta, 50, 535-550, 1986.

Tera, F., J.D. Morris, J. Ryan, W.P. Leeman, and A. Tsvetskov, Significance of the ${ }^{10} \mathrm{Be}-$

${ }^{9} \mathrm{Be}$ correlation in lavas of the Kurile-Kamchatka arc, EOS Trans. Am. Geophys. Union, 74, 674, 1993.

Thomas, R.B., M.M. Hirschmann, H. Cheng, M.K. Reagan, and R.L. Edwards, $\left({ }^{213} \mathrm{~Pa} /{ }^{235} \mathrm{U}\right)-\left({ }^{230} \mathrm{Th} /{ }^{238} \mathrm{U}\right)$ of young mafic volcanic rocks from Nicaragua and Costa Rica and the influence of flux melting on U-series systematics of arc lavas, Geochim. Cosmochim. Acta, 66, 4287-4309, 2002.

Valentine, R.B., J.D. Morris, and J. Duncan, D., Sediment subduction, accretion, underplating, and arc volcanism along the margin of Costa Rica: Constraints from $\mathrm{Ba}$, $\mathrm{Zn}, \mathrm{Ni}$, and ${ }^{10} \mathrm{Be}$ concentrations, EOS Trans. AGU, 78, 46, 1997.

Valentine, R.B., J.D. Morris, and S.-H. Zheng, Sediment subduction, accretion, underplating and erosion along the Costa Rica margin: Constraints provided by cosmogenic ${ }^{10} \mathrm{Be}$, submitted to J. Geophys. Res.

van de Zedde, D.M.A., M.J.R. and Wortel, Shallow slab detachment as a transient source of heat at midlithospheric depths, Tectonics, 20, 868-882, 2001.

Vannucchi, P., D.W. Scholl, M. Meschede, and K. McDougall-Reid, Tectonic erosion and consequent collapse of the Pacific margin of Costa Rica: combined implications from ODP Leg 170, seismic offshore data, and regional geology of the Nicoya Peninsula, Tectonics, 20, 649-668, 2001.

von Huene, R.J. and S.E. Lallemand, Tectonic erosion along the Japan and Peru convergent margin, Geol. Soc. Amer. Bull., 102, 704-720, 1990.

von Huene, R.J., and D.W. Scholl, Observations at Convergent Margins concerning sediment subduction, subduction erosion, and the growth of continental crust, Rev. Geophysics, 29, 279-316, 1991. 
von Huene, R., et al., Morphotectonics of the Pacific convergent margin, in: Geologic and Tectonic Development of the Caribbean Plate Boundary in Southern Central America, edited by P. Mann, Geol. Soc. Amer. Spec. Pap., 295, 291-307, 1995.

von Huene, R., C.R. Ranero, W. Weinrebe, and K. Hinz, Quaternary convergent margin tectonics of Costa Rica, segmentation of the Cocos plate, and Central American volcanism, Tectonics, 19, 314-334, 2000.

Walker, J.A., M.J. Carr, L.C. Patino, C.M. Johnson, M.D. Feigenson, and R.L. Ward, Abrupt change in magma generation processes across the Central American arc in southeastern Guatemala: flux-dominated melting near the base of the wedge to decompression melting near the top of the wedge, Contrib. Mineral. Petrol., 120, 378$390,1995$.

Walker, J.A., L.C. Patino, B.I. Cameron, and M.J. Carr, Petrogenetic insights provided by compositional transects across the Central American arc: Southeastern Guatemala and Honduras, J. Geophys. Res., 105, 18,949-18-963, 2000.

Walther, C.H.E., The crustal structure of the Cocos Ridge off Costa Rica, J. Geophys. Res., 108, doi:10.1029/2001JB000888, 2003.

Walther, C.H.E., E.R. Flueh, C.R. Ranero, R. von Huene, and W. Strauch, Crustal structure across the Pacific margin of Nicaragua: evidence for ophiolitic basement and a shallow mantle sliver, Geophys. J. Int., 141, 759-777, 2000.

Weinberg, R.F., Neotectonic development of western Nicaragua, Tectonics, 11, 10101017, 1992.

Weyl, R., Geology of Central America ( $2^{\text {nd }}$ edition), Berlin-Stuttgart, Gebrueder Borntraeger, 371 p., 1980.

Wilson, D.S., Fastest known spreading on the Miocene Cocos-Pacific plate boundary, Geophys. Res. Lett., 23, 3003-3006, 1996.

Wilson D.S. and R.N. Hey, History of rift propagation and magnetization intensity for the Cocos-Nazca spreading center, J. Geophys. Res. 100, 10,041-10,056, 1995. 
Ye, S., J. Bialas, E.R. Flueh, A. Stavenhagen, R. von Huene, G. Leandro, and K. Hinz, Crustal structure of the Middle American Trench off Costa Rica from wide-angle seismic data, Tectonics, 15, 1006-1021, 1996.

Yiou, F., and G.M. Raisbeck, Half-life of ${ }^{10}$ Be, Phys. Rev. Lett., 29, 372-375, 1972.

You, C.-F., J.D. Morris, J.M. Gieskes, R. Rosenbauer, S.H. Zheng, X. Xu, T.L. Ku, and J.L. Bischoff, Mobilization of Be in the sedimentary column at convergent margins, Geochim. Cosmochim. Acta, 58, 4887-4897, 1994.

You, C.-F., P. Castillo, J.M. Gieskes, L.C. Chan, and A.F. Spivack, Trace element behavior in hydrothermal experiments: implications for fluid processes at shallow depths in subduction zones, Earth Planet. Sci. Lett., 140, 41-52, 1996.

Zhang, Z., and S. Schwartz, Depth distribution of moment release in underthrusting earthquakes at subduction zones, J. Geophys. Res., 97, 537-544, 1992. 


\title{
Chapter IV
}

\section{${ }^{10} \mathrm{Be}$ Variability in Surficial Sediments at the Middle America Trench}

\begin{abstract}
The presence of cosmogenic radionuclide ${ }^{10} \mathrm{Be}$ in volcanic arc lavas is an unequivocal tracer of shallow sediment subduction. Enrichment of ${ }^{10} \mathrm{Be}$ in the Central American Volcanic Arc requires significant ${ }^{10} \mathrm{Be}$ concentrations in the subducting sediment. In order to compare variations in ${ }^{10} \mathrm{Be}$ along the arc to changes in tectonic or geochemical parameters, it is necessary to determine the extent to which these variations are influenced by the incoming sedimentary ${ }^{10} \mathrm{Be}$ budget delivered to the trench. ${ }^{10} \mathrm{Be}$ analyses of 34 bulk sediment samples from piston and gravity cores located seaward of the Middle America Trench from offshore of Guatemala, El Salvador, Nicaragua, and northwestern Costa Rica indicate that there is no significant difference in the accumulation of ${ }^{10} \mathrm{Be}$ along strike of the arc. These results confirm the prevailing theory that the large range in ${ }^{10} \mathrm{Be}$ observed in the Central American Volcanic Arc is unrelated to geographical changes in the initial ${ }^{10} \mathrm{Be}$ concentrations in the subducting sediment. Incorporating ${ }^{143} \mathrm{Nd} /{ }^{144} \mathrm{Nd},{ }^{87} \mathrm{Sr} /{ }^{86} \mathrm{Sr}$, major, and trace element data for a subset of the core samples demonstrates that localized variations in ${ }^{10} \mathrm{Be}$ concentrations within the sediments are due to simple mixing between endmember components of mature detrital clays and young, volcanogenic particles. ${ }^{10} \mathrm{Be}$ is decoupled from stable isotope ${ }^{9} \mathrm{Be} .{ }^{9} \mathrm{Be}$ is strongly associated with detrital phases. Grain size measurements show that ${ }^{10} \mathrm{Be}$ concentration is positively correlated with the proportion of grains $<32 \mu \mathrm{m}$ in diameter, and that ${ }^{10} \mathrm{Be}$ concentrations increase as median grain size decreases. High ${ }^{10} \mathrm{Be}$ concentrations in the fine-grained bulk sediments appear to be diluted by the addition of coarser grained material that scavenges less ${ }^{10} \mathrm{Be}$ from the water column.
\end{abstract}




\section{Introduction}

Beryllium-10 is a cosmogenic radionuclide generated from cosmic ray spallation reactions on oxygen and nitrogen in the atmosphere. ${ }^{10} \mathrm{Be}$ is carried via precipitation to the ocean, where it is highly particle adsorptive (e.g., Kusakabe et al., 1987). Due to its relatively short half-life of $1.5 \times 10^{6}$ yrs (Yiou and Raisbeck, 1972), ${ }^{10} \mathrm{Be}$ is typically only found in significant concentrations in the upper tens of meters of marine sediment. As mantle values for ${ }^{10} \mathrm{Be}$ are below detection limits, the presence of enriched concentrations of ${ }^{10} \mathrm{Be}$ detected in arc lavas requires that the youngest sediment be subducted to the arc volcanic roots (Brown et al., 1982; Tera et al., 1986; Ryan and Langmuir, 1988; Monaghan et al., 1988; Morris and Tera, 1989; Morris et al., 1990). However, the variations in, and occurrence of, ${ }^{10} \mathrm{Be}$ in these volcanic arcs are not always well explained by simple subduction zone systematics. Because the incorporation of ${ }^{10} \mathrm{Be}$ into arc lavas indicates the subduction of the very youngest sediments, its variability in a single volcanic arc can allow us to identify the relative importance of potential factors governing ${ }^{10} \mathrm{Be}$ recycling heterogeneity.

The Central American Volcanic Arc exhibits a wide range of ${ }^{10} \mathrm{Be}$ from background to highly enriched. The pattern of enrichment progresses from moderate in Guatemala to high in Nicaragua and then rapidly diminishes toward Costa Rica, which shows little to no ${ }^{10} \mathrm{Be}$ (Figure 1). Recent ${ }^{10} \mathrm{Be}$ measurements with a detection limit of 0.1 million a/g precisely map the transition from Nicaragua to Costa Rica. Lavas from southeastern Nicaragua have ${ }^{10} \mathrm{Be}$ concentrations of $8-27$ million a/g, and ${ }^{10} \mathrm{Be} /{ }^{9} \mathrm{Be}$ ratios in the range 20-60 x 10 $0^{-11}$ (Tera et al., 1986; Morris et al., 1990; Morris et al., 2002; Table 1, Chapter II). This contrasts sharply with lavas from northwestern Costa Rica, which have ${ }^{10} \mathrm{Be}$ concentrations of 1.3-1.8 million a/g, yielding ${ }^{10} \mathrm{Be} /{ }^{9} \mathrm{Be}$ ratios of $<5 \times 10^{-11}$ (Morris et al., 2002; Table 1, Chapter II). Farther to the southeast in Costa Rica, lavas have ${ }^{10} \mathrm{Be}$ concentrations $=0.7-0.8$ million a/g and ratios of $<2 \times 10^{-11}$ (Morris et al., 1990; Morris et al., 2002; Table 1, Chapter II). The new measurements demonstrate that the northwestern Costa Rican lavas have a small, but real enrichment in ${ }^{10} \mathrm{Be}$. This asymmetric bell-shaped pattern of ${ }^{10} \mathrm{Be}$ enrichment observed in the Central American 
Volcanic Arc encompasses the entire range of ${ }^{10} \mathrm{Be}$ concentrations that have been observed in arc volcanic rocks world-wide (Morris et al., 1990).

There are four main processes that can affect ${ }^{10} \mathrm{Be}$ enrichment in arc volcanic rocks: (1) ${ }^{10} \mathrm{Be}$ concentration in the downgoing sediments, (2) convergence rates, (3) dynamics of sediment subduction (e.g., tectonic erosion or subduction accretion), and (4) geochemical processes during magmatic sediment incorporation (Figure 2). A critical first step toward understanding the variations in ${ }^{10} \mathrm{Be}$ concentrations in arc volcanic rocks is to define the spatial variability of ${ }^{10} \mathrm{Be}$ in sediment on the downgoing plate. Clearly, knowledge of the geochemical composition of subducting sediments is crucial to obtaining a mass balance for sediment input and output in subduction zones. However, to date, relatively little data has been compiled to determine the distribution of ${ }^{10} \mathrm{Be}$ in trench sediments. The effect of particle lithologies or grain size variations on the scavenging and transport rate of ${ }^{10} \mathrm{Be}$ to the ocean floor is uncertain and may vary regionally (e.g., Southon et al., 1987; Lao et al., 1992; Chase et al., 2002). Furthermore, the influence of post-depositional processes such as diagenesis, compaction, and fluid flow on the distribution of ${ }^{10} \mathrm{Be}$ remains poorly understood.

This paper focuses on the degree of ${ }^{10} \mathrm{Be}$ heterogeneity supplied to the Middle America Trench. We establish this baseline for ${ }^{10} \mathrm{Be}$ surficial sediment input to determine if incoming ${ }^{10} \mathrm{Be}$ concentrations mirror the along strike variation observed in the Central American Volcanic Arc. We also examine the role of lithology in controlling ${ }^{10} \mathrm{Be}$ concentrations in these sediments, which will improve our understanding of ${ }^{10} \mathrm{Be}$ systematics, in particular the use of ${ }^{10} \mathrm{Be}$ as a tracer of particle scavenging or biogenic paleoproductivity.

\section{Methods}

\subsection{Sample Selection}

Sediment samples were acquired from 17 gravity and piston cores ( 9 geographical sites) located along the Middle America Trench offshore of Guatemala to Costa Rica (Figure 3). The most significant spatial gap in samples occurs offshore of Nicaragua, for 
which there were no existing cores near or in the trench. The principal sediment lithologies are hemipelagic clay, volcanic ash, and carbonate. Subsample sediment descriptions downcore are given in Appendix 1. The samples from R/V Ewing cruise EW0104 cores (GC09, GC/PC18, GC/PC36, PC37, GC/PC38, and GC43) were collected using a plastic syringe sampler, which was capped and wax sealed immediately after sampling to preserve water content. The remaining core samples (PC RC12-32, TW/PC VM15-26, TW/PC VM15-22, TW/PC VM15-24, and PC RC12-29) were obtained from the Lamont-Doherty Earth Observatory (LDEO) Core Repository. The LDEO samples are stored at room temperature. Prior to geochemical processing for isotope analysis, water loss was recorded from all samples dried at $60^{\circ} \mathrm{C}$ for 24 hours, eliminating pore water but preserving water bound in mineral lattices (Table 1).

Samples for ${ }^{10} \mathrm{Be}$ analysis were selected to provide a maximum age span within each core by using the topmost and bottommost samples, though age constraints are unavailable for most of the cores. Six ash samples were selected to provide a volcanogenic endmember. Other samples were chosen to represent different lithologies within a core. For example, in GC09 samples were selected based on variable carbonate contents, and in GC43, the hemipelagic clay characteristics appeared different downcore. As organic carbon and carbonate content were not actually measured for any of these cores, selection of lithologies was made based on visual assessment and available core descriptions.

\subsection{Isotopic, Major and Trace Element Analysis}

32 samples $(0.1-1 \mathrm{~g})$ plus two replicates were spiked with ${ }^{9} \mathrm{Be}$ as a stable carrier and subsequently digested in an $\mathrm{HF}$ and $\mathrm{HNO}_{3}$ mixture to dissolve silicates. After the $\mathrm{HF}$ and $\mathrm{HNO}_{3}$ were evaporated, the precipitate was dissolved in $3 \mathrm{~N} \mathrm{HCl}$ and then dried. Samples were then put back into solution in $2 \mathrm{~N} \mathrm{HCl}$, to bind cations ( $\mathrm{Fe}, \mathrm{Mg}, \mathrm{Ti}, \mathrm{Be}, \mathrm{Ca}, \mathrm{Na}$, and K) as chlorides. After $\mathrm{NH}_{4}(\mathrm{OH})$ was added to $\mathrm{pH} 8$, the solution was centrifuged and the supernate discarded, removing $\mathrm{Mg}, \mathrm{Ca}, \mathrm{Na}$, and $\mathrm{K}$. The remaining plug consisted of $\mathrm{Be}$, $\mathrm{Al}, \mathrm{Fe}$, and Ti hydroxides. The precipitate was then treated with $2 \mathrm{~N} \mathrm{HBr}$. $\mathrm{NH}_{4}(\mathrm{OH})$ was 
added to $\mathrm{pH} 4$, the homogenized solution was centrifuged, and the supernate (containing $\mathrm{Al}$ and $\mathrm{Be}$ ) was retained. $\mathrm{NH}_{4}(\mathrm{OH})$ was added until the $\mathrm{pH}$ reached 8 , then the solution was centrifuged, and the precipitate was retained. $\mathrm{NH}_{4}(\mathrm{OH})$ was added to the remaining solid, followed by centrifuging and discarding of the supernate. This step was then repeated, which has the effect of mechanically shortening the aluminum hydroxide bonds, making it less soluble in dilute HF than BeOH. 5\% HF was added to the final precipitate to reach $\mathrm{pH} 4 . \mathrm{NH}_{4}(\mathrm{OH})$ was then added to bring the solution back to $\mathrm{pH} 8$. The solution was centrifuged and the supernate containing $\mathrm{BeOH}$ was retained. The solution was dried down to solid $\mathrm{BeOH}$. The final $\mathrm{BeOH}$ precipitate was combusted to $\mathrm{BeO}$. $\mathrm{BeO}$ powder absent other elements should be white. Most of the 34 samples were cream to white, but a few had an orange to red tint, indicating residual Fe that wasn't effectively removed during the geochemical processing, which can add to measurement uncertainty due to interferences. Of the discolored samples, hemipelagic sample VM1522 0-1 cm and ash sample RC12-32 440-441 cm had higher measurement uncertainties than the other analyses, and PC37 2-3 cm Rep\#2 did not fall within measurement uncertainties of the other two replicates for that core sample, though it is within $15 \%$. As this latter deviation could have occurred because of inhomogeneities within the sediment sample itself, an average of the three replicates is used for PC37 $2-4 \mathrm{~cm}$. The high measurement uncertainty for carbonate sample GC09 293-295 cm, which did not have any discoloration, is most likely due to the very low ${ }^{10} \mathrm{Be}$ concentration for this sample.

A blank was prepared for each set of digestions following the same processing procedure but without the sediment sample added. ${ }^{10} \mathrm{Be} /{ }^{9} \mathrm{Be}$ ratios were measured at the Purdue Rare Isotope Measurement Laboratory on an accelerator mass spectrometer (AMS) and converted to ${ }^{10} \mathrm{Be}$ concentrations (atoms/g) from the known spike and sample weights (Table 1). Blank concentrations were very small and within measurement errors for the sedimentary ${ }^{10} \mathrm{Be}$ concentrations, so no correction was applied.

Of the samples chosen for ${ }^{10} \mathrm{Be}$ analysis, 24 (hemipelagic clay and volcanic ash as designated by core descriptions) were processed for $\mathrm{Sr}$ and $\mathrm{Nd}$ isotopes. Sediments were digested in $\mathrm{HNO}_{3}$ and $\mathrm{HF}$. Nd was collected by eluting solution through an anion 
exchange column with a succession of $\mathrm{HCl}$ and $\mathrm{HNO}_{3}$ washes. $\mathrm{Sr}$ was separated using $\mathrm{HNO}_{3}$ and $\mathrm{H}_{2} \mathrm{O}$ elutions. Sr and Nd isotopic ratios were measured on a VG-Micromass Sector 54 thermal ionization mass spectrometer (TIMS) at the Southampton Oceanography Centre, UK (Table 2). ${ }^{143} \mathrm{Nd} /{ }^{144} \mathrm{Nd}$ was determined in multi-dynamic mode, exponentially corrected for instrumental fractionation relative to ${ }^{146} \mathrm{Nd} /{ }^{144} \mathrm{Nd}=$ 0.7219. The JNdi ${ }^{143} \mathrm{Nd} /{ }^{144} \mathrm{Nd}$ standard was measured as $0.512105 \pm 9(2 \sigma, \mathrm{n}=26)$, and the data has been corrected to 0.512115 (Tanaka et al., 2000). The Sr data was also measured in multi-dynamic mode. Fractionation was corrected relative to ${ }^{86} \mathrm{Sr} /{ }^{88} \mathrm{Sr}=0.1194$. NBS $987{ }^{87} \mathrm{Sr} /{ }^{86} \mathrm{Sr}$ gave a value of $0.710252 \pm 17(2 \sigma, \mathrm{n}=35)$. The data was corrected relative to NBS987 value 0.710250 .20 samples ( 14 hemipelagic sediments and 6 potential ashes) were analyzed for major and trace element concentrations at the Boston University Stable Isotope Lab on inductively coupled plasma mass spectrometer (ICPMS) and inductively coupled plasma emission spectrometer (ICP-ES) following the bulk digestion procedure of Kelley et al. (2003) (Table 3). These samples were dried at $100^{\circ} \mathrm{C}$ overnight for water loss measurement, then combusted at $950^{\circ} \mathrm{C}$ to yield Loss on Ignition (LOI).

Due to limited sample amounts ( $<2 \mathrm{~g}$ for Lamont samples), physical separation to assure the purity of the ash samples was not attempted prior to geochemical analysis. Based on both the Nd and Sr isotope results, as well as the major and trace element data, three samples designated as ash layers from their core descriptions, VM15-26 573-574 $\mathrm{cm}$, VM15-24 750-752 cm, and RC12-29 893-894 cm, were judged to have significant amounts of hemipelagic sediment mixed in, though they are more volcanogenic than the nearest hemipelagic sediment samples within the same core. The other three ash samples, RC12-32 440-441 cm, GC09 85-87 cm, and PC38 687-694 cm appeared to have little if any hemipelagic sediment component.

\subsection{Contamination in Vema Cores}

The samples chosen for major and trace element analysis included cores collected during EW0104 (R/V Ewing), VM15 (R/V Vema), and RC12 (R/V Robert Conrad). Five 
samples taken from VM15 cores (VM15-24: TW2-3 cm, 750-752 cm, 869-870 cm; VM15-26: $573-574 \mathrm{~cm}, 671-673 \mathrm{~cm}$ ) contained anomalous $\mathrm{Zn}$ concentrations an order of magnitude greater than would be expected in sediments from this region (e.g., Plank and Langmuir, 1998). According to the curator at the Lamont-Doherty Core Repository, these core intervals had been marked by metal tacks that rusted before being removed, potentially explaining the $\mathrm{Zn}$ contamination. There does not seem to be a spike in either the $\mathrm{Fe}_{2} \mathrm{O}_{3}$ measurement or other trace metals that might be associated with steel, but this does not rule out this contamination mechanism. Certain trace metal concentrations could still be suspect, as proton microprobe analysis of stainless steel indicated high concentrations of $\mathrm{Fe}, \mathrm{Cr}, \mathrm{Mn}$, and $\mathrm{Ni}$ (in wt.\%) and $\mathrm{Co}, \mathrm{Cu}$, and $\mathrm{Nb}$ (ppm) (Kurosawa et al., 1999). Without knowing the exact composition of the source of the $\mathrm{Zn}$ contamination, it is hard to judge which elements may have been affected in the absence of a visible anomaly.

Six Vema core samples (VM15-22: TW0-1 cm; VM15-24 cm: TW2-3 cm, 869-870 $\mathrm{cm}$; VM15-26 cm: TW2-3 cm, 573-574 cm, 671-673 cm) recorded LOI values around $10 \mathrm{wt} . \%$ higher than average hemipelagic, non-carbonate sediments (T. Plank, pers. comm.). The source of this additional combustible material is currently unknown. Additionally, the three trigger weight samples from cores VM15-22, VM15-24, and VM15-26 had anomalously high $\mathrm{Na}_{2} \mathrm{O}$ values, the source of which may be seawaterderived crystallized halides that may be added to the sample if the sampling procedure did not avoid sediments that were in contact with the sides of the container. As the other hemipelagic sediments have values ranging from $~ 9.5-14.5 \mathrm{wt} . \%$ LOI and 3.5-6.4 wt.\% $\mathrm{Na}_{2} \mathrm{O}$, and the anomalous VM15 values are $\sim 18-26$ wt. $\% \mathrm{LOI}$ and $8.8-18.1 \mathrm{wt} . \% \mathrm{Na}_{2} \mathrm{O}$, this represents a potential mass dilution of 10-20\% (depending on combination of $\mathrm{Na}$ with LOI) for which the other elements would have to be corrected. In addition to the six VM15 core samples reflecting contamination in $\mathrm{Na}_{2} \mathrm{O}$ and/or LOI, two other VM15 samples (from the same cores) not measured for major and trace elements were analyzed for ${ }^{10} \mathrm{Be}$ concentrations. These ${ }^{10} \mathrm{Be}$ concentrations may also be diluted by halide or LOI contamination. 
Barring trace metal contamination from components that go into manufacturing steel, this dilution will not modify ratios such as ${ }^{10} \mathrm{Be} /{ }^{9} \mathrm{Be}$, as they would be corrected by the same mass fraction, but it could affect general patterns when plotting elements against each other. Absolute concentrations for the uncontaminated elements in the Vema cores are probably too low by at least $\sim 10 \%$, assuming the high LOI values are not from a phase normal to sediments such as carbonate. Smear slide and core descriptions recording little to no foraminifera argue against large amounts of carbonate in the piston cores, as do the $<1$ wt.\% measured carbonate contents for Deep Sea Drilling Program (DSDP) Site 495 and Ocean Drilling Program (ODP) Site 1039 hemipelagic sediments (Aubouin et al., 1982; Kimura et al., 1997). Element concentrations are presented without correcting for LOI and $\mathrm{Na}_{2} \mathrm{O}$, but all Vema core samples are distinguished from the other samples in figures. Where potential corrections could affect the interpretation of the results, this will be addressed assuming an LOI correction to $13 \mathrm{wt} . \%$ and a $\mathrm{Na}_{2} \mathrm{O}$ correction to $5 \mathrm{wt}$.\% (the average of the other sediments) for the anomalous samples. This is not ideal, but it is a workable solution in lieu of further constraints on contamination effects. For the two Vema core ${ }^{10} \mathrm{Be}$ samples for which LOI data is not available, a constant mass correction of $10 \%$ is applied.

\section{Middle America Trench/Central American Volcanic Arc System}

\subsection{Middle America Trench Sediment}

Two drill sites, DSDP Site 495 offshore of Guatemala, and ODP Site 1039 offshore of Costa Rica (located in Figure 3), have provided the bulk of the information regarding the sedimentary parameters outboard of the Middle America Trench. There are no drill sites located on the downgoing plate offshore of Nicaragua. Analyses of the DSDP and ODP sites display general similarities in the sediment being subducted into the Middle America Trench (Aubouin et al., 1982; Kimura et al., 1997; Plank and Langmuir, 1993, 1998). Approximately 437 meters of hemipelagic and carbonate sediment was recovered at DSDP Site 495 (Aubouin et al., 1982). Farther south, offshore of Costa Rica, ODP Site 1039 recovered 400 meters of hemipelagic and carbonate oozes (Kimura et al., 1997). 
Even though the sediment thickness at DSDP Site 495 is slightly greater than that recovered at ODP Site 1039, the hemipelagic sediments total $~ 38 \%$ of the sediment column in ODP Site 1039 but only 22\% in DSDP Site 495 (Aubouin et al., 1982; Kimura et al., 1997). The biostratigraphy indicates that the sedimentation rate for the upper 150 meters at ODP Site 1039 is higher than that determined at DSDP Site 495 (Aubouin et al., 1982; Kimura et al., 1997). Despite the fact that the sedimentation rate at ODP Site 1039 is faster and the uppermost $19 \mathrm{~m}$ of the section drilled at DSDP Site 495 was not recovered (Aubouin et al., 1982), the sediments recovered at DSDP Site 495 appear to have higher concentrations of ${ }^{10} \mathrm{Be}$ than those measured at ODP Site 1039 by about $30 \%$ (Figure 4; Valentine et al., 1997, submitted).

As the arc volcanic ${ }^{10} \mathrm{Be}$ concentrations in Guatemala are only two to three times greater than the small enrichments in northwestern Costa Rica, this variability highlighted the need to study ${ }^{10} \mathrm{Be}$ concentrations in surficial sediments. The ${ }^{10} \mathrm{Be}$ flux to the trench may be compared with the ${ }^{10} \mathrm{Be}$ flux out of the arc, in the light of seismic imaging to constrain sediment subduction, frontal accretion, underplating, and erosion (Valentine et al., 1997; Morris et al., 2002; Valentine et al., submitted). However, all such models necessarily assume steady state in the subduction parameters and also in the ${ }^{10} \mathrm{Be}$ sediment concentrations along and across strike. The surficial sediment composition along the trench appears to be relatively uniform as far south as the Nicoya Peninsula of Costa Rica (Figure 5), but other depositional processes may influence the accumulation of ${ }^{10} \mathrm{Be}$. As the top ten meters of sediment contain $20-30 \%$ of the ${ }^{10} \mathrm{Be}$ (Zheng et al., 1994), it is essential to establish the distribution of ${ }^{10} \mathrm{Be}$ in the youngest sediments throughout the region in order to place rigorous constraints on the mass balance of sediment subduction in the region (Tera et al., 1986; Morris and Tera, 1989; Morris et al., 1990).

\section{2 ${ }^{10}$ Be Concentrations Along the Middle America Trench}

${ }^{10} \mathrm{Be}$ concentrations vary both within each core (Figure 6) as well as geographically along the trench (Figure 7). Limited age constraints can partially account for changes due 
solely to ${ }^{10} \mathrm{Be}$ decay (Table 4). Agreement between the shallowest samples and the age corrected deep samples within each core would strongly support the accuracy of the age constraints as well as the minimal influence of other effects. However, if age-corrected bottom concentrations are still significantly different than in the topmost samples, it may not be possible to distinguish between the likely sources of the variations: uncertainties in the age estimations, turbidite dilution, or geochemical and lithological partitioning. As these controls could be a factor in determining the ${ }^{10} \mathrm{Be}$ concentrations throughout the core, an additional level of complication arises when trying to ascertain the original zeroage ${ }^{10} \mathrm{Be}$ concentrations. Variations in ${ }^{10} \mathrm{Be}$ concentrations as a function of parameters unrelated to age, such as grain size, lithology, or particle flux, are more fully discussed in Section 4.

Cores RC12-32, VM15-26, and RC12-29 have tephrochronology information available based on correlated ash layer geochemistry (Ledbetter, 1985). The multiple dated ash layers in each of these cores also allowed sedimentation rates to be calculated. These rates were then used to estimate the ages of samples in this study that were deeper than the lowest dated ash layers. In RC12-32, the lowest tephra layer, which was also sampled for this study, is located from $432-460 \mathrm{~cm}$ and dated at $270 \mathrm{ka}$ (Ledbetter, 1985). This age was combined with a deposition rate of $\sim 0.00086 \mathrm{~cm} / \mathrm{yr}$ for the lower portion of the core to give an age correction of $\sim 293,000$ yrs for sample RC12-32 $480-481 \mathrm{~cm}$. This age correction results in a close agreement between the zero-age ${ }^{10} \mathrm{Be}$ concentrations in the top and bottom samples of this core.

Tephrochronology in VM15-26 yielded an age of $279 \mathrm{ka}$ for an ash-filled burrow from $570-584 \mathrm{~cm}$ and a consistent sedimentation rate throughout the core of $0.002 \mathrm{~cm} / \mathrm{yr}$ (Ledbetter, 1985). Sample VM15-26 671-673 cm was therefore corrected to 329,000 yrs. Both prior to and after applying the age correction, the ${ }^{10} \mathrm{Be}$ concentration for the base of the core is significantly higher than for the trigger weight core sample. This difference also remains after applying the LOI and $\mathrm{Na}_{2} \mathrm{O}$ corrections, with the bottom sample of VM15-26 increasing to the high end of the range for ${ }^{10} \mathrm{Be}$ in all samples. Cores VM15-22 and VM15-24 do not have available age data, so the sedimentation rate from VM15-26, 
the nearest core with similar lithology (Appendix 1), was used to correct for the age of the deeper samples. The ${ }^{10} \mathrm{Be}$ concentrations measured in VM15-22 do not have a simple ${ }^{10} \mathrm{Be}$ decay relationship downcore either before or after the age correction. The effect of the LOI corrections (and $\mathrm{Na}_{2} \mathrm{O}$ correction for the trigger core) is to increase all concentrations. In VM15-24, the bottom sample is higher in ${ }^{10} \mathrm{Be}$ than the trigger core sample after the age correction is applied. However, applying the LOI correction to both samples and the $\mathrm{Na}_{2} \mathrm{O}$ correction to the trigger core results in the surface sample having a higher ${ }^{10} \mathrm{Be}$ concentration.

An alternative possibility for these two unconstrained cores is to assume a consistent age relationship between the ${ }^{10} \mathrm{Be}$ concentrations, rather than imposing a sedimentation rate to determine age. In this scenario, the age difference between the top and bottommost sample of VM15-24 at $870 \mathrm{~cm}$ depth was calculated to be slightly less than $200,000 \mathrm{yrs}$, yielding a sedimentation rate of $0.0044 \mathrm{~cm} / \mathrm{yr}$, more than double the sedimentation rate of VM15-26 but still well within the total range of rates for this region (including the rates for the upper parts of the drill cores DSDP Site 495 and ODP Site 1039). With the mass correction, the time difference increases to $\sim 280,000$ yrs and the sedimentation rate decreases to $0.0031 \mathrm{~cm} / \mathrm{yr}$. However, this same method applied to the lower two samples of VM15-22 $(175 \mathrm{~cm}$ and $478 \mathrm{~cm})$ produces a time span between these samples of almost $518,000 \mathrm{yrs}$ and a sedimentation rate of $0.0006 \mathrm{~cm} / \mathrm{yr}$, which is very low compared to the other cores in this region (e.g., Ledbetter, 1985). As both VM15-22 and VM15-24 are located near or within the Middle America Trench, the possibility that turbidite dilution is occurring for some of these samples is high, but this can not be quantified with the currently available data. For subsequent discussions, we therefore use the VM15-22 and VM15-24 ${ }^{10} \mathrm{Be}$ concentrations that were age corrected based on the sedimentation rate of $0.002 \mathrm{~cm} / \mathrm{yr}$.

The highest measured ${ }^{10} \mathrm{Be}$ value, 3100 million atom $/ \mathrm{g}$, is found in core $\mathrm{RC} 12-29$ offshore of southeastern Nicaragua. An ash layer located at $893 \mathrm{~cm}$ depth in this core was dated at $148,000 \mathrm{ka}$ and the sedimentation rate was calculated to be $0.006 \mathrm{~cm} / \mathrm{yr}$ (Ledbetter, 1985). After age correction, there is no significant difference in ${ }^{10} \mathrm{Be}$ 
concentration between the top and bottom samples of RC12-29, which are $10.5 \mathrm{~m}$ apart. It should also be noted that RC12-29 is the farthest core from the Middle America Trench in this study (excluding carbonate core GC09). Concentrations may decrease with proximity to the trench due to higher deposition rates, the possible ramifications of which will be addressed in Section 3.4.

Calculated age-depth models for the upper sediments at ODP Site 1039 in the Middle America Trench exhibit a range of deposition rates, from very rapid accumulation in the upper $20 \mathrm{~m}(\sim 0.01 \mathrm{~cm} / \mathrm{yr})$ to more moderate rates for the bulk of the Pleistocene sediments (Kimura et al., 1997). Index microfossils average $0.0046 \mathrm{~cm} / \mathrm{yr}$ from $50-120$ meters below seafloor (mbsf), while paleomagnetic estimates are $0.003 \mathrm{~cm} / \mathrm{yr}$ for this part of the sediment column. However, it should be noted that these are averages of individual rates that vary within each age-dated section (see Table 9 for ODP Site 1039 in Kimura et al., 1997).

EW0104 cores are not located as near to the trench as ODP Site 1039, though PC/GC 18 and PC/GC 38 are much closer than the other cores (Figure 3). Based on the current convergence rate of $85 \mathrm{~mm} / \mathrm{yr}$ for this portion of the Cocos plate (DeMets, 2001), the deposition of these sediments, which range in depth from 0-10 mbsf, probably fell within the geographical range that would correspond to the section of ODP Site 1039 between 50 and $120 \mathrm{mbsf}$. As such, a rate of $0.0046 \mathrm{~cm} / \mathrm{yr}$ was used for the age correction on the hemipelagic samples of the Ewing cores. Unfortunately, this method has a few glaring pitfalls.

Though sedimentation rate (Kimura et al., 1997) and the ${ }^{10} \mathrm{Be}$ geochemistry (Figure 4) argue for a turbidite flow in the upper $20 \mathrm{~m}$ of ODP Site 1039, and therefore that high accumulation was recorded only locally, the Pleistocene rate of $0.003-0.0046 \mathrm{~cm} / \mathrm{yr}$ may still be too slow for the upper sediments of the Ewing cores, especially for PC18 and PC38. Additionally, applying the Pleistocene rate based on geographical location requires that productivity or other controls on particle flux did not significantly change with time, which is unlikely. It is very possible that using this moderate rate will overestimate the age correction. Fortunately, the difference between using $0.01 \mathrm{~cm} / \mathrm{yr}$ and $0.0046 \mathrm{~cm} / \mathrm{yr}$ 
for the cores in question (PC18, PC36, PC37, PC38, and GC43) is less than 5\% of the ${ }^{10} \mathrm{Be}$ concentrations, only slightly greater than measurement uncertainty. Ideally, future work will enable age constraints to be placed on the Ewing cores, which will delineate both temporal and geographical changes in sediment accumulation rates.

As some of the EW0104 piston cores also lost shallow material during sediment penetration, when a concurrent ash layer was observed in both the trigger core and the piston core, the displacement was used to estimate the true depth of the bottom piston core samples. In $\mathrm{GC} 18$, the first gray ash layer occurs at 142-145 cm; in PC18, this layer appears at 43-44 cm, so a depth correction of $99 \mathrm{~cm}$ was made for PC18 788-790 cm. In GC38 and PC38, a thin black ash layer is observed at the same depth within both cores so no depth correction was made. The $1 \mathrm{~m}$ trigger core GC36 did not sample the gray ash layer at the top of PC36. Therefore, a minimum depth correction of $1 \mathrm{~m}$ was applied to PC36 494-496 cm based on the assumption that the ash layer at the top of PC36 is not the water/sediment interface. The top and bottom samples for PC37 were both taken from the piston core, so no depth correction was needed.

After age correction, the top and bottom samples for PC18 are in much closer agreement. PC38 and PC 36 both have lower ${ }^{10} \mathrm{Be}$ concentrations in the trigger core samples compared to the bottommost piston core samples. PC 37 has a higher ${ }^{10} \mathrm{Be}$ concentration in its upper sample, and the bottom sample concentration remains much lower, even after age correction. GC43 does not show a simple age relationship in its ${ }^{10} \mathrm{Be}$ concentrations either before or after age correction. One caveat to the interpretation of the EW0104 cores is that they were all sampled on topographic highs where the sediment layer was considerably thinner than the surrounding seafloor (Fisher et al., 2001). If erosional processes due to the relative exposure of these basement highs resulted in age discontinuities downcore, it would be difficult to distinguish that in the absence of detailed chronologies for each core. The application of a constant sedimentation rate is a best estimate with the current data available, but it may not be equally appropriate for each core. 
The lowest ${ }^{10} \mathrm{Be}$ concentrations of all the samples were recorded in GC09, the values decreasing as the clay sediment transitioned to carbonate chalk downcore. This is a function of either the low affinity of ${ }^{10} \mathrm{Be}$ for carbonate particles (Chase et al., 2002), or, more likely, the age of the sediments. The carbonate layer in both drill cores at the Middle America Trench occurs at $>150$ mbsf, late Miocene to early Pliocene in age ( $\sim 5$ $\mathrm{Ma}$ ). For a shallow gravity core to sample carbonate sediment in this region, intermediate hemipelagic layers had most likely been removed by erosional processes. This interpretation is consistent with the sampling locality of GC09, sited on a topographic high about $200 \mathrm{~m}$ above the surrounding seafloor (Fisher et al., 2001).

The ash layer GC09 85-87 cm and hemipelagic sample GC09 89-91 cm occurred within the section of the core that was dominantly hemipelagic silty clay, though GC09 $89-91 \mathrm{~cm}$ was mottled gray and brown, indicating possible mixing with the overlying ash layer. These two samples were interpreted as being deposited recently (i.e., Holocene) and regionally and so the age correction using the ODP Site 1039 sedimentation rate was applied. The lower samples selected for ${ }^{10} \mathrm{Be}$ analysis, in contrast, were located within a transition zone in which the clays were increasingly nannofossil rich toward the contact with carbonate chalk (GC09 293-295 cm was completely within the chalk sequence). Since the core top sampled the sediment/water interface and therefore zero-age sediments, an age discontinuity almost certainly exists within this core. However, the lack of true age data makes this identification difficult. Given the possible early Pliocene to late Miocene (or older) age of the lowermost samples, age corrections could elevate the ${ }^{10} \mathrm{Be}$ concentrations to that comparable to Equatorial Pacific open ocean pelagic calcareous sediments (e.g., $2000 \times 10^{6}$ atom/g, Lao et al., 1992).

The ${ }^{10} \mathrm{Be}$ concentrations in the analyzed ash layers from RC12-32, PC38, and GC09 are an order of magnitude smaller than in the bulk of the hemipelagic sediments, even after age correction. The three mixed ash/sediment samples have ${ }^{10} \mathrm{Be}$ concentrations on the low end of the hemipelagic range. This distribution of ${ }^{10} \mathrm{Be}$ between the primary sediment components of hemipelagic and volcanogenic material reflects the way in which ${ }^{10} \mathrm{Be}$ can be dramatically partitioned between sediment types in marine cores. The source of the 
difference in ${ }^{10} \mathrm{Be}$ between the ash and hemipelagic layers, as well as of other smaller scaled partitioning effects, is attributed to endmember mixing and grain size characteristics (see Section 4).

\subsection{Implications for Arc Volcanic ${ }^{10} \mathrm{Be}$}

The concentrations of ${ }^{10} \mathrm{Be}$ in surface sediment along the Middle America Trench have some geographical variability, but not to the extent observed in arc volcanic ${ }^{10} \mathrm{Be}$. Dramatic differences in the arc lava ${ }^{10} \mathrm{Be} /{ }^{\rho} \mathrm{Be}$ ratios, especially between Nicaragua and Costa Rica, are not mirrored in ${ }^{10} \mathrm{Be}$ concentrations of sediment subducting at the trench (Figure 8 ). Normalizing arc volcanic ${ }^{10} \mathrm{Be}$ to ${ }^{9} \mathrm{Be}$ removes effects of partial melting and can reveal true variability more clearly than ${ }^{10} \mathrm{Be}$ concentrations alone. This normalization is not necessary to effectively compare changes in sedimentary ${ }^{10} \mathrm{Be}$ to the arc, as ${ }^{10} \mathrm{Be}$ is the controlling factor in ${ }^{10} \mathrm{Be} /{ }^{9} \mathrm{Be}$ ratios in the sediments (Figure 9). If sedimentary ${ }^{10} \mathrm{Be} /{ }^{9} \mathrm{Be}$ is used, the core samples for which ${ }^{9} \mathrm{Be}$ is available range from moderate enrichment offshore of Guatemala (RC12-32) to the peak in RC12-29 offshore of Nicaragua, but there is even less difference between RC12-29 and PC38 offshore of Costa Rica than was apparent comparing ${ }^{10} \mathrm{Be}$ concentrations alone (Table 5).

The small range in maximum concentrations of ${ }^{10} \mathrm{Be}$ (prior to age correction) within each of the regions along the trench illustrates that ${ }^{10} \mathrm{Be}$ is deposited fairly consistently in these shallow sediments and that variable sedimentary ${ }^{10} \mathrm{Be}$ concentrations are unlikely to be a dominant factor in the variable enrichment of ${ }^{10} \mathrm{Be}$ in the Central American Volcanic Arc. The goal of this study was to evaluate the possibility that the differences in ${ }^{10} \mathrm{Be}$ between DSDP Site 495 and ODP Site 1039 account for the respective variation in Guatemalan and Costa Rican arc volcanic rocks. Instead, the results demonstrate that sediments offshore of Costa Rica have ${ }^{10} \mathrm{Be}$ concentrations similar to sediments sampled outboard of the entire Middle America Trench. Through the addition of this more comprehensive suite of ${ }^{10} \mathrm{Be}$ data, it is evident that dilution effects such as turbidite layers (as seen at ODP Site 1039) are localized rather than characteristic of an entire geographic region. 


\subsection{Proximity to Trench}

There is still a data gap at or near the trench offshore of most of Nicaragua. RC12-29 offshore of southeastern Nicaragua contains the highest ${ }^{10} \mathrm{Be}$ concentrations and ${ }^{10} \mathrm{Be} /{ }^{9} \mathrm{Be}$ values of all the cores selected for this study, and this sample location is opposite high ${ }^{10} \mathrm{Be} /{ }^{9} \mathrm{Be}$ ratios in arc lavas. However, when the highest DSDP Site $495{ }^{10} \mathrm{Be}$ concentrations in atom $/ \mathrm{cm}^{3}$-wet sediment are converted to atom/g-dry sediment (assuming a density of $1.62 \mathrm{~g} / \mathrm{cm}^{3}$ and $49 \mathrm{wt} . \%$ water loss; Aubouin et al., 1982), the values are very similar to those of RC12-29. The uppermost samples at DSDP Site 495 were $20 \mathrm{mbsf}$, the deposition of which may have occurred at some distance seaward of the trench, possibly comparable to that for the upper sample of RC12-29. Without sediment samples taken from the trench offshore of Nicaragua, it is difficult to assess whether the high ${ }^{10} \mathrm{Be}$ concentrations from RC12-29 accurately reflect the shallowest trench sediments.

${ }^{10} \mathrm{Be}$ surface sediment concentrations for the region of RC12-29 may even be reduced with progression toward the trench. ${ }^{10} \mathrm{Be}$ concentrations within a sediment column are necessary to calculate the bulk ${ }^{10} \mathrm{Be}$ supplied to a trench. However, concentrations measured with increasing distance from a trench will be correspondingly less appropriate to use as predictors of surficial trench sediment concentrations because of the complex interplay of sediment accumulation rates and effects such as boundary scavenging on ${ }^{10} \mathrm{Be}$ deposition. ${ }^{10} \mathrm{Be}$ concentrations in the open ocean are frequently much higher than concentrations at margins along a constant latitudinal transect (e.g., Anderson, 1990; Lao et al., 1992, 1993). However, increased particle fluxes at margins compared to the open ocean contribute to more efficient scavenging of particle reactive nuclides such as ${ }^{10} \mathrm{Be}$, a higher flux of ${ }^{10} \mathrm{Be}$ atoms to the seafloor, and a higher accumulation rate of ${ }^{10} \mathrm{Be}$ in seafloor sediment, despite absolute concentrations being lower (e.g., Anderson, 1990; Lao et al., 1992, 1993). Therefore, if sedimentation rates were to increase between RC1229 and the trench, ${ }^{10} \mathrm{Be}$ concentrations might decrease, yet an integrated calculation over 
the entire sediment column would most likely show greater total amounts of ${ }^{10} \mathrm{Be}$ within the sediment column in close proximity to the trench.

\subsection{Summary}

Drill core ${ }^{10} \mathrm{Be}$ data such as that at DSDP Site 495 and ODP Site 1039 provide a reasonable estimate of the ${ }^{10} \mathrm{Be}$ budget in the bulk sediment column subducting at the trench, yet as is observed in ODP Site 1039 the shallowest sediments are not necessarily representative of the remainder of the core. Normal enhanced deposition due to particle scavenging can be masked by localized dilution events such as turbidites. Based on seismic data, stratal geometry suggests that gravity flows may be the dominant process infilling the trench (e.g., Aubouin et al., 1982). However, more detailed core analyses are needed to determine the extent of gravity flows based on sedimentological evidence. Subduction flux estimates of ${ }^{10} \mathrm{Be}$ using drill core data can be enhanced by the addition of regional piston and gravity cores that define the spatial variability of ${ }^{10} \mathrm{Be}$ concentrations in sediments outboard of the trench.

This study shows that the variable ${ }^{10} \mathrm{Be}$ concentrations subducting at the Middle America Trench do not play a significant part in causing variations in the arc volcanic output. Nevertheless, these results fill a crucial gap in the effort to effectively balance the recycling of this element to the arc. The EW0104 cores demonstrate that the depressed ${ }^{10} \mathrm{Be}$ concentrations measured in the shallow sediments at ODP Site 1039 compared to DSDP Site 495 are not signifying a regional trend as much as local variability along the margin. Additionally, the increasing convergence rate southeastward along the trench would reduce even further any differences between Costa Rica and the rest of the trench in the delivery flux of ${ }^{10} \mathrm{Be}$ to the subduction zone. Though perhaps not unexpected, the conclusion that the large variation in arc ${ }^{10} \mathrm{Be}$ from Guatemala to Costa Rica is unrelated to the initial sedimentary ${ }^{10} \mathrm{Be}$ concentrations subducting at the trench is an important contribution to the broader goal of deriving accurate mass balances at subduction zones. 


\section{Local Influences on ${ }^{10} \mathrm{Be}$ in Surficial Middle America Trench Sediment}

\section{$4.1{ }^{10}$ Be Depositional Systematics}

In addition to serving as a useful tracer of sediment subduction to volcanic arcs, ${ }^{10} \mathrm{Be}$ deposition in marine sediments is a key process in studies evaluating changes in paleoproductivity (e.g., Frank et al., 1995), paleomagnetism (e.g., Frank et al., 1997), climate (e.g., Eisenhauer et al., 1994), and boundary scavenging (e.g., Luo et al., 2001). These types of investigations require an understanding of the primary controls on ${ }^{10} \mathrm{Be}$ accumulation in sediments in order to separate these effects from those of the larger scale factors such as paleomagnetic variations. However, the relative dominance of characteristics such as preferred carrier phase, grain size, particle flux, or productivity does not appear completely constant. In order to utilize ${ }^{10} \mathrm{Be}$ as an extensive paleo-tracer, it is necessary to identify competing depositional systematics throughout the ocean. By combining ${ }^{10} \mathrm{Be}$ concentrations with the isotopic, major and trace element characteristics of the Middle America Trench sediments, this information can contribute to our understanding of ${ }^{10} \mathrm{Be}$ in similar regions on a global level.

The depositional systematics of ${ }^{10} \mathrm{Be}$ change dramatically from the open ocean to margins. In the open ocean, ${ }^{10} \mathrm{Be}$ exhibits a nutrient-like behavior, with depletion in the upper water column due to particle scavenging (offset at the very surface by the atmospheric input) and regeneration due to particle dissolution in deep waters (e.g., Kusakabe et al., 1987; 1990). In Pacific deep ocean waters, the covariance of ${ }^{10} \mathrm{Be}$ with ${ }^{9} \mathrm{Be}$ denotes that these isotopes are in tracer equilibrium despite their different sources (Kusakabe et al., 1987). Correlations between ${ }^{10} \mathrm{Be},{ }^{9} \mathrm{Be}$, and ${ }^{27} \mathrm{Al}$ in sediment traps and surface sediments imply that in the open ocean, ${ }^{10} \mathrm{Be}$ is preferentially scavenged by detrital aluminosilicate clays (e.g., Sharma et al., 1987; Southon et al., 1987), the deposition of which can also be enhanced by aggregates of fecal pellets that can incorporate large amounts of clay particles and bear them efficiently to the seafloor (Lal, 1980).

The $500-1200 \mathrm{yr}$ residence time of ${ }^{10} \mathrm{Be}$ in the open ocean, on the same order as the oceanic mixing time, allows for lateral transport of ${ }^{10} \mathrm{Be}$ to margins (e.g., Anderson et al., 
1990). At margins, the increased particle flux scavenges ${ }^{10} \mathrm{Be}$ equivalently throughout the water column (Lao et al., 1993), reducing the residence time to less than $100 \mathrm{yrs}$ (Kusakabe et al., 1990; Anderson et al., 1990; Lao et al., 1992). The magnitude of this effect results in approximately $70 \%$ of the total ${ }^{10} \mathrm{Be}$ introduced to the Pacific accumulating in margin sediments covering only $10 \%$ of the ocean floor (Lao et al., 1992). Even an open ocean region with high productivity, and therefore increased biogenic particle flux, was observed to be depleted in ${ }^{10} \mathrm{Be}$ due to the effects of boundary scavenging (Frank et al., 1994).

As the various continental margins studied in terms of ${ }^{10} \mathrm{Be}$ deposition can have widely varying characteristics, there has been little consensus as to the importance of one type of carrier phase over another, or whether particle flux offsets lithological affinities. In Congo Fan sediments, high ${ }^{10} \mathrm{Be}$ was associated with the flux of $\mathrm{Al}_{2} \mathrm{O}_{3}$, indicating the dominant influence of terrigenous sediment particles from the Congo River on ${ }^{10} \mathrm{Be}$ flux (Rutsch et al., 1995). In the northeast Pacific, Lao et al. (1993) observed that the scavenging rates of ${ }^{10} \mathrm{Be}$ were correlated with particle flux. However, as Chase et al. (2002) pointed out, distinguishing between particle flux and particle composition as the more important control can be difficult because of the typical association of high fluxes with a specific particle type, such as biogenic opal due to productivity (e.g., Buesseler, 1998), or a terrigenous riverine flux as seen in the Congo Fan. Attempts to quantify a particle composition effect can also be difficult when particle composition is not independent of particle size, as is often the case for clay, carbonate, and organic matter, because changes in the surface area to mass ratio can affect settling velocity, which in turn affects the efficiency of scavenging (Chase et al., 2002).

It has been recently suggested that particle composition is a more consistent control on ${ }^{10} \mathrm{Be}$ deposition at continental margins, rather than the classic idea of boundary scavenging operating solely as a function of particle flux (Chase et al., 2002, 2003). A comprehensive comparison between open ocean and marginal regions included varying particle flux rates and endmember compositions of biogenic silica, lithogenic particles, and carbonate (Chase et al., 2002). Chase et al. (2002) found that while ${ }^{10} \mathrm{Be}$ had a strong 
affinity for both lithogenic and biogenic silica particles over carbonate, it was scavenged from the water column to a higher degree with increasing opal but not with increasing lithogenic fraction. When particle flux increased, the partitioning of ${ }^{10} \mathrm{Be}$ between particulate matter and the water column was not affected.

It seems likely that both particle flux and particle composition significantly impact ${ }^{10} \mathrm{Be}$ scavenging. However, as marine particles in some marginal settings may be predominantly biogenic silica, the greater ability of opal to scavenge ${ }^{10} \mathrm{Be}$ compared to other compositions can overshadow the contribution of particle flux to boundary scavenging processes (Chase et al., 2002, 2003). Of course, as principle particle composition and flux rate will vary from region to region, it is most effective to view ${ }^{10} \mathrm{Be}$ deposition in light of the characteristics particular to each study area.

\subsection{Geochemical Characteristics of Surficial Middle America Trench Sediments}

Measurements of organic carbon, calcium carbonate, and opal are currently unavailable for the sediment samples used in this study, but they are unlikely to be very different from DSDP Site 495 and ODP Site 1039 shallow sediments, which have less than $1 \mathrm{wt} . \%$ carbonate and $\sim 2$ wt.\% organic carbon content (Aubouin et al., 1982; Kimura et al., 1997). The surficial Middle America Trench sediments considered in this study are principally composed of terrigenous and volcanogenic detritus with varying dilutions from biogenic material. A comprehensive discussion of the broad implications of major and trace element concentrations in marine sediments, which will not be attempted here, can be found in Plank and Langmuir (1998).

The twenty Cocos plate piston core sediment samples chosen for major and trace element analysis exhibit generally similar patterns between the hemipelagic, ash, and mixed hemipelagic/ash samples (Figure 10). More enriched in the incompatible elements compared to N-MORB (Sun and McDonough, 1989; Figure 10a), these samples follow the same trends as both the globally averaged subducting sediment (GLOSS) as well as the average DSDP Site 495 hemipelagic sediment (Plank and Langmuir, 1998). The ashes are slightly enriched relative to the other hemipelagic sediments in some of the detrital 
(i.e., non-biogenic) elements, such as $\mathrm{Rb}, \mathrm{Th}, \mathrm{Nb}$, and the light rare earth elements (LREEs) (Plank and Langmuir, 1998; Figures 10 and 11). As might be expected from distinct volcanic eruption layers, the three ash samples also differ from each other, displaying a typical "arc" chemical signature, but with some variation in high field strength element (HFSE) depletion or Eu anomaly (Figures 10 and 11). All samples have peaks in $\mathrm{Ba}, \mathrm{U}$, and $\mathrm{Sr}$, most likely indicating the variable presence of organic and biogenic material, though volcaniclastic material can be more enriched in Sr relative to continental crust (Plank and Langmuir, 1998) and might be a source for Sr in lowcarbonate sediments. The Sr-Nd isotope geochemistry of the hemipelagic sediments is consistent with a component of young volcanogenic particulate matter mixing with input from a mature continental source, such as aeolian dust or riverine run-off (Figure 12).

Post-Archean shale (PAAS, Taylor and McLennan, 1985) is a mature detrital continental endmember for marine sediment compositions (e.g., Plank and Langmuir, 1998). In the REEs, the ashes actually have a flatter element pattern relative to PAAS than the hemipelagic sediments do (Figure 11). Therefore, it is unlikely that PAAS is an ideal representation of the detrital source for the hemipelagic sediments in this region. The igneous basement of Central America is dominantly young volcanic arc and Caribbean Large Igneous Province (CLIP) material (e.g., Weyl, 1980). Erosion from Central America as well as ash deposited from Central American Volcanic Arc eruptions will result in sediments that are more volcanogenic and less mature in their position along mixing lines with global bulk upper continental crust estimates.

\section{$4.3{ }^{10}$ Be Associations in the Middle America Trench Region}

An overarching goal of this work was to evaluate variations in ${ }^{10} \mathrm{Be}$ subducting along the Middle America Trench for comparison to the Central American Volcanic Arc. An exhaustive investigation of ${ }^{10} \mathrm{Be}$ depositional systematics for this region, such as the type

carried out by Chase et al. (2002), was beyond the scope of this project. To rigorously identify the mechanisms controlling even minor variations in sedimentary ${ }^{10} \mathrm{Be}$ concentrations, it would be necessary to incorporate all potential variables, such as 
particle flux and distribution in the overlying water column, extensive accumulation rate assessments, and separation by grain size fractions and particle composition. However, with the use of bulk sediment samples analyzed for ${ }^{10} \mathrm{Be}$ in conjunction with isotopes, major, and trace elements, we are still able to take the first steps toward isolating the important components that govern ${ }^{10} \mathrm{Be}$ systematics in this region.

In contrast to $\mathrm{Be}$ isotope behavior in suspended deep-water particles and seafloor sediments in the open ocean (e.g., Kusakabe et al., 1987), ${ }^{10} \mathrm{Be}$ and ${ }^{9} \mathrm{Be}$ in the Middle America Trench sediments are highly decoupled (Figure 13). Lithogenic input from continents, such as by aeolian dust or riverine particulate matter, is the primary source of ${ }^{9}$ Be in marine sediments (e.g., Kusakabe et al., 1990, 1991; Brown et al., 1992; Wang et al., 1996). In subducting sediments and oceanic crust, white mica is thought to be the dominant mineral host of Be (Domanik et al., 1993; Bebout et al., 1993, 1999). The association between $\mathrm{Be}$ and continentally-derived clay material is borne out in the hemipelagic Middle America Trench sediments by the strong correlations of ${ }^{9} \mathrm{Be}$ with other detrital elements, such as $\mathrm{Al}_{2} \mathrm{O}_{3}, \mathrm{Rb}$, Th, the HFSEs (Hf, $\mathrm{Zr}$, and Ta), and the LREEs (Figure 14). A continental detrital source for ${ }^{9} \mathrm{Be}$ is also consistent with the observation that the ash layers and mixed ash/sediment samples do not necessarily fall along the co-varying trend lines.

Unlike ${ }^{9} \mathrm{Be},{ }^{10} \mathrm{Be}$ shows no distinct correlations with the same detrital elements, making it unlikely that ${ }^{10} \mathrm{Be}$ is preferentially scavenged by terrigenous particles at this margin (Figure 14). Without measurements of biogenic silica, it is hard to determine if ${ }^{10} \mathrm{Be}$ concentrations are a function of the amount of opal, as observed by Chase et al. (2002, 2003). ${ }^{10} \mathrm{Be}$ has a weak relationship with $\mathrm{Ba}$ (Figure 15), an element that can track productivity (e.g., Dymond et al., 1992), but the behavior of Ba during deposition in sediments can be complicated by other phases such as carbonate, organic matter, and terrigenous components (e.g., Schroeder et al., 1997; Plank and Langmuir, 1998), complicating a simple comparison.

The two elements found to have a better correlation with ${ }^{10} \mathrm{Be}$ than any others (though outliers are present) are $\mathrm{Li}$ and $\mathrm{Cu}$ (Figure 15). Li exists in high concentrations in clay- 
rich hemipelagic sediments (e.g., Chan and Kastner, 2000). In aluminosilicate muds of the Nile delta, $\mathrm{Cu}$ was carried in the organic fraction (Rifaat et al., 1992). However, the positive relationships of ${ }^{10} \mathrm{Be}$ with $\mathrm{Li}$ and $\mathrm{Cu}$ are evident only with the inclusion of the ash and ash/sediment mix samples in addition to the hemipelagic sediments. This is in contrast to the strong element relationships observed with ${ }^{9} \mathrm{Be}$, in which the inclusion of the non-hemipelagic samples typically weakens the correlations. Therefore, it seems likely that the covariations of ${ }^{10} \mathrm{Be}$ with $\mathrm{Li}$ and $\mathrm{Cu}$ are unrelated to particle lithology.

${ }^{10} \mathrm{Be}$ for all samples also displays a strong negative correlation with ${ }^{143} \mathrm{Nd} /{ }^{144} \mathrm{Nd}$, but only a weak positive relationship with ${ }^{87} \mathrm{Sr} /{ }^{86} \mathrm{Sr}$, probably due to the higher sensitivity of ${ }^{87} \mathrm{Sr} /{ }^{86} \mathrm{Sr}$ to carbonate or seawater addition (Figure 16). The relationship of ${ }^{10} \mathrm{Be}$ with isotopic $\mathrm{Nd}$ as well as with $\mathrm{Li}$ and $\mathrm{Cu}$ reflects a probable mixing trend with endmembers of pure volcanic ash and detrital clays. The positive correlation of ${ }^{10} \mathrm{Be}$ with LOI (excluding the high LOI Vema core samples) also seems indicative of mixing between clay and ash, with an increasing hydrogenous clay component contributing to higher LOI via loss from water bound in clay minerals (Figure 17). The distribution of ${ }^{10} \mathrm{Be}$ between clays and ashes may be due to the specific particle composition; however, the association of higher concentrations of ${ }^{10} \mathrm{Be}$ with clays is most likely reinforced by, or as a result of, mechanical controls on the way in which these particle types scavenge ${ }^{10} \mathrm{Be}$, i.e., grain size and particle flux to the seafloor.

Volcanic eruptions deposit large volumes of ash or tephra shards on the seafloor in a short period of time (i.e., days to months; Ledbetter and Sparks, 1979). In addition to a simple dilution effect on concentration because of the high accumulation rate (similar to the change between open ocean and marginal concentrations of sedimentary ${ }^{10} \mathrm{Be}$ as discussed in Section 3.4), the higher settling velocity of the larger ash particles means they spend less time in the water column and therefore have less time to scavenge ${ }^{10} \mathrm{Be}$. Though the residence time of ${ }^{10} \mathrm{Be}$ at continental margins is an order of magnitude smaller than in the open ocean, the time it takes for most ash layers to descend to the seafloor is significantly shorter than both the ${ }^{10} \mathrm{Be}$ residence time and the settling times of finer grained particles (e.g., Ledbetter and Sparks, 1979). When this effect is combined 
with an extremely high accumulation rate, the result will be small concentrations of ${ }^{10} \mathrm{Be}$ in the sediment.

\subsection{Grain Size and ${ }^{10} \mathrm{Be}$}

A higher surface area to mass ratio, such as with smaller diameter grains, provides a more efficient scavenging capacity for ${ }^{10} \mathrm{Be}$. Even with a high particle flux of finer grained sediments, the accumulation rate is less likely to induce the same magnitude of dilution in concentration that results from rapidly deposited volcanic ashes. Yet the results of previous efforts to quantify the effect of particle size on adsorption and subsequent deposition of ${ }^{10} \mathrm{Be}$ have been equivocal. Sharma et al. (1987) suggested that the seasonal dependence of open ocean particulate ${ }^{10} \mathrm{Be}$ fluxes in the eastern Pacific meant that downward transportation of Be occurred over a length of time corresponding to the settling velocity (based on Stokes' Law) of particles $>80 \mu \mathrm{m}$. In contrast, a study of beryllium in Holocene sediments from the Nile delta found that Be concentrations increased with increasing proportion of particles $<32 \mu \mathrm{m}$ (Dominik and Stanley, 1993).

The resolution to these seemingly conflicting grain size influences on ${ }^{10} \mathrm{Be}$ may lie in the mechanism by which fine-grained particles travel to the seafloor. As Sharma et al. (1987) also concluded that ${ }^{10} \mathrm{Be}$ was carried by micron-sized aluminosilicates, they hypothesized that these smaller phases aggregate into large particulate masses (i.e., $>80$ $\mu \mathrm{m}$ ), such as through incorporation by fecal pellets. This particle accretion then results in a more rapid settling velocity for the fine ${ }^{10} \mathrm{Be}$-bearing particles. While aggregation could have been an operative mode of vertical transport for the finer phases in the Nile delta sediments, these large conglomerations may not maintain cohesion during laboratory grain size separation, thus masking this process. It is also possible that the occurrence of particle accretion may depend on regional characteristics. Therefore, it seems likely that fine-grained particles scavenge ${ }^{10} \mathrm{Be}$ more effectively than individual coarse grains, but that larger aggregates of small particles can enhance the flux of these phases in some areas. 
To identify a link between ${ }^{10} \mathrm{Be}$ and particle size in the surficial Middle America Trench sediments, grain size measurements were performed on ten hemipelagic and two ash samples using a laser diffraction particle size analyzer (Table 6). These data were compared to the bulk sample ${ }^{10} \mathrm{Be}$ concentrations. All sediments measured for grain size were EW0104 core samples. By comparing cores that are fairly close geographically, variations in other potential controlling parameters such as particle flux and lithological proportions (i.e., biogenic silica vs. terrigenous clays) are minimized. For example, all EW0104 cores lie outside the high-productivity Costa Rica dome that encompasses the cores offshore of El Salvador and Nicaragua (Fiedler et al., 1991). Future analyses of organic carbon, carbonate, and biogenic silica will confirm the extent to which the EW0104 core samples differ in particle composition.

Using the age-corrected ${ }^{10} \mathrm{Be}$, some distinct relationships with grain size emerged (Figure 18, 19). With the exception of GC43 samples $1-3 \mathrm{~cm}$ and $73-75 \mathrm{~cm}$, which are consistent outliers, ${ }^{10} \mathrm{Be}$ concentrations show a clear negative correlation with increasing median grain size (Figure 18b) and a positive correlation with the proportion of grains less than $32 \mu \mathrm{m}$ (Figure 19). A diameter of $32 \mu \mathrm{m}$ was chosen for comparison with the results of Dominik and Stanley (1993) - this diameter does not represent a specific limit in terms of grain size classifications. The relationship of ${ }^{10} \mathrm{Be}$ with grain size fraction less than $32 \mu \mathrm{m}$ is stronger than that of ${ }^{10} \mathrm{Be}$ with only the fraction less than $10 \mu \mathrm{m}$ (Figure 20a). When grain sizes larger than $32 \mu \mathrm{m}$ are compared to ${ }^{10} \mathrm{Be}$, the positive correlation is no longer maintained (Figure 20b, c). The dependence of ${ }^{10} \mathrm{Be}$ concentration on the fraction less than $32 \mu \mathrm{m}$ implies that above this point, even with the greater surface area in larger grain sizes, additional scavenging will become offset and therefore diluted with respect to concentration by the additional mass of larger particles. Otherwise, there should also be a positive correlation of ${ }^{10} \mathrm{Be}$ with fractions above $32 \mu \mathrm{m}$.

These results confirm the hypothesis that changes in the ${ }^{10} \mathrm{Be}$ concentrations in this region occur via mixing, with more efficient deposition on the seafloor (in terms of concentration) by finer grained particles, combined with dilution by the coarser grained material. The final concentration will ultimately be a result of the competing effects of 
surface area to mass ratio, scavenging time in the water column (i.e., settling velocity), accumulation rate (particle flux), and grain density. As discussed above, finer grained particles are more likely to optimize the surface area to mass ratio with a residence time in the water column that is not greater (or much more so) than that of the ${ }^{10} \mathrm{Be}$ itself; though particle flux of these fractions may still be high at continental margins, the accumulation rates will be less likely to overwhelm the elemental signal (with the obvious exception of clay-rich turbidite flows). Larger particles have smaller surface area to mass ratios and higher settling velocities (and therefore are less effective at scavenging relative to final concentration). Typical coarse grained particle lithologies at this margin may also be more likely to have high accumulation rates (i.e., volcanic ash layers), therefore acting as a consistent diluent of ${ }^{10} \mathrm{Be}$ concentrations during deposition. The overall degree of dilution will depend on the proportion of larger grain sizes.

If grain size is a dominant control, this could potentially have the effect of linking ${ }^{10} \mathrm{Be}$ with certain compositional phases - clays and organic matter are finer grained compared to foraminifera and diatoms. Therefore, in determining the preferential partitioning of ${ }^{10} \mathrm{Be}$ with particle lithologies, it will always be necessary to consider the dependence of grain size on composition (Chase et al., 2002). The compositional effect of particles on the scavenging efficiency of ${ }^{10} \mathrm{Be}$ may be the source of the deviation of GC43 samples from the grain size trend of the other EW0104 samples. If GC43 were more rich in opal, a phase shown by Chase et al. $(2002,2003)$ to be a preferential scavenger of ${ }^{10} \mathrm{Be}$, this might have the dual result of increasing average grain size while offsetting the general dilution effect that higher grain sizes would normally have on sedimentary ${ }^{10} \mathrm{Be}$ concentrations in this region.

\section{Conclusions}

${ }^{10} \mathrm{Be}$ concentrations in shallow sediments seaward of the Middle America Trench do not exhibit the same magnitude of variability observed in the Central American Volcanic Arc. Maximum ${ }^{10} \mathrm{Be}$ concentrations in sediments offshore of northwestern Costa Rica are less than $20 \%$ smaller than maximum ${ }^{10} \mathrm{Be}$ concentrations in sediments offshore of 
Nicaragua, and the entire range in the cores offshore of Costa Rica is comparable to sediments offshore of Guatemala and El Salvador. In contrast, ${ }^{10} \mathrm{Be}$ concentrations in arc lavas between southeastern Nicaragua and northwestern Costa Rica decrease by an order of magnitude (e.g., Morris et al., 1990). In the absence of a significant variability in the incoming trench sediments to explain the arc volcanic pattern of ${ }^{10} \mathrm{Be}$, along-strike changes in sediment dynamics (i.e., complete sediment subduction vs. underplating) are a potential source of the large disparity in arc volcanic ${ }^{10} \mathrm{Be}$, at least between southeastern Nicaragua and northwestern Costa Rica (e.g., Chapter II). Rather than relying solely on two deep drill cores to represent the entire region, the quantification of ${ }^{10} \mathrm{Be}$ concentrations in surficial sediments along the length of the arc provides information necessary to establishing a detailed mass balance for each segment of the arc.

Smaller scale variability in sedimentary ${ }^{10} \mathrm{Be}$ concentrations appears to be primarily due to mixing between young, volcanogenic particles and mature, detrital material such as terrigenous clays. The association of higher ${ }^{10} \mathrm{Be}$ concentrations with the clay endmember may be caused by the more efficient scavenging ability of particles $<32 \mu \mathrm{m}$ in diameter compared to coarser grained material. The effect of particle composition (i.e., lithogenic, biogenic, or organic) on ${ }^{10} \mathrm{Be}$ partitioning is unknown for these sediments. ${ }^{10} \mathrm{Be}$ is decoupled from ${ }^{9} \mathrm{Be}$, which shows a strong correlation with detrital (and therefore terrigenous) elements. However, ${ }^{10} \mathrm{Be}$ also appears unrelated to elements that co-vary with biogenic activity. It seems likely that grain size controls on ${ }^{10} \mathrm{Be}$ concentrations will be dominant within a region such as the Middle America Trench where particle flux and the relative distribution of particle compositions may not change significantly. The association of ${ }^{10} \mathrm{Be}$ with finer grained phases may be offset if there is a significant local addition of a different highly adsorptive phase, such as opal, that is not homogeneous throughout the region. These initial efforts in exploring the depositional systematics of ${ }^{10} \mathrm{Be}$ for this region will lay the groundwork for future studies that require isolating specific controls on ${ }^{10} \mathrm{Be}$ concentrations in seafloor sediments. 


\begin{tabular}{|c|c|c|}
\hline 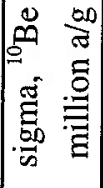 & $\pm 0 \%$ & 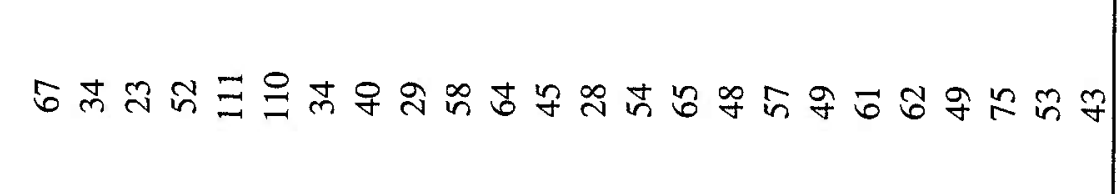 \\
\hline 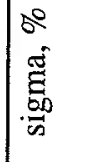 & $\bar{m} \sharp a$ & 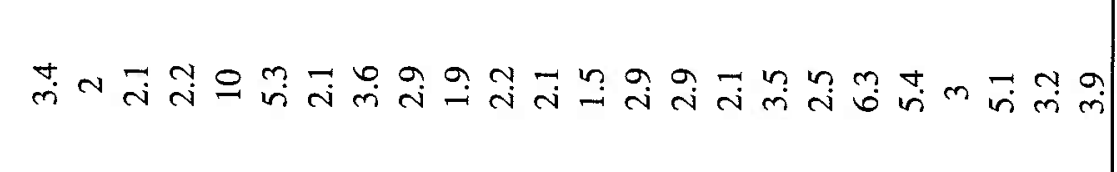 \\
\hline 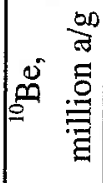 & 声㠻 & 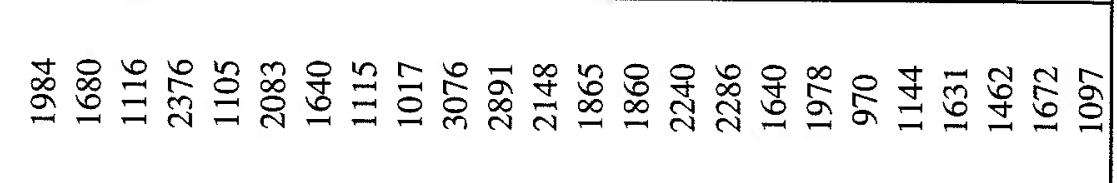 \\
\hline 产 & $-\stackrel{+}{\rightarrow} \stackrel{\infty}{-}$ & 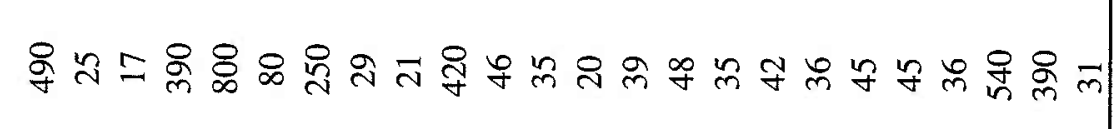 \\
\hline 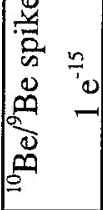 & $\min _{\infty} \underset{\infty}{\infty}$ & 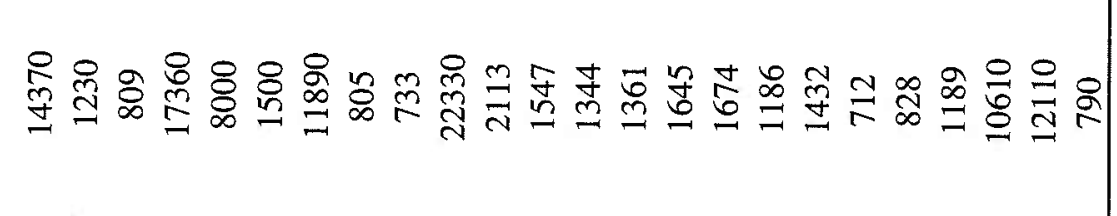 \\
\hline 砶 & $\mid$ & 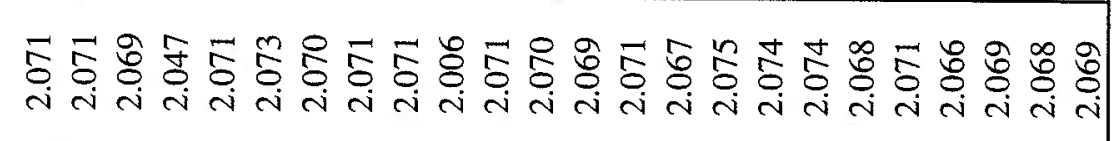 \\
\hline 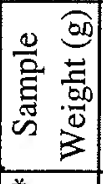 & 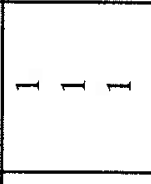 & 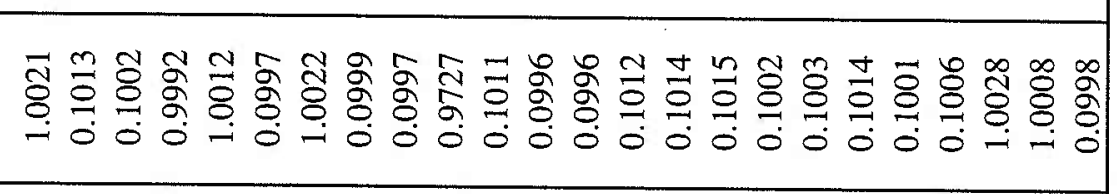 \\
\hline 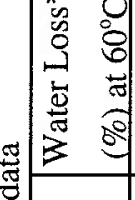 & & $8 B=88$ 요 \\
\hline 䒴 & 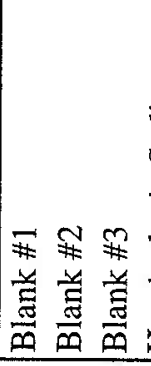 & 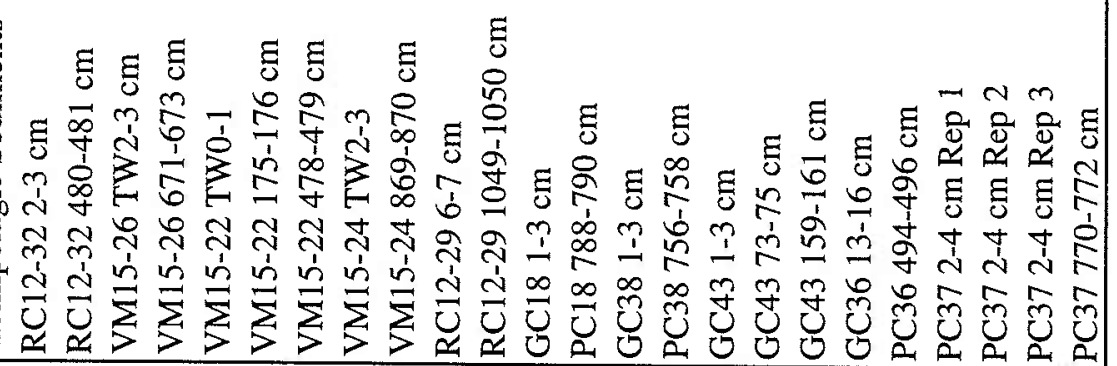 \\
\hline
\end{tabular}




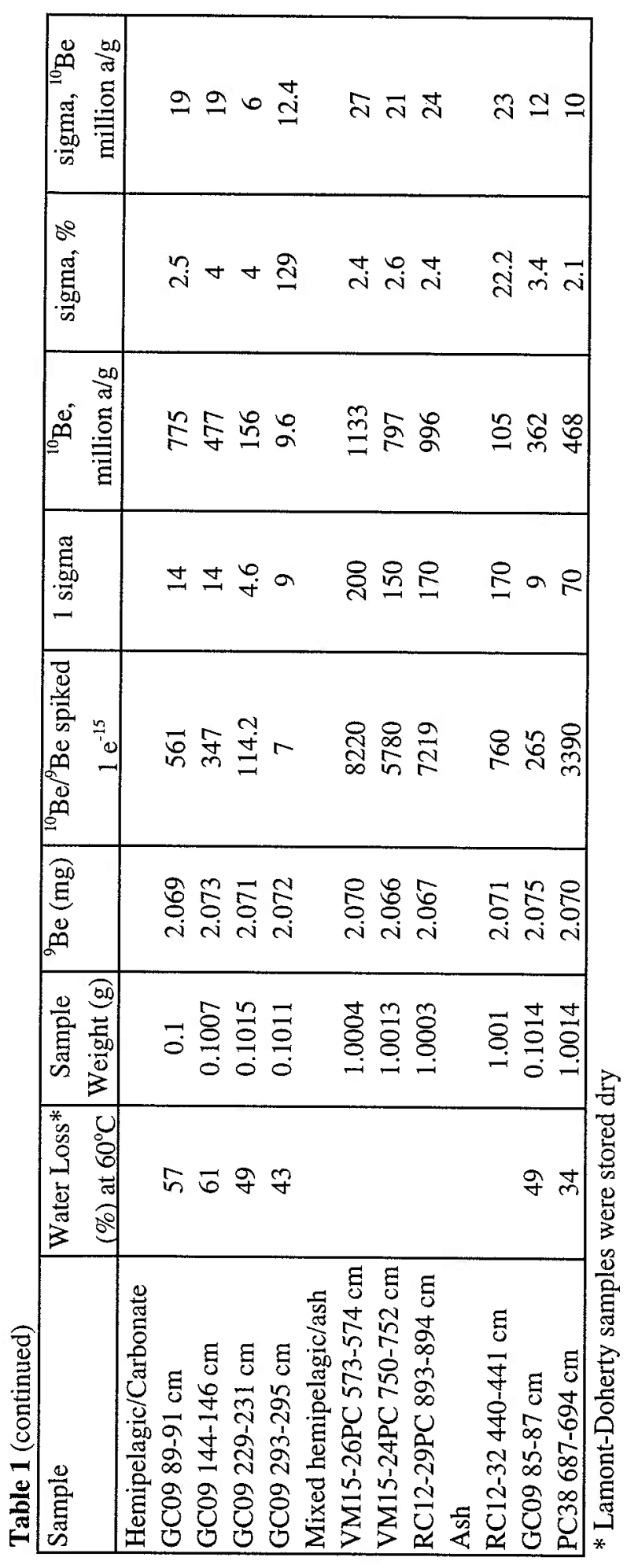


Table $2 \mathrm{Nd}$ and $\mathrm{Sr}$ isotopic data

\begin{tabular}{|l|c|c|c|c|}
\hline Sample & ${ }^{143} \mathrm{Nd} /{ }^{144} \mathrm{Nd}$ & 1 sigma & ${ }^{87} \mathrm{Sr} /{ }^{86} \mathrm{Sr}$ & 1 sigma \\
\hline Hemipelagic Sediments & & & & \\
$\mathrm{RC} 12-322-3 \mathrm{~cm}$ & 0.512749 & 8 & 0.705938 & 8 \\
$\mathrm{RC} 12-32480-481 \mathrm{~cm}$ & 0.5127936 & 6 & 0.70616 & 10 \\
$\mathrm{VM} 15-26671-673 \mathrm{~cm}$ & 0.512829 & 5 & 0.706419 & 11 \\
$\mathrm{VM} 15-22478-479 \mathrm{~cm}$ & 0.512878 & 6 & 0.706869 & 20 \\
VM15-24 869-870 cm & 0.512908 & 6 & 0.707651 & 11 \\
$\mathrm{RC} 12-296-7 \mathrm{~cm}$ & 0.512806 & 7 & 0.707328 & 10 \\
$\mathrm{RC} 12-291049-1050 \mathrm{~cm}$ & 0.512806 & 5 & 0.707482 & 8 \\
GC18 1-3 cm & 0.5128501 & 6 & 0.706312 & 10 \\
$\mathrm{PC} 18788-790 \mathrm{~cm}$ & 0.51286 & 7 & 0.706913 & 11 \\
GC38 1-3 cm & 0.5128618 & 8 & 0.706312 & 11 \\
$\mathrm{PC} 38756-758 \mathrm{~cm}$ & 0.5128854 & 9 & 0.707125 & 10 \\
$\mathrm{GC} 431-3 \mathrm{~cm}$ & 0.51283 & 6 & 0.707016 & 16 \\
GC43 73-75 cm & 0.512902 & 5 & 0.705619 & 28 \\
GC43 159-161 cm & 0.512851 & 6 & 0.70716 & 11 \\
GC36 13-16 cm & 0.5129487 & 7 & 0.706598 & 13 \\
PC36 494-496 cm & 0.5128903 & 7 & 0.706702 & 16 \\
PC37 2-4 cm & & & 0.705962 & 10 \\
PC37 770-772 cm & 0.5128785 & 21 & 0.707405 & 10 \\
Mixed hemipelagic/ash & & & & \\
VM15-26PC 573-574 cm & 0.512919 & 9 & 0.705584 & 11 \\
VM15-24PC 750-752 cm & 0.512924 & 5 & 0.706184 & 11 \\
RC12-29PC 893-894 cm & 0.512885 & 9 & & \\
Ash & & & & \\
RC12-32 440-441 cm & 0.51295 & 9 & 0.704305 & 10 \\
GC09 85-87 cm & 0.512984 & 6 & 0.705046 & 10 \\
PC38 687-694 cm & & & 0.704206 & 10 \\
\hline
\end{tabular}




\begin{tabular}{|c|c|c|c|}
\hline & 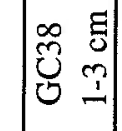 & 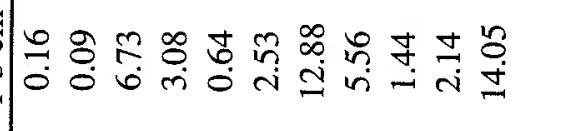 & 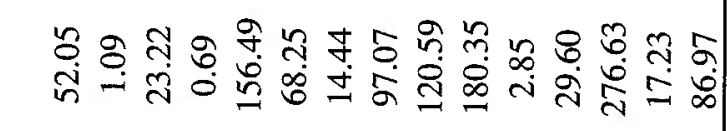 \\
\hline & 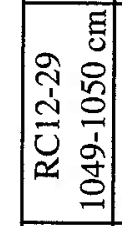 & 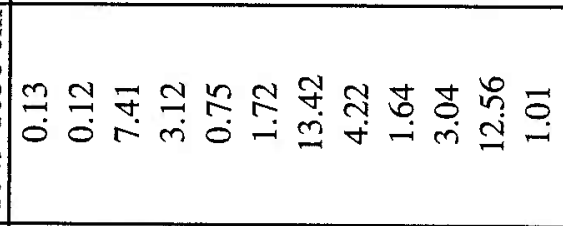 & 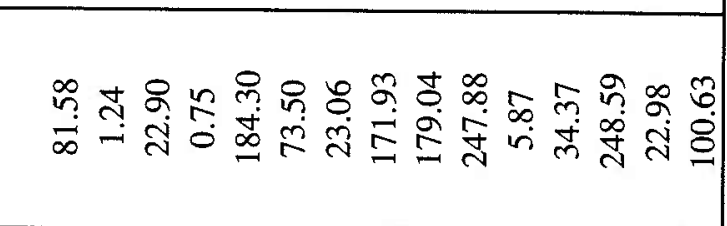 \\
\hline & 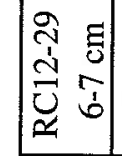 & 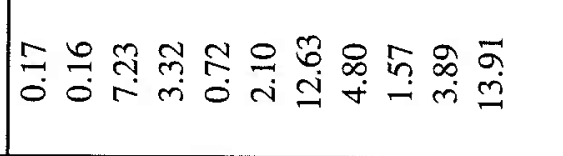 & 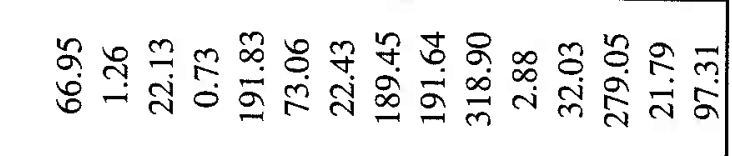 \\
\hline & 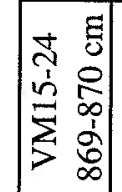 & 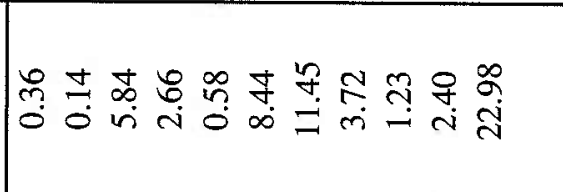 & 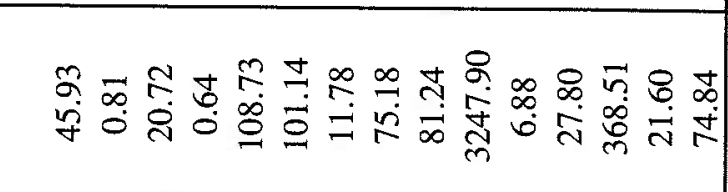 \\
\hline & 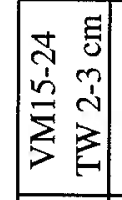 & 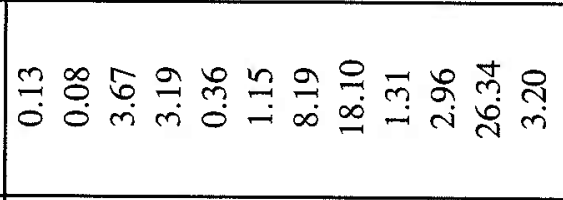 & 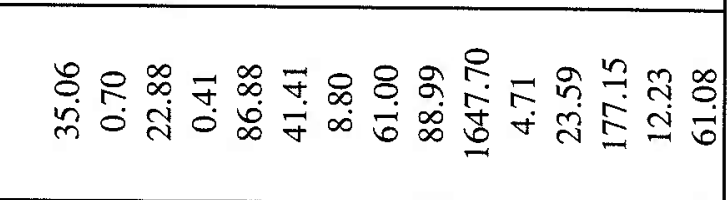 \\
\hline & 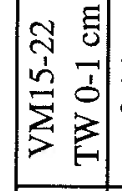 & 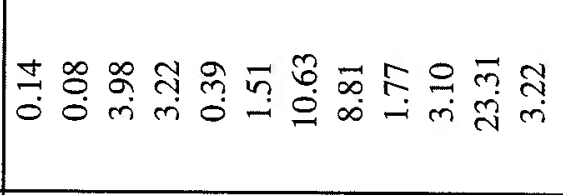 & 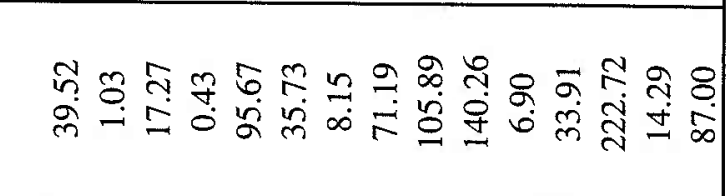 \\
\hline & 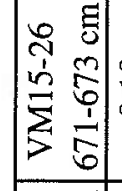 & 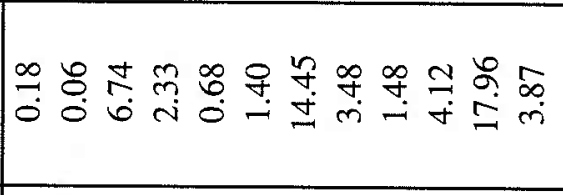 & 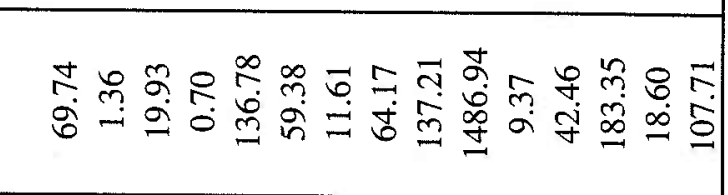 \\
\hline & 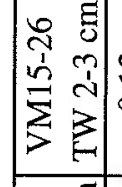 & 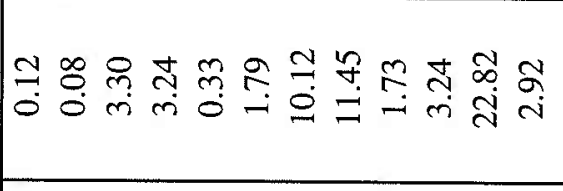 & 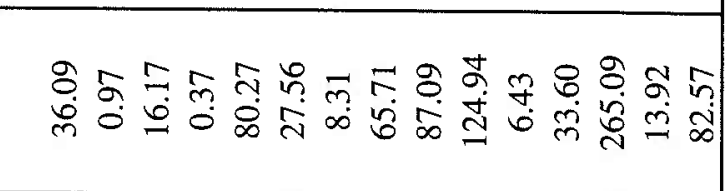 \\
\hline : & 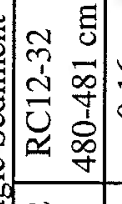 & 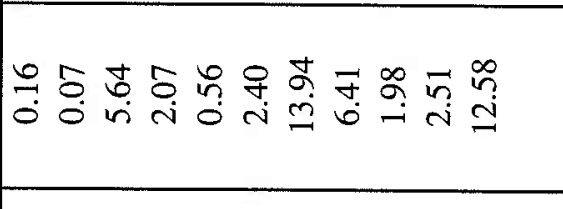 & 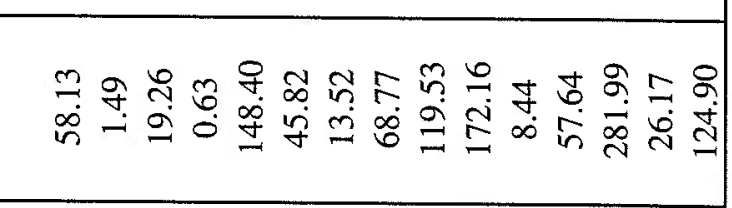 \\
\hline : & 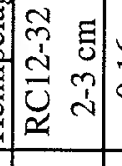 & $\begin{array}{l}0 \\
0 \\
0\end{array}$ & 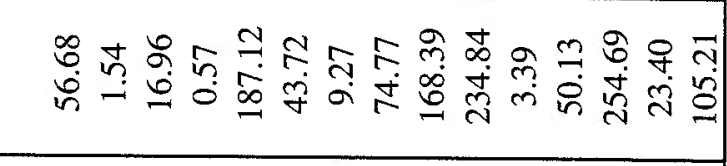 \\
\hline 2 & 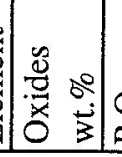 & 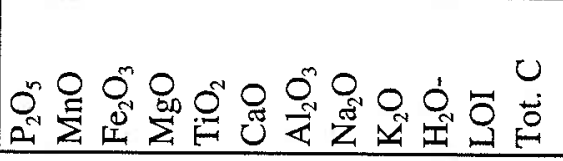 & 氮 \\
\hline
\end{tabular}




\begin{tabular}{|c|c|c|}
\hline & 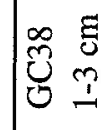 & 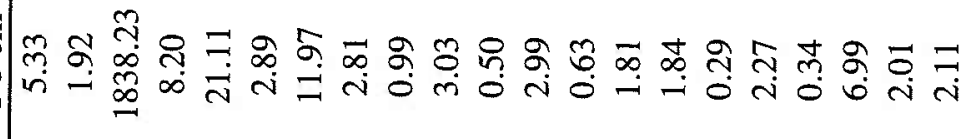 \\
\hline & 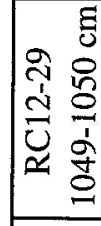 & 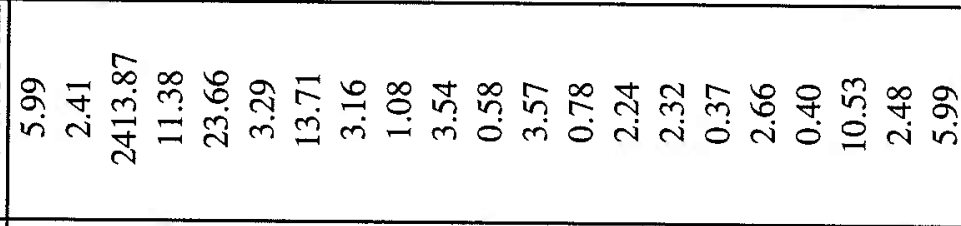 \\
\hline & 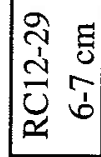 & 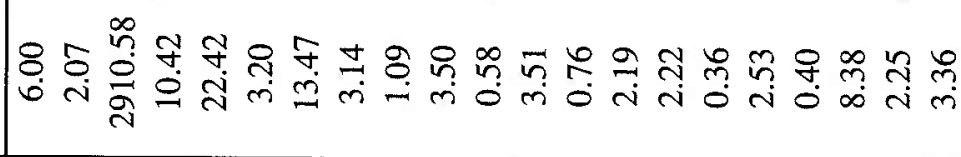 \\
\hline & 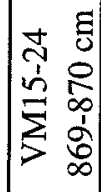 & 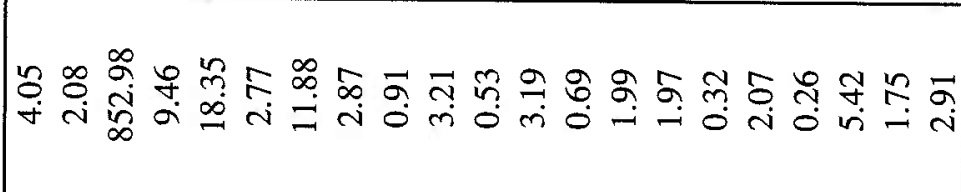 \\
\hline & 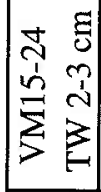 & 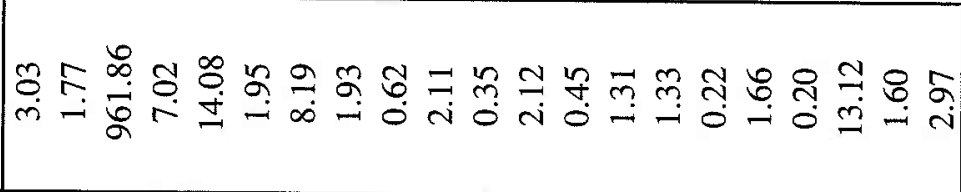 \\
\hline & 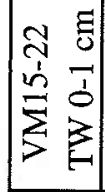 & 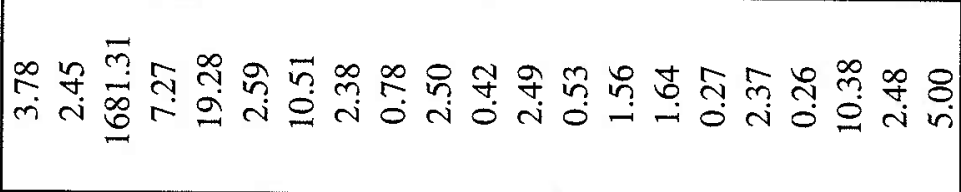 \\
\hline & 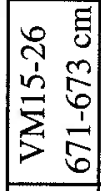 & 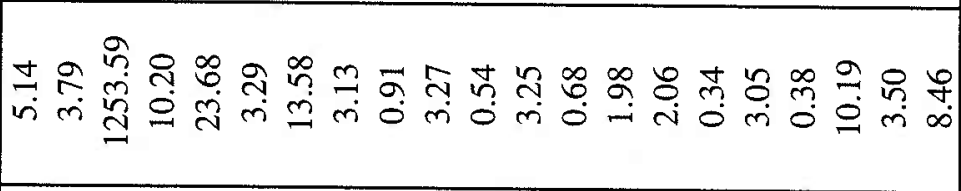 \\
\hline & 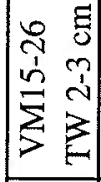 & 市 \\
\hline 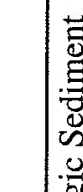 & 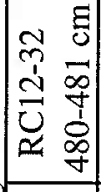 & 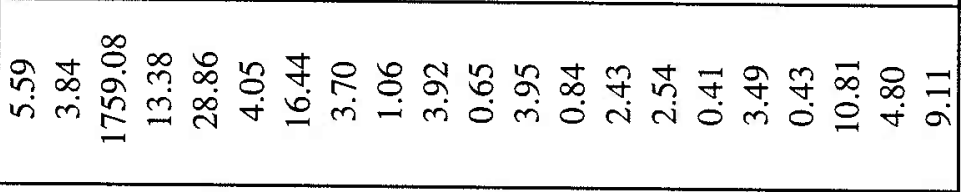 \\
\hline 部离 & 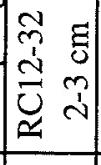 & 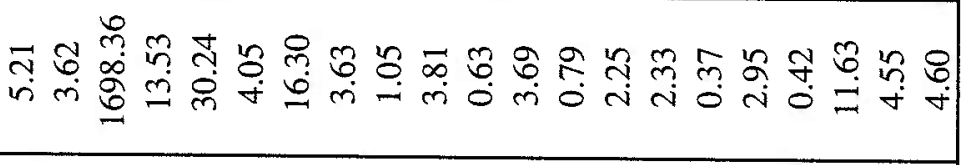 \\
\hline 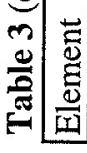 & ह & 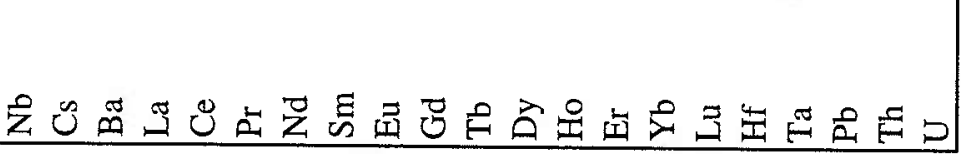 \\
\hline
\end{tabular}




\begin{tabular}{|c|c|c|c|}
\hline & $\mid \begin{array}{rr} & घ \\
\infty & 0 \\
0 & 0 \\
0 & 0 \\
0 & 0 \\
0 & 0\end{array}$ & 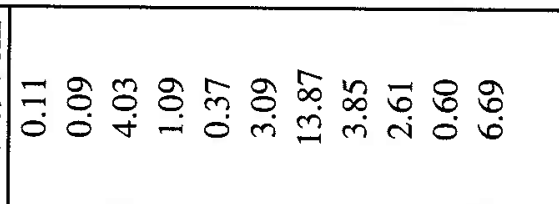 & 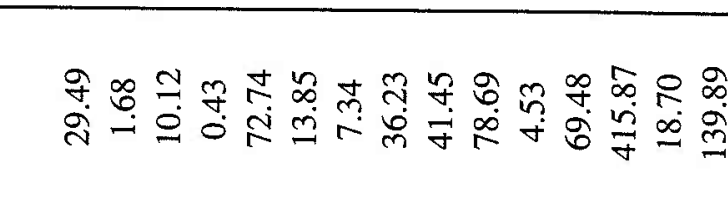 \\
\hline & $\left|\begin{array}{cc}0 \\
0 \\
0 & 0 \\
0 & 0 \\
0 & 0 \\
\infty\end{array}\right|$ & 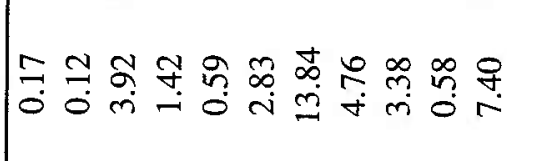 & 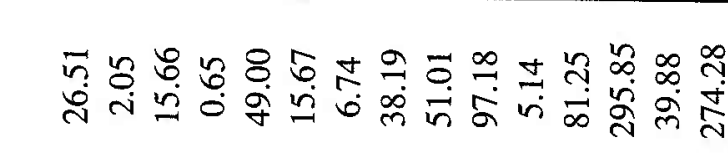 \\
\hline & 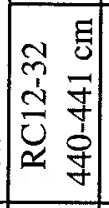 & 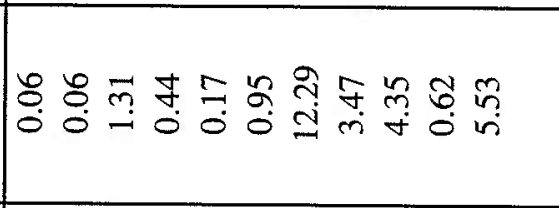 & 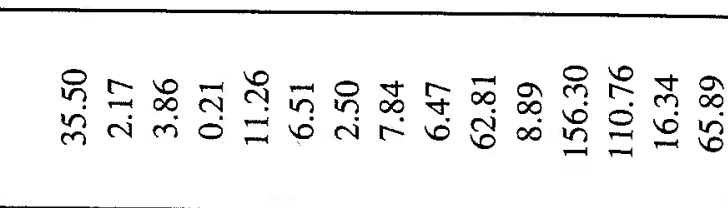 \\
\hline & 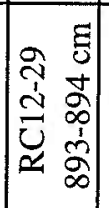 & 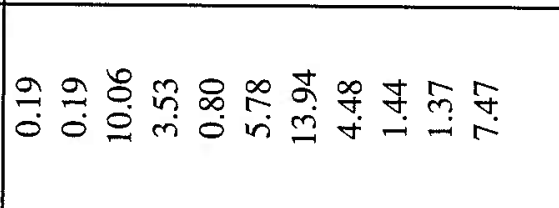 & 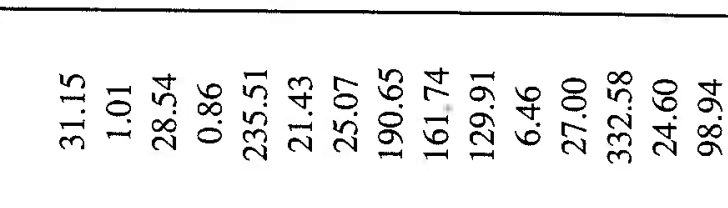 \\
\hline & 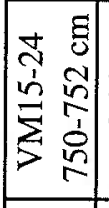 & 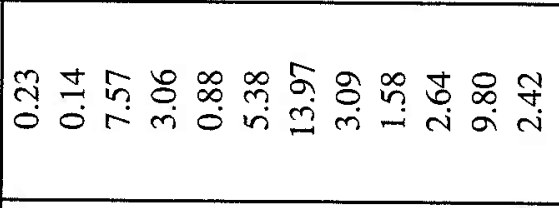 & 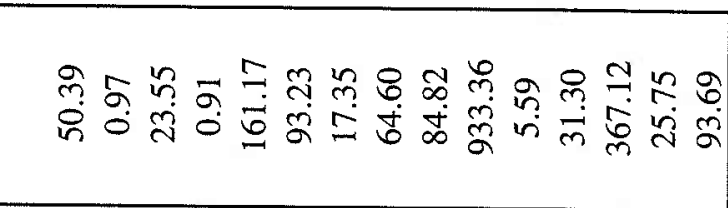 \\
\hline & 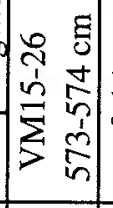 & țo & 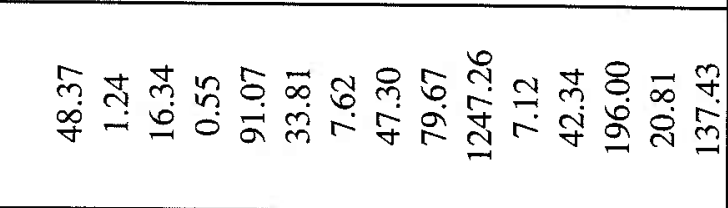 \\
\hline & 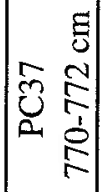 & 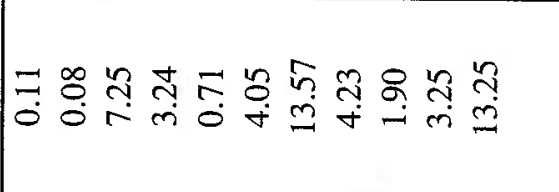 & 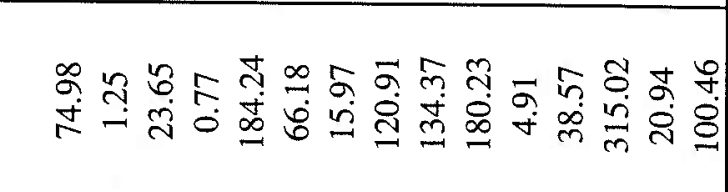 \\
\hline & 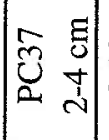 & 응 & 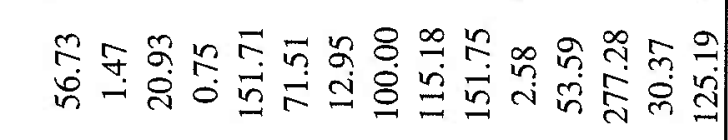 \\
\hline : & 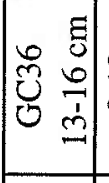 & 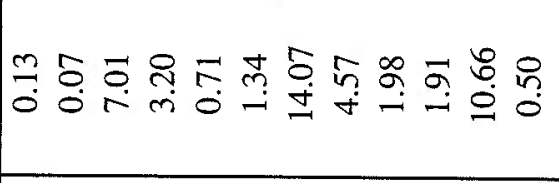 & 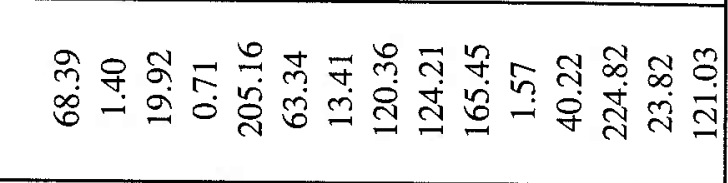 \\
\hline 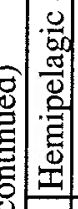 & 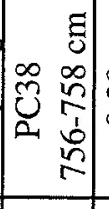 & 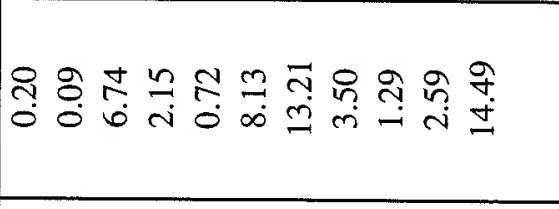 & 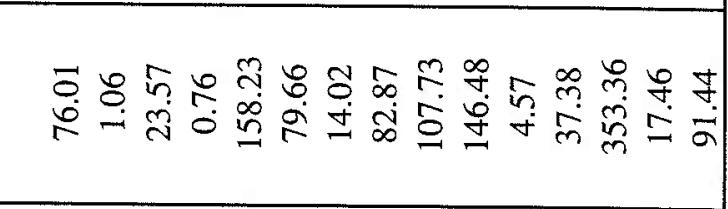 \\
\hline$\frac{0}{\square}$ & $\left|\begin{array}{cc}0 & 0 \\
\frac{0}{2} & 0 \\
0 & 0 \\
\end{array}\right|$ & 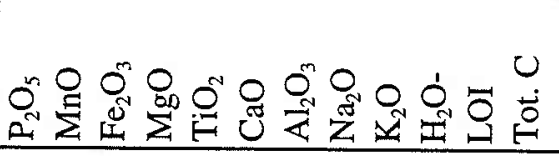 & 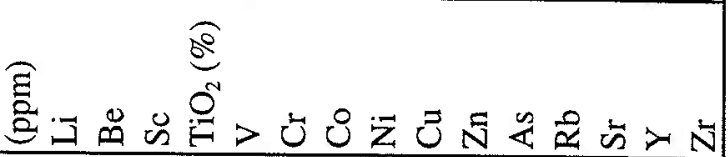 \\
\hline
\end{tabular}




\begin{tabular}{|c|c|c|}
\hline & 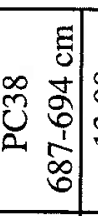 & 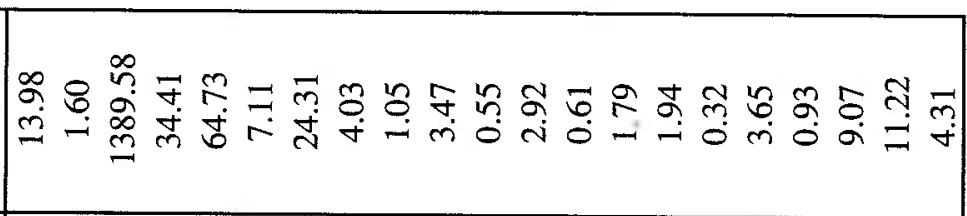 \\
\hline & & 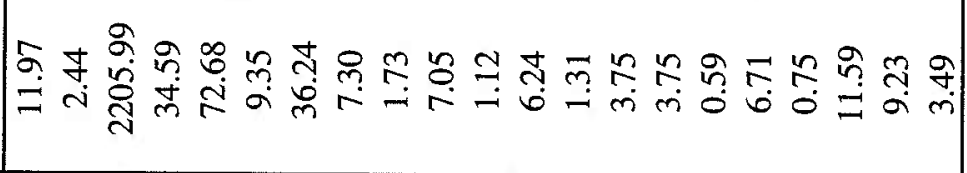 \\
\hline & & 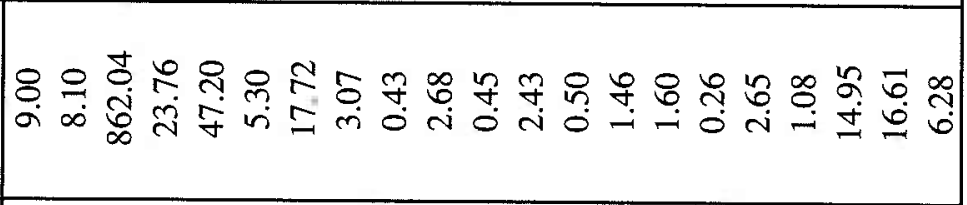 \\
\hline & & 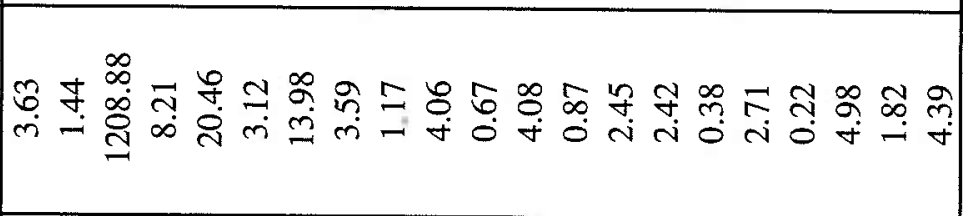 \\
\hline & & لُ \\
\hline & & 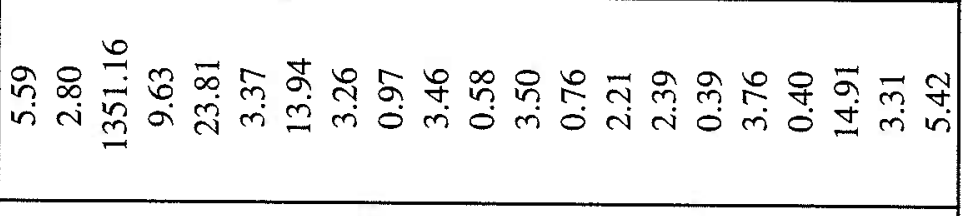 \\
\hline & & 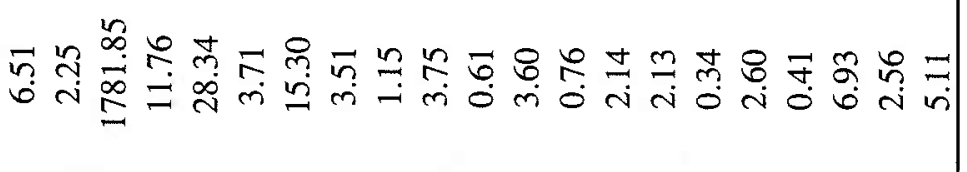 \\
\hline & & 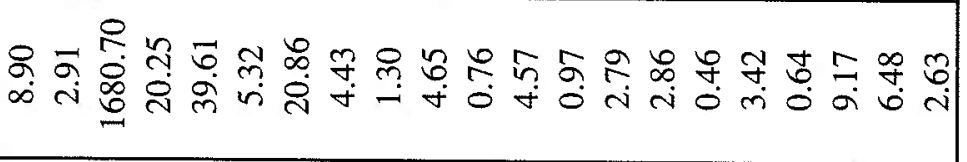 \\
\hline & & 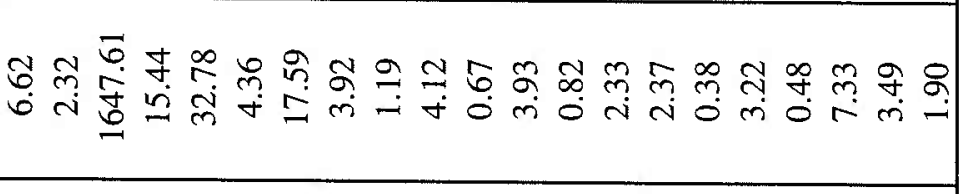 \\
\hline & 象 & 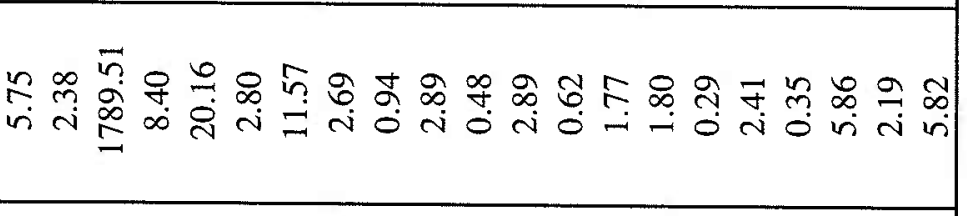 \\
\hline & & \\
\hline
\end{tabular}


Table 4 Age corrected ${ }^{10} \mathrm{Be}$ data

\begin{tabular}{|c|c|c|c|}
\hline Sample & $\begin{array}{l}{ }^{10} \mathrm{Be}, \\
\text { million a/g }\end{array}$ & $\begin{array}{l}\text { Age correction } \\
(\mathrm{yrs})\end{array}$ & $\begin{array}{l}\text { Age corrected }{ }^{10} \mathrm{Be} \\
\text { million atom } / \mathrm{g}\end{array}$ \\
\hline \multicolumn{4}{|l|}{ Hemipelagic Sediments } \\
\hline $\mathrm{RC} 12-322-3 \mathrm{~cm}$ & 1984 & none & \multirow{3}{*}{1924} \\
\hline $\mathrm{RC} 12-32480-481 \mathrm{~cm}$ & 1680 & 293,000 & \\
\hline VM15-26 TW2-3 cm & 1116 & none & \\
\hline VM15-26 671-673 cm & 2376 & 329,000 & \multirow[t]{2}{*}{2766} \\
\hline VM15-22 TW0-1 & 1105 & none & \\
\hline VM15-22 $175-176 \mathrm{~cm}$ & 2083 & 87,500 & 2169 \\
\hline VM15-22 478-479 cm & 1640 & 239,000 & \multirow[t]{2}{*}{1831} \\
\hline VM15-24 TW2-3 & 1115 & none & \\
\hline VM15-24 869-870 cm & 1017 & 434,500 & \multirow[t]{2}{*}{1243} \\
\hline $\mathrm{RC} 12-296-7 \mathrm{~cm}$ & 3076 & none & \\
\hline $\mathrm{RC} 12-291049-1050 \mathrm{~cm}$ & 2891 & 174,000 & \multirow[t]{2}{*}{3133} \\
\hline $\mathrm{GC1} 181-3 \mathrm{~cm}$ & 2148 & none & \\
\hline PC18 788-790 cm & 1865 & 193,044 & \multirow[t]{2}{*}{2039} \\
\hline GC38 1-3 cm & 1860 & none & \\
\hline PC38 756-758 cm & 2240 & 164,348 & \multirow[t]{2}{*}{2417} \\
\hline GC43 1-3 cm & 2286 & none & \\
\hline GC43 73-75 cm & 1640 & 15,870 & 1652 \\
\hline GC43 $159-161 \mathrm{~cm}$ & 1978 & 34,565 & \multirow[t]{2}{*}{2010} \\
\hline $\mathrm{GC} 3613-16 \mathrm{~cm}$ & 970 & none & \\
\hline PC36 494-496 cm & 1144 & 129,130 & \multirow[t]{2}{*}{1214} \\
\hline PC37 2-4 cm Rep 1 & $1588^{*}$ & none & \\
\hline PC37 770-772 cm & 1097 & 167,391 & \multirow[t]{6}{*}{1185} \\
\hline GC09 89-91 cm & 775 & age uncertain & \\
\hline GC09 144-146 cm & 477 & age uncertain & \\
\hline GC09 229-231 cm & 156 & age uncertain & \\
\hline GC09 293-295 cm & 9.6 & age uncertain & \\
\hline Mixed hemipelagic/ash & & & \\
\hline VM15-26PC 573-574 cm & 1133 & 279,000 & 1289 \\
\hline VM15-24PC $750-752 \mathrm{~cm}$ & 797 & 375,000 & 948 \\
\hline $\mathrm{RC} 12-29 \mathrm{PC} 893-894 \mathrm{~cm}$ & 996 & 148,000 & 1066 \\
\hline $\begin{array}{l}\text { Ash } \\
\text { RC12-32 440-441 cm }\end{array}$ & 105 & 270,000 & 119 \\
\hline $\mathrm{GC} 0985-87 \mathrm{~cm}$ & 362 & 18,478 & 365 \\
\hline PC38 687-694 cm & 468 & 149,348 & 501 \\
\hline
\end{tabular}

* Average of three Replicates 


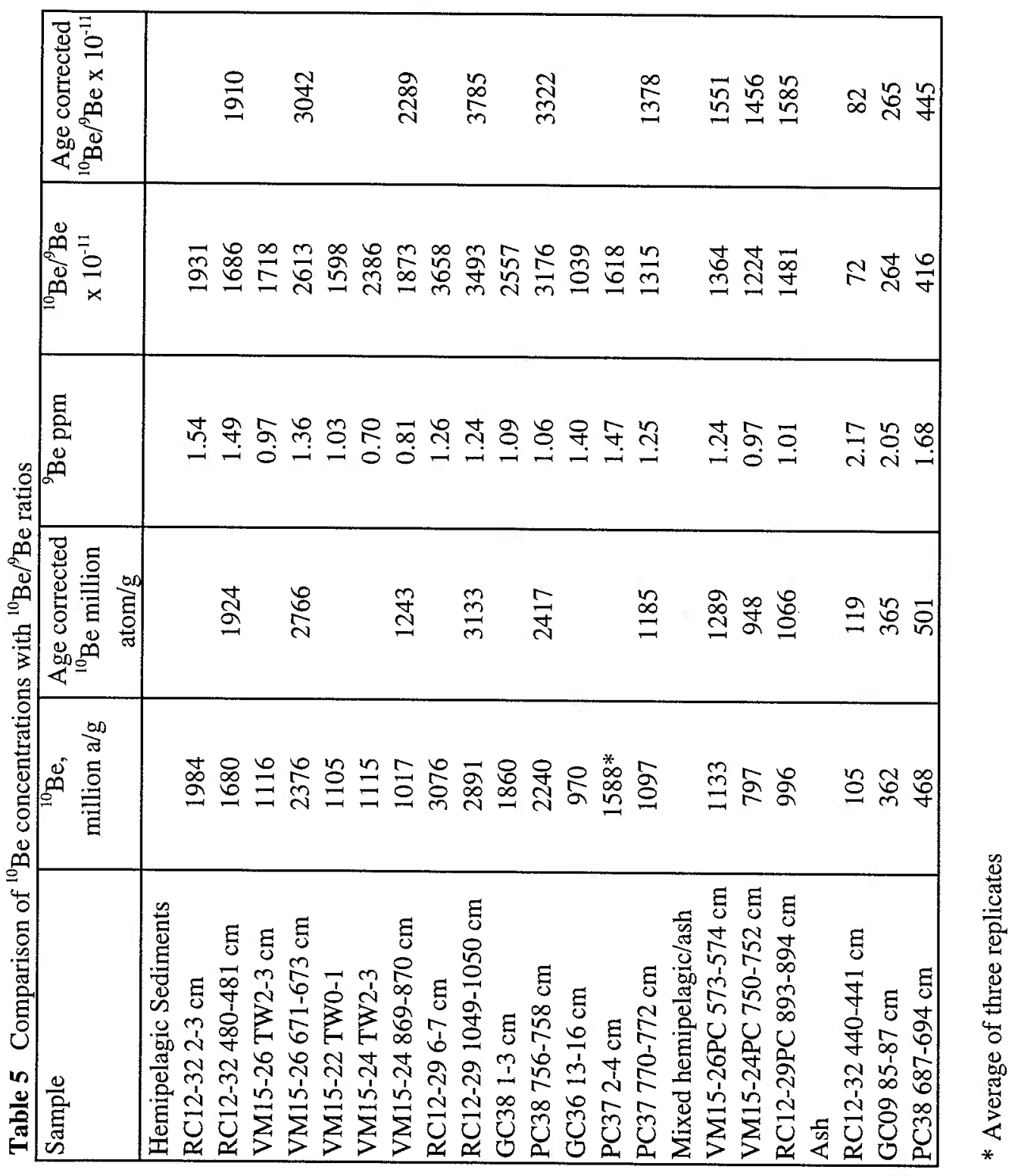




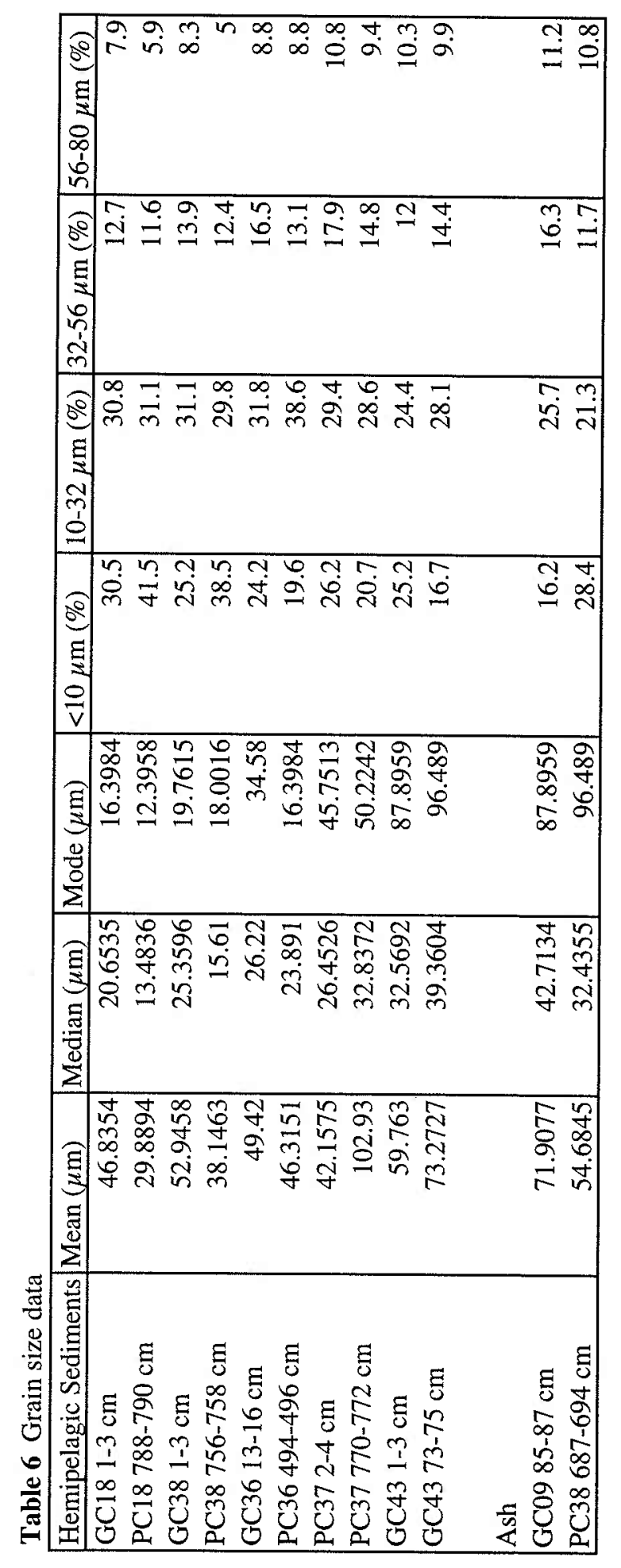


Figure 1. The Central American Volcanic Arc shows a wide range in enrichment, from moderate ${ }^{10} \mathrm{Be} /{ }^{9} \mathrm{Be}$ values in Guatemala to a global high in southeastern Nicaragua. Between Nicaragua and Costa Rica, ${ }^{10} \mathrm{Be} /{ }^{9} \mathrm{Be}$ drops to minimal but measurable enrichment in the northwestern portion before decreasing to values indistinguishable from background. ${ }^{10} \mathrm{Be} /{ }^{9} \mathrm{Be}$ data from Tera et al. (1986), Morris et al. (1990), Reagan et al. (1994), Morris et al. (2002), and Table 1, Chap. II. Symbols: X = Guatemala; Squares $=$ El Salvador; Diamonds = Western Nicaragua; Triangles $=$ Eastern Nicaragua; Circles = Northwestern Costa Rica; + = Central Costa Rica. 


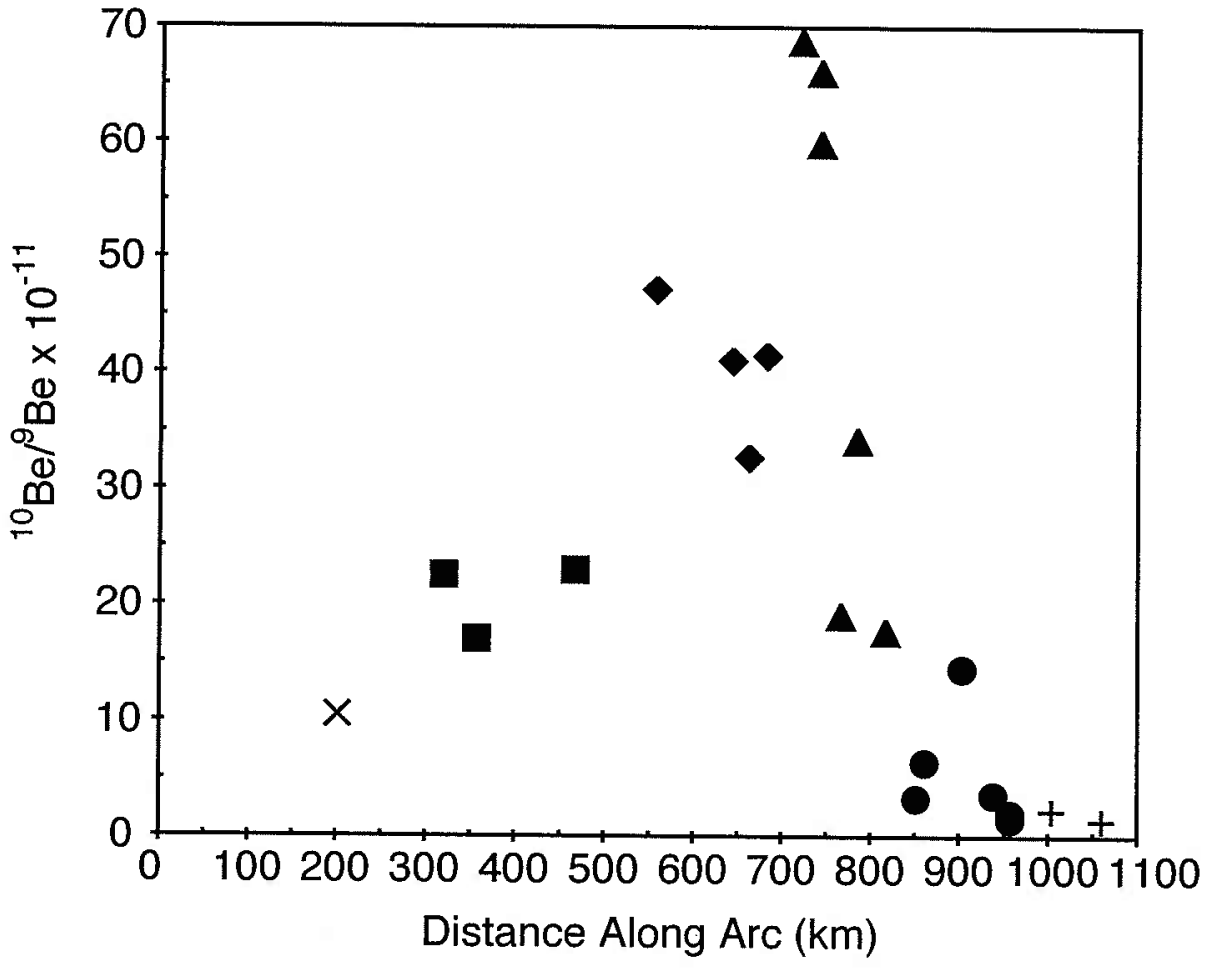


Figure 2. The principal subduction controls on ${ }^{10} \mathrm{Be}$ enrichment in arc volcanics are (1) variations in sedimentary ${ }^{10} \mathrm{Be}$ on the downgoing plate (2) convergence rates (3) subduction style such as offscraping, underplating, and tectonic erosion (4) geochemical processes during magmatic sediment incorporation. 


\section{Processes that Affect ${ }^{10}$ Be Enrichment in Arc Volcanics \\ in Arc Volcanics \\ 3}

(1) Variations in ${ }^{10} \mathrm{Be}$ concentrations in subducted

(2) sediment

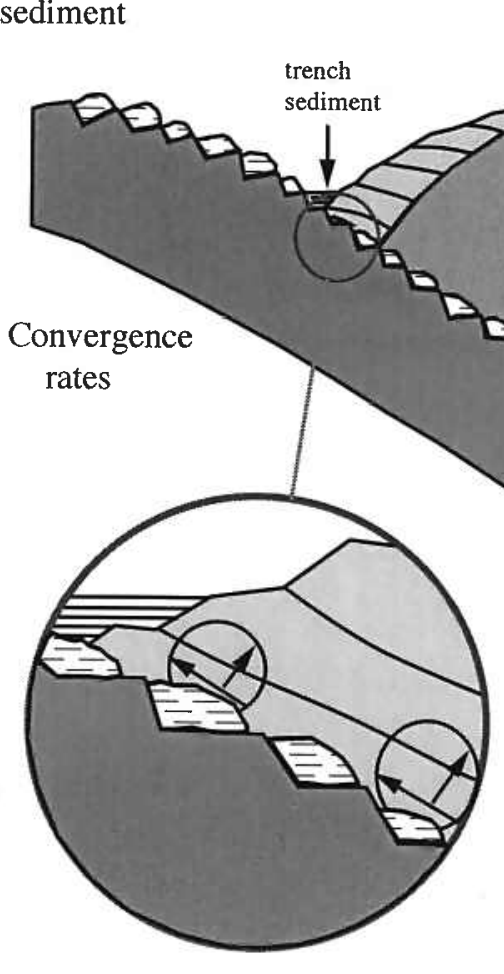

(3) Offscraping, underplating, or tectonic erosion

3 
Figure 3. Piston and gravity cores located seaward of the trench were collected by the R/V Robert Conrad (RC12 samples), the R/V Vema (VM15 samples), and the R/V Ewing (EW0104 samples). Samples were taken for analysis of ${ }^{10} \mathrm{Be}$ to span the geographic and depth ranges of these cores. DSDP Site 495 and ODP Site 1039 are shown for reference. 


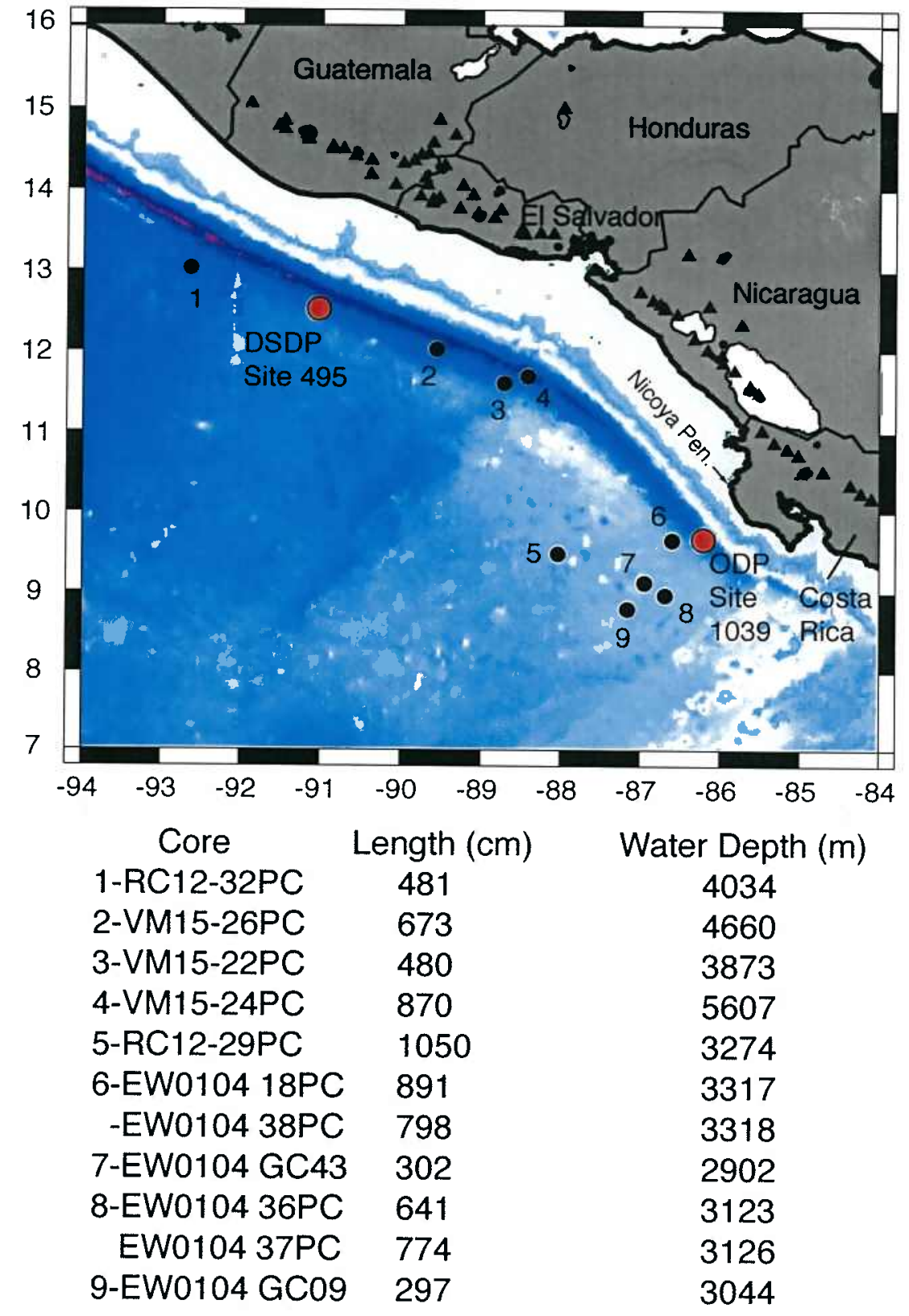


Figure 4. A) DSDP Site 495 offshore of Guatemala and B) ODP Site 1039 offshore of Costa Rica exhibit differences in the profile of ${ }^{10} \mathrm{Be}$ with depth on the order of $\sim 30 \%$. The ${ }^{10} \mathrm{Be}$ concentration in the top layer of the drilled portion ODP Site 1039 is anomalous (with respect to the radioactive decay curve) due to a turbidite layer. Note the upper section of DSDP Site 495 was not recovered (<19.6 mbsf). ${ }^{10} \mathrm{Be}$ data and projected decay curves from Valentine et al. (submitted). 

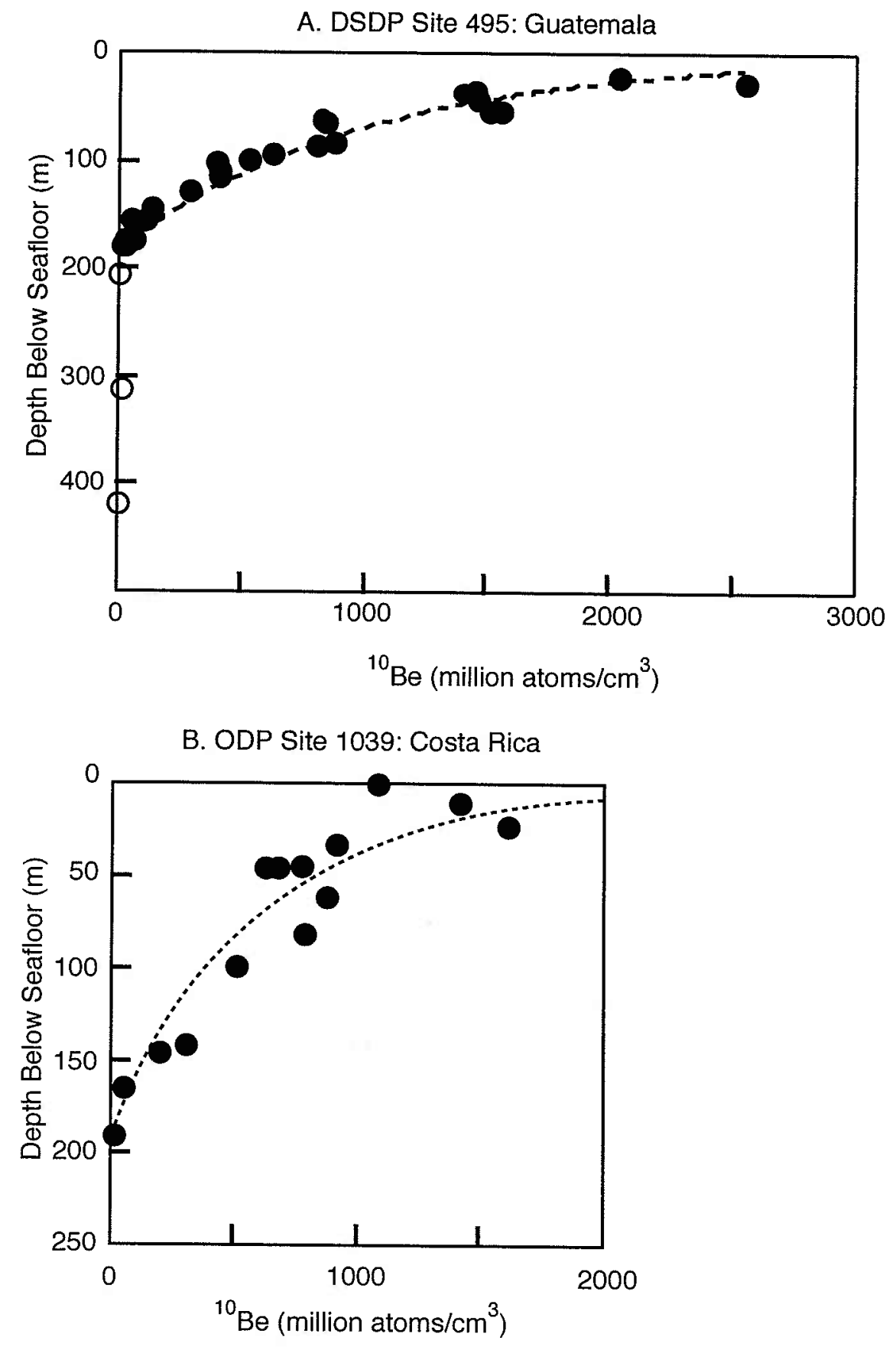
Figure 5. The surficial sediment composition immediately outboard of the Middle America Trench is primarily silty mud. Local areas of pelagic clay and calcareous marl occur offshore of Costa Rica in the southeast. The calcareous marl coincides with the aseismic Cocos Ridge. Recreated from an Office of Naval Research (ONR) sediment map. 

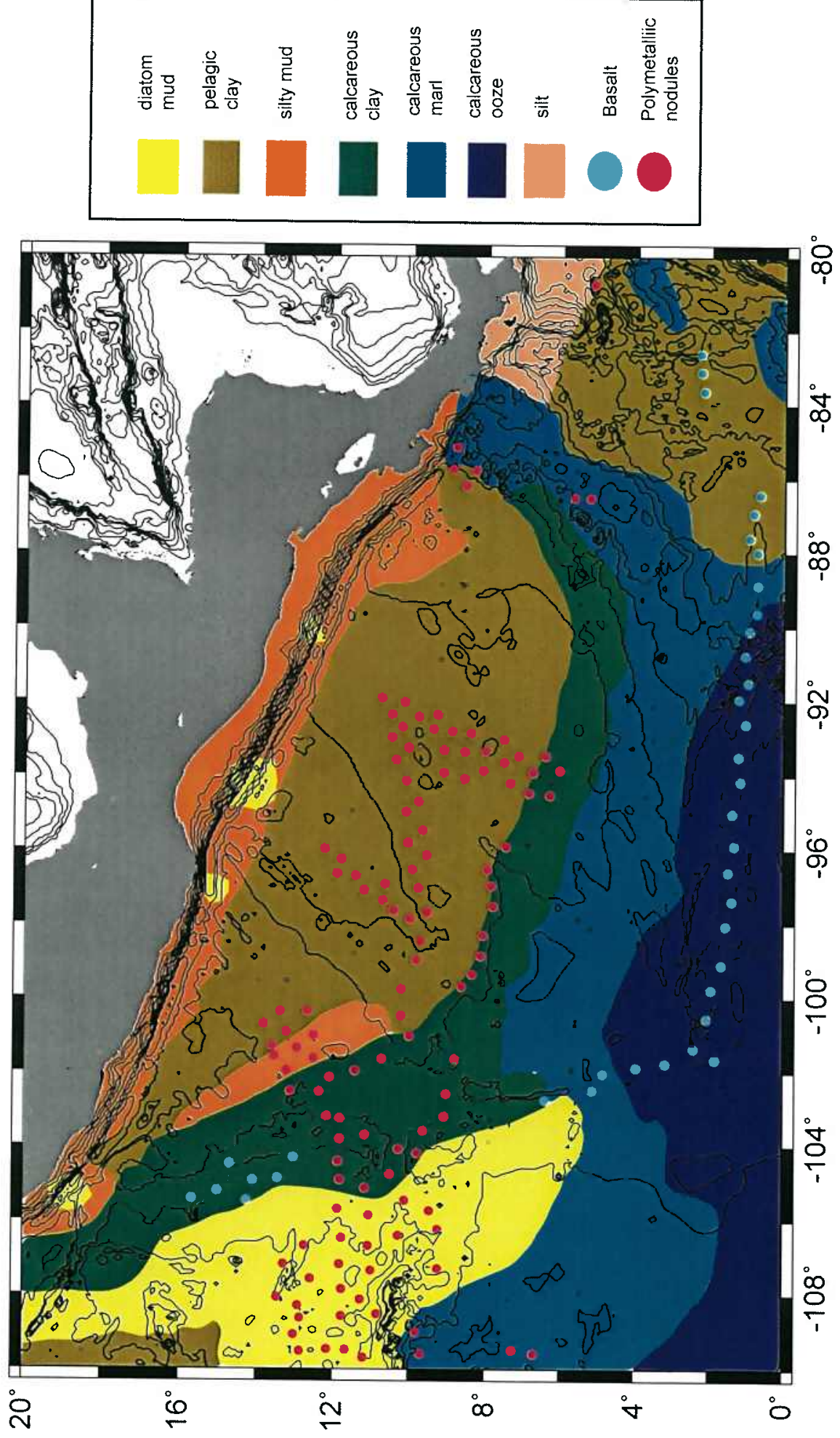
Figure 6. ${ }^{10} \mathrm{Be}$ results are plotted with depth in each core, in the context of the sediment lithologies. The black squares mark the depth in core of each sample on the $y$-axis and ${ }^{10} \mathrm{Be}$ in million atoms/g. ${ }^{10} \mathrm{Be}$ concentrations are initial measurements uncorrected for age or mass. Mixed sediment in VM15-24 indicates heavy minerals/ash laminae present throughout core (see core description in Appendix 1). Mixed sediment in GC09 indicates a transition from hemipelagic clay sediments at shallower depths to carbonate chalk at the bottom of the core. WR = section removed for whole round. 


\section{Lithology Legend}

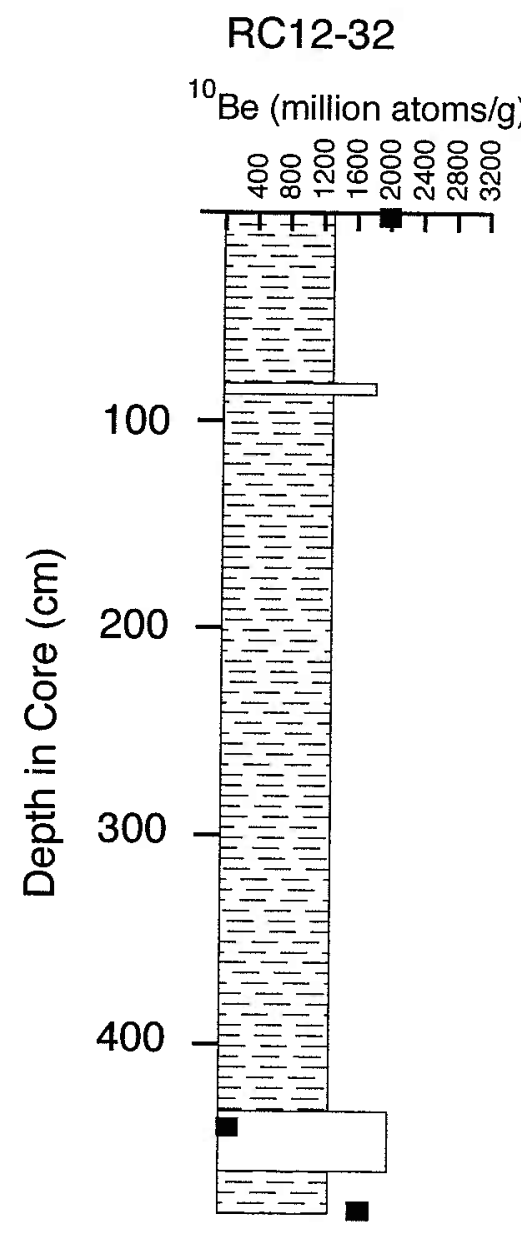

yellowish brown, brown, olive clay $\begin{array}{ll}=z & \text { dark olive gray } \\ = & \text { hemipelagic mud }\end{array}$ mixed sediment nannofossil chalk
VM15-26 TW

${ }^{10} \mathrm{Be}$ (million atoms $/ \mathrm{g}$ )

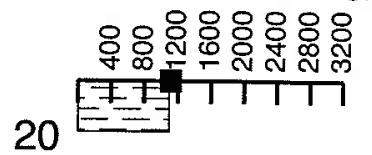

VM15-26

${ }^{10} \mathrm{Be}$ (million atoms $/ \mathrm{g}$ )

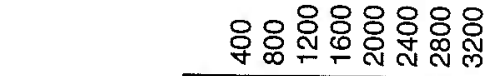

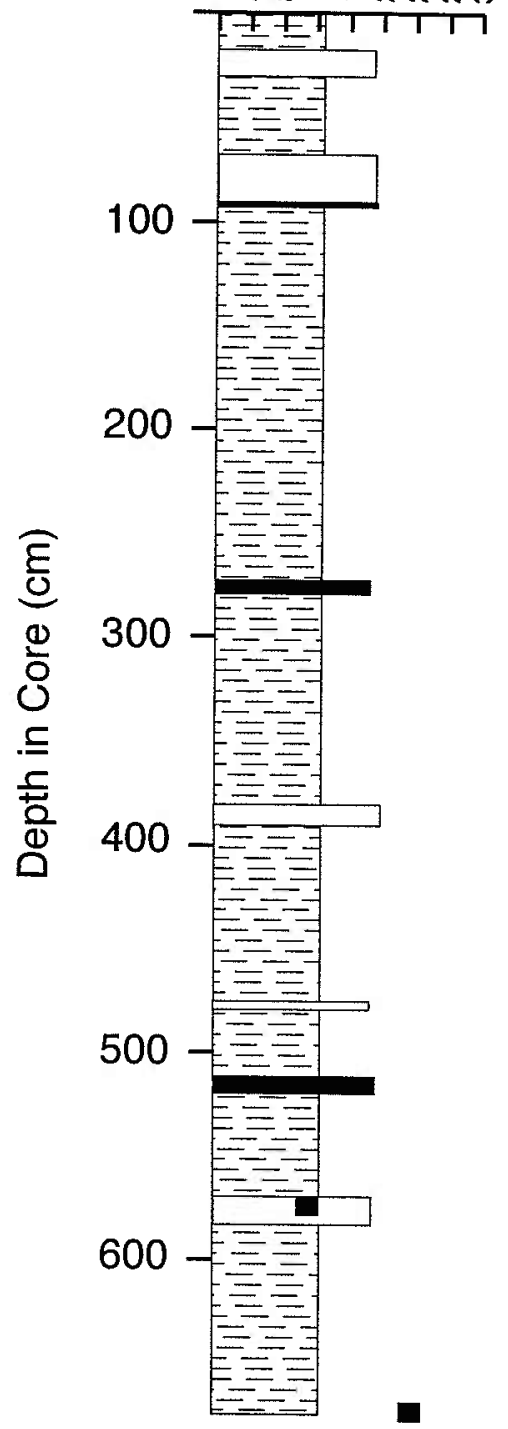

gray/white volcanic ash, bed/burrow

black volcanic ash, bed/burrow 
Figure 6 continued. 

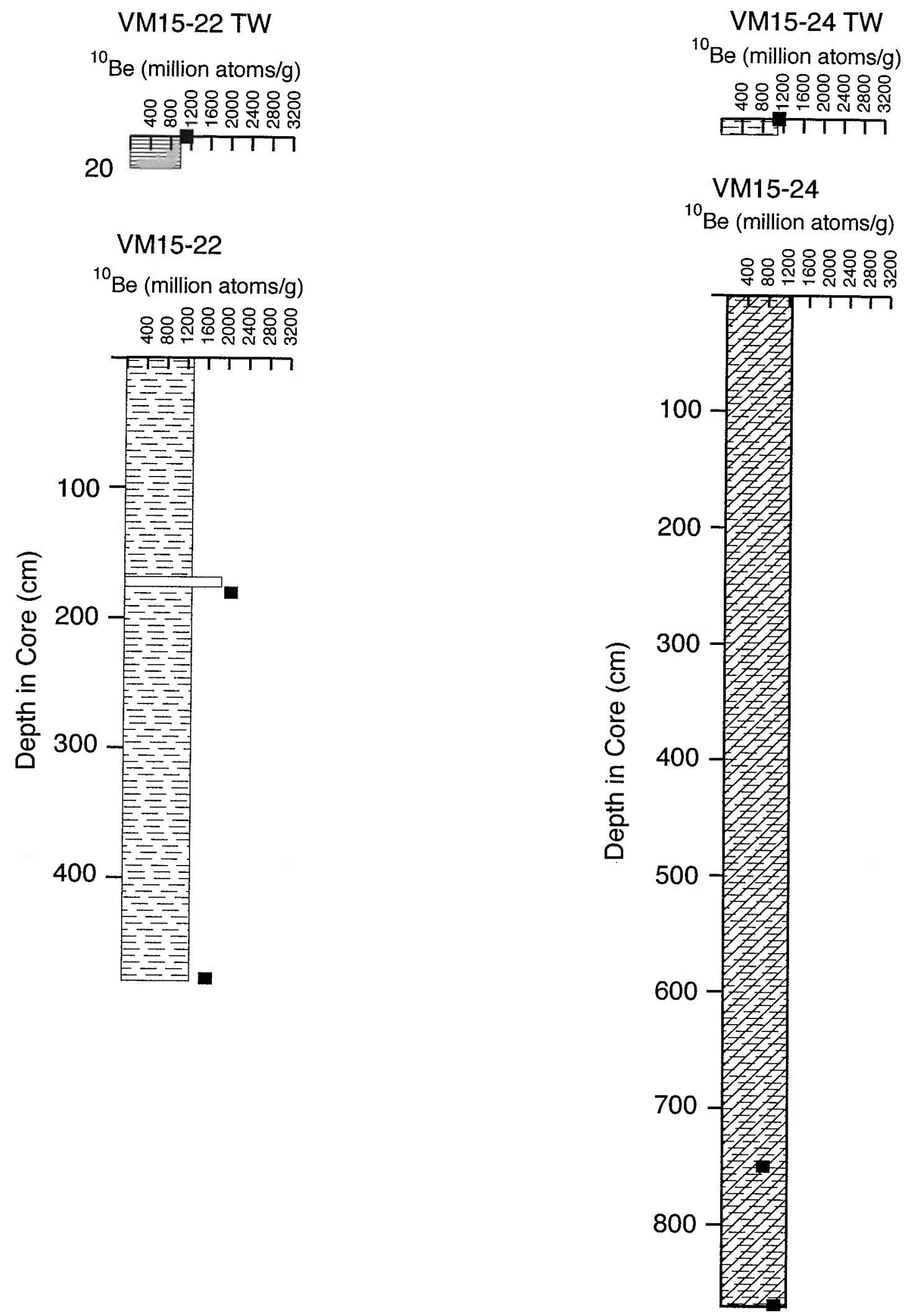
Figure 6 continued. 

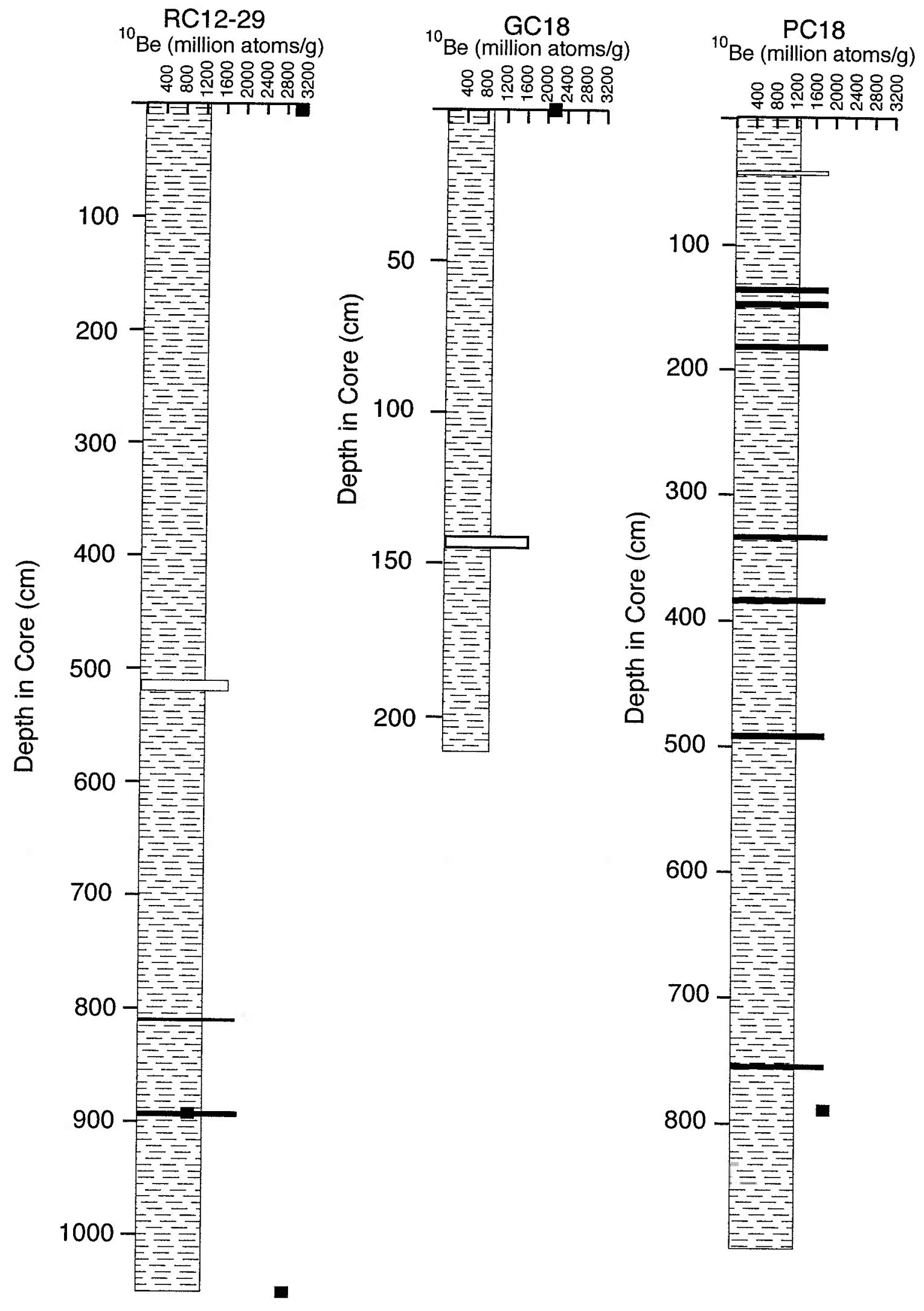
Figure 6 continued. 

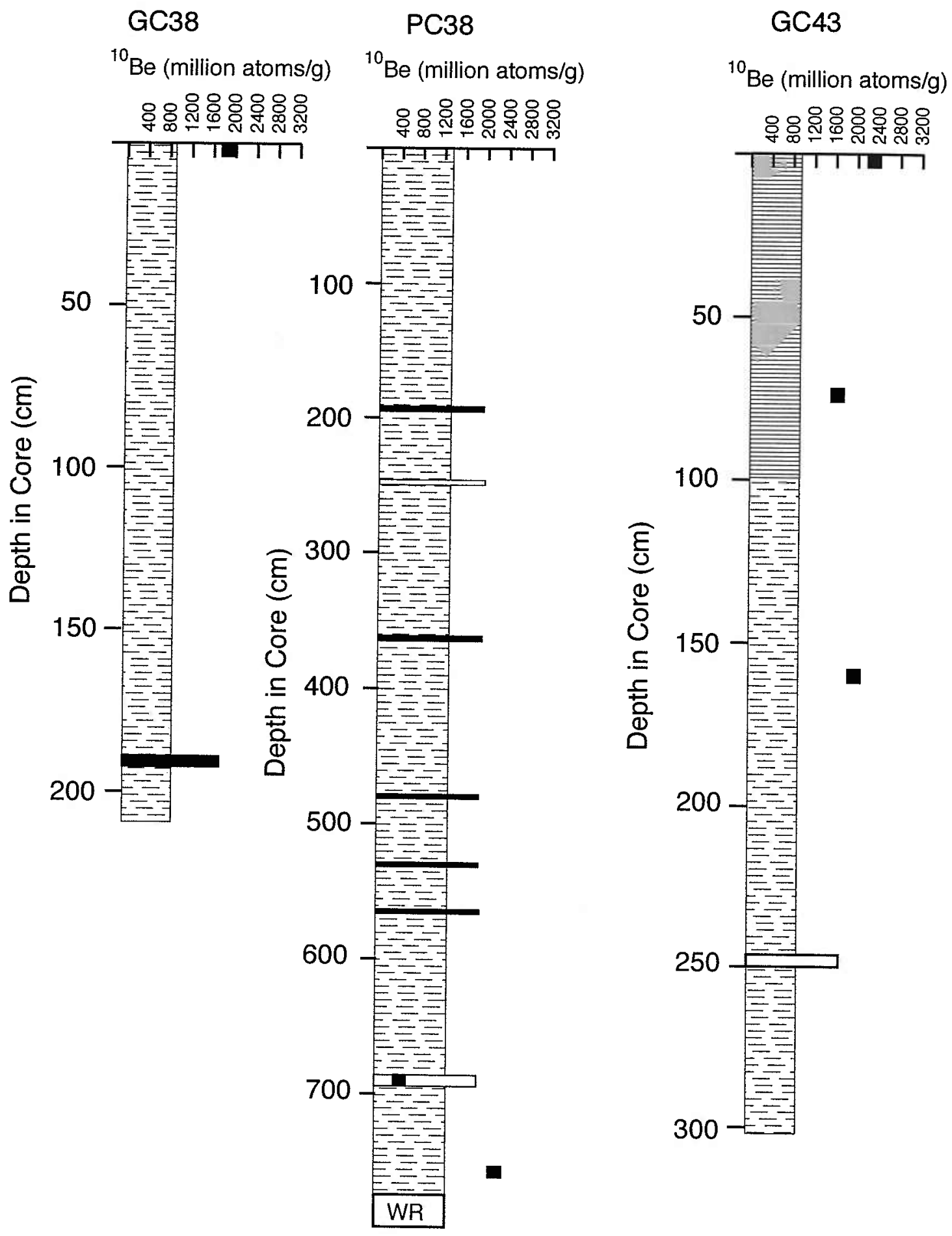
Figure 6 continued. 


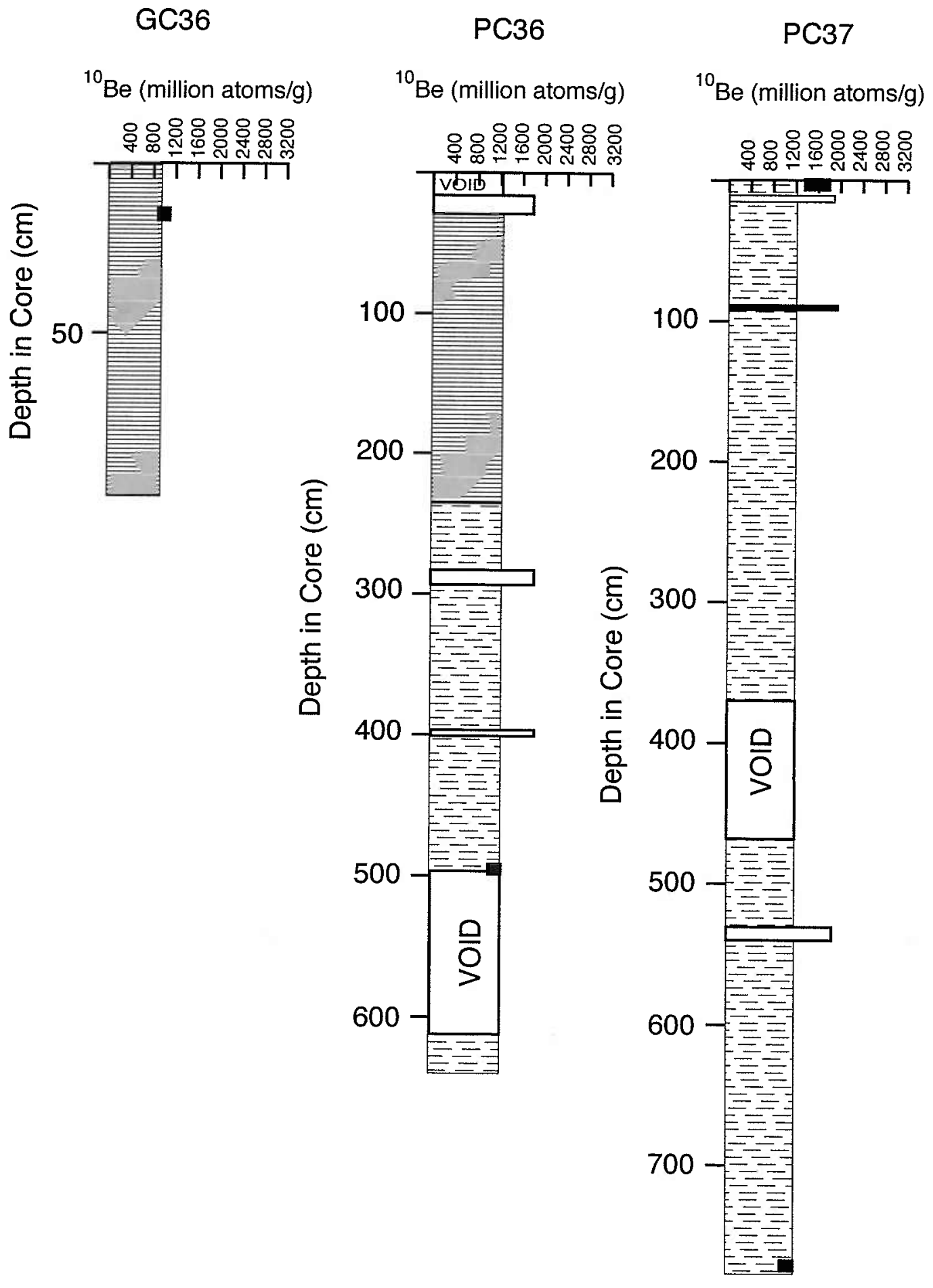


Figure 6 continued. 


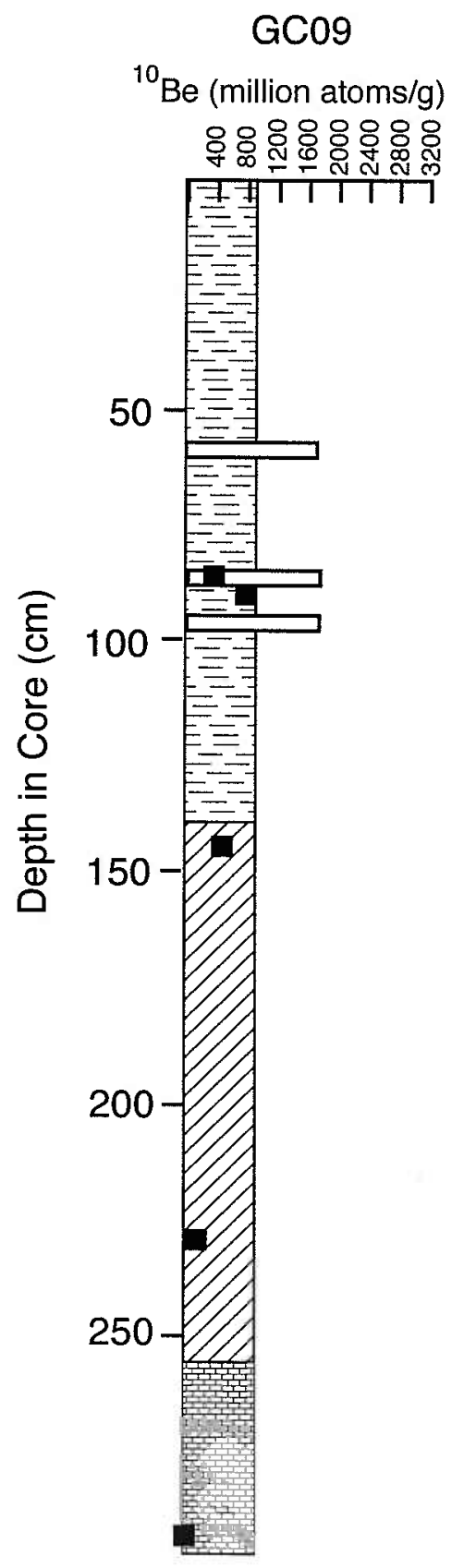


Figure 7. ${ }^{10} \mathrm{Be}$ concentrations from Figure 6 are shown relative to their offshore geographical area. Mix denotes samples that were mixed hemipelagic and ash components. Ash denotes tephra layer that were sampled with little to no hemipelagic sediment. 


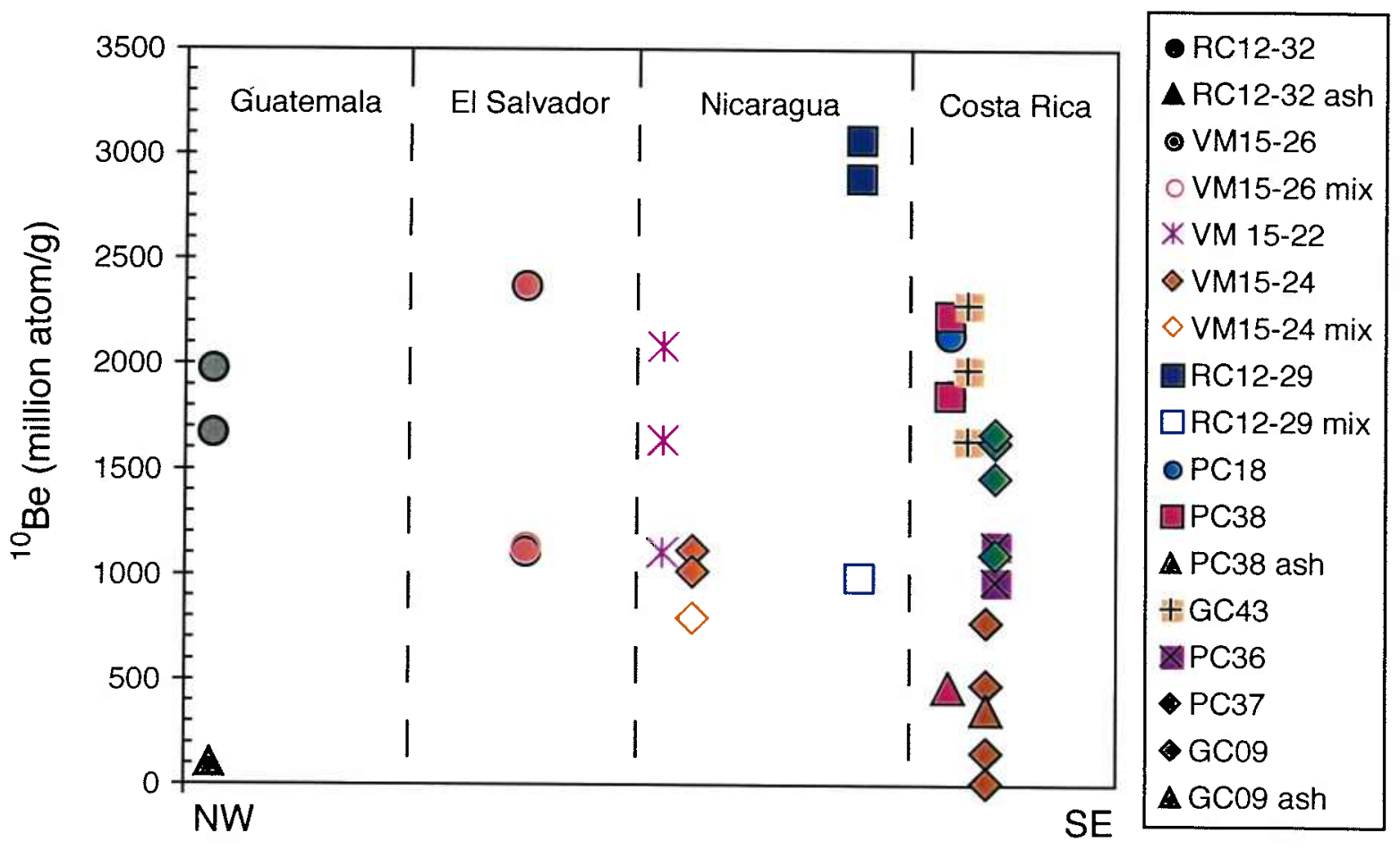


Figure 8. Uncorrected ${ }^{10} \mathrm{Be}$ concentrations are compared to the opposing ${ }^{10} \mathrm{Be} /{ }^{9} \mathrm{Be}$ values for the Central American Volcanic Arc. ${ }^{10} \mathrm{Be}$ data is not age corrected because the intention is to illustrate the current range in ${ }^{10} \mathrm{Be}$ concentrations of shallow sediment subducting at the trench. Brown cylinders represent the core sediments. The top of the dark brown layer (bottom half) marks the minimum measured ${ }^{10} \mathrm{Be}$ concentration for each core, with the top of the light brown layer (top half) for the maximum measured ${ }^{10} \mathrm{Be}$. White cylinder represents the carbonate piston core, GC09. Gray pyramids mark volcanoes for which ${ }^{10} \mathrm{Be} /{ }^{9} \mathrm{Be}$ values exist. The cores are vertically scaled relative to each other, as are the volcanoes, but there is no relationship between the scale for cores and volcanoes. Compared to the magnitude of the variation in the Central American Volcanic Arc, there is no corresponding variation in ${ }^{10} \mathrm{Be}$ concentrations in the subducting sediment. ${ }^{10} \mathrm{Be}$ concentration data for the sediments are given in Table 1. Volcanic ${ }^{10} \mathrm{Be} /{ }^{9} \mathrm{Be}$ data from Morris et al. (1990) and Table 1, Chapter II. 


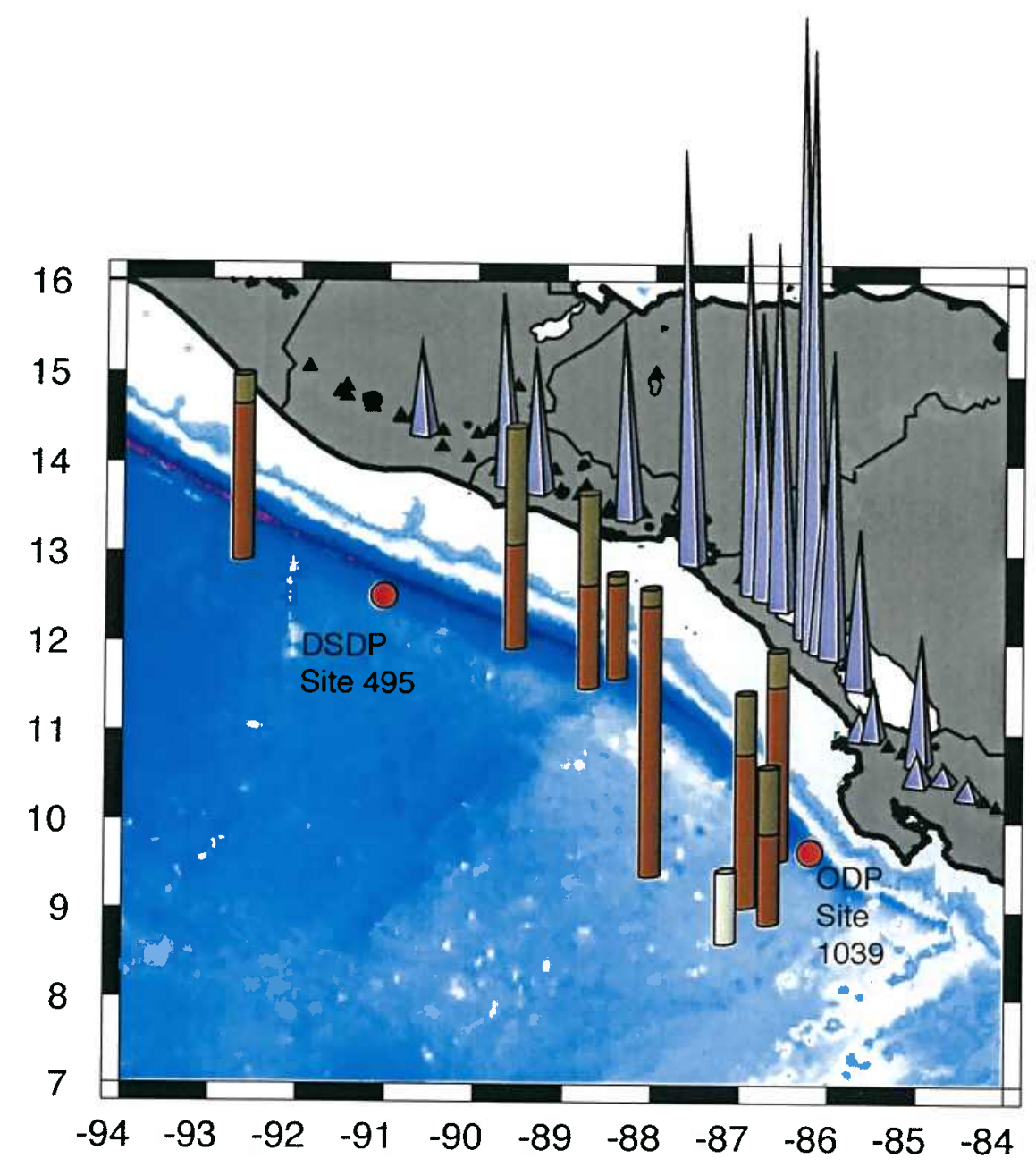


Figure 9. ${ }^{10} \mathrm{Be} /{ }^{9} \mathrm{Be}$ in the sediments is controlled by changes in the ${ }^{10} \mathrm{Be}$ concentration. ${ }^{10} \mathrm{Be}$ data is age corrected. The $\mathrm{x}$ 's represent the initial age corrected ${ }^{10} \mathrm{Be}$ concentrations for the Vema cores that have anomalously high LOI and $\mathrm{Na}_{2} \mathrm{O}$. Arrows point to the mass corrected ${ }^{10} \mathrm{Be}$ concentrations (white circles and white diamond), assuming an average LOI of $13 \mathrm{wt} . \%$ and $\mathrm{Na}_{2} \mathrm{O}$ of $5 \mathrm{wt} . \%$ (see text for further discussion). Correcting for anomalous mass improves the correlations. Gray circles are non-Vema hemipelagic sediment samples. Gray diamond is the mixed hemipelagic/ash sample from RC12-29. White diamonds are the mixed hemipelagic/ash samples from VM15-24 and VM15-26. Black triangles are the three ash samples. 


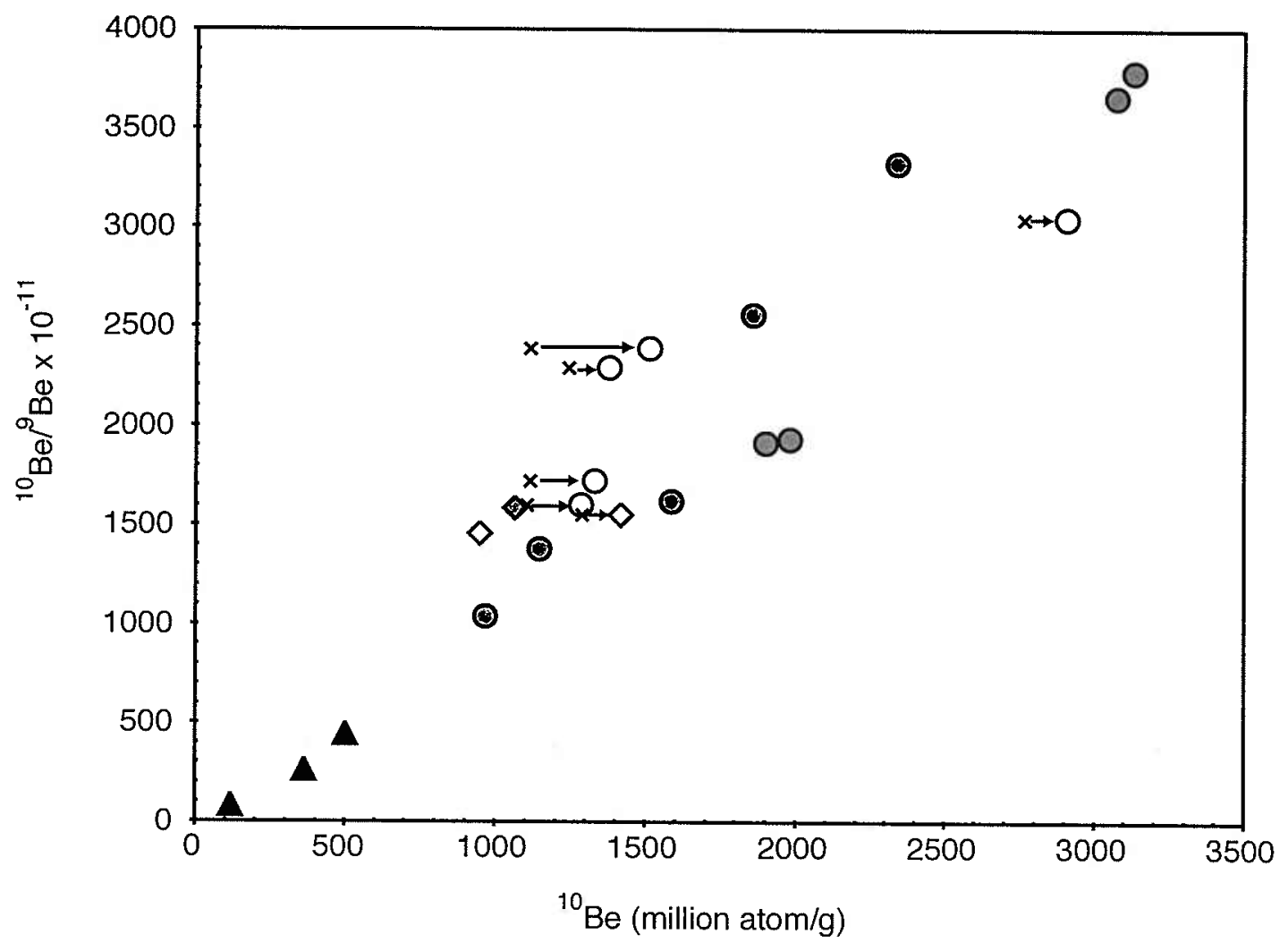


Figure 10. Geochemical characteristics for the suite of samples measured for major and trace elements are shown relative to (A) N-MORB (Sun and McDonough, 1989; top) and (B) Post-Archean Shale (PAAS, Taylor and McLennan, 1985; bottom). Gray circles are non-Vema hemipelagic sediments, gray diamond is mixed hemipelagic/ash sample, white circles and white diamonds are Vema hemipelagic sediments and hemipelagic/ash mix, respectively (no mass correction applied). DSDP Site 495 hemipelagic sediment and GLOSS (global subducting sediment; Plank and Langmuir, 1998) are shown for comparison. Green triangles mark the ash samples, which show separation from the hemipelagic sediments for many of the elements. Missing fields indicate no data for the normalizing elements. 

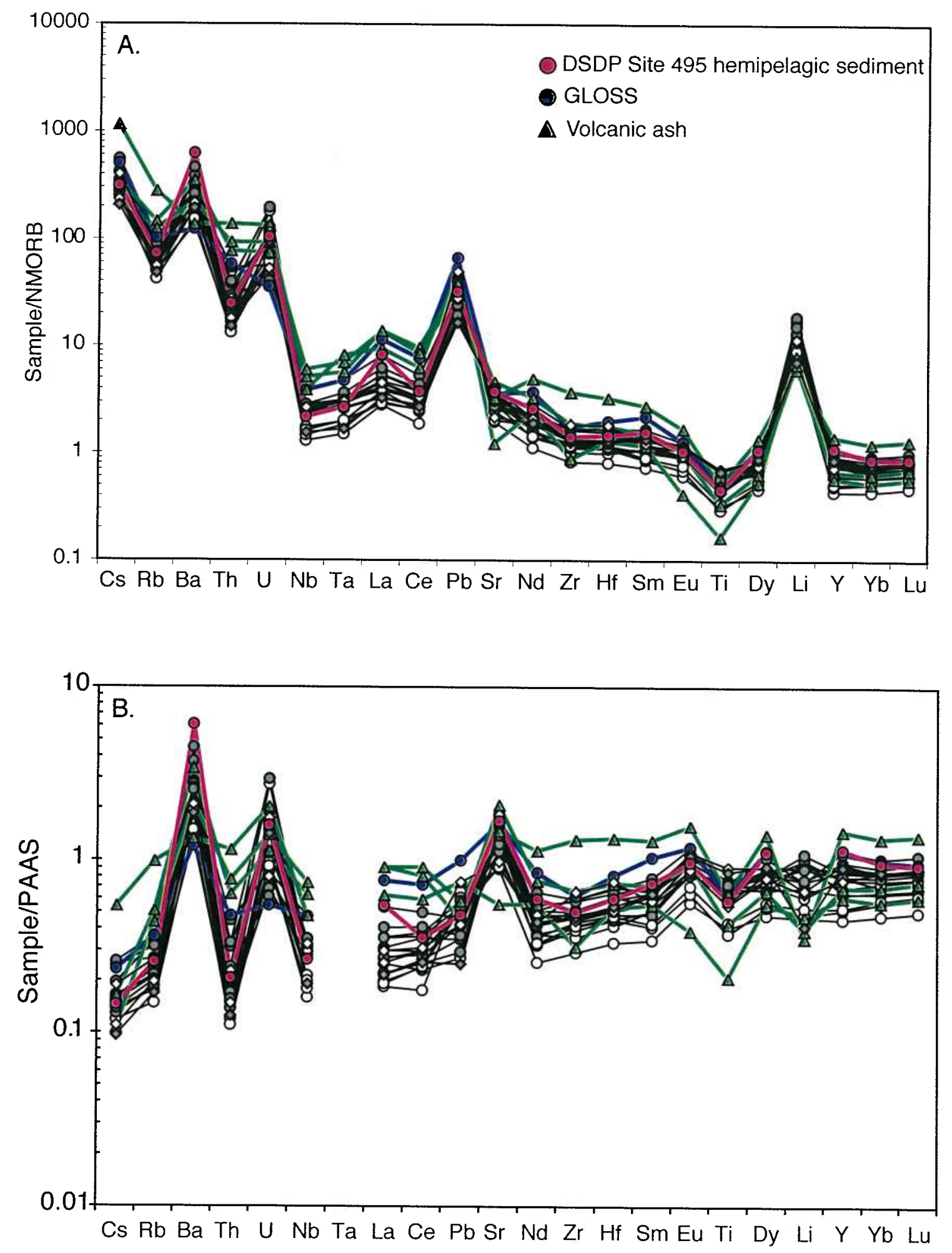
Figure 11. Rare earth elements are normalized to (A) chondrite and (B) PAAS. Symbol designations are the same as in Figure 10. Missing fields indicate no data for the normalizing elements. 

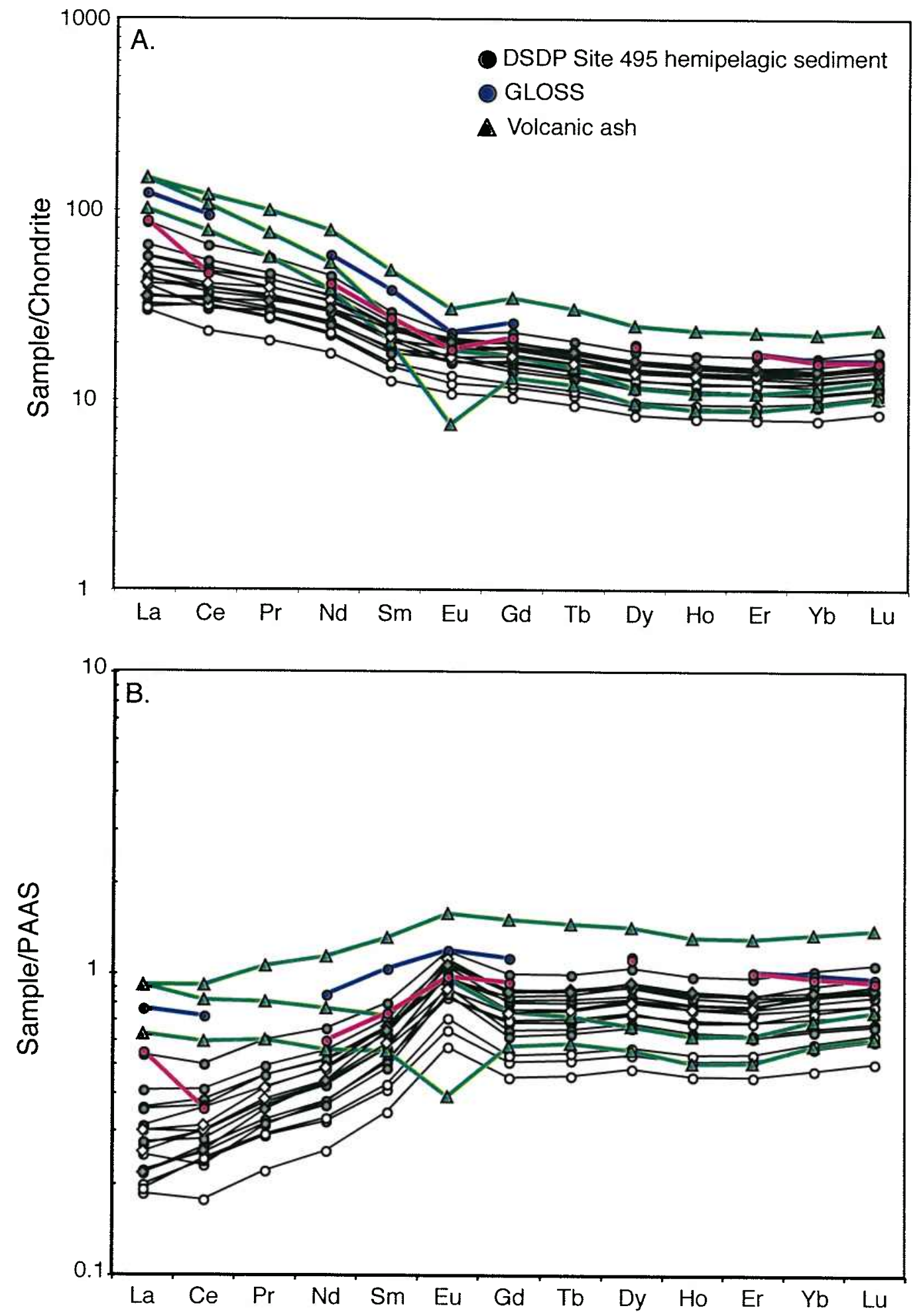
Figure 12. The Nd and Sr isotopic array for the Middle America Trench sediments illustrates probable mixing between young volcanic ash or volcanogenic components and mature, terrigenous clays. Average DSDP Site 495 hemipelagic sediment (Plank and Langmuir, 1998) is shown for reference. The Central American Volcanic Arc (CAVA; Carr et al., 2003) and Nicoya Complex (Sinton et al., 1997) arrays are also shown to indicate potential sources of dilution of clays by volcanic material. The offset of RC1232 , offshore of Guatemala, may be reflecting addition from Guatemalan volcanic ash. Gray circles are non-Vema hemipelagic sediments, white circles and white diamonds are Vema hemipelagic sediments and hemipelagic/ash mix, respectively, and black triangles are volcanic ash samples. 


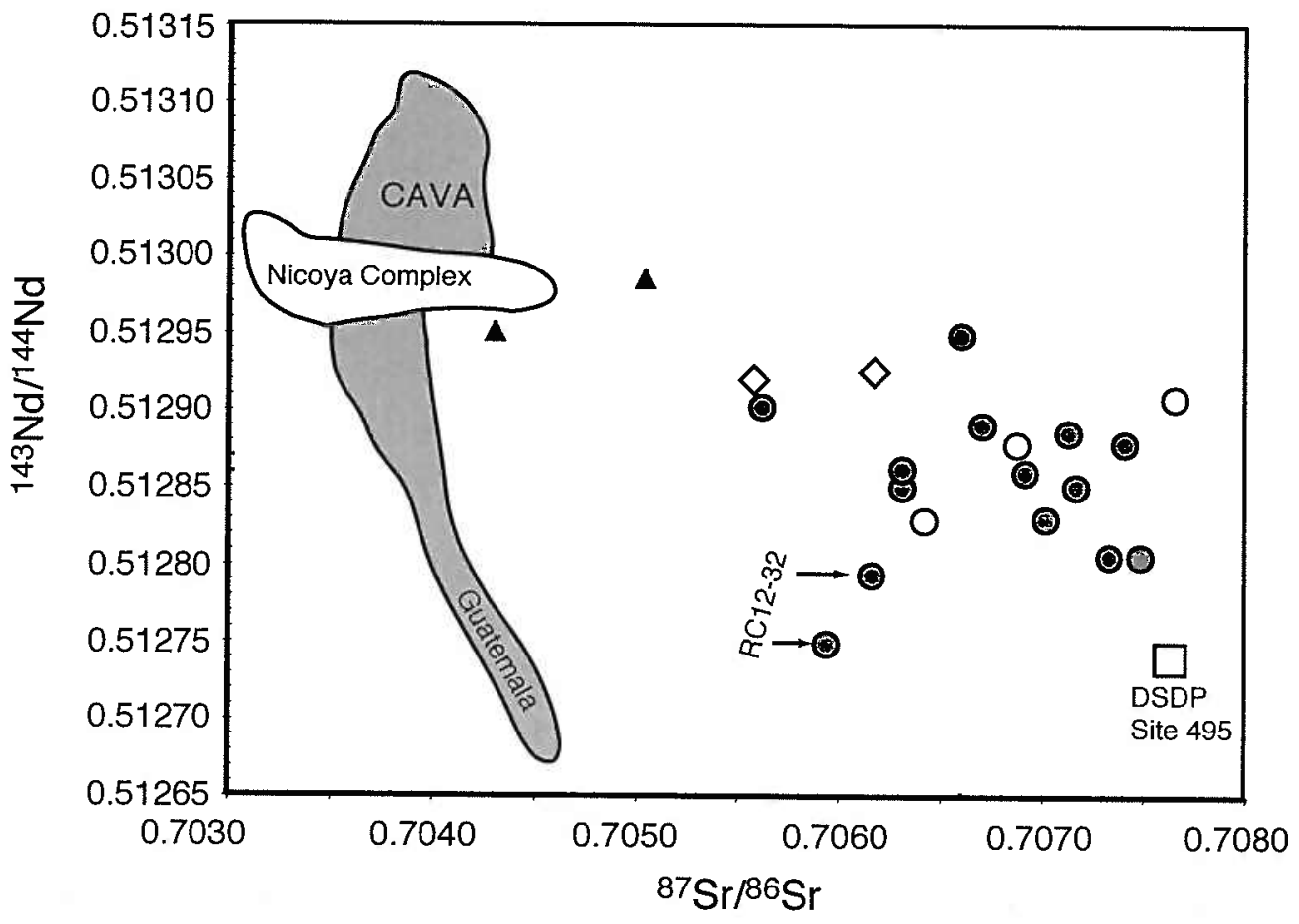


Figure 13. ${ }^{10} \mathrm{Be}$ concentrations show no relationship to ${ }^{9} \mathrm{Be}$ in the sediments. Symbols are the same as in Figure 9. Correcting for anomalous mass does not significantly change the overall pattern. 


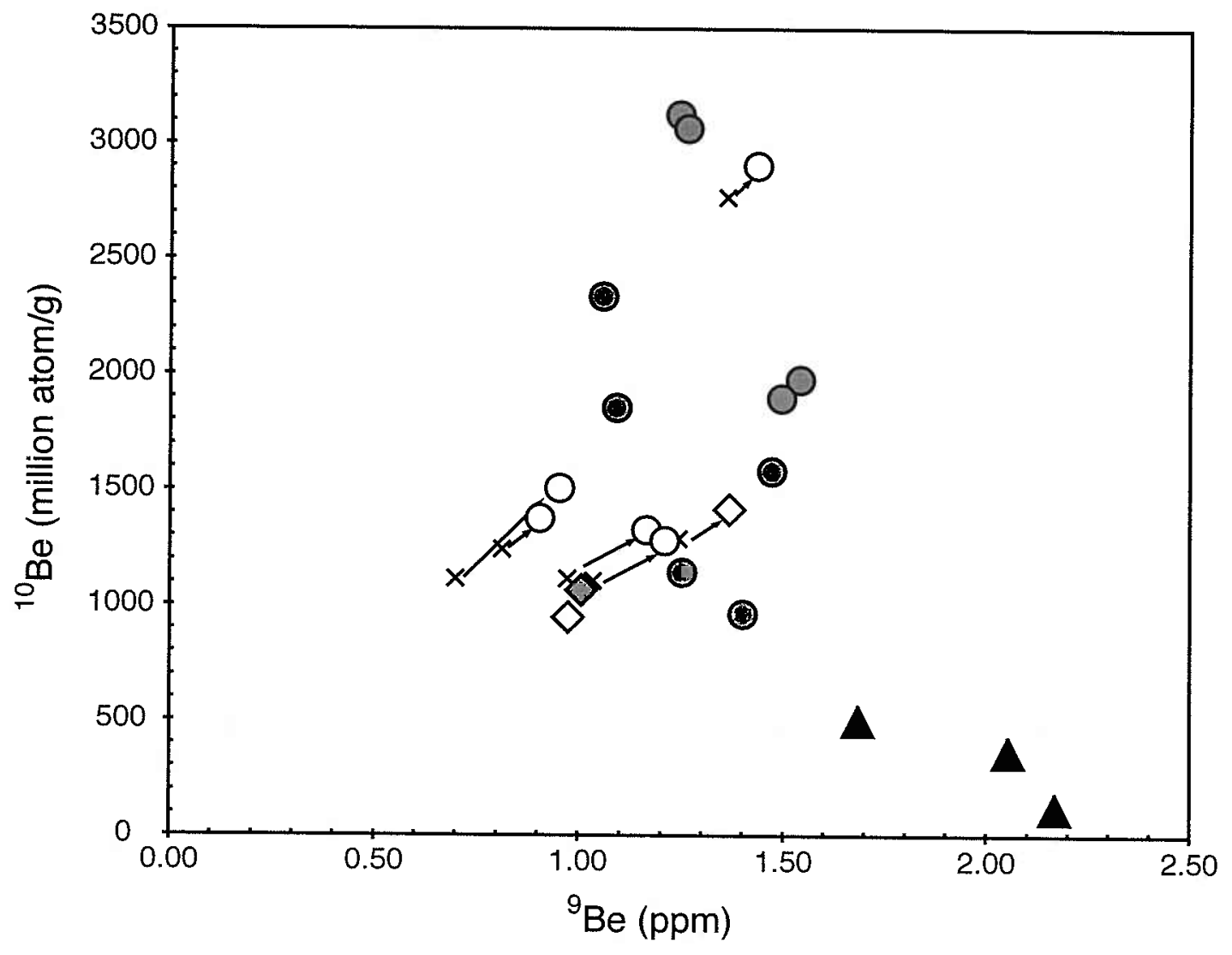


Figure 14. ${ }^{9} \mathrm{Be}$ concentrations show strong correlations with elements that are considered typical of detrital origins (e.g., Plank and Langmuir, 1998). In contrast, age corrected ${ }^{10} \mathrm{Be}$ concentrations show no similar relationships, indicating that it is unlikely that ${ }^{10} \mathrm{Be}$ is preferentially scavenged by detrital particulate matter. Gray circles are non-Vema hemipelagic sediments, gray diamond is mixed hemipelagic/ash sample, white circles and white diamonds are Vema hemipelagic sediments and hemipelagic/ash mix, respectively, and black triangles are volcanic ash samples. The mass correction for the anomalous Vema samples has not been applied for simplicity. Correcting for the additional mass would not significantly change the overall pattern for each pair of elements; the effect would be to move the Vema samples up and to the right by a small degree. In general, this will cluster the Vema samples closer to the other sediment samples. 

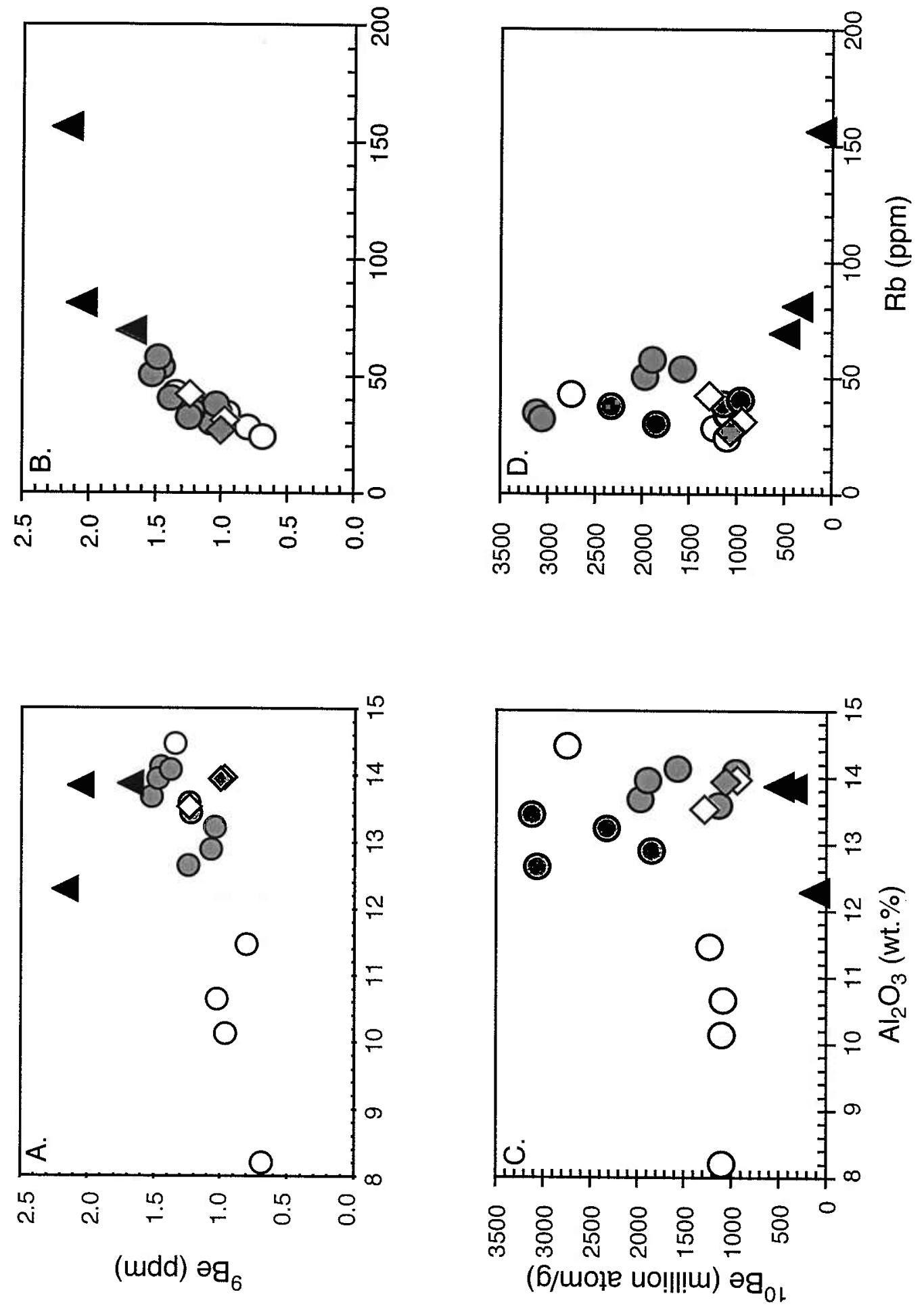
Figure 14 continued. 

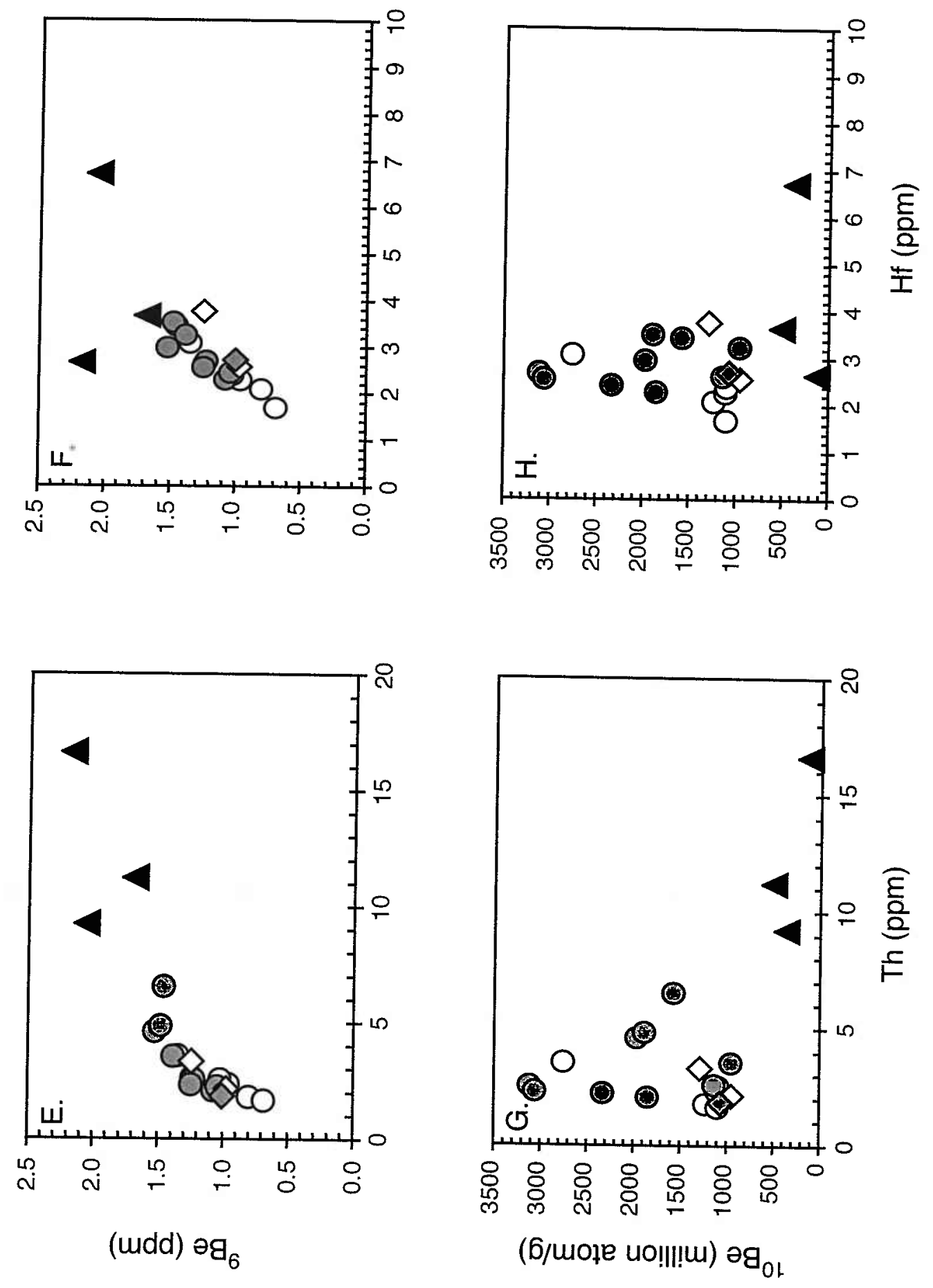
Figure 14 continued. 

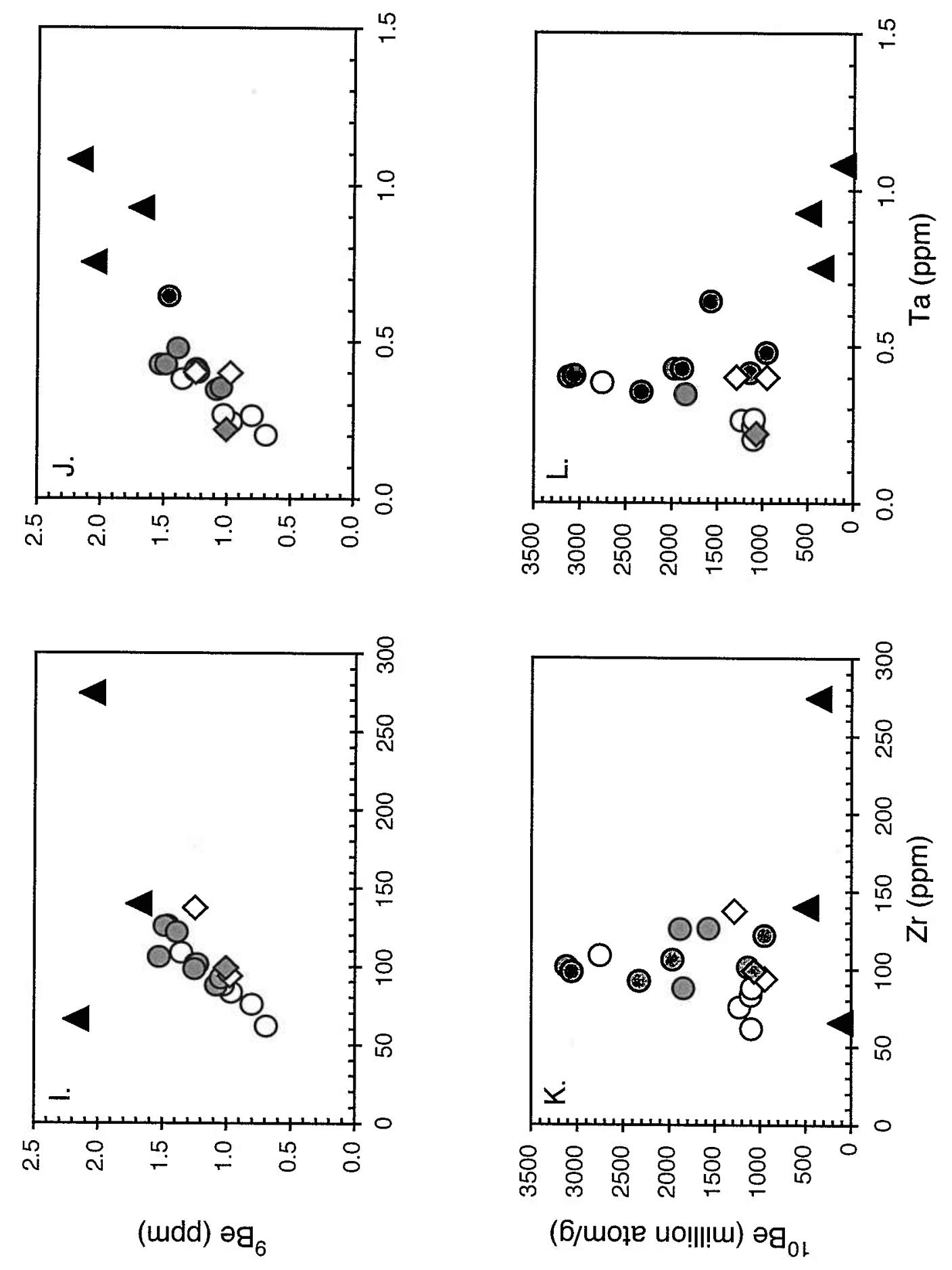
Figure 14 continued. 

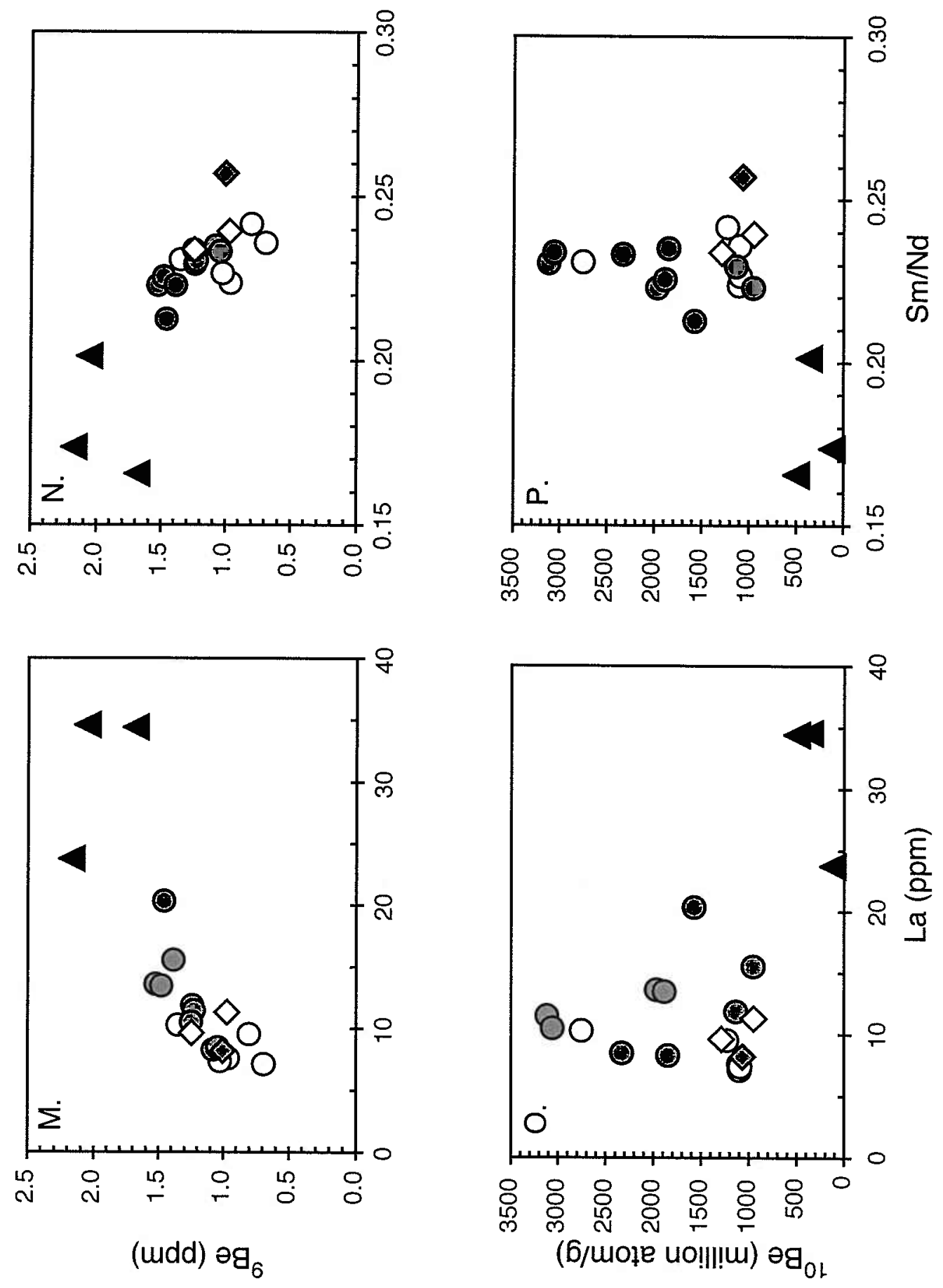
Figure 15. Age corrected ${ }^{10} \mathrm{Be}$ shows a weak relationship with (A) Ba, but there is a general positive trend of ${ }^{10} \mathrm{Be}$ with (B) $\mathrm{Li}$ and (C) $\mathrm{Cu}$, though there are two outliers for the $\mathrm{Li}$ plot and the field is somewhat diffuse for $\mathrm{Cu}$. Symbols are the same as for Figure 14. No mass correction has been applied (see Figure 14 caption). 

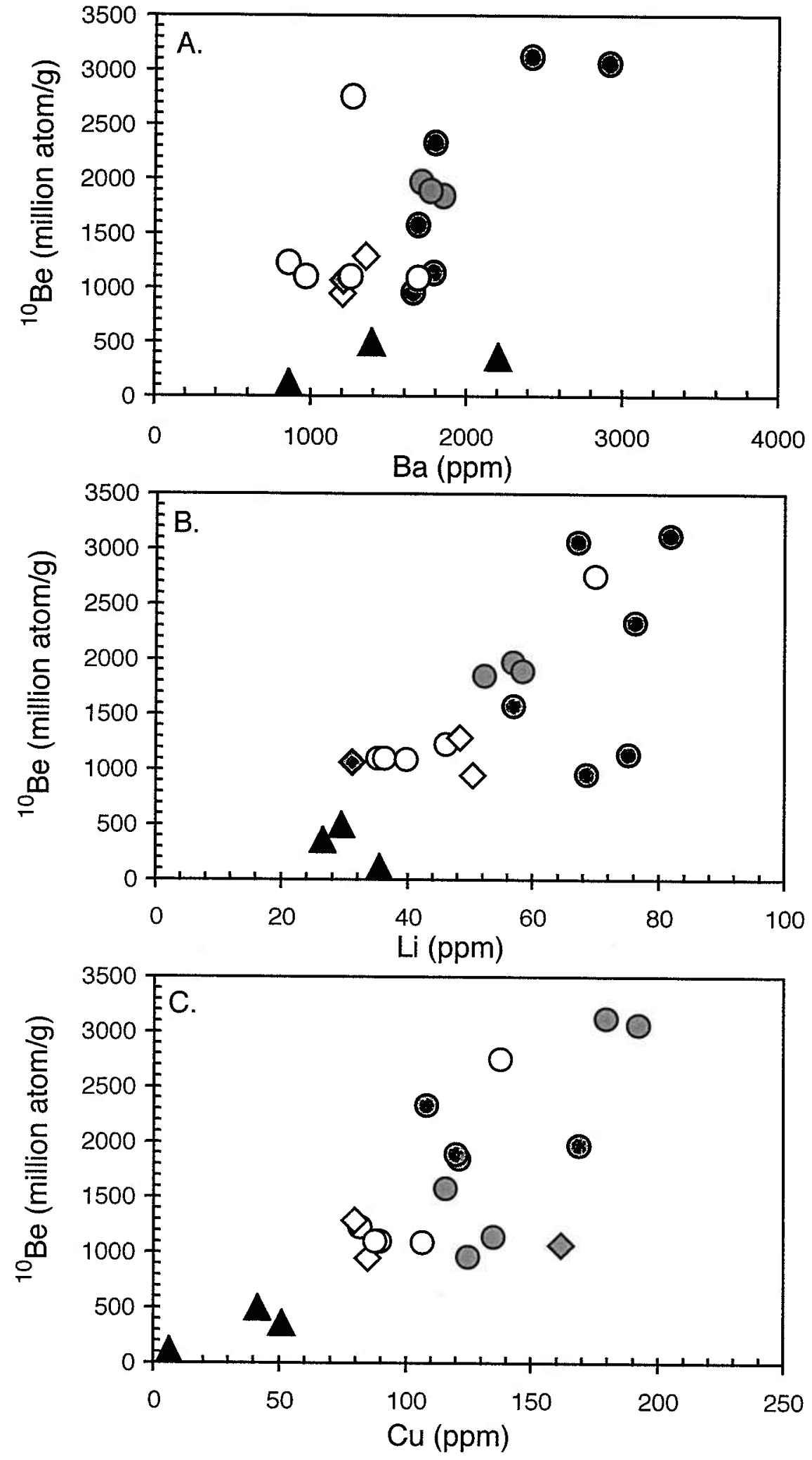
Figure 16. (A) Age corrected ${ }^{10} \mathrm{Be}$ exhibits a strong negative correlation with ${ }^{143} \mathrm{Nd} /{ }^{144} \mathrm{Nd}$. The two outliers from RC12-32 may be due to the influence of mixing with Guatemalan ash as seen in Figure 12. (B) The relationship of ${ }^{10} \mathrm{Be}$ with ${ }^{87} \mathrm{Sr} /{ }^{86} \mathrm{Sr}$ is less defined, probably due to the higher sensitivity of $\mathrm{Sr}$ isotopes to carbonate or seawater addition. These trends point to mixing between volcanogenic and mature, detrital clay endmembers. The mass correction for ${ }^{10} \mathrm{Be}$ in the Vema samples has not been applied, as it would not significantly change the correlations. 

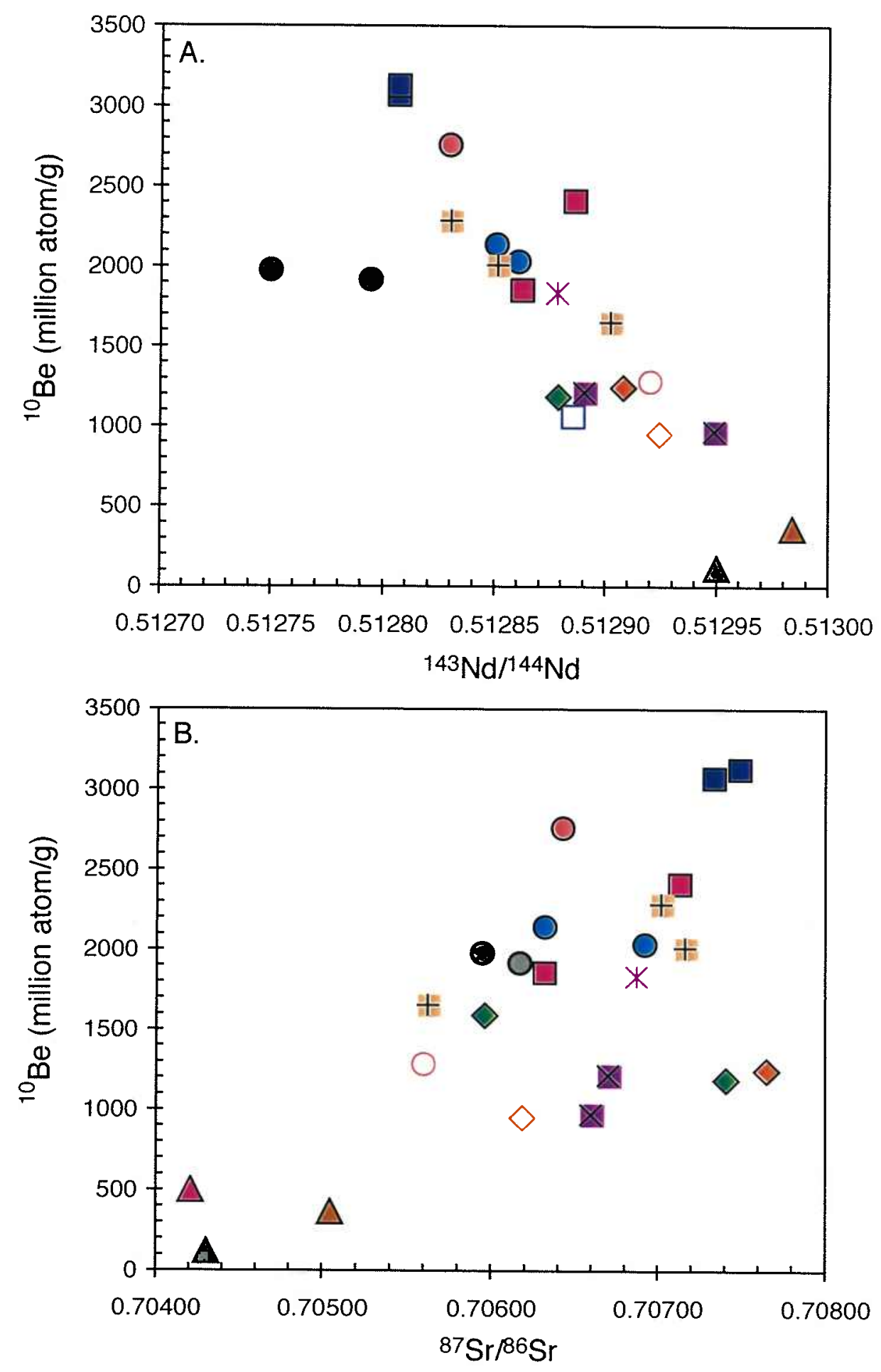
Figure 17. Age corrected ${ }^{10} \mathrm{Be}$ increases with increasing LOI. Vema samples are not included. Gray circles are non-Vema hemipelagic sediments, gray diamond is mixed hemipelagic/ash sample, white diamond is a Vema hemipelagic/ash mix sample that did not require a mass correction, and black triangles are volcanic ash samples. This trend supports the hypothesis that variations in ${ }^{10} \mathrm{Be}$ represent mixing behavior between the volcanogenic and clay components that dominate the shallow Middle America Trench sediment. With increasing amounts of hydrogenous clays, LOI will also be higher due to the additional water. The ${ }^{10} \mathrm{Be}$ appears to be concentrated in the clay fraction, probably due to grain size effects. 


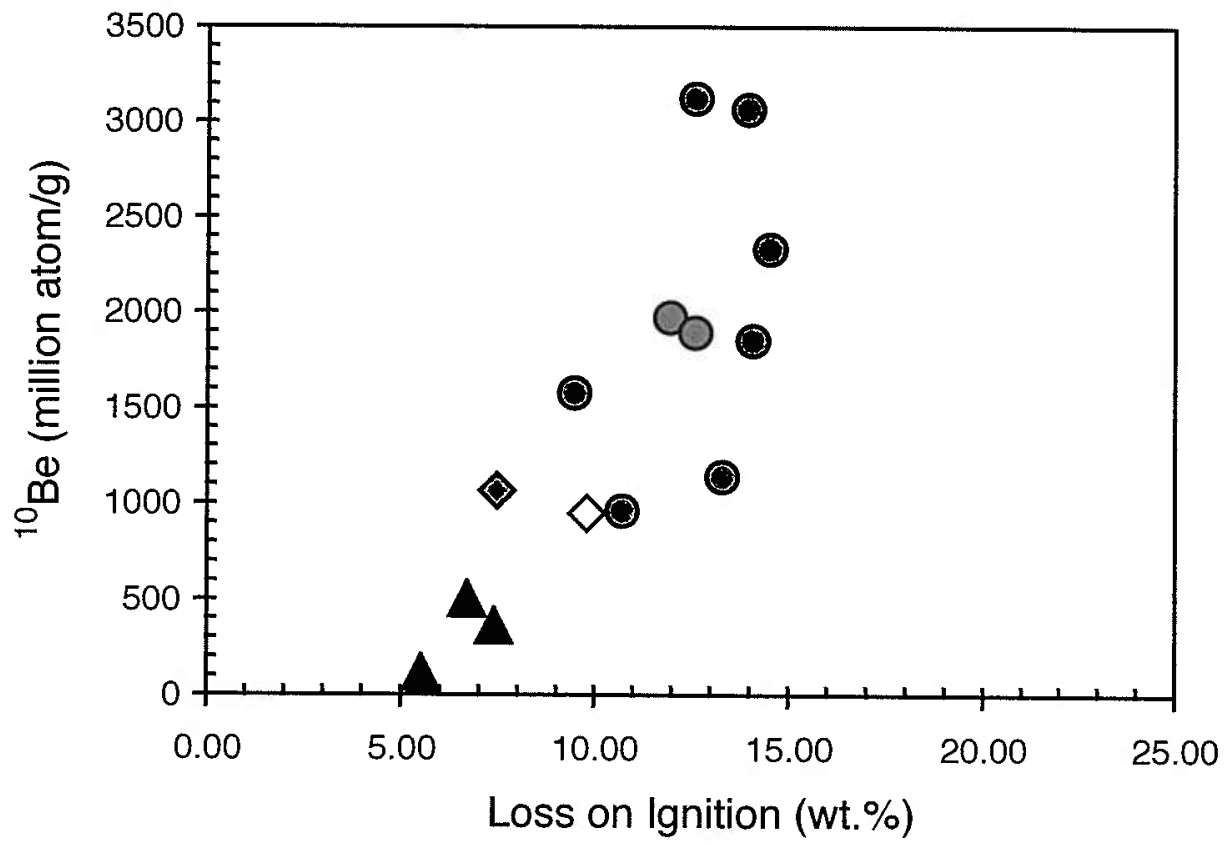


Figure 18. (A) Age corrected ${ }^{10} \mathrm{Be}$ concentrations in the EW0104 sediment samples decrease with increasing median grain size, though the relationship is less distinct when considering (B) mean and (C) modal grain sizes. GC43 samples do not fall along the general trend, possibly due to a difference in the amount of biogenic material relative to the other cores. Symbol designations are the same as in Figure 16. 

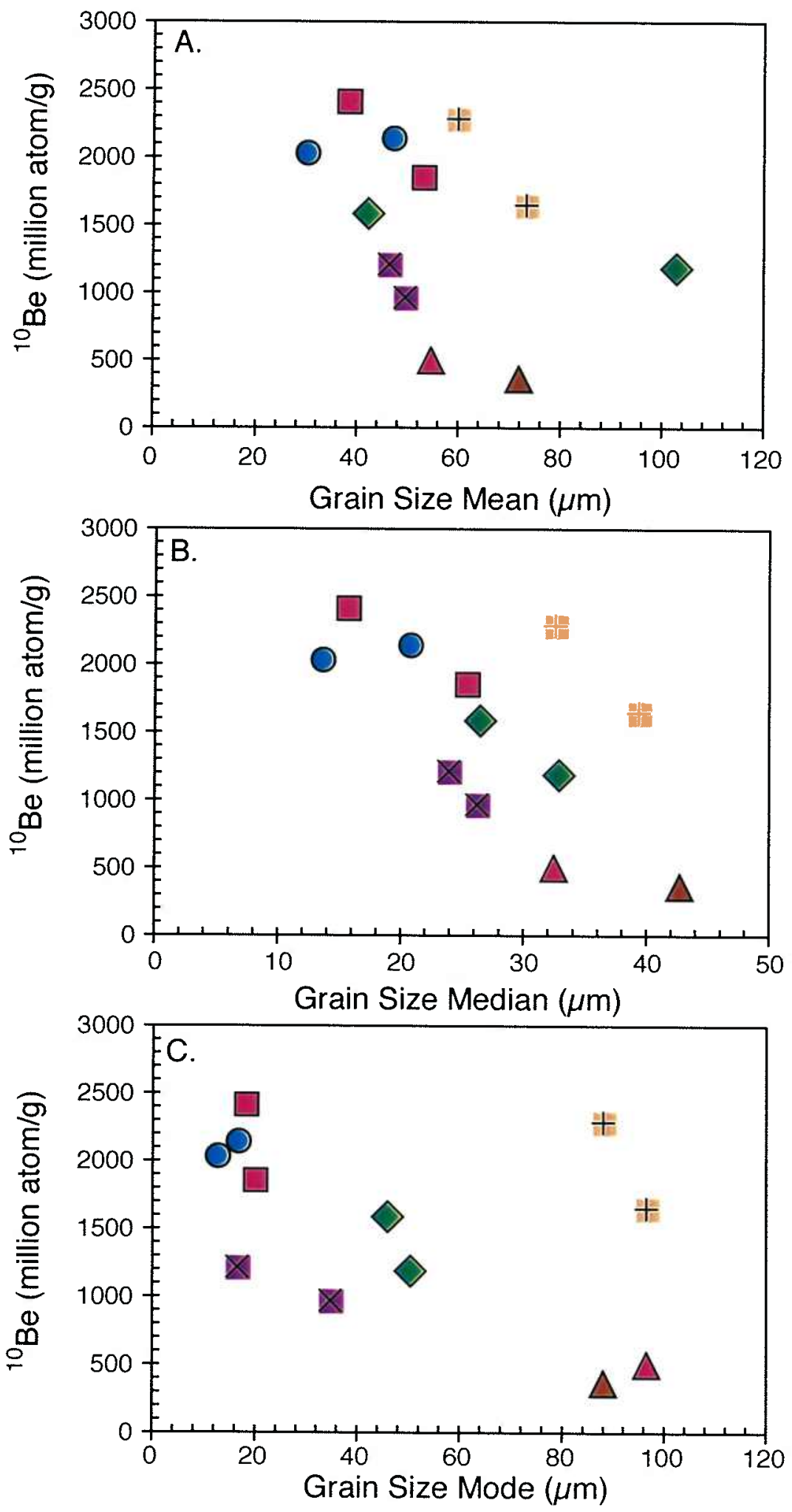
Figure 19. Age corrected ${ }^{10} \mathrm{Be}$ concentrations increase with increasing proportion of grains $<32 \mu \mathrm{m}$ in diameter. GC43 samples are offset from the positive trend. 


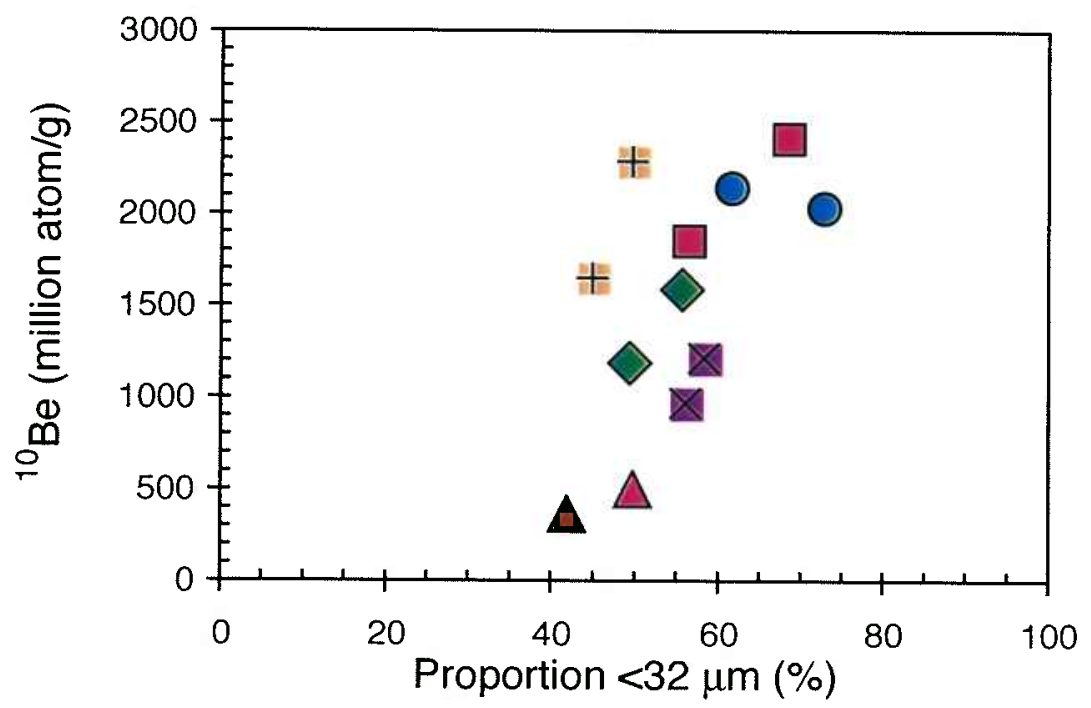


Figure 20. (A) The positive correlation of ${ }^{10} \mathrm{Be}$ with proportion of grains $<10 \mu \mathrm{m}$ is less defined than that with proportion $<32 \mu \mathrm{m}$. (B-C) When grain sizes larger than $32 \mu \mathrm{m}$ are incorporated, no positive relationship is observed. It is likely that ${ }^{10} \mathrm{Be}$ scavenging efficiency is maximized for smaller grain sizes due to a higher surface area to mass ratio and a residence time in the water column that is not significantly less than that of ${ }^{10} \mathrm{Be}$. For grain sizes above $32 \mu \mathrm{m}$, particle accumulation acts as more of a diluent than a concentratorrof ${ }^{10} \mathrm{Be}$ atoms. 

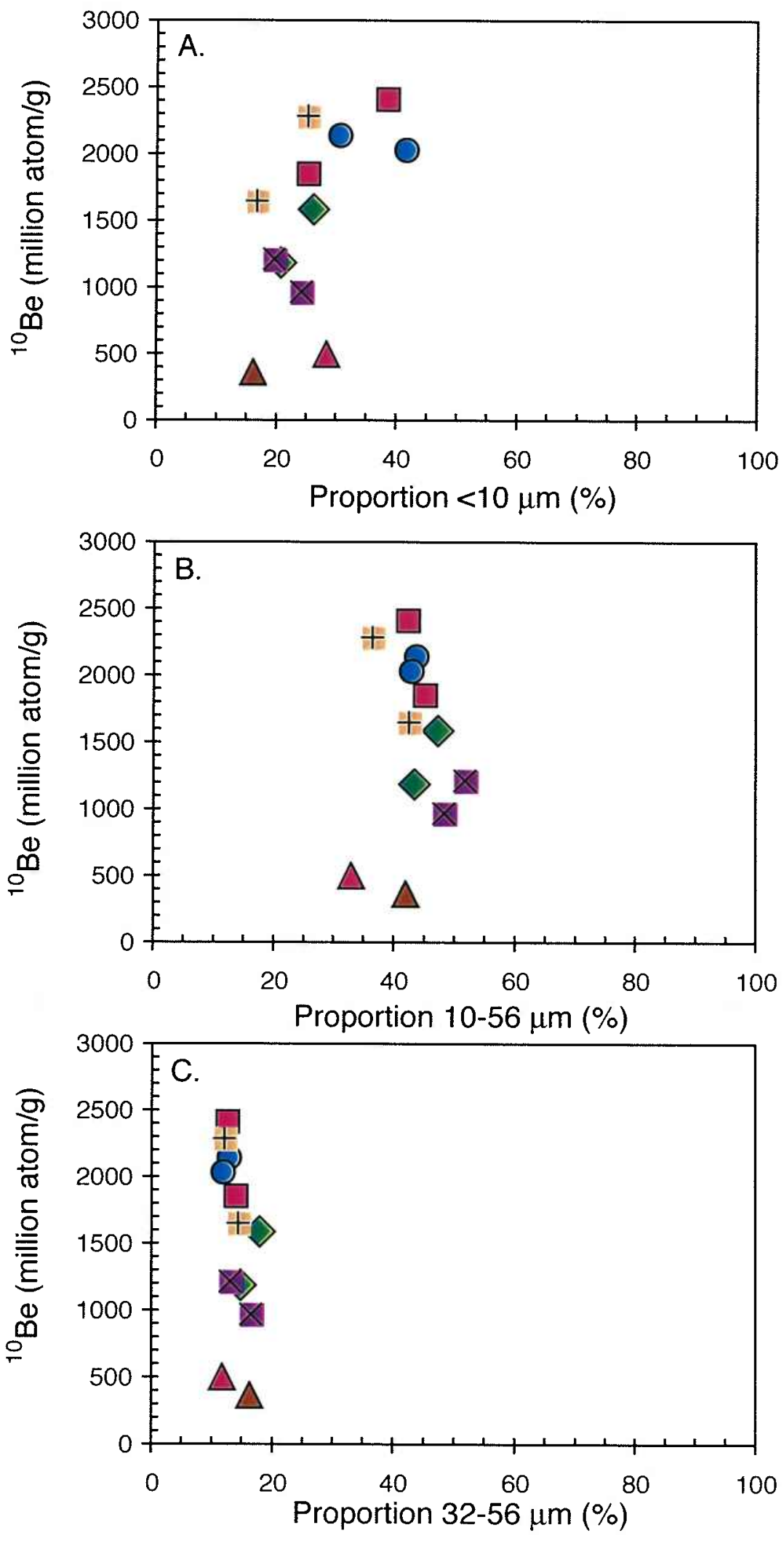


\section{References}

Anderson, R.F., Y. Lao, W.S. Broecker, S.E. Trumbore, H.J. Hofmann, and W. Wolfi, Boundary scavenging in the Pacific Ocean: a comparison of ${ }^{10} \mathrm{Be}$ and ${ }^{231} \mathrm{~Pa}$, Earth Planet. Sci. Lett., 96, 287-304, 1990.

Aubouin, J., R. von Huene, et al., Init. Repts. DSDP, 67, US Govt. Printing Office, Washington, DC, 1982.

Brown, E.T., C.I. Measures, J.M. Edmond, D.L. Bourles, G.M. Raisbeck, and F. Yiou, Continental inputs of beryllium to the oceans, Earth Planet. Sci. Lett., 114, 101-111, 1992.

Brown, L., J. Klein, R. Middleton, I. Selwyn Sacks, and F. Tera, ${ }^{10}$ Be in island-arc volcanoes and implications for subduction, Nature, 299, 718-720, 1982.

Buesseler, K.O., The decoupling of production and particulate export in the surface ocean, Glob. Biogeochem. Cycles, 12, 297-310, 1998.

Chan, L.-H., and M. Kastner, Lithium isotopic compositions of pore fluids and sediments in the Costa Rica subduction zone: implications for fluid processes and sediment contribution to the arc volcanoes, Earth Planet. Sci. Lett., 183, 275-290, 2000.

Chase, Z., R.F. Anderson, M.Q. Fleisher, and P.W. Kubik, The influence of particle composition and particle flux on scavenging of $\mathrm{Th}, \mathrm{Pa}$ and $\mathrm{Be}$ in the ocean, Earth Planet. Sci. Lett., 204, 215-229, 2002.

Chase, Z., R.F. Anderson, M.Q. Fleisher, and P.W. Kubik, Scavenging of ${ }^{230} \mathrm{Th},{ }^{231} \mathrm{~Pa}$, and ${ }^{10} \mathrm{Be}$ in the Southern Ocean (SW Pacific sector): the importance of particle flux, particle composition and advection, Deep-Sea Res. II, 50, 739-768, 2003.

DeMets, C., A new estimate for present day Cocos-Caribbean plate motion: Implications for slip along the Central American volcanic arc, Geophys. Res. Lett., 28, 2001.

Dominik, J., and D.J. Stanley, Boron, beryllium and sulfur in Holocene sediments and peats of the Nile delta, Egypt: Their use as indicators of salinity and climate, Chem. Geol., 104, 203-216, 1993.

Dymond, J.E., E. Seuss, and M. Lyle, Barium in deep-sea sediment: A geochemical proxy for paleoproductivity, Paleoceanography, 7, 163-181, 1992. 
Eisenhauer, A., R.F. Spielhagen, M. Frank, G. Hentzschel, A. Mangini, P.W. Kubik, B.

Dittrich-Hannen, and T. Billen, ${ }^{10} \mathrm{Be}$ records of sediment cores from high northern latitudes: Implications for environmental and climatic changes, Earth Planet. Sci. Lett., 124, 171-184, 1994.

Fiedler, P.C., V. Philbrick, and F.P. Chavez, Oceanic upwelling and productivity in the Eastern Tropical Pacific, Limnol. Ocean., 36, 1834-1850, 1991.

Fisher, A., et al., Preliminary Cruise Report, TicoFlux I Expedition, R/V Maurice Ewing, EW0104, 2001.

Frank, M., J. Eckhardt, A. Eisenhauer, P.W. Kubik, B. Dittrich-Hannen, M. Segl, and A. Mangini, Beryllium 10, thorium 230, and protactinium 231 in Galapagos microplate sediments: Implications of hydrothermal activity and paleoproductivity changes during the last 100,000 years, Paleoceanography, 9, 559-578, 1994.

Frank, M., A. Eisenhauer, W.J. Bonn, P. Walter, H. Grobe, P.W. Kubik, B. DittrichHannen, and A. Mangini, Sediment redistribution versus paleoproductivity change: Weddell Sea margin sediment stratigraphy and biogenic particle flux of the last 250,000 years deduced from ${ }^{230} \mathrm{Th}_{\mathrm{ex}},{ }^{10} \mathrm{Be}$ and biogenic barium profiles, Earth Planet. Sci. Lett., 136, 559-573, 1995.

Frank, M., B. Schwarz, S. Baumann, P.W. Kubik, M. Suter, and A. Mangini, A 200 kyr record of cosmogenic radionuclide production rate and geomagnetic field intensity from ${ }^{10} \mathrm{Be}$ in globally stacked deep-sea sediments, Earth Planet. Sci. Lett., 149, 121 $129,1997$.

Kelley, K.A., T. Plank, J. Ludden, and H. Staudigel, The composition of altered oceanic crust at ODP Sites 801 and 1149, Geochem. Geophys. Geosys., in press, 2003.

Kelly, R.K., and N.W. Driscoll, Structural controls on Beryllium-10 occurrences in arc lavas, EOS Trans. AGU, 79, 396, 1998.

Kimura, G., E. Silver, P. Blum, et al., Proc. ODP. Init. Repts., 170, College Station, TX (Ocean Drilling Program), 1997. 
Kurosawa, M., J.L. Campbell, W.J. Teesdale, H. Ohyi, Y. Deguchi, and S. Murao, Quantitative trace element analyses of silicate reference materials and a stainless steel using the proton microprobe, Chem. Geol., 160, 241-250, 1999.

Kusakabe, M., T.L. Ku, J.R. Southon, S. Liu, J.S. Vogel, D.E. Nelson, S. Nakaya, and G.L. Cusimano, Be isotopes in rivers/estuaries and their oceanic budgets, Earth Planet. Sci. Lett., 102, 265-276, 1991.

Kusakabe, M., T.L. Ku, J.R. Southon, and C.I. Measures, Beryllium isotopes in the ocean, Geochem. J., 24, 263-272, 1990.

Kusakabe, M., T.L. Ku, J.R. Southon, J.S. Vogel, D.E. Nelson, C.I. Measures, and Y. Nozaki, Distribution of ${ }^{10} \mathrm{Be}$ and ${ }^{9} \mathrm{Be}$ in the Pacific Ocean, Earth Planet. Sci. Lett., 82, 231-240, 1987.

Lal, D., Comments on some aspects of particulate transport in the oceans, Earth Planet. Sci. Lett., 49, 520-527, 1980.

Lao, Y., R.F. Anderson, W.S. Broecker, H.J. Hofmann, and W. Wolfi, Particulate fluxes of ${ }^{230} \mathrm{Th},{ }^{231} \mathrm{~Pa}$, and ${ }^{10} \mathrm{Be}$ in the northeastern Pacific Ocean, Geochim. Cosmochim. Acta, 57, 205-217, 1993.

Lao, Y., R.F. Anderson, W.S. Broecker, S.E. Trumbore, H.J. Hofmann, and W. Wolfi, Transport and burial rates of ${ }^{10} \mathrm{Be}$ and ${ }^{231} \mathrm{~Pa}$ in the Pacific Ocean during the Holocene period, Earth Planet. Sci. Lett., 113, 173-179, 1992.

Ledbetter, M.T., Tephrochronology of marine tephra adjacent to Central America, Geol. Soc. Amer. Bull., 96, 77-82, 1985.

Ledbetter, M.T., and R.S.J. Sparks, Duration of large-magnitude explosive eruptions deduced from graded bedding in deep-sea ash layers, Geology, 7, 240-244, 1979.

Luo, S., T.L. Ku, L. Wang, J.R. Southon, S.P. Lund, and M. Schwartz, ${ }^{26} \mathrm{Al},{ }^{10} \mathrm{Be}$, and UTh isotopes in Blank Outer Ridge sediments: implications for past changes in boundary scavenging, Earth Planet. Sci. Lett., 185, 135-147, 2001.

Monaghan, M.C., J. Klein, and C.I. Measures, The origin of ${ }^{10} \mathrm{Be}$ in island-arc volcanic rocks, Earth Planet. Sci. Lett., 89, 1988. 
Morris, J.D., J. Gosse, S. Brachfeld, and F. Tera, Cosmogenic Be-10 and the Solid Earth: Studies in Geomagnetism, Subduction Zone Processes, and Active Tectonics, in Beryllium: Mineralogy, Petrology, and Geochemistry, Reviews in Mineralogy and Geochemistry, 50, edited by E.S. Grew, pp. 207-270, Mineralogical Society of America, Washington, D.C., 2002.

Morris, J.D., W.P. Leeman, and F. Tera, The subducted component in island arc lavas: constraints from Be isotopes and B-Be systematics, Nature, 344, 31-36, 1990.

Morris, J.D., and F. Tera, ${ }^{10} \mathrm{Be}$ and ${ }^{9} \mathrm{Be}$ in mineral separates and whole rocks from volcanic arcs: Implications for sediment subduction, Geochim. Cosmochim. Acta, 53, 3197-3206, 1989.

Patino, L.C., M.J. Carr, and M.D. Feigenson, Local and regional variations in Central American arc lavas controlled by variations in subducted sediment input, Contrib. Mineral. Petrol., 138, 265-283, 2000.

Plank, T., and C.H. Langmuir, Tracing trace elements from sediment input to volcanic output at subduction zones, Nature, 362, 739-743, 1993.

Plank, T., and C.H. Langmuir, The chemical composition of subducting sediment and its consequences for the crust and mantle, Chem. Geol., 145, 325-394, 1998.

Rifaat, A.E., M.K. El-Sayed, A. Beltagy, M.A. Morsy, and A. Nawar, Geochemical predictive models of manganese, zinc, nickel, copper and cadmium in Nile shelf sediments, Mar. Geol., 108, 59-71, 1992.

Rutsch, H.-J., A. Mangini, G. Bonani, B. Dittrich-Hannen, P.W. Kubik, M. Suter, and M. Segl, ${ }^{10} \mathrm{Be}$ and $\mathrm{Ba}$ concentrations in West African sediments trace productivity in the past, Earth Planet. Sci. Lett., 133, 129-143, 1995.

Ryan, J.G., and C.H. Langmuir, Beryllium systematics in young volcanic rocks: Implications for ${ }^{10} \mathrm{Be}$, Geochim. Cosmochim. Acta, 52, 1988.

Schroeder, J.O., R.W. Murray, M. Leinen, R.C. Pflaum, and T.R. Janecek, Barium in equatorial Pacific carbonate sediment: Terrigenous, oxide, and biogenic associations, Paleoceanography, 12, 125-146, 1997. 
Sharma, P., R. Mahannah, W.S. Moore, T.L. Ku, and J.R. Southon, Transport of ${ }^{10} \mathrm{Be}$ and

${ }^{9} \mathrm{Be}$ in the ocean, Earth Planet. Sci. Lett., 86, 1987.

Sinton, C.W., R.A. Duncan, and P. Denyer, Nicoya Peninsula, Costa Rica: A single suite of Caribbean oceanic plateau magmas, J. Geophys. Res., 102, 15,507-15,520, 1997.

Southon, J.R., T.L. Ku, D.E. Nelson, J.L. Reyss, J.C. Duplessy, and J.S. Vogel, ${ }^{10}$ Be in a deep-sea core: implications regarding ${ }^{10} \mathrm{Be}$ production changes over the past $420 \mathrm{ka}$, Earth Planet. Sci. Lett., 85, 356-364, 1987.

Sun, S.S., and W.F. McDonough, Magmatism in the Ocean Basins, Geol. Soc. Amer. Spec. Pap., 42, edited by A.D. Saunders, and M.J. Norry, pp. 313-345, 1989.

Tanaka, T., et al., JNdi-1: a neodymium isotopic reference in consistency with La Jolla neodymium, Chem. Geol., 168, 279-281, 2000.

Taylor, S.R., and S.M. McLennan, The continental crust: its composition and evolution, 312 pp., Blackwell Scientific Publications, Oxford, 1985.

Tera, F., L. Brown, J.D. Morris, I. Selwyn Sacks, J. Klein, and R. Middleton, Sediment incorporation in island-arc magmas: Inferences from ${ }^{10} \mathrm{Be}$, Geochim. Cosmochim. Acta, 50, 535-550, 1986.

Valentine, R.B., J.D. Morris, and J. Duncan, D., Sediment subduction, accretion, underplating, and arc volcanism along the margin of Costa Rica: Constraints from $\mathrm{Ba}$, $\mathrm{Zn}, \mathrm{Ni}$, and ${ }^{10} \mathrm{Be}$ concentrations, EOS Trans. AGU, 78, 46, 1997.

Wang, L., T.L. Ku, S. Luo, J.R. Southon, and M. Kusakabe, ${ }^{26} \mathrm{Al}-{ }^{10}$ Be systematics in deep-sea sediments, Geochim. Cosmochim. Acta, 60, 109-119, 1996.

Weyl, R., Geology of Central America ( $2^{\text {nd }}$ edition), Berlin-Stuttgart, Gebrueder Borntraeger, 371 p., 1980.

Yiou, F., and G.M. Raisbeck, Half-life of ${ }^{10} \mathrm{Be}$, Phys. Rev. Lett., 29, 1972.

Zheng, S.H., J.D. Morris, F. Tera, J. Klein, and R. Middleton, Beryllium isotopic investigation of sedimentary columns outboard of subduction zones, ICOG, 8, 1994. 


\section{Chapter V}

\section{Summary}

\section{1. ${ }^{10} \mathrm{Be}$ in the Central American Volcanic Arc}

The Central American Volcanic Arc exhibits a wide range of ${ }^{10} \mathrm{Be}$ concentrations from background to highly enriched (e.g., Morris et al., 1990). The transition between highest and lowest ${ }^{10} \mathrm{Be}$ concentrations occurs between southeastern Nicaragua and northwestern Costa Rica, in an area where many of the primary tectonic characteristics as well as most of the geochemical tracers in the arc change only moderately and in a gradational rather than abrupt manner (e.g., Protti et al., 1995; Patino et al., 2000; Barckhausen et al., 2001).

This thesis research examined geophysical and geochemical data to introduce a new tectonic model that links arc volcanic ${ }^{10} \mathrm{Be}$ variability between Nicaragua and Costa Rica with changes in the fault morphology of the subducting plate. By considering the major tectonic parameters of the Middle America Trench/Central American Volcanic Arc subduction system, ${ }^{10} \mathrm{Be}$ enrichment was discussed not just within the focus of one narrow region but also within the context of the entire arc.

The first components of a subduction zone system that will affect concentrations of

${ }^{10} \mathrm{Be}$ in the arc volcanic rocks are the ${ }^{10} \mathrm{Be}$ budget in the subducting sediment column and the rate of its delivery to the trench. Drill cores from DSDP Site 495 offshore of Guatemala and ODP Site 1039 offshore of Costa Rica recorded similar thicknesses of the trench sediment package (Aubouin et al., 1982; Kimura et al., 1997). Multichannel seismic (MCS) data from this thesis, and in the literature (e.g., Aubouin et al., 1982; Christeson et al., 1999; Ranero et al., 2000), also imaged comparable sediment thicknesses offshore of Guatemala, Nicaragua, and Costa Rica. The downcore ${ }^{10} \mathrm{Be}$ analyses of the aforementioned drill sites indicate that the total ${ }^{10} \mathrm{Be}$ in the two regions differs by about $30 \%$, but the uppermost portion within each drill site was potentially unrepresentative of most of the trench. The shallowest sections of the drill cores (the top ten meters) contain $20-30 \%$ of the ${ }^{10} \mathrm{Be}$ budget (Zheng et al., 1994) and the zero-age ${ }^{10} \mathrm{Be}$ concentration, a critical value to integrating ${ }^{10} \mathrm{Be}$ over the total sediment column. 
Therefore, part of this thesis research was to measure ${ }^{10} \mathrm{Be}$ concentrations in surficial Middle America Trench sediments that were located along the length of the entire trench.

Though some variability in sedimentary ${ }^{10} \mathrm{Be}$ concentrations was observed both within and between cores, there is no evidence that suggests fluctuations in the sedimentary ${ }^{10} \mathrm{Be}$ as the source of the arc volcanic ${ }^{10} \mathrm{Be}$ pattern. Additionally, along the trench there is a consistently short recycling period of $\sim 2-2.5 \mathrm{Myr}$ due to the relatively fast convergence rate of $73-85 \mathrm{~mm} / \mathrm{yr}$ from northwest to southeast, with the faster convergence rates being offset by shorter distances from trench to the base of the volcanic arc (DeMets, 2001; Morris et al., 2002). By eliminating changes in incoming ${ }^{10} \mathrm{Be}$ concentrations as the primary control on arc volcanic ${ }^{10} \mathrm{Be}$, sediment subduction dynamics (i.e., offscraping, underplating, or tectonic erosion), and/or geochemical influences on incorporation of ${ }^{10} \mathrm{Be}$ into arc magmas must be invoked.

The arc volcanic ${ }^{10} \mathrm{Be}$ concentrations that smoothly increase from Guatemala to northwestern Nicaragua co-vary robustly with other slab tracers such as $\mathrm{Ba} / \mathrm{La}$ and $\mathrm{B} / \mathrm{Be}$, indicating that there is no geochemical decoupling beneath the arc during magmatic incorporation. The most likely explanation for ${ }^{10} \mathrm{Be}$ changes in this portion of the arc is also the one used to explain the behavior of the other tracers, which is that the steepening slab dip at depths beneath the arc from Guatemala to northwestern Nicaragua causes increased slab flux, and therefore an increased slab-derived geochemical component to the arc (Carr et al., 1990). However, this hypothesis breaks down between southeastern Nicaragua and northwestern Costa Rica, where the slab dip at depth beneath the arc and the slab tracers in the arc with which ${ }^{10} \mathrm{Be}$ is normally associated, i.e., $\mathrm{Ba} / \mathrm{La}$ and $\mathrm{B} / \mathrm{Be}$, remain constant, yet ${ }^{10} \mathrm{Be}$ concentrations drop from the highest globally observed to values that indicate only a minimal contribution of the shallow sediments that carry ${ }^{10} \mathrm{Be}$. Additionally, beneath central Costa Rica the slab dip beneath the arc is comparable to that beneath Guatemala, yet Guatemalan lavas are moderately enriched in ${ }^{10} \mathrm{Be}$ whereas the Costa Rican lava concentrations are indistinguishable from mantle values of ${ }^{10} \mathrm{Be}$.

The decoupling of ${ }^{10} \mathrm{Be}$, present in enriched concentrations only in shallow sediments, from $\mathrm{Ba} / \mathrm{La}$, which is constant through the entire sediment column, indicates that there 
might be a change in subduction systematics that affects the surficial, ${ }^{10} \mathrm{Be}$-bearing sediments but not the bulk of the sediment column. The observation that high-relief basement faults with throws as great as the overlying sediment thickness occur offshore of Nicaragua but not Costa Rica led to a principal underlying hypothesis for the thesis. We proposed that the pronounced basement roughness offshore of Nicaragua enables efficient shallow sediment subduction and therefore transportation of ${ }^{10} \mathrm{Be}$ to the depths of magma genesis, but the absence of these faults in the subducting crust offshore of Costa Rica allows for removal of the sedimentary ${ }^{10} \mathrm{Be}$ through underplating.

A correlation between fault relief associated with plate bending and arc volcanic ${ }^{10} \mathrm{Be}$ variations between southeastern Nicaragua and northwestern Costa Rica was verified by utilizing a second-order stochastic statistical model (Goff and Jordan, 1988) to analyze fault relief as imaged in high-resolution swath bathymetry and MCS data. We demonstrated that the transition in fault relief was spatially coincident with the transition in arc volcanic ${ }^{10} \mathrm{Be}$ concentrations. Large basement faults offshore of Nicaragua likely inhibit formation of the décollement within the subducting sediment layer, providing a means by which the entire sediment column can be subducted to depths beneath the arc. Below a certain fault throw, the faults can no longer effectively interfere with relocation of the décollement along a weak stratigraphic layer or slip surface within the subducting sediment column (e.g., von Huene and Scholl, 1991; Pickering, 1993).

Though underplating has not yet been unequivocally identified within seismic data, this conceptual model is consistent with a process that can dramatically affect ${ }^{10} \mathrm{Be}$ concentrations in the arc while the range of other slab tracers such as $\mathrm{Ba} / \mathrm{La}$ remains constant (e.g., Valentine et al., 1997). As tectonic erosion and net subsidence have been measured in the lower forearc slope since 16-17 Ma (Vannucchi et al., 2001), underplating, which would require some amount of uplift landward of the trench, was probably episodic. It is likely that on the short recycling time scale of ${ }^{10} \mathrm{Be}$ in this region (i.e., since $2 \mathrm{Ma}$ ), underplating has been the dominant mechanism controlling shallow sediment recycling, whereas tectonic erosion has been more important over longer times scales. Studies of uplift since the Pleistocene in the forearc region of northwestern Costa 
Rica have been sparse, but this quantification would be necessary to further demonstrate the viability of the underplating scenario as the cause of the low to background ${ }^{10} \mathrm{Be}$ concentrations in northwestern Costa Rican arc volcanic rocks.

\section{Future Work}

Through the course of this thesis research exploring the processes governing ${ }^{10} \mathrm{Be}$ enrichment in the Central American Volcanic Arc, some interesting geodynamic and geochemical relationships revealed likely avenues of future work. The cause of the transition in bending-induced fault relief in the Cocos plate was not immediately apparent, as the specific location did not directly coincide with any of the major tectonic boundaries in the region. We found that fault relief was linearly related to plate curvature (as calculated by slope of the plate at the trench) and trench depth. But what was causing the flexural shape of the plate to change in this particular way? The age of the plate was not significantly different, yet there was a systematic southeastward shoaling of the plate offshore of southeastern Nicaragua and northwestern Costa Rica that could not be easily explained.

If the age of a bending plate is not the source of flexural differences, the other likely cause will be a change in buoyancy due to crustal thickness and/or thermal regime. Though variations in these controls do not exist where the trench depth and plate curvature begin to decrease, offshore of Costa Rica to the southeast is a region that includes thick, hot, and young crust due to the Fisher seamounts and the aseismic Cocos Ridge, which is a track of the magmatic interplay between the Galapagos hot spot and the Cocos-Nazca Spreading Center (Hey, 1977; Lonsdale and Klitgord, 1978). Crustal thickness reaches a maximum of $21 \mathrm{~km}$ at the center of the Cocos Ridge, $\sim 400 \mathrm{~km}$ away from the Nicaragua/Costa Rica border, but the crust is still 8-10 km thick at the northwest edge of the Cocos Ridge region (Walther, 2003). It seems likely that this buoyant load in the Cocos plate offshore of southeastern Costa Rica could be inducing a lateral flexural response in the plate to the northwest, resulting in the reduction in plate curvature and trench depth observed offshore of southeastern Nicaragua and northwestern Costa Rica. 
We plan to conduct flexural modeling of this region to determine if the lateral flexural wavelength of the Cocos plate is consistent with the increase in buoyancy from the Fisher seamount and Cocos Ridge crustal characteristics.

The general geophysical techniques used to study basement fault characteristics in the Cocos plate can also be expanded and applied to investigations that have wider implications. For example, fault reactivation during subduction in Tonga was linked to the generation of intermediate depth earthquakes (Jiao et al., 2000). Quantifying the distribution of faulting and deformation in the upper plate can identify events of slope failure and erosion due to wedge instability and the subduction of high-relief bathymetric features such as seamounts. As catastrophic tsunamigenic earthquakes have been induced by or connected to both large-scale slope failures and the subduction of major seafloor features such as aseismic ridges and tectonic boundaries (e.g., Bourgeois et al., 1999), this type of work can contribute to the assessment of marine and coastal tsunami risk factors.

The observation of local variations in ${ }^{10} \mathrm{Be}$ concentrations within the subducting sediments can also serve as a building block for future research. This section of the thesis (Chapter IV) will be strengthened in the future by the addition of organic carbon, carbonate, and biogenic silica data for the sediment samples. With this more exhaustive data set, the mixing behavior observed between endmember sediment components can be used to investigate the relative influence of different sources, such as riverine flux, volcanic ash, aeolian dust, biogenic productivity, or continental erosion of Central America, in controlling the geochemical makeup of Middle America Trench sediments. Additionally, as ${ }^{10} \mathrm{Be}$ concentrations in sediment are commonly used as tracers of paleoproductivity, paleomagnetism, and paleoclimate variability, quantification of the smaller scale factors that produce changes in ${ }^{10} \mathrm{Be}$ within these sediments will provide an important baseline to paleoceanographic investigations of ${ }^{10} \mathrm{Be}$ in the Middle America Trench region. 


\section{References}

Aubouin, J., R. von Huene, et al., Init. Repts. DSDP, 67, US Govt. Printing Office, Washington, DC, 1982.

Barckhausen, U., C.R., Ranero, R. von Huene, S.C. Cande, and H.A. Roeser, Revised tectonic boundaries in the Cocos Plate off Costa Rica; implications for the segmentation of the convergent margin and for plate tectonic models, J. Geophys. Res., 106, 19,207-19,220, 2001.

Bourgeois, J., C. Petroff, H. Yeh, V. Titoc, C.E. Synolakis, B. Benson, J. Kuroiwa, J.

Lander, and E. Norabuena, Geologic setting, field survey, and modeling of the

Chimbote, northern Peru, tsunami of 21 February 1996, Pure Appl. Geophys., 154, $513-$ $540,1999$.

Carr, M.J., M.D. Feigenson, and E.A. Bennett, Incompatible element and isotopic evidence for tectonic control of source mixing and melt extraction along the Central American arc, Contrib. Mineral. Petrol., 105, 369-380, 1990.

Christeson, G.L., K.D. McIntosh, T.H. Shipley, E. Flueh, H. Goedde, and G. Leandro, Structure of Costa Rica convergent margin, offshore Nicoya Peninsula, J. Geophys. Res., 104, 25,442-25,468, 1999.

DeMets, C., A new estimate for present day Cocos-Caribbean plate motion: Implications for slip along the Central American volcanic arc, Geophys. Res. Lett., 28, 2001.

Goff, J. A., and T.H. Jordan, Stochastic modeling of seafloor morphology: Inversion of Seabeam data for second-order statistics, J. Geophys. Res., 93, 13,589-13,608, 1988.

Hey, R., Tectonic evolution of the Cocos-Nazca spreading center, Geol. Soc. Am. Bull., $88,1404-1420,1977$.

Jiao, W., P.G. Silver, W. Fei, and C.T. Prewitt, Do intermediate- and deep-focus earthquakes occur on preexisting weak zones? An examination of the Tonga subduction zone, J. Geophys. Res., 105, 28,125-28,138, 2000.

Kimura, G., E. Silver, P. Blum, et al., Proc. ODP. Init. Repts., 170, College Station, TX (Ocean Drilling Program), 1997. 
Lonsdale, P. and K.D. Klitgord, Structure and tectonic history of the eastern Panama Basin, Geol. Soc. Am. Bull. 89, 981-999, 1978.

Morris, J.D., W.P. Leeman, and F. Tera, The subducted component in island arc lavas: constraints from Be isotopes and B-Be systematics, Nature, 344, 31-36, 1990.

Morris, J.D., J. Gosse, S. Brachfeld, and F. Tera, Cosmogenic Be-10 and the Solid Earth: Studies in Geomagnetism, Subduction Zone Processes, and Active Tectonics, in Beryllium: Mineralogy, Petrology, and Geochemistry, Reviews in Mineralogy and Geochemistry, 50, edited by E.S. Grew, pp. 207-270, Mineralogical Society of America, Washington, D.C., 2002.

Patino, L.C., M.J. Carr, and M.D. Feigenson, Local and regional variations in Central American arc lavas controlled by variations in subducted sediment input, Contrib. Mineral. Petrol., 138, 265-283, 2000.

Pickering, K.T., Is the décollement in Nankai accretionary prism localized at a lithological change? New evidence from rare earth elements, and other geochemical data, Terra Abstracts, 5, p. 345, 1993.

Protti, M., F. Guendel, and K. McNally, Correlation between the age of the subducting Cocos plate and the geometry of the Wadati-Benioff zone under Nicaragua and Costa Rica, in: Geologic and Tectonic Development of the Caribbean Plate Boundary in Southern Central America, P. Mann, ed., GSA Spec. Pap., 295, 309-326, 1995.

Ranero, C.R., R. von Huene, E. Flueh, M. Duarte, D. Baca, and K. McIntosh, A cross section of the convergent Pacific margin of Nicaragua, Tectonics, 19, 335-357, 2000.

Valentine, R.B., J.D. Morris, and J. Duncan, D., Sediment subduction, accretion, underplating, and arc volcanism along the margin of Costa Rica: Constraints from $\mathrm{Ba}$, $\mathrm{Zn}, \mathrm{Ni}$, and ${ }^{10} \mathrm{Be}$ concentrations, EOS Trans. AGU, 78, 46, 1997.

Vannucchi, P., D.W. Scholl, M. Meschede, and K. McDougall-Reid, Tectonic erosion and consequent collapse of the Pacific margin of Costa Rica: combined implications from ODP Leg 170, seismic offshore data, and regional geology of the Nicoya Peninsula, Tectonics, 20, 649-668, 2001. 
von Huene, R.J., and D.W. Scholl, Observations at Convergent Margins concerning sediment subduction, subduction erosion, and the growth of continental crust, Rev. of Geophysics, 29, 279-316, 1991.

Walther, C.H.E., The crustal structure of the Cocos Ridge off Costa Rica, J. Geophys. Res., 108, doi:10.1029/2001JB000888, 2003.

Zheng, S.H., J.D. Morris, F. Tera, J. Klein, and R. Middleton, Beryllium isotopic investigation of sedimentary columns outboard of subduction zones, ICOG, 8, 1994. 
Appendix 1. Core descriptions are provided for the cores from which samples in this study were taken. Core descriptions for EW0104 cores are from M. Underwood (EW0104 Shipboard Party; Fisher et al., 2001). Core descriptions for Lamont-Doherty cores are from the Lamont-Doherty Earth Observatory Core Repository. 


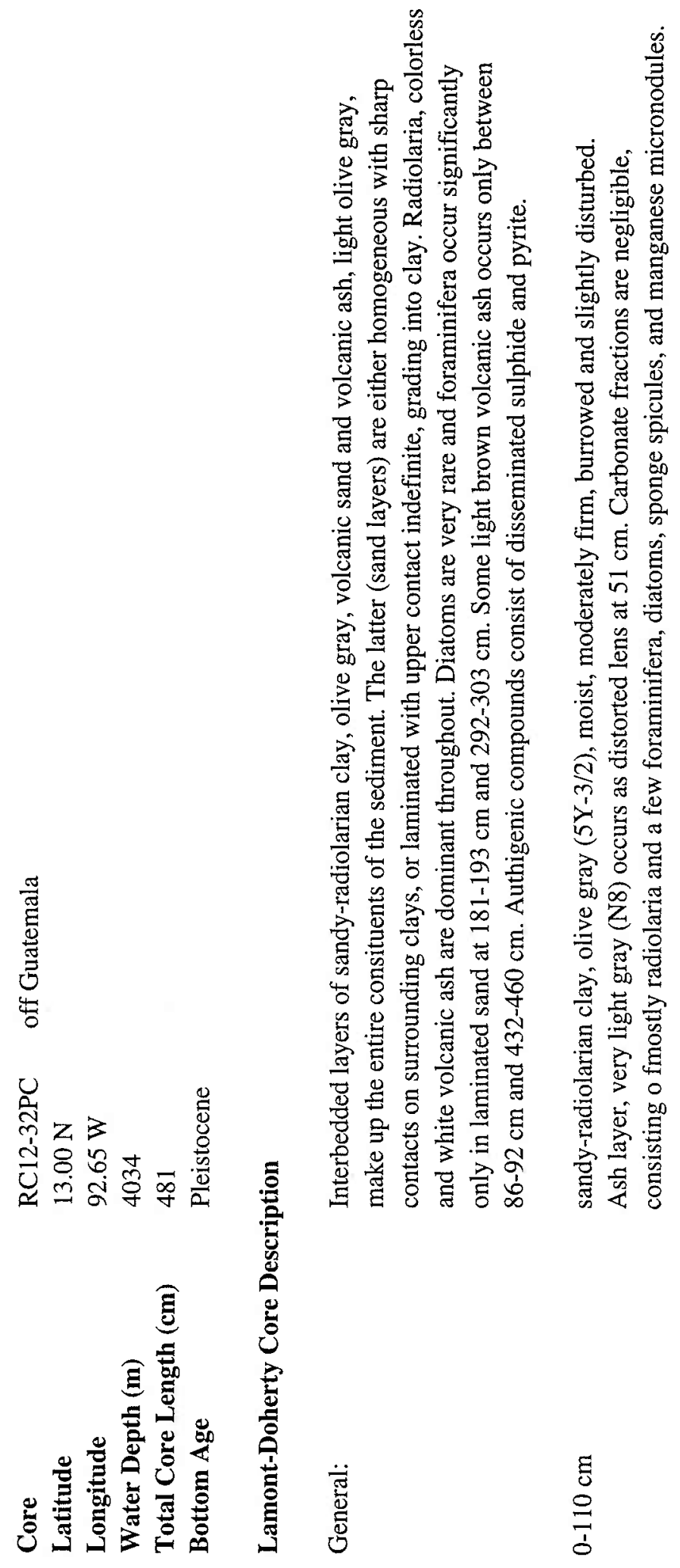


Core

Latitude

Longitude

Water Depth (m)

Total Core Length $(\mathrm{cm})$

Bottom Age No age determinable.

\section{Lamont-Doherty Core Description}

$0-5 \mathrm{~cm}$ dark green lutite mottled with black hydrotroilite

5-7 cm dark green lutite slightly burrowed. Burrow contains olive green lutite.

$17-30 \mathrm{~cm} \quad$ gray white volcanic ash burrowed with green lutite.

30-67 cm dark green lutite, slightly burrowed. Silt-like grit may be more volcanic ash.

$67-90 \mathrm{~cm}$ white to green-white volcanic ash burrow in matrix of green lutite. Lighter colors contain almost pure ash zones.

90-92 cm black ash burrow containing 70-80\% black ash and green lutite.

92-200 cm green lutite with very sparse olive green burrowing. Slight grit present possibly volcanic shards. Lighter colors do not appear to indicate an increase in ash content

$200-210 \mathrm{~cm}$ piston effect

$210-272 \mathrm{~cm}$ uniform, dark green lutite. Light olive green to green burrowing present.

$272-276 \mathrm{~cm}$ black volcanic ash burrows in green lutite matrix.

276-380 cm green lutite, slightly burrowed. Light green burrows contain silty material (probably ash). Shards are visible throughout as glistening silt-size flecks.

$380-390 \mathrm{~cm}$ white ash burrows in green lutite matrix.

$390-474 \mathrm{~cm} \quad$ uniform green lutite. Numerous silt-sized shards easily visible.

$474-478 \mathrm{~cm}$ white volcanics ash bed, slightly burrowed.

$478-512 \mathrm{~cm} \quad$ uniform green lutite. Shards present throughout.

$512-519 \mathrm{~cm}$ black volcanic ash burrow in matrix of green lutite.

$519-539 \mathrm{~cm}$ uniform green lutite with shards disseminated throughout.

$539-542 \mathrm{~cm} \quad$ black volcanic ash bed showing very slight burrowing. 
VM15-26 continued

$542-570 \mathrm{~cm}$ green lutite with fine sand/silt size shards. Occasional burrows of black ash present.

$570-584 \mathrm{~cm}$ white ash burrow in matrix of green lutite.

$584-673 \mathrm{~cm} \quad$ green lutite with fine sand-silt sized shards. Very slight burrowing present.

\section{Trigger Weight}

0-20 cm clay, pale olive (10Y-6/2), hard and dry. Carbonate content nil. Coarse fraction about $15 \%$, consisting mostly of terrigenous quartz, feldspar, mica, magnetite and gypsum crystals. Planktonic foraminifera and radiolaria are negligible. 


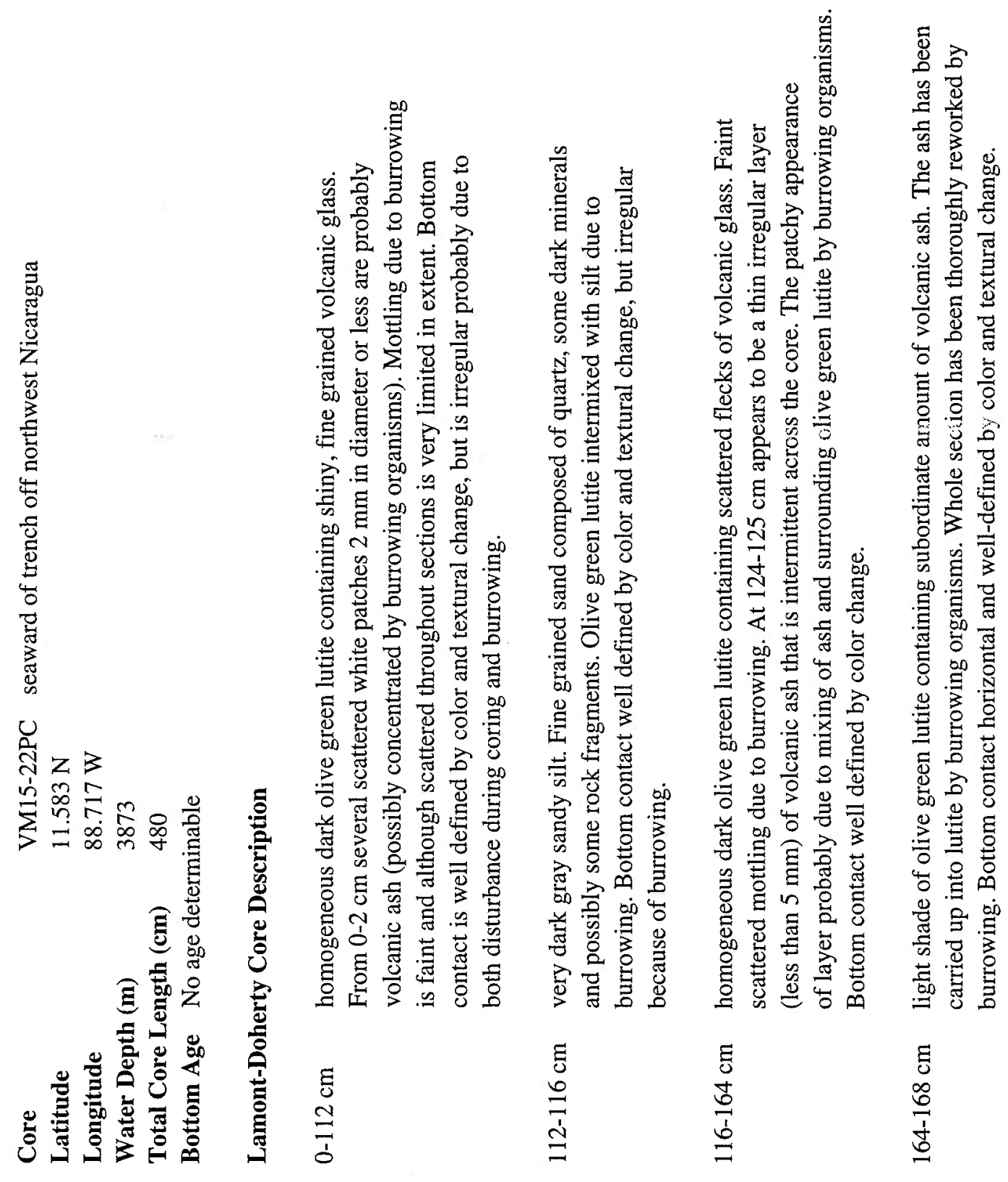




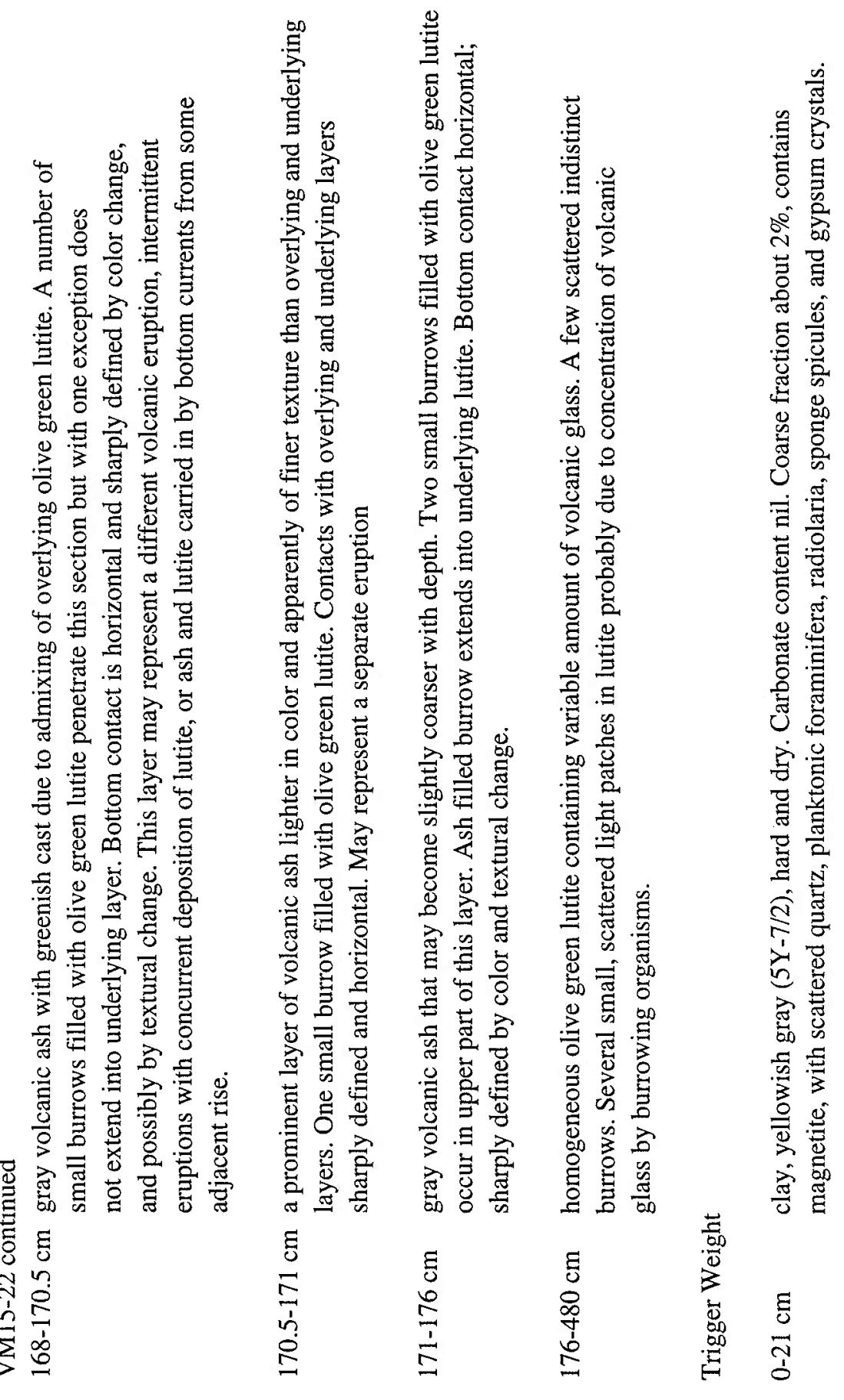




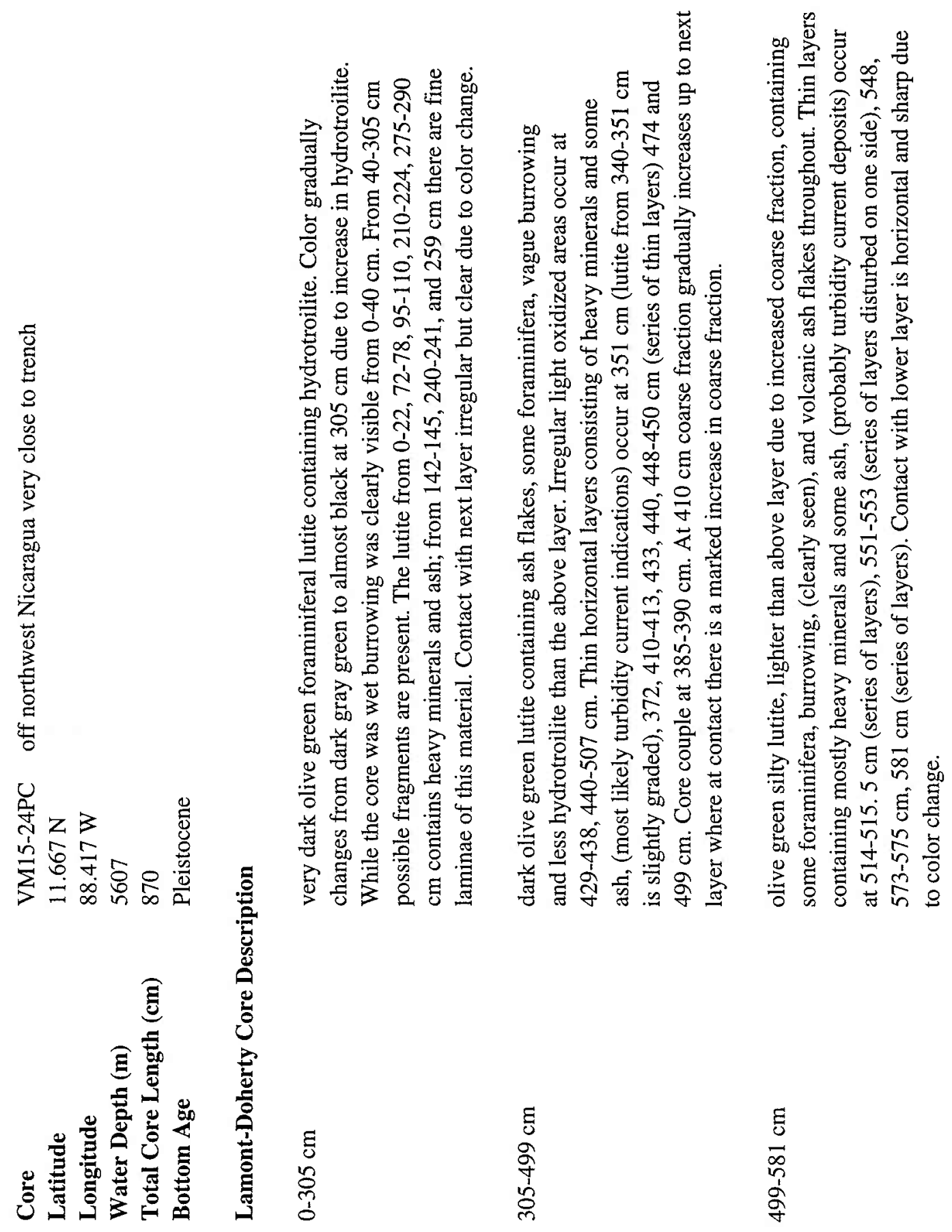




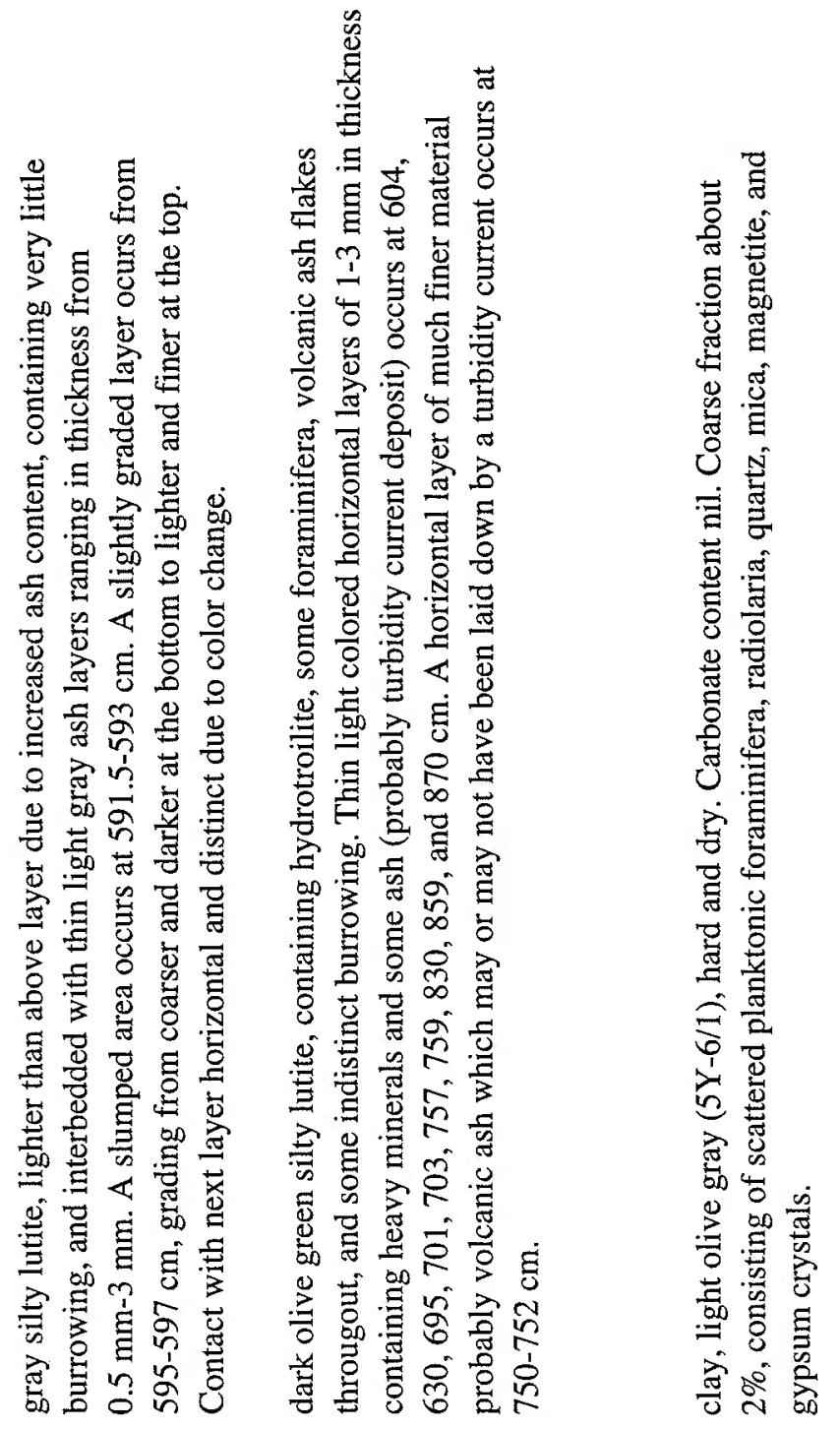

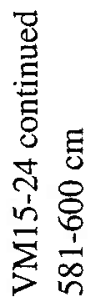

E
8
0
0
8
0

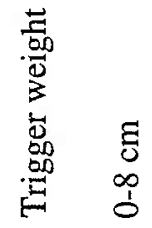




\author{
Core RC12-29PC off Nicaragua seaward of the outer rise bulge \\ Latitude $\quad 9.45 \mathrm{~N}$ \\ Longitude $\quad 88.033 \mathrm{~W}$ \\ Water Depth (m) 3274 \\ Total Core Length $(\mathbf{c m}) \quad 1050$ \\ Bottom Age Early, lower Pleistocene
}

\title{
Lamont-Doherty Core Description
}

General: $\quad$ Grayish olive clay, with white ash layer between $510 \mathrm{~cm}$ and $519 \mathrm{~cm}$ and scattered concentrations of brown vesicular glass. Burrows are common; the burrowing process has resulted in concentrations of brown glass within the burrows. Carbonate content nil. Coarse fraction generally $10 \%$ in clay, consisting of radiolaria, planktonic foraminifera, diatoms and scattered brown glass; $90 \%$ in white ash layer, consisting of white ash; and $50 \%$ in black layers, consisting of brown vesicular glass, radiolaria, planktonic foraminifera, and diatoms. Bottom contacts are sharp.

0-510 cm clay, grayish olive (10Y 4/2), moist, firm, plastic and burrowed. Carbonate content nil. Coarse fraction 5-10\%, consisting of radiolaria, diatoms, planktonic foraminifera and scattered brown vesicular and white glass. Bottom contact a sharp color and lithologic change.

$510-519 \mathrm{~cm}$ volcanic ash, between very pale orange (10YR 8/2) and white (N9), moist, firm, compact and graded. Carbonate content nil. Coarse fraction $90 \%$, consisting of white ash. Bottom contact a sharp lithologic and color change on disturbed surface.

$519-809 \mathrm{~cm}$ clay, grayish olive (10Y 4/2) becoming dark greenish gray (5 GY/1), moist, firm, plastic and burrowed. Carbonate content nil. Coarse fraction 5-10\%, consisting of radiolaria, planktonic foraminifera, diatoms, and scattered brown vesicular glass. Bottom contact a sharp color and lithologic change.

$809-810 \mathrm{~cm}$ radiolarian-volcanic ash, olive black (5Y 2/1), moist, firm and plastic. Carbonate content nil. Coarse fraction $50 \%$, half of which consists of brown vesicular glass and the remainder being radiolaria and diatoms. Bottom contact a sharp color and lithologic change.

$810-891 \mathrm{~cm}$ clay, dark greenish gray (5 GY 4/1), moist, firm, plastic and burrowed. Carbonate content nil. Coarse fraction $10 \%$, consisting of brown vesicular glass, radiolaria, and scarce diatoms with planktonic foraminifera. Bottom contact a sharp color and lithologic change.

$891-893 \mathrm{~cm}$ radiolarian-volcanic ash, olive black (5Y 2/1), moist, firm, plastic and burrowed. Carbonate content nil. Coarse fraction $50 \%$, consisting of brown vesicular glass, radiolaria, diatoms, and rare planktonic foraminifera. Bottom contact a sharp color and lithologic change on burrowed surface. 
RC12-29 continued

893-1008 cm clay, greenish black (5 GY 2/1), moist, firm, plastic and burrowed. Similar to 810 $891 \mathrm{~cm}$ interval. Bottom contact a sharp color change at burrowed surface.

$1008-1050 \mathrm{~cm}$ clay, grayish olive (10Y 4/2), moist, firm, plastic and burrowed. Carbonate content nil. Coarse fraction 5\%, consisting of radiolaria and scarce planktonic foraminifera. 


$\begin{array}{lll}\text { Core } & \text { GC18 } & \text { Smear Slide Description } \\ & \text { (PC 18 trigger core) } & \text { none } \\ \text { Latitude } & 940.573 \mathrm{~N} & \\ \text { Longitude } & 8634.124 \mathrm{~W} & \\ \text { Water Depth }(\mathbf{m}) & 3317 & \\ \text { Total Core Length }(\mathrm{cm}) & 212 & \end{array}$

\section{EW0104 Core Description}

$0-150 \mathrm{~cm}$

homogeneous silty clay, dark olive gray

$142-145 \mathrm{~cm}$ (5Y-3/2) soupy and deformed from top to $25 \mathrm{~cm}$ white volcanic ash, inclined bed

$150-212 \mathrm{~cm}$

homogeneous dark olive gray silty clay

\section{Core \\ Latitude \\ Longitude \\ Water Depth (m) \\ Total Core Length $(\mathrm{cm})$}

\section{EW0104 Core Description}

\section{Section}

$0-41 \mathrm{~cm}$

$41-75 \mathrm{~cm}$

$75-221 \mathrm{~cm}$

$221-371 \mathrm{~cm}$
PC18

$940.573 \mathrm{~N}$

$8634.124 \mathrm{~W}$

3317

891
Smear Slide Description

none

subsection

(distance from top

of section)

dark olive gray (5Y-3/2) silty clay soupy at top, mottled to homogeneous

$2-3 \mathrm{~cm}$

white volcanic ash

rest of section dark olive gray silty clay

mottled, dark olive gray, silty clay

zoophycos common, irregular patches of black

ash

$62-63 \mathrm{~cm} \quad$ ash layer

$72-78 \mathrm{~cm} \quad$ vertical burrow filled with black heavily

altered ash

$106-107 \mathrm{~cm}$ ash layer

0-150 cm mottled dark olive gray silty clay

$110-114 \mathrm{~cm}$ irregular patch of black volcanic ash 
PC18 continued

$371-525 \mathrm{~cm}$

$0-154 \mathrm{~cm}$ mottled, dark olive gray silty clay

$8-12 \mathrm{~cm} \quad$ inclined patch of black ash

$122 \mathrm{~cm} \quad$ irregular patch of black ash

$525-675 \mathrm{~cm}$

$0-150 \mathrm{~cm}$ mottled, dark olive gray silty clay

$675-891 \mathrm{~cm}$

$0-116 \mathrm{~cm}$ mottled, dark olive gray silty clay

$55-56 \mathrm{~cm} \quad$ irregular patch of ash

$80-81 \mathrm{~cm}$ thin black volcanic ash layer 


$\begin{array}{lll}\text { Core } & \text { GC38 } & \text { Smear Slide Description } \\ & \text { (PC38 trigger core) none } \\ \text { Latitude } & 940.588 \mathrm{~N} \\ \text { Longitude } & 8634.132 \mathrm{~W} \\ \text { Water Depth }(\mathbf{m}) & 3318 \\ \text { Total Core Length }(\mathrm{cm}) & 208\end{array}$

\section{EW0104 Core Description}

$\begin{array}{ll}0-130 \mathrm{~cm} & \begin{array}{l}\text { homogeneous dark olive gray silty clay } \\ \text { top } 20 \mathrm{~cm} \text { soupy } \\ \text { homogeneous dark olive gray silty clay }\end{array} \\ 130-208 \mathrm{~cm} & \text { irregular patch of black volcanic ash }\end{array}$

$\begin{array}{ll}\text { Core } & \text { PC38 } \\ \text { Latitude } & 940.588 \mathrm{~N} \\ \text { Longitude } & 8634.132 \mathrm{~W} \\ \text { Water Depth }(\mathbf{m}) & 3318 \\ \text { Total Core Length }(\mathbf{c m}) & 798\end{array}$

EW0104 Core Description

Section

0-150 cm

$150-222 \mathrm{~cm}$

$222-372 \mathrm{~cm}$

$372-527 \mathrm{~cm}$ subsection (distance from top of section)

$0-72 \mathrm{~cm}$

$44 \mathrm{~cm}$

$0-150 \mathrm{~cm}$

$20-28 \mathrm{~cm}$

$0-155 \mathrm{~cm}$

$107-108 \mathrm{~cm}$

\section{Smear Slide Description} general: clay minerals, qtz/plag, silt, diatoms, radiolarian fragments, silica needles, traces of volcanic glass, some coccoliths ash: clear to moderately altered glass, plag, pyroxene, opaque grains, some heavily altered glass homogeneous to mottled, dark olive gray $(5 Y-3 / 2)$ silty clay top $20 \mathrm{~cm}$ soupy mottled dark olive gray silty clay very thin layer of black volcanic ash mottled, dark olive gray silty clay scattered zoophycos burrow filled with light gray volcanic ash mottled dark olive gray silty clay thin irregular layer of black volcanic ash 
PC38 continued

$527-677 \mathrm{~cm}$

$677-798 \mathrm{~cm}$

$0-150 \mathrm{~cm}$

4-5 cm

$30-37 \mathrm{~cm}$

$0-97 \mathrm{~cm}$

$10-20 \mathrm{~cm}$

$97-121 \mathrm{~cm}$ mottled dark olive gray silty clay

irregular patches of black volcanic

ash

mottled, dark olive gray silty clay

irregular patch of gray volcanic ash

fine sand sized

whole round for pore waters 
Core

Latitude

Longitude

Water Depth (m)

Total Core Length $(\mathrm{cm})$

\section{EW0104 Core Description}

$0-22 \mathrm{~cm}$

$22-100 \mathrm{~cm}$

$100-150 \mathrm{~cm}$
$150-302 \mathrm{~cm}$

$247-250 \mathrm{~cm}$

$282-302 \mathrm{~cm}$
GC43

$98.144 \mathrm{~N}$

Smear Slide Description

$8654.845 \mathrm{~W}$

2902

302

none metal core top, soupy dark olive gray silty clay, top $2 \mathrm{~cm}$ organic rich

dark grayish brown $(2.5 \mathrm{Y}-4 / 2)$ to gray

$(5 Y-5 / 1)$ clay to silty clay

dark olive gray (5Y-3/2) silty clay,

mottled contacts, subtle color changes

mostly due to diatom content, clay

homogeneous to mottled, dark olive gray

silty clay

light gray volcanic ash irregular layer

core cutter extruded 


\begin{tabular}{lll} 
Core & GC36 & \multicolumn{1}{c}{ Smear Slide Description } \\
& (PC36 trigger core) & mostly clay minerals, plag, silt, some \\
Latitude & $856.250 \mathrm{~N}$ & medium to coarse, very little biogenic \\
Longitude & $8640.953 \mathrm{~W}$ & grains \\
Water Depth (m) & 3123 & \\
Total Core Length (cm) & 98 &
\end{tabular}

EW0104 Core Description

$0-98 \mathrm{~cm} \quad$ olive brown $(2.5 \mathrm{Y}-4 / 4)$ clay to silty

clay, homogeneous, upper $20 \mathrm{~cm}$ soupy

$\begin{array}{lll}\text { Core } & \text { PC36 } & \text { Smear Slide Description } \\ \text { Latitude } & 856.250 \mathrm{~N} & 17 \mathrm{~cm} \text { volcanic ash: slightly altered glass } \\ \text { Longitude } & 8640.953 \mathrm{~W} & \text { plag, opaque grains, vitric rock fragments } \\ \text { Water Depth }(\mathbf{m}) & 3123 & \text { general: mostly clay, minor radiolarians, } \\ \text { Total Core Length }(\mathbf{c m}) & 641 & \text { plag silt, trace coccolith, glass shards } \\ & & \begin{array}{l}282 \mathrm{~cm} \text { ash: clear fresh glass, plagioclase } \\ \text { xtls }\end{array}\end{array}$

EW0104 Core Description

Section

$0-85 \mathrm{~cm}$

subsection

(distance from top

of section)

$0-17 \mathrm{~cm} \quad$ void

$17-30 \mathrm{~cm} \quad$ grayish brown $(2.5 \mathrm{Y}-5 / 2)$ volcanic ash, sand sized, sharp base, top not intact

$30-85 \mathrm{~cm} \quad$ olive brown $(2.5 \mathrm{Y}-4 / 4)$ clay to silty clay, homogeneous

$85-235 \mathrm{~cm}$

$0-37 \mathrm{~cm}$

dark grayish brown clay, diffuse lower boundary, homogeneous

$37-120 \mathrm{~cm}$ dark gray silty clay, subtle color variations mottled

$120-150 \mathrm{~cm}$ dark olive gray silty clay, homogeneous

$235-390 \mathrm{~cm}$

dark gray to dark olive gray, $5 \mathrm{Y}-4 / 1$

to $5 \mathrm{Y}-3 / 2$, silty clay

0-47 cm scattered zoophycos

47-57 cm gray to light gray volcanic ash, sharp base, fine sand sized normal grading

$57-155 \mathrm{~cm} \quad$ scattered zoophycos 
PC36 continued

$390-496 \mathrm{~cm}$

0-6 cm homogeneous dark olive gray silty clay

6-15 cm light gray volcanic ash, sharp base, irregular salt and pepper, sand sized

$15-106 \mathrm{~cm} \quad$ homogeneous dark olive gray silty clay

496-641 cm

0-115 cm void-filled with seawater

$115-145 \mathrm{~cm} \quad$ extruded from core liner, dark olive

gray, silty clay, soupy, layering not intact 
Core

Latitude

Longitude

Water Depth (m)

Total Core Length $(\mathrm{cm})$

\section{EW0104 Core Description}

Section

$0-120 \mathrm{~cm}$

$120-200 \mathrm{~cm}$

$200-350 \mathrm{~cm}$

$350-504 \mathrm{~cm}$

$504-654 \mathrm{~cm}$

654-774 cm
PC37

$856.453 \mathrm{~N}$

$8641.11 \mathrm{~W}$

3126

774
Smear Slide Description

none

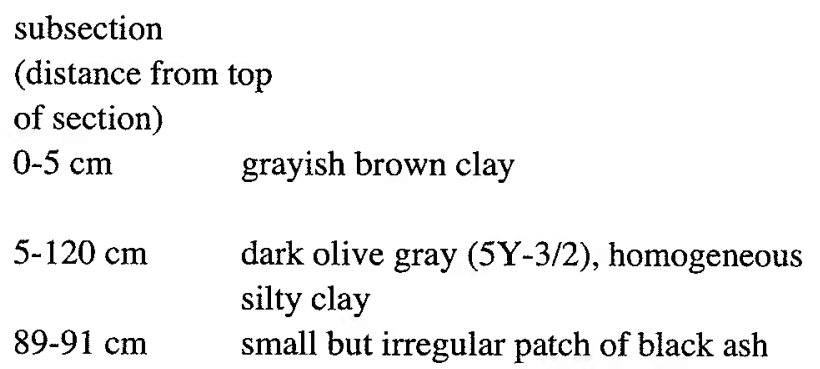

0-80 $\mathrm{cm}$ homogeneous dark olive gray silty clay

$0-150 \mathrm{~cm}$ homogeneous dark olive gray silty clay

$0-18 \mathrm{~cm} \quad$ homogeneous dark olive gray silty clay

$18-115 \mathrm{~cm} \quad$ Void

$115-154 \mathrm{~cm}$ dark olive gray silty clay, disrupted

$0-25 \mathrm{~cm}$ dark olive gray homogeneous clay

$25-35 \mathrm{~cm} \quad$ light gray volcanic ash, sharp base, irregular deformed top, fine sand sized

$35-150 \mathrm{~cm}$ dark olive gray homogeneous silty clay

$0-120 \mathrm{~cm}$ homogeneous dark olive gray silty clay 
Core

Latitude

Longitude

Water Depth (m)

Total Core Length $(\mathrm{cm})$
GC09

$844.519 \mathrm{~N}$

$8712.820 \mathrm{~W}$

3044

297

\section{EW0104 Core Description}

Smear Slide Description

none

top $35 \mathrm{~cm}$ extruded from metal core top

$0-150 \mathrm{~cm}$

$58-60 \mathrm{~cm}$

$85-87 \mathrm{~cm}$

$95-97 \mathrm{~cm}$

$150-255 \mathrm{~cm}$

$255-297 \mathrm{~cm}$

core catcher not kept light olive brown to light yellowish brown silty clay slightly mottled, gradual lightening of color down core thin volcanic ash beds, sand sized to silt sized glass shards, clear fresh glass

light gray to pale yellow, locally mottled, silty clay gradual lightening down core due to increase in coccoliths, nanno-rich toward contact w/chalk white chalk mottled contact, homogeneous below 
Appendix 2. Kelly, R.K., P. Kelemen, and M. Jull, Buoyancy of the Continental Upper Mantle, Geochemistry, Geophysics, Geosystems, v. 4, doi:10.1029/2002GC000399, 2003. 


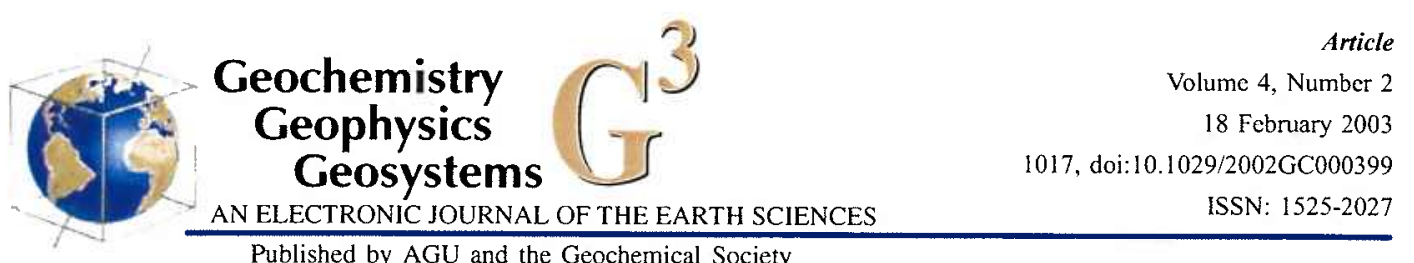

Published by AGU and the Geochemical Society

\title{
Buoyancy of the continental upper mantle
}

\author{
Robyn K. Kelly \\ Department of Geology and Geophysics, MIT-Woods Hole Oceanographic Institution Joint Program, Woods Hole, \\ Massacbusetts 02543, USA (rkelly@wboi.edu) \\ Peter B. Kelemen and Matthew Jull \\ Department of Geology and Geophysics, Woods Hole Oceanographic Institution, Woods Hole, Massacbusetts O2543, USA
}

[1] The thermal boundary layer beneath continental cratons extends into the Earth's mantle to depths of at least $200 \mathrm{~km}$. It has been proposed that chemical depletion of the lithospheric mantle during partial melting offsets the effect of increased density from conductive cooling, resulting in neutral buoyancy with respect to the underlying asthenosphere. Mineral compositions of gamet peridotite xenoliths in the Kaapvaal craton give equilibration temperatures and pressures that define a continental conductive geotherm intersecting a mantle adiabat with a potential temperature of $1300^{\circ} \mathrm{C}$ at $\sim 60 \mathrm{kbar}$. We calculated normative densities for a "low-temperature" garnet and spinel peridotite xenolith suite using Mg\#. At their temperatures and pressures of equilibration, all the low-temperature peridotites are positively buoyant with respect to the convecting mantle, which is inconsistent with the hypothesis of a neutrally buoyant thermal boundary layer. To account for the possibility that pressure, temperature, and mineral proportions may have varied over time, equilibrium solidus mineral assemblages for the low-temperature xenoliths over a range of pressures and temperatures were generated by free energy minimization using the program Perplex (http://www.perplex.ethz.ch). The equilibrium solidus densities for xenolith compositions along a $40 \mathrm{~mW} /$ $\mathrm{m}^{2}$ conductive geotherm were compared with the density of pyrolite along a mantle adiabat with a potential temperature of $1300^{\circ} \mathrm{C}$. These density calculations show that most of the xenoliths are positively buoyant with respect to asthenospheric mantle ("pyrolite") at their temperatures and pressures of equilibration, confirming the results from the normative density calculations. Also, at the onset of the accretion of the Kaapvaal craton, when the thermal boundary layer was thinner and hotter than today, these Kaapvaal peridotites would have been positively buoyant with respect to the convecting mantle at shallower pressures. Therefore we propose that peridotite at the base of the Kaapvaal "plate," in the mantle thermal boundary layer, was and is positively buoyant. Combined with evidence from the geoid and geomorphology, which suggests that cratons are isostatically compensated and neutrally buoyant, our results imply that there must be dense layers within cratonic crust or upper mantle that offset the positive buoyancy of depleted cratonic mantle peridotites.

Components: 9775 words, 14 figures.

Keywords: Kaapval craton; xenoliths; density; peridotites; buoyancy; mantle.

Index Terms: 1025 Geochemistry: Composition of the mantle; 8120 Tectonophysics: Dynamics of lithosphere and mantlegeneral; 3640 Mineralogy and Petrology: Igneous petrology; 8124 Tectonophysics: Earth's interior-composition and state (old 8105).

Received 21 June 2002; Revised 11 October 2002; Accepted 15 October 2002; Published 18 February 2003.

Kelly, R. K., P. B. Kelemen, and M. Jull, Buoyancy of the continental upper mantle, Geochem. Geophys. Geosyst., 4(2), 1017, doi: 10.1029/2002GC000399, 2003. 


\section{Introduction}

[2] Seismological and petrological studies have determined that beneath the continental cratons, the thermal boundary layer extends much deeper into the Earth's mantle than it does beneath younger continental and oceanic crust [Jordan, 1975a, 1975b]. Constraints from equilibration pressures and temperatures of mantle xenoliths erupted within cratons indicate a conductive thermal boundary layer thickness of about 180 to $240 \mathrm{~km}$ [e.g., Finnerty and Boyd, 1987; Rudnick and Nyblade, 1999; Ryan et al., 1996; Poudjom Djomani et al., 2001]. Teleseismic tomography has shown that this "tectosphere" [Jordan, 1975a] might locally extend to over $300 \mathrm{~km}$ depth [Jordan, 1988], an observation supported by the large flexural rigidities for old continental platforms [Karner and Watts, 1983; Karner et al., 1983; Kusznir and Karner, 1985; Forsyth, 1985; Lowry and Smith, 1994; Poudjom Djomani et al., 1995, 1999].

[3] If the thickness of the continental thermal boundary layer were not limited by small scale convective disruption at its base, and instead could continue thickening due to conductive cooling [e.g., Parsons and Sclater, 1977], the thermal boundary layer in the subcratonic mantle could conceivably achieve the depth that is inferred from seismic data beneath the cratons [Jordan, 1988]. However, there are indications that the cratonic thermal boundary layers do not develop due to conductive cooling alone [Jordan, 1988]. Though conductive cooling could explain the thickening of the lithosphere, it would also require subsidence of the surface to the point that the cratons should either be under water or should have overlying sedimentary layers more than $\sim 5$ $\mathrm{km}$ thick, neither of which is observed [Jordan, 1975a; Oxburgh and Parmentier, 1978; Poupinet and de Voogd, 1981]. Also, if the cratonic upper mantle were simply a thick thermal boundary layer with near-surface isostatic compensation, this shallow compensation would be reflected in the long-wavelength geoid. This compensation is not evident [Jordan, 1975a; Haxby and Turcotte, 1978; Parsons and Richter, 1980; Richards and Hager, 1984].
[4] Long-term conductive cooling will also result in the lithosphere becoming negatively buoyant with respect to the underlying convecting mantle. This negative buoyancy could create convective instability of the lithosphere, with all or part of the thermal boundary layer foundering into the convecting mantle [e.g., Bird, 1979; Houseman et al., 1981]. The thickness and stability of the thermal boundary layer underneath cratons, as indicated seismically and based on xenolith studies, suggest that convective instabilities have not removed large parts of the cratonic upper mantle for several billion years [Jordan, 1975a; Parsons and McKenzie, 1978].

[5] To explain the formation and accretion of stable cratonic upper mantle, Jordan [1988] postulated the existence of a chemical boundary layer in the mantle beneath cratons that is sufficiently buoyant and viscous to be stabilized against convection. This chemical boundary layer is depleted in basaltic materials relative to the mantle beneath mid-ocean ridges, counteracting the effect of increased density due to conductive cooling. At a given temperature, peridotites with high $\mathrm{Mg} \#$ (molar $100 * \mathrm{Mg} /(\mathrm{Mg}+$ Fe)) due to extraction of heavier basaltic components have a lower density than those with lower Mg\# [O'Hara, 1975; Boyd and McCallister, 1976; Green and Lieberman, 1976; Jordan, 1979]. Jordan [1988] derived a relationship between whole rock $\mathrm{Mg} \#$ and density normalized to a standard temperature and pressure (normative density) demonstrating how compositional changes affect the buoyancy of continental mantle material. According to this relationship, a one unit increase in the $\mathrm{Mg \#}$ will counteract the negative buoyancy caused by a temperature decrease of $\sim 200^{\circ} \mathrm{C}$. The proposed chemical boundary layer would be composed of residual mantle peridotites whose depletion by partial melting resulted in higher $\mathrm{Mg \# s}$ than in the mantle beneath younger continental regions and oceanic plates. Jordan [1988] hypothesized an "isopycnic" condition whereby the increased buoyancy caused by depletion exactly offsets the thermally induced density contrast between the relatively cold thermal boundary layer and the comparatively hot asthenospheric mantle, creating a neutrally buoyant chemical boundary layer (Figure 1). 


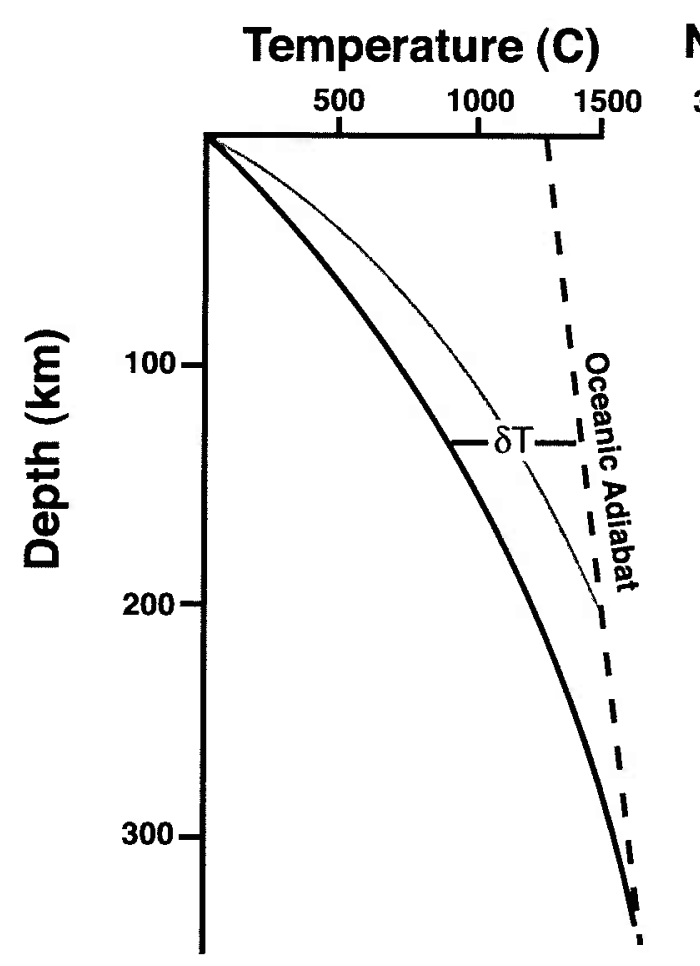

\section{Normative Density $\left(\mathrm{gm} / \mathrm{cm}^{3}\right)$}

$3.30 \quad 3.35 \quad 3.40$
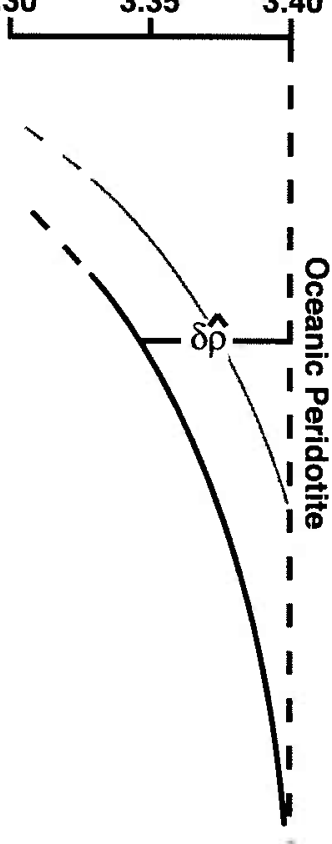

Figure 1. Illustration of the "isopycnic hypothesis" [Jordan, 1988], in which the cratonic upper mantle, extending to depths as great as $350 \mathrm{~km}$, is neutrally buoyant with respect to the asthenosphere. The effect of low temperatures along a conductive geotherm is offset by chemical buoyancy, resulting from $\mathrm{Fe}$ extraction during large degrees of partial melting. Assuming that compressibilities and expansivities are the same for all mantle peridotites, a neutrally buoyant chemical boundary layer has a "normative density" at 1 bar and $25^{\circ} \mathrm{C}$ that offsets the density difference due to the temperature contrast between craton and asthenosphere at a given depth. Thus, for

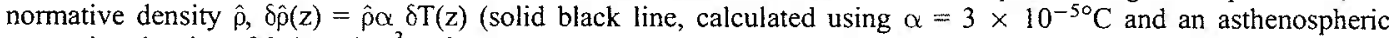
normative density of $3.4 \mathrm{gm} / \mathrm{cm}^{3}$ ). If the thermal boundary layer is thinner, as suggested by thermobarometric data which indicate intersection of the cratonic geotherm and a mantle adiabat at about $200 \mathrm{~km}$ depth (solid gray line), then isopycnic densities must be higher at any given depth. Modified from Jordan [1988] by permission of the Oxford University Press.

[6] Building on the idea of a positively buoyant cratonic mantle [e.g., Boyd and McCallister, 1976], Kelemen et al. [1998] postulated that buoyant regions within the subcratonic lithospheric mantle form the thick thermal boundary observed beneath the cratons via tectonic thickening (via pure shear, imbrication, or compositional convection) of initially thin, neutrally buoyant, shallow mantle peridotite depleted by large degrees of decompression melting. Transport of shallow, high $\mathrm{Mg} \#$ peridotite to greater depths and higher temperatures during thickening would produce a positive buoyancy contrast between the conductively cooling mantle lithosphere and the surrounding, convecting mantle. A stratified thermal boundary layer formed in this way, with a region of buoyant, residual peridotite near its base, would be more stable against convective instability than the neutrally buoyant mantle lithosphere proposed by Jordan [1988].

[7] Mantle xenoliths from cratonic regions provide the primary data on the chemical composition of the mantle near the base of the cratonic thermal boundary layer. The pressures and temperatures of 
equilibration of these xenoliths, as well as their composition, vary from craton to craton. However, the xenolith suites from each craton exhibit similar characteristics. The Kaapvaal craton in South Africa, for example, has yielded suites of xenoliths that include both "high-temperature" xenoliths preserving equilibration pressures ranging from $55 \mathrm{kbar}$ to $70 \mathrm{kbar}(165-210 \mathrm{~km})$, and "lowtemperature" xenoliths with equilibration pressures less than $60 \mathrm{kbar}(180 \mathrm{~km})$ [e.g., Finnerty and Boyd, 1987]. These xenoliths include both garnet and spinel peridotites and have higher $\mathrm{Mg \# s}$ than residual, oceanic peridotites dredged from the midocean ridges ("abyssal peridotites"). This indicates the xenoliths have undergone higher degrees of melting at some point in their history [e.g., Menzies, 1990; Boyd, 1989]. Xenoliths from other cratons such as Siberia, central East Greenland, central West Greenland, and northern North America all have Mg\#s comparable to Kaapvaal, pointing to similar degrees of melting [Boyd et al., 1997; Bernstein et al., 1998; Mitchell, 1977, 1978; Eggler et al., 1987; Larsen, 1982; Kopylova et al., 1998, 1999].

[8] Geothermobarometry together with density estimates for cratonic mantle xenolith compositions can be used to differentiate between the neutrally buoyant chemical boundary layer proposed by Jordan [1988] and the positively buoyant layer that Kelemen et al. [1998] proposed. Boyd et al. [1999] calculated the density of the Kaapvaal xenoliths at 1 bar and $25^{\circ} \mathrm{C}$ using the observed mode and mineral compositions. They found that along a continental geotherm that extends to 350 $\mathrm{km}$ depth, the shallow, low-temperature Kaapvaal peridotites are positively buoyant, while the deeper, high-temperature peridotites are negatively buoyant compared to "pyrolite" mantle [Ringwood, 1966] along an adiabat (Figure 2). These peridotite xenolith compositions do not fall along the isopycnic curve, yet - taken together - they might still form a neutrally buoyant thermal boundary layer. In contrast, for a continental geotherm that extends to $200 \mathrm{~km}$, the majority of both the low- and high-temperature xenoliths are positively buoyant compared to pyrolite mantle along an adiabat (Figure 2). In this case, for the entire craton to be neutrally buoyant, the positive buoyancy of mantle peridotite (represented by the xenoliths) would have to be offset by the presence of highdensity layers (e.g., eclogites) in the lower crust or upper mantle (Figure 3).

[9] Several recent studies support the result that the Archean cratonic mantle is positively buoyant due to depletion of basaltic components [Griffin et al., 1998, 1999; Lee and Rudnick, 1999; Lee et al., 2001; Poudjom Djomani et al., 2001; O'Reilly et al., 2001]. Griffin et al. [1998, 1999] determined an average bulk composition, modal assemblage, and density for the upper mantle at 1 bar and $20^{\circ} \mathrm{C}$ in Kaapvaal using garnet mineral concentrate data. Poudjom Djomani et al. [2001] calculated the density change with depth for this mean constant composition as a function of the thermal expansivity and bulk compressibility. They then integrated over depth to find the cumulative density of the subcratonic lithospheric mantle. In both cases, they found that the Archean cratonic thermal boundary layer is less dense than convecting asthenosphere below $60-100 \mathrm{~km}$ depth.

[10] These results may be consistent with the topography of the southern African plateau, more than $1 \mathrm{~km}$ above sea level, though most cratons average between 400 and $500 \mathrm{~m}$ in elevation [Nyblade and Robinson, 1994]. However, the anomalous elevation can also be modeled by invoking dynamic topography, where flow in the underlying mantle supports the excess topography [e.g., LithgowBertelloni and Gurnis, 1997; Lithgow-Bertelloni and Silver, 1998]. The dynamic topography hypothesis may be consistent with the deep mantle low-velocity anomaly and long-wavelength geoid high beneath southern Africa [Dziewonski, 1984; Richards and Hager, 1984; Hager et al., 1985; Su et al., 1994; Li and Romanowicz, 1996; Grand et al., 1997; van der Hilst et al., 1997; LithgowBertelloni and Gurnis, 1997; Lithgow-Bertelloni and Silver, 1998]. Additionally, other cratons that are as refractory as Kaapvaal (e.g., Greenland, Siberia, Superior) do not display the same elevation and geoid anomalies [Dziewonski, 1984; Richards and Hager, 1984; Hager et al., 1985; Su et al., 1994; Li and Romanowicz, 1996; Grand et al., 1997; van der Hilst et al., 1997; Goes and 


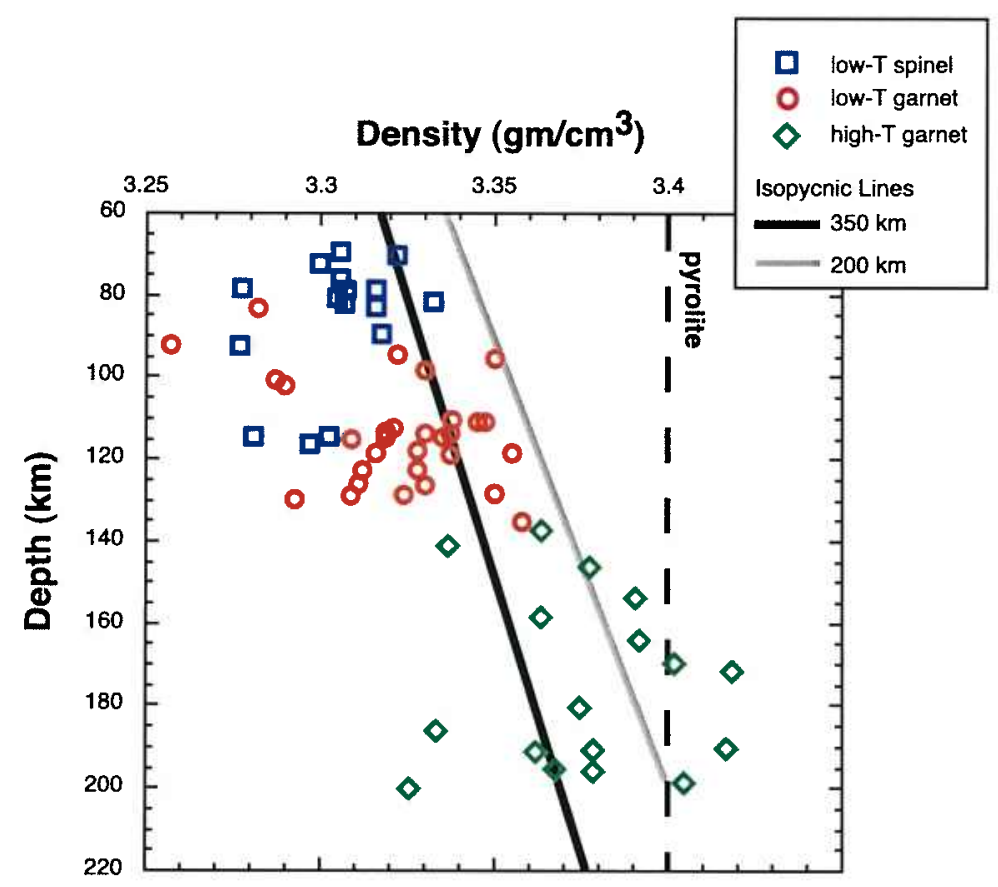

Figure 2. Densities for a suite of Kaapvaal garnet and spinel peridotite xenoliths at 1 bar and $25^{\circ} \mathrm{C}$, calculated using the observed mode and mineral compositions, versus depth of equilibration, redrawn after Boyd et al. [1999] with addition of $200 \mathrm{~km}$ isopycnic curve. Open blue squares are spinel peridotites, open red circles are "low-temperature" garnet peridotites, and open green diamonds are "high-temperature" gamet peridotites. The dashed black line represents a pyrolite asthenosphere at a normative density of $3.4 \mathrm{gm} / \mathrm{cm}^{3}$ [Jordan, 1988]. The black solid line represents the isopycnic condition for a thermal boundary layer that is $350 \mathrm{~km}$ thick [e.g., Jordan, 1988], and the gray solid line is the isopycnic condition for a thermal boundary layer that is $200 \mathrm{~km}$ thick [e.g., Rudnick and Nyblade, 1999]. Relative to the isopycnic curve for a $350 \mathrm{~km}$ thick thermal boundary layer, low-temperature Kaapvaal peridotites are more buoyant than convecting mantle with the composition of pyrolite, while deeper, high-temperature peridotites are denser than adiabatic mantle. However, for a thermal boundary layer only $200 \mathrm{~km}$ thick, almost all the Kaapvaal peridotites are more buoyant than the convecting mantle.

van der Lee, 2002]. For example, Goes and van der Lee [2002] estimated that the elevation of the Superior craton could be accounted for by depleted mantle with an average $\mathrm{Mg} \# 89-90$ from the Moho to $250 \mathrm{~km}$. A larger depletion over a smaller depth range could also explain the same topographic data. Average $\mathrm{Mg \# s}$ of Archean cratonic xenoliths are in the range of 92-93 [Boyd et al., 1997; Bernstein et al., 1998; Mitchell, 1977, 1978; Eggler et al., 1987; Larsen, 1982; Kopylova et al., 1998, 1999].

[11] In order to place constraints on the lithospheric density structure beneath Archean cratons, we consider the possibility that the xenolith densities calculated by Boyd et al. [1999] at 1 bar and $25^{\circ} \mathrm{C}$ may not be representative of the density of these xenoliths at pressures and temperatures along a continental geotherm. For example, garnet is stable only at relatively high pressure, and at any pressure garnet proportions are smaller in $\mathrm{Fe}$ - and $\mathrm{Al}$-poor depleted mantle compositions relative to fertile pyrolite. Using the same suite of low- and hightemperature Kaapvaal garnet and spinel peridotite xenoliths used by Boyd et al. [1999], we recalculated the pressure and temperature conditions of phase equilibration. In contrast to the Griffin et al. [1998, 1999] and Poudjom Djomani et al. [2001] methodology, we then used the bulk compositions of the peridotite xenoliths to calculate the equili- 

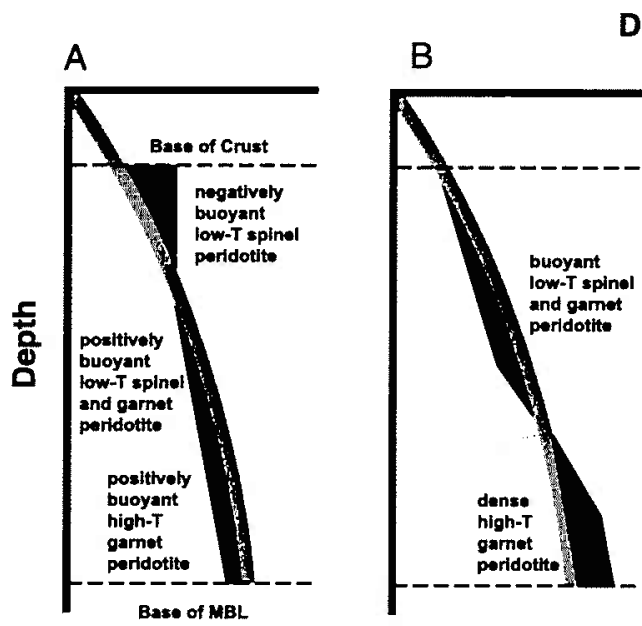

Density
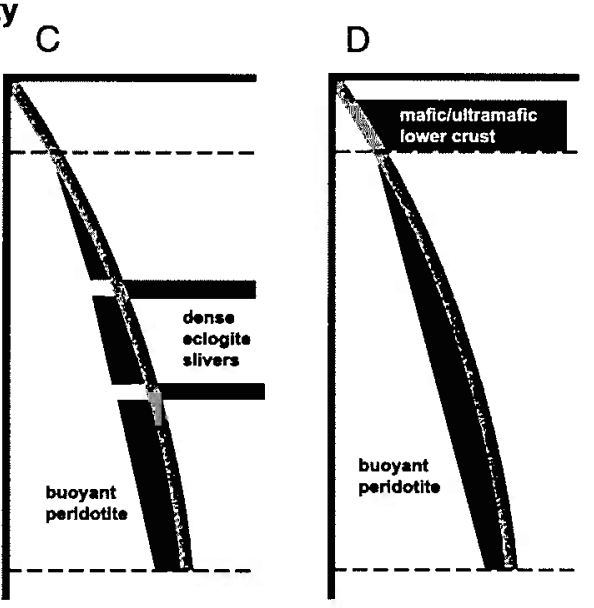

Figure 3. Possible density structures for a neutrally buoyant craton. The thermal boundary layer in the cratonic upper mantle could be neutrally buoyant if the density of the upper mantle fit an isopycnic condition at every depth (not shown). However, this is unlikely in detail and is not borne out by data. Alternatively, the cratonic mantle could be neutrally buoyant if (a) negatively buoyant, shallow peridotites were offset by positively buoyant, deeper peridotites, (b) shallow, highly depleted, positively buoyant material were offset by deeper, more Fe-rich, negatively buoyant material, or (c) positively buoyant, depleted peridotites were offset by layers of dense, basaltic rock in eclogite facies. (d) In addition, if the entire cratonic mantle is positively buoyant, this could still be offset by dense lower crust, for example by abundant garnet granulites near the base of the crust, to produce an isostatic cratonic section.

brium phase proportions over a range of pressures and temperatures, allowing us to determine the densities of the xenoliths over this range and not just at the pressure and temperature of equilibration. By doing so, we are able to assess the possible importance of varying phase proportions on density of these xenoliths and thus predict the density structure of the lithospheric mantle. Also, to make these calculations we used an internally consistent thermodynamic data set [Holland and Powell, 1998], which accounts for possible compositional effects on compressibility and expansivity.

\section{Methodology}

[12] Bulk rock compositions, modal assemblages, and mineral compositions for a large suite of garnet and spinel peridotite xenoliths from Kaapvaal were provided by F.R. Boyd. Pressures and temperatures of equilibration for the low- and high-temperature garnet peridotites were calculated using a two-pyroxene thermometer and Al-in-opx/ garnet barometer, as discussed by Brey and Kohler
[1990]. For the spinel peridotites, only temperatures of equilibration could be calculated, using a thermometer based on Al-Cr exchange between orthopyroxene and spinel [Witt-Eickschen and Seck, 1991]. Pressures of equilibration for the spinel peridotites were determined by interpolation along a $40 \mathrm{~mW} / \mathrm{m}^{2}$ continental geotherm [Pollack and Chapman, 1977] using the calculated temperatures.

[13] Densities were calculated using two different methods. The first method was a normative density $(\hat{\rho})$ calculation (density normalized to 1 bar and $25^{\circ} \mathrm{C}$ ) using Jordan's [1988] empirical relationship between whole rock $\mathrm{Mg \#}$ and normative density:

$$
\hat{\rho}=[5.093-0.0191 * 100 * \mathrm{Mg} /(\mathrm{Mg}+\mathrm{Fe})] \mathrm{gm} / \mathrm{cm}^{3} \text { (1) }
$$

The second method utilized a subsolidus phase equilibrium calculation program called Perplex [Connolly, 1990] that uses thermodynamic data (in our case, Holland and Powell [1998]) to calculate the equilibrium phase assemblage at a given pressure and temperature based on the principle of free energy minimization in a multi- 
component system. Densities were then calculated from the resulting equilibrium mineral assemblage, together with data on the compressibility and thermal expansion of minerals. These densities were compared to densities calculated in the same manner for a pyrolite mantle composition along an adiabatic geotherm with a potential temperature of $1300^{\circ} \mathrm{C}$. (Using a potential temperature of $1350^{\circ} \mathrm{C}$ would not make a significant difference to our results; for example, this lowers the calculated density for pyrolite on an adiabat by $\sim 0.001 \mathrm{gm} /$ $\mathrm{cm}^{3}$ ). This method is potentially better than the normative density approach [Jordan, 1988] and an empirical approach based on calculating densities at $\mathrm{P}$ and $\mathrm{T}$ from observed mineral proportions and compilations of mineral compressibility and expansivity [Boyd and McCallister, 1976; Jordan, 1979; Griffin et al., 1998, 1999; Boyd et al., 1999; Lee et al., 2001; Poudjom Djomani et al., 2001], because it provides a thermodynamically selfconsistent result that includes variations in phase proportions as a function of temperature and pressure, and compositional effects on mineral compressibility and expansivity. In practice, we do not predict dramatic variations in phase proportions once peridotites are in the garnet stability field, and the method we have used involves several approximations, as discussed in section 3.2 , so we view our results as complementary to the normative density and empirical approaches.

\section{Results}

\subsection{Calculated Geotherms for Kaapvaal Garnet and Spinel Mantle Peridotites}

[14] Geothermobarometry calculations were performed on three suites of mantle peridotite xenoliths from the Kaapvaal craton (22 low-temperature garnet/spinel-bearing peridotites, 18 low-temperature spinel-only peridotites, and 19 high-temperature garnet-bearing peridotites). The equilibration pressures and temperatures for the garnet-bearing mantle xenoliths are shown in Figure 4. Estimated equilibration conditions for the garnet peridotites differ slightly from those of Boyd et al. [1999], because they used a Ca-in-opx thermometer together with the Brey and Kohler [1990] opx/ garnet barometer, whereas we used the two-pyroxene thermometer and the opx/garnet barometer from Brey and Kohler [1990]. Our calculations yield slightly higher equilibration temperatures and pressures compared to Boyd et al. [1999], but these differences do not significantly affect any of the results reported in this paper.

[15] Many of the low- and, especially, the hightemperature garnet peridotites have equilibration temperatures that are slightly hotter than those along the $40 \mathrm{~mW} / \mathrm{m}^{2}$ geotherm. Rudnick and Nyblade [1999] projected different model geotherms through suites of African peridotite thermobarometric data and found that $47 \pm 2 \mathrm{~mW} / \mathrm{m}^{2}$ seemed to provide the best fit for the data. However, the high-temperature xenoliths preserve disequilibrium textures and zoning within minerals, so they may not record temperatures along a steady state geotherm. Throughout this paper, we used a $40 \mathrm{~mW} / \mathrm{m}^{2}$ geotherm to calculate the equilibration pressures for spinel peridotites, and the densities of all the xenoliths, with the expectation that this procedure will yield maximum density estimates.

\subsection{Phase Assemblage and Density Variation From Bulk Rock Compositions}

[16] Perplex is a series of programs (http://www. perplex.ethz.ch) that take a bulk rock chemical analysis and calculate the equilibrium subsolidus mineral assemblage at a given temperature and pressure using the principle of free energy minimization (see Connolly [1990] for details on method) and incorporating the most up-to-date, self-consistent thermodynamic data available [e.g., Holland and Powell, 1998]. Determination of the equilibrium mineral assemblage at a designated temperature and pressure allows the density of the sample to be calculated. In our calculations, below $800^{\circ} \mathrm{C}$, the modal assemblages were held constant, as reaction rates are considered to be too slow to further modify phase proportions [e.g., Hacker, 1996]. Thus, below $800^{\circ} \mathrm{C}$, the mineral assemblage at $800^{\circ} \mathrm{C}$ and the same pressure is used for density calculations, together with compressibilities and expansivities for that phase assemblage. Because the solid solution models for minerals in Perplex do not account well for the distribution of 


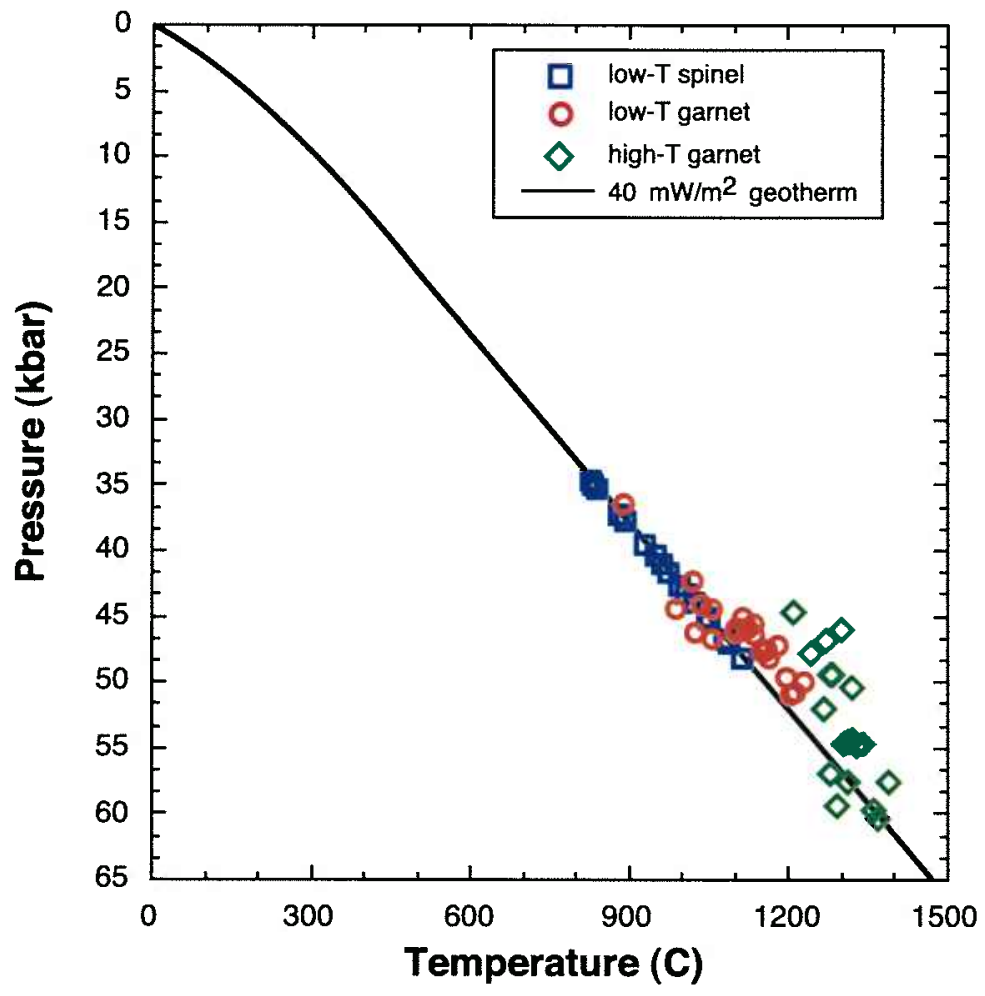

Figure 4. Estimated equilibration conditions for a suite of Kaapvaal spinel and garnet mantle peridotite xenoliths, compared to a $40 \mathrm{~mW} / \mathrm{m}^{2}$ conductive geotherm [Pollack and Chapman, 1977]. The open blue squares denote spinelonly peridotites. The open red circles represent low-temperature garnet-bearing peridotites. The open green diamonds are high-temperature garnet peridotites. Equilibration pressures and temperatures of the garnet-bearing peridotites were calculated using a two-pyroxene geothermometer and an Al-in-opx/garnet geobarometer [Brey and Kohler, 1990]. These define a conductive geotherm close to the $40 \mathrm{~mW} / \mathrm{m}^{2}$ geotherm, although they are also consistent with a hotter geotherm as proposed by Rudnick and Nyblade [1999]. For spinel-only peridotites, equilibration temperatures were calculated using a Cr- and Al-in-opx/spinel thermometer [Witt-Eickschen and Seck, 1991], and the equilibration pressures were interpolated from a $40 \mathrm{~mW} / \mathrm{m}^{2}$ conductive geotherm using the equilibration temperatures. Using these estimated pressures, the majority of the spinel peridotites are inferred to have equilibrated at lower pressures than the garnet-bearing peridotites.

$\mathrm{Ti}, \mathrm{Cr}, \mathrm{Mn}, \mathrm{K}$, and $\mathrm{P}$, in this paper concentrations of six components were specified when calculating the equilibrium phase assemblage: $\mathrm{SiO}_{2}, \mathrm{Al}_{2} \mathrm{O}_{3}$, $\mathrm{FeO}, \mathrm{MgO}, \mathrm{CaO}$, and $\mathrm{Na}_{2} \mathrm{O}$. Comparisons of the calculated mineral modes for each bulk rock composition to the observed modes of each low-temperature peridotite at the respective pressure and temperature of equilibration are shown in Figure 5.

[17] Figure 6 provides a specific example of the calculated phase assemblages for spinel peridotite
FRB 1382 and garnet peridotite PHN 4274 over a range of temperatures and pressures. As in the examples illustrated, none of the spinel peridotites formed spinel at their equilibrium conditions; instead, all formed garnet. Solid solutions in Perplex do not include $\mathrm{Cr}$ in any phase. The effect of $\mathrm{Cr}$ in natural systems is to stabilize spinel in peridotites, leading to the appearance of garnet and the disappearance of spinel at higher pressures than in a $\mathrm{Cr}$ free system. Perplex also tended to overpredict the proportion of olivine while underpredicting the 

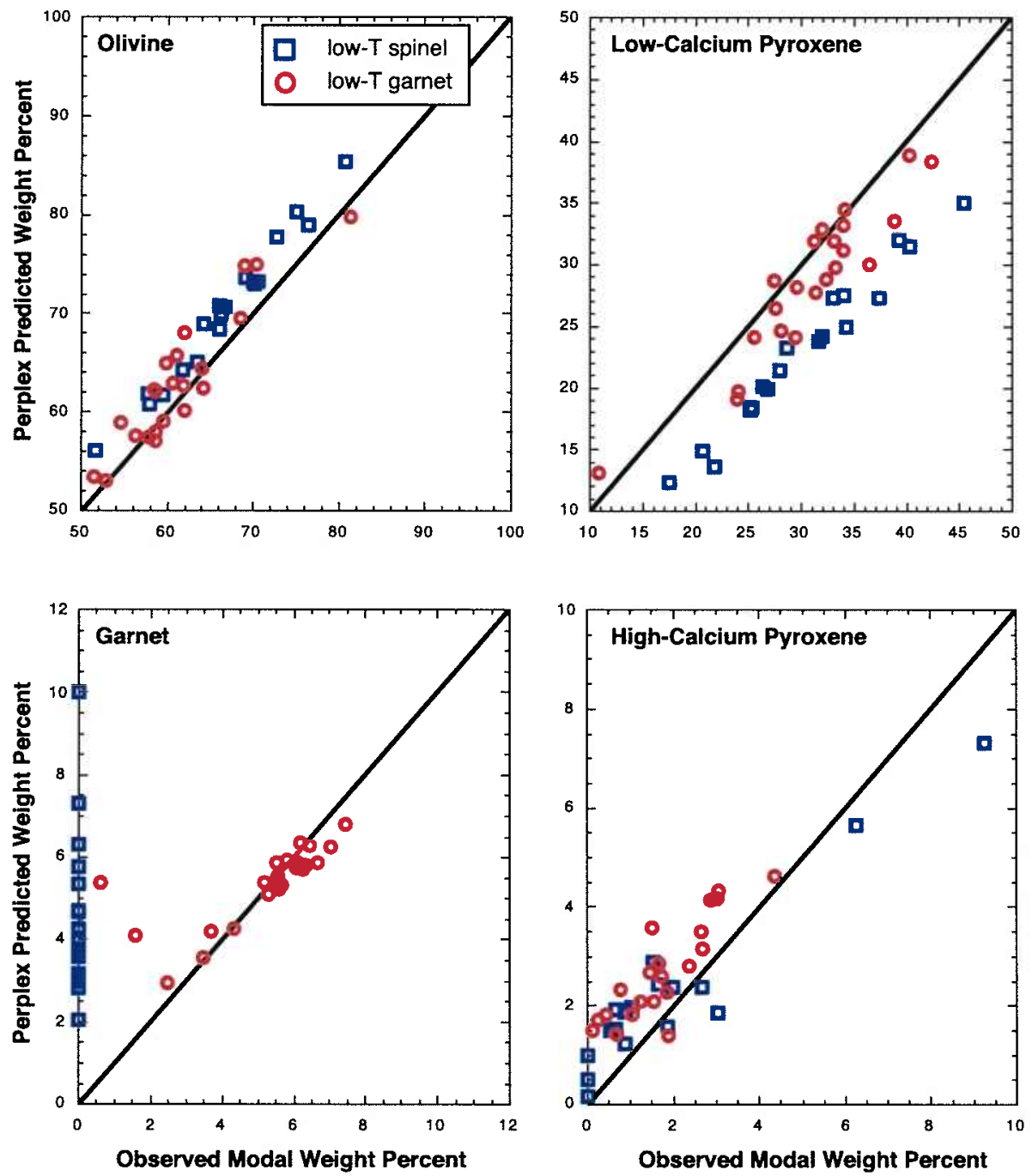

Figure 5. Comparison of calculated phase assemblages at the pressure and temperature of equilibration to observed phase assemblages for the low-temperature peridotites. The program Perplex was used to calculate phase assemblages from the bulk composition [Connolly, 1990]. Agreement between calculated and observed phase proportions is good, particularly for the garnet-bearing xenoliths. Calculated modes for spinel peridotites have gamet and no spinel at their equilibrium conditions. In addition, the calculated modes overpredict olivine and underpredict enstatite. This is most likely due, at least in part, to the presence of $\mathrm{Cr}_{2} \mathrm{O}_{3}$ in the spinel peridotites. Perplex does not account for $\mathrm{Cr}_{2} \mathrm{O}_{3}$ in peridotites, the presence of which enhances spinel stability and suppresses garnet formation.

proportion of enstatite for the spinel peridotites (Figure 5). This is related to the overabundance of garnet and the lack of spinel in the predicted phase assemblages, via the general reaction pyroxene + spinel $=$ garnet + olivine. We can estimate the effect of the overprediction of gamet + olivine proportions on peridotite density using end-member data at 1 bar and $25^{\circ} \mathrm{C}$ for pyrope, almandine, uvarovite, grossular, spinel, hercynite, enstatite, ferrosilite, forsterite and fayalite from Bass [1995], and assuming ideal 


\section{(A) FRB1382}
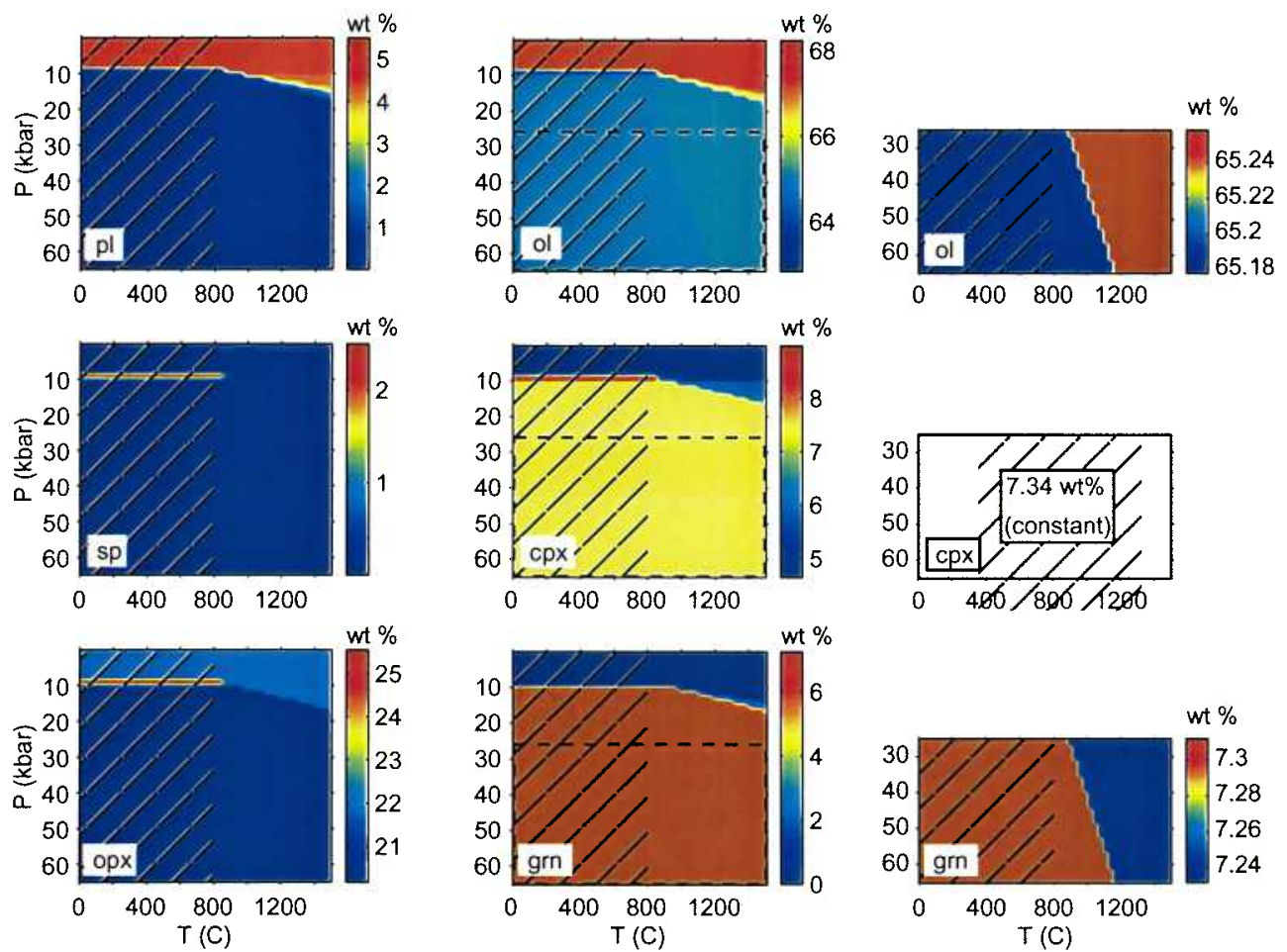

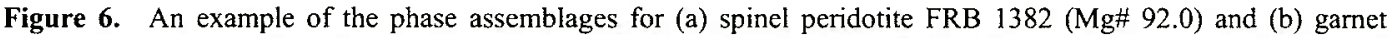
peridotite PHN 4274 (Mg\# 93.2) calculated over a range of temperatures and pressures using Perplex. Detailed panels on the right-hand side of Figures $6 \mathrm{a}$ and $6 \mathrm{~b}$ (regions indicated by dashed borders) illustrate that formation of Al-rich pyroxene and $\mathrm{Fe} / \mathrm{Mg}$ exchange between garnet and olivine do not have a large effect on the mineral proportions and density of the calculated phase assemblage. Diagonal lines indicate that the modal assemblages were held constant below $800^{\circ} \mathrm{C}$.

mixing to estimate the density of $\mathrm{MgCr}$ and $\mathrm{FeCr}$ garnets. For the reactions

$$
\begin{aligned}
& 2 \mathrm{Mg}_{2} \mathrm{Si}_{2} \mathrm{O}_{6}+\mathrm{MgAl}_{2} \mathrm{O}_{4}=\mathrm{Mg}_{3} \mathrm{Al}_{2} \mathrm{Si}_{3} \mathrm{O}_{12}+\mathrm{Mg}_{2} \mathrm{SiO}_{4}, \\
& 2 \mathrm{Fe}_{2} \mathrm{Si}_{2} \mathrm{O}_{6}+\mathrm{FeAl}_{2} \mathrm{O}_{4}=\mathrm{Fe}_{3} \mathrm{Al}_{2} \mathrm{Si}_{3} \mathrm{O}_{12}+\mathrm{Fe}_{2} \mathrm{SiO}_{4}, \\
& 2 \mathrm{Mg}_{2} \mathrm{Si}_{2} \mathrm{O}_{6}+\mathrm{MgCr}_{2} \mathrm{O}_{4}=\mathrm{Mg}_{3} \mathrm{Cr}_{2} \mathrm{Si}_{3} \mathrm{O}_{12}+\mathrm{Mg}_{2} \mathrm{SiO}_{4}, \\
& 2 \mathrm{Fe}_{2} \mathrm{Si}_{2} \mathrm{O}_{6}+\mathrm{FeCr}_{2} \mathrm{O}_{4}=\mathrm{Fe}_{3} \mathrm{Cr}_{2} \mathrm{Si}_{3} \mathrm{O}_{12}+\mathrm{Fe}_{2} \mathrm{SiO}_{4},
\end{aligned}
$$

density changes at 1 bar and $25^{\circ} \mathrm{C}$ calculated in this way are $+0.173,+0.265,+0.089$, and $+0.190 \mathrm{gm} /$ $\mathrm{cm}^{3}$, respectively. Since the garnet + olivine products for all of these reactions are denser than the pyroxene + spinel reactants, it is apparent that our calculated densities for $\mathrm{Cr}$-free bulk compositions using Perplex are upper limits on the actual density of the peridotite assemblages at a given pressure and temperature. In this paper, we emphasize that our calculated densities are lower than those inferred from the isopycnic hypothesis. We suggest that most cratonic upper mantle peridotites are buoyant with respect to the convecting mantle. As a result, it is appropriate that our calculated densities are upper bounds for relatively $\mathrm{Cr}$-rich cratonic peridotites. 


\section{(B) PHN 4274}
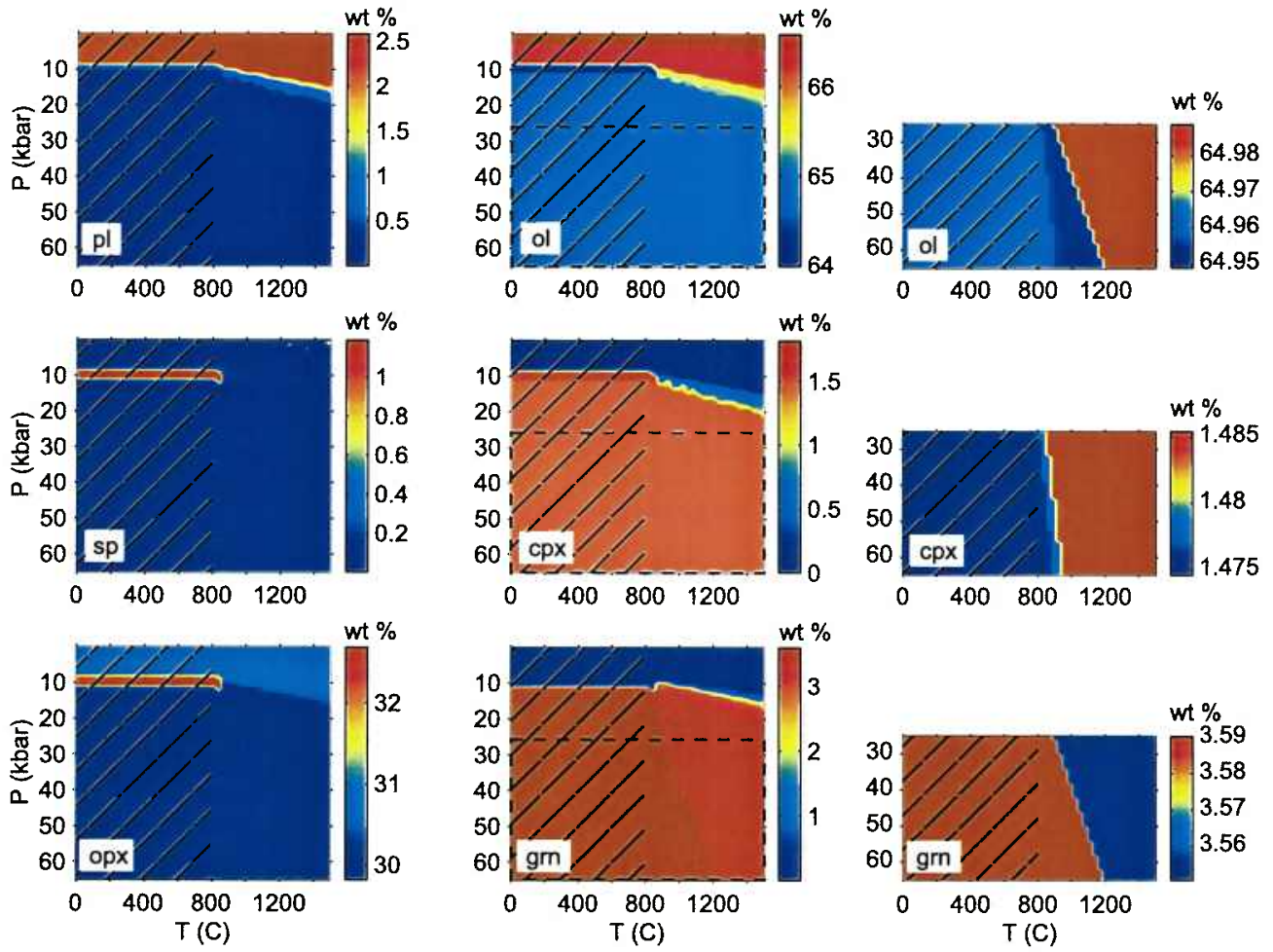

Figure 6. (continued)

[18] Figure 6 also shows three different types of reactions involving garnet formation and breakdown. The first type, associated with an abrupt increase in density over a narrow pressure interval, are familiar reactions at the low-pressure bound of the garnet lherzolite facies: pyroxene + spinel $=$ garnet + olivine, and olivine + plagioclase $=$ garnet \pm jadeite-rich pyroxene. The others are reactions within the garnet lherzolite stability field that involve high-temperature formation of Al-rich pyroxene at the expense of garnet via reactions of the type

$$
\mathrm{Mg}_{3} \mathrm{Al}_{2} \mathrm{Si}_{3} \mathrm{O}_{12}=\mathrm{MgAl}_{2} \mathrm{SiO}_{6}+\mathrm{Mg}_{2} \mathrm{Si}_{2} \mathrm{O}_{6}
$$

and $\mathrm{Fe} / \mathrm{Mg}$ exchange between garnet and olivine, decreasing the weight proportion of garnet and increasing the weight proportion of olivine at high temperature via

$$
\mathrm{Fe}_{3} \mathrm{Al}_{2} \mathrm{Si}_{3} \mathrm{O}_{12}+\mathrm{Mg}_{2} \mathrm{SiO}_{4}=\mathrm{Mg}_{3} \mathrm{Al}_{2} \mathrm{Si}_{3} \mathrm{O}_{12}+\mathrm{Fe}_{2} \mathrm{SiO}_{4} \text {. }
$$

[19] The effect of these reactions is illustrated in the detailed panels on the right-hand side of Figures $6 \mathrm{a}$ and $6 \mathrm{~b}$ (regions indicated by dashed borders). As can be seen, we found that formation of Al-rich pyroxene and $\mathrm{Fe} / \mathrm{Mg}$ exchange between garnet and olivine do not have a large effect on the mineral proportions and density of the calculated phase assemblage.

[20] The calculated densities at the equilibration pressures on the $40 \mathrm{~mW} / \mathrm{m}^{2}$ geotherm are compared to the calculated densities at the equilibration pressures and the equilibration temperatures for 

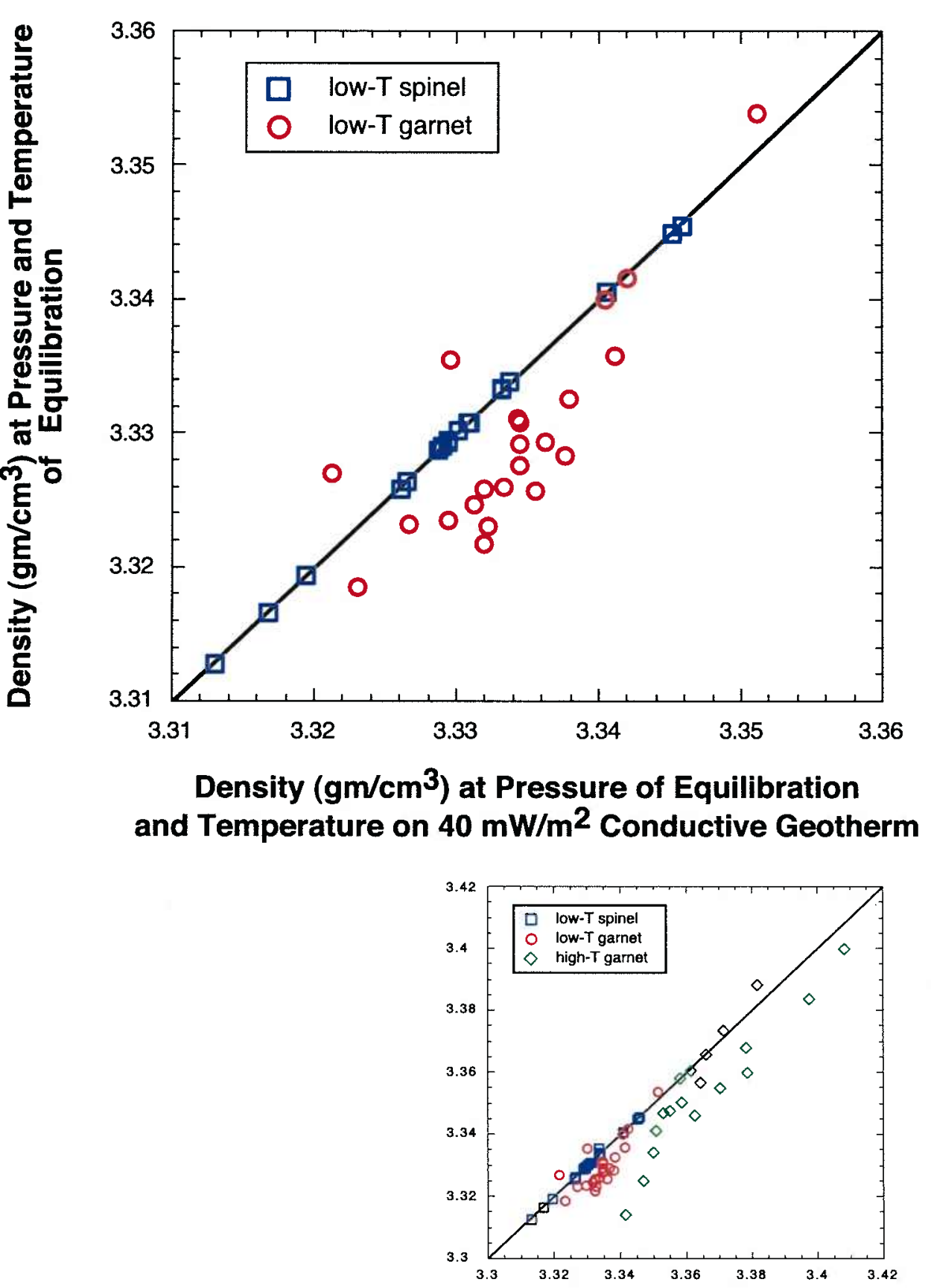

Figure 7. Comparison of densities calculated at equilibration temperatures with densities calculated at temperatures along a $40 \mathrm{~mW} / \mathrm{m}^{2}$ conductive geotherm; equilibration pressures were used for both density calculations. Lowtemperature spinel and garnet peridotites are indicated with blue squares and red circles, respectively. The inset also includes high-temperature garnet peridotites in green diamonds. As discussed in the text, using equilibration pressures together with temperatures along a $40 \mathrm{~mW} / \mathrm{m}^{2}$ conductive geotherm provides higher density estimates for the bulk rock compositions, compared with density estimates using equilibration pressures and equilibration temperatures. 


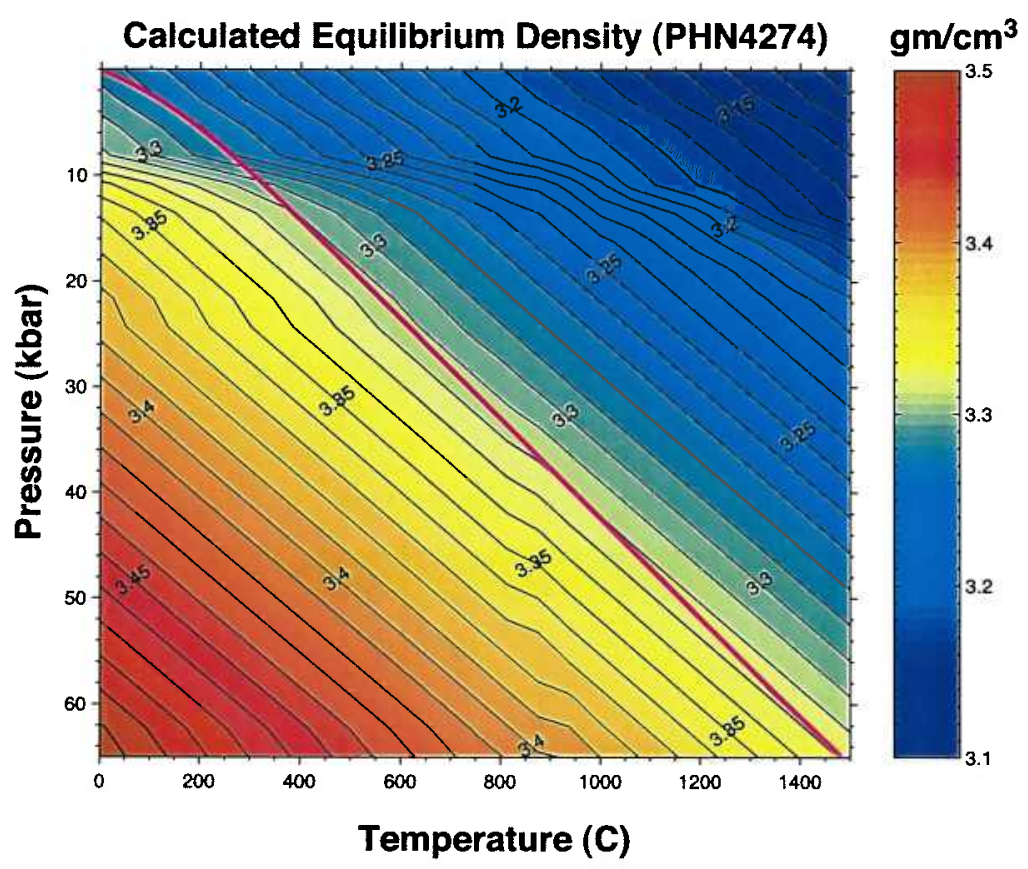

Figure 8. Contours of equilibrium density calculated using Perplex for low-temperature, garnet-bearing peridotite PHN $4274\left(\mathrm{Mg \#} \mathrm{93.2)} \mathrm{from} 0-65 \mathrm{kbar}\right.$ and $0-1500^{\circ} \mathrm{C}$. The magenta line represents a $40 \mathrm{~mW} / \mathrm{m}^{2}$ conductive geotherm.

all samples in Figure 7. For most of the garnet peridotites, densities along the $40 \mathrm{~mW} / \mathrm{m}^{2}$ geotherm are higher than densities at the same depth and the equilibration temperature. Thus, the densities along the $40 \mathrm{~mW} / \mathrm{m}^{2}$ geotherm are upperbound estimates of the actual densities of mantle peridotites along the Kaapvaal geotherm. As we pointed out in the previous paragraph, because we emphasize in this paper how low our calculated densities are compared to the convecting mantle, it is appropriate that we use upper-bound estimates for the calculated densities of cratonic peridotites.

[21] Pyrolite [Ringwood, 1966] was chosen as a reference mantle composition for comparison with the Kaapvaal mantle peridotite xenoliths. For the pyrolite composition and each of the garnet and spinel peridotites from Kaapvaal, equilibrium density grids for a temperature range of $0-1500^{\circ} \mathrm{C}$ and a pressure range of $0-65 \mathrm{kbar}$ were calculated. Figure 8 is a contoured equilibrium density grid for garnet peridotite xenolith PHN 4274. A $40 \mathrm{~mW} / \mathrm{m}^{2}$ conductive geotherm is shown in magenta. For this particular sample, the conductive geotherm generally falls between the $3.31 \mathrm{gm} / \mathrm{cm}^{3}$ and $3.33 \mathrm{gm} / \mathrm{cm}^{3}$ contour lines. The equilibrium density grid for pyrolite is shown in Figure 9 with both the conductive geotherm and the adiabat with a potential temperature of $1300^{\circ} \mathrm{C}$. The adiabat intersects the conductive geotherm at $\sim 60 \mathrm{kbar}$ where pyrolite has a calculated equilibrium density of $3.388 \mathrm{gm} / \mathrm{cm}^{3}$.

[22] The normative densities [Jordan, 1988] and the Perplex-calculated equilibrium densities of the Kaapvaal garnet and spinel mantle peridotite xenoliths are plotted against pressure in Figure 10, using the equilibration pressures for the garnet peridotites and the inferred pressures for the spinel peridotites along a $40 \mathrm{~mW} / \mathrm{m}^{2}$ geotherm. The normative densities (Figure 10a) are compared to the isopycnic densities for a $200 \mathrm{~km}$ thick thermal boundary layer using an oceanic reference norma- 


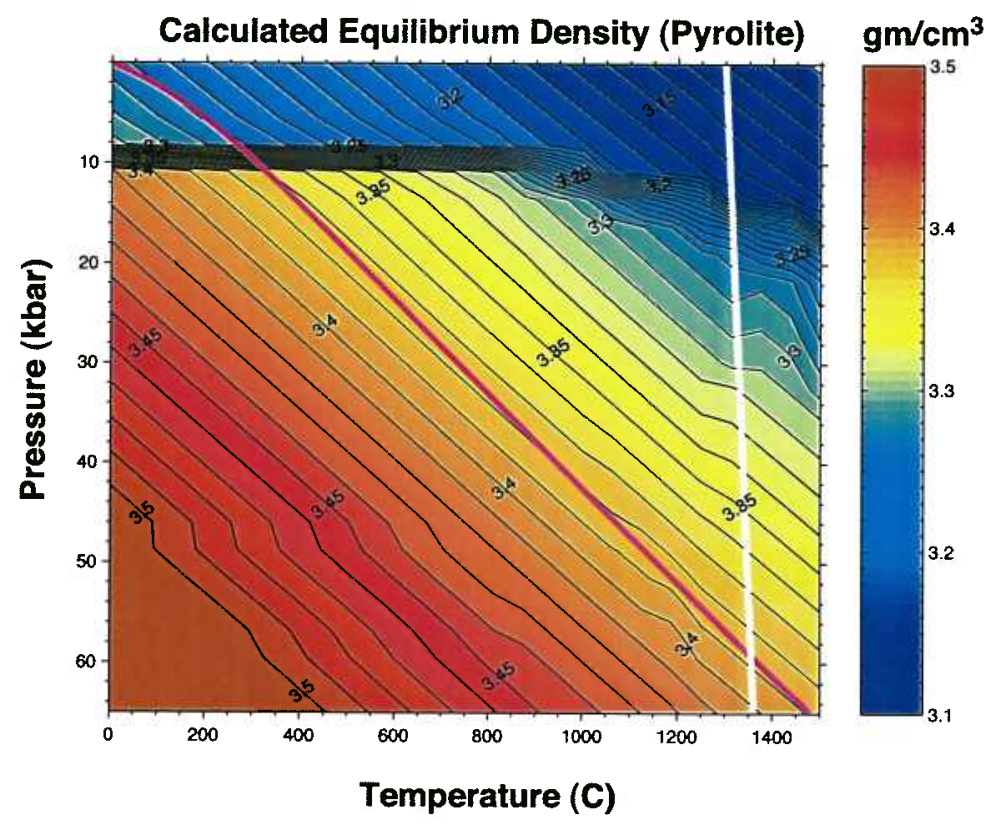

Figure 9. Contours of equilibrium density calculated using Perplex for pyrolite [Ringwood, 1966] from 0-65 kbar and $0-1500^{\circ} \mathrm{C}$. The magenta line represents a $40 \mathrm{~mW} / \mathrm{m}^{2}$ conductive geotherm, and the white line illustrates an adiabat with a mantle potential temperature of $1300^{\circ} \mathrm{C}$.

tive density of $3.4 \mathrm{gm} / \mathrm{cm}^{3}$ [Jordan, 1988]. Since normative density is a linear function of $\mathrm{Mg \#}$, it can be inferred from Figure 10a that Mg\# does not vary systematically with depth in the Kaapvaal low-temperature xenolith suite. This appears to be true in Archean cratons worldwide, with the exception of the Alakit kimberlite xenoliths in the Siberian craton [Gaul et al., 2000]. The model equilibrium densities are shown relative to the Perplex-calculated density of pyrolite along an adiabat with a potential temperature of $1300^{\circ} \mathrm{C}$ (Figure 10b). The great majority of the xenolith samples have both a lower normative density and a lower equilibrium density at their pressures of equilibration than would be expected for an isopycnic condition.

[23] Pyrolite densities at each pressure along an adiabatic geotherm with a potential temperature of $1300^{\circ} \mathrm{C}$ (Figure 9) were subtracted from the mantle xenolith equilibrium densities at the corresponding pressures over the entire range of temperatures.
This produced a value for the density difference, $\Delta \rho$, for each sample at any temperature and pressure relative to pyrolite at the same pressure along the $1300^{\circ} \mathrm{C}$ adiabat. Figure 11 illustrates $\Delta \rho$ for garnet peridotite xenolith PHN 4274 in Figure 8. Where $\Delta \rho$ is positive, samples are denser than the convecting mantle at a given pressure; where $\Delta \rho$ is negative, samples are buoyant with respect to the convecting mantle at the same depth.

[24] Values of $\Delta \rho$ for all the peridotites along a $40 \mathrm{~mW} / \mathrm{m}^{2}$ conductive geotherm ( $\rho$ sample on geotherm - $\rho$ pyrolite on adiabat) are plotted as a function of pressure in Figure 12. For reference, a line for $\Delta \rho$ for pyrolite along a conductive geotherm is included. Rectangles illustrate the range of pressures for which Kaapvaal mantle peridotite xenoliths are neutrally buoyant compared to pyrolite along a $1300^{\circ} \mathrm{C}$ adiabat.

[25] Figure 13 compares equilibration pressures and the pressures at which equilibrium densities 

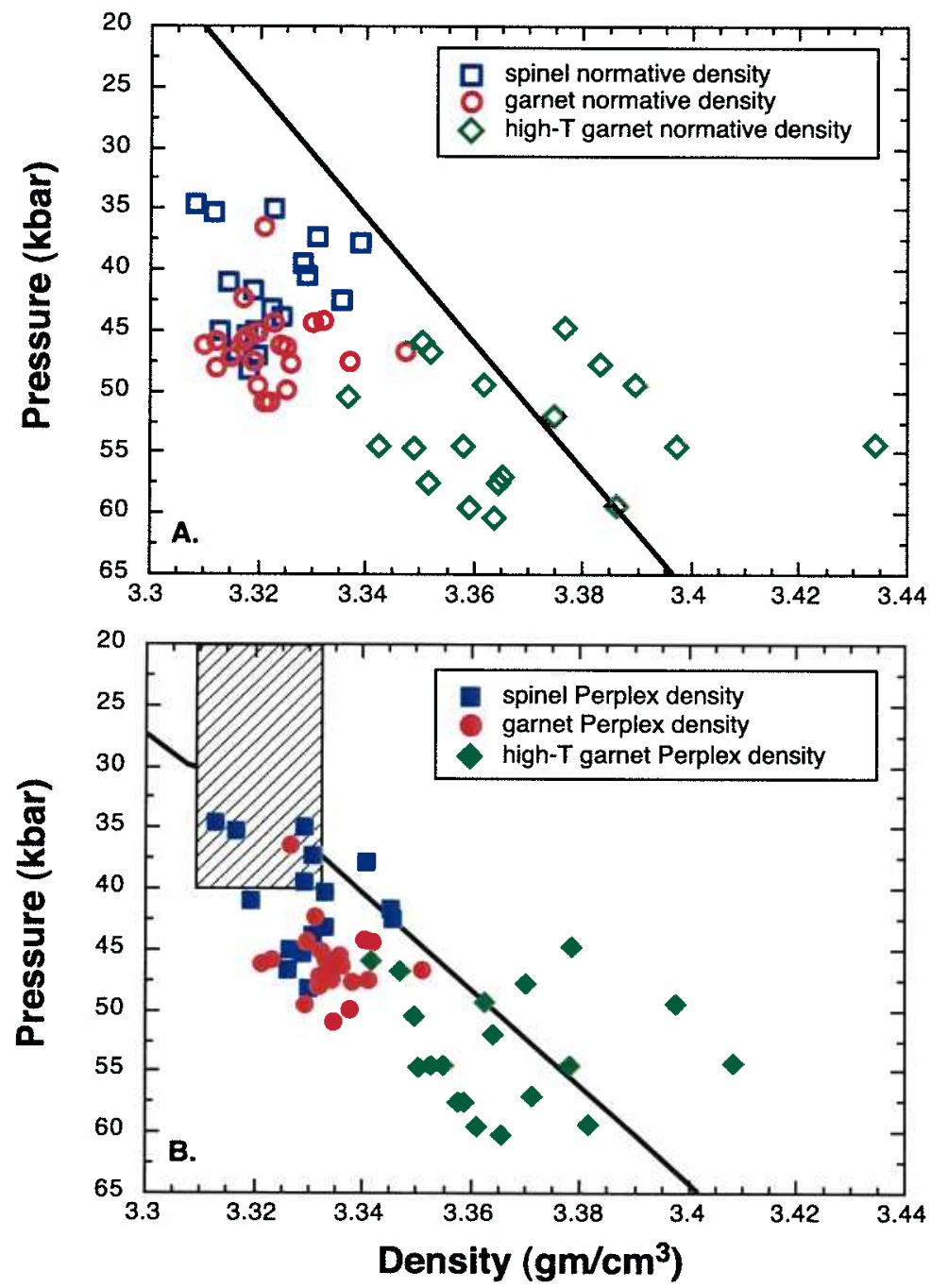

Figure 10. (a) Normative densities [Jordan, 1988] for the garnet and spinel peridotite xenoliths plotted at the equilibration pressures for each sample. Open blue squares are spinel peridotites, open red circles are low-temperature gamet-bearing peridotites, and open green diamonds are high-temperature garnet peridotites. The black line represents isopycnic densities for a thermal boundary layer thickness of $200 \mathrm{~km}(66.67 \mathrm{kbar})$ using a normative asthenospheric density of $3.4 \mathrm{gm} / \mathrm{cm}^{3}$ [Jordan, 1988]. Most normative densities for the Kaapvaal mantle xenoliths are positively buoyant relative to the isopycnic line. Only a few high-temperature garnet peridotites have higher normative density compared to the convecting asthenosphere at the same depth. (b) Calculated equilibrium densities (Perplex) for the Kaapvaal spinel and garnet mantle peridotite suite along a $40 \mathrm{~mW} / \mathrm{m}^{2}$ conductive geotherm plotted at the pressures of equilibration for each sample. The majority of xenoliths have a lower density than the asthenospheric mantle (Perplex-calculated pyrolite density) along an adiabat with a potential temperature of $1300^{\circ} \mathrm{C}$ (black line). Gray, diagonally ruled rectangle shows the range of densities for hypothetical spinel peridotites in the uppermost mantle, as presented in Figure 14 and accompanying text. 


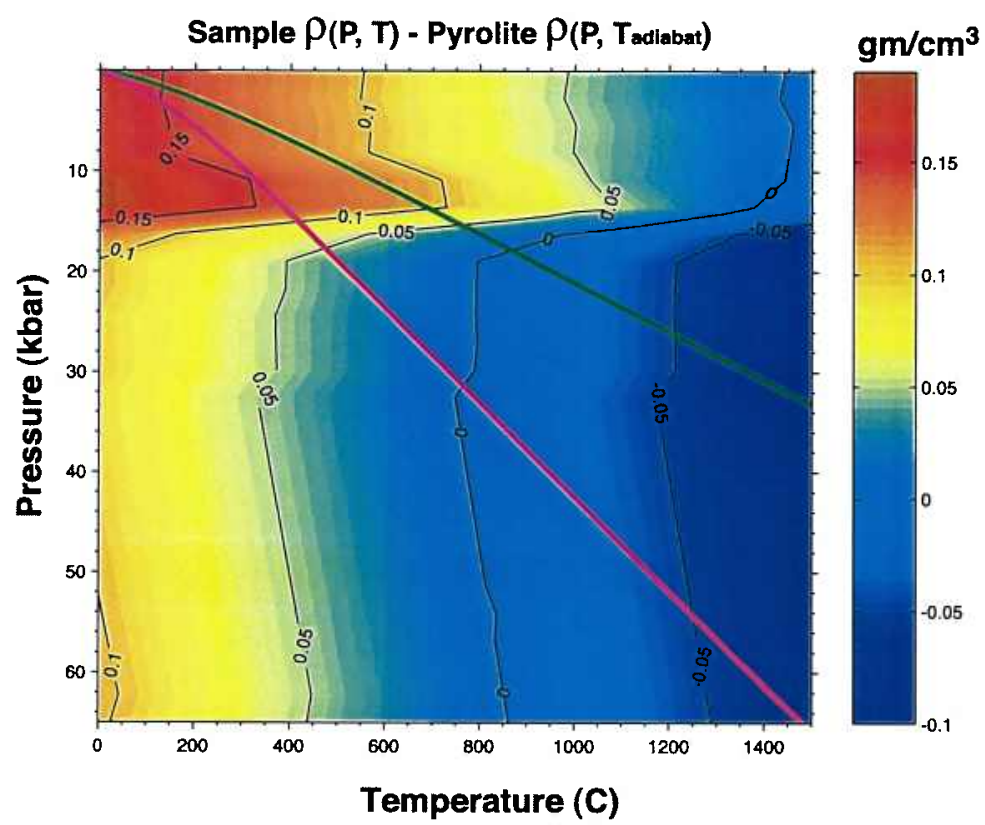

Figure 11. Difference between equilibrium densities for Kaapvaal garnet-bearing peridotite PHN 4274 (Figure 8) and pyrolite densities along an adiabat with a mantle potential temperature of $1300^{\circ} \mathrm{C}$ (Figure 9), where $\Delta \rho=\rho_{\text {sample }}$ $(\mathrm{P}, \mathrm{T})-\rho_{\text {pyrolite }}\left(\mathrm{P}, \mathrm{T}_{\text {adiabat }}\right)$. Any geotherm can be selected within this grid to determine the density difference between the Kaapvaal peridotite and pyrolite along an adiabat. A $40 \mathrm{~mW} / \mathrm{m}^{2}$ conductive geotherm is shown in magenta, and a hypothetical conductive geotherm during craton formation, which intersects a $1500^{\circ} \mathrm{C}$ adiabat at 100 $\mathrm{km}$, is shown in green. The point at which $\Delta \rho=0$ along the conductive geotherm is the "crossover pressure," above which a peridotite with this bulk composition will become positively buoyant relative to pyrolite. Crossover pressures are much lower on a hotter "Archean" geotherm, compared to the $40 \mathrm{~mW} / \mathrm{m}^{2}$ geotherm.

on a conductive geotherm are neutrally buoyant relative to pyrolite on an adiabat $(\Delta \rho=0)$. Pressures of neutral buoyancy are systematically lower than pressures of equilibration.

\section{Discussion}

\subsection{Thermobarometry and Phase Assemblages}

[26] Thermobarometry of mantle peridotite xenoliths from Archean cratons such as the Kalahari, Slave, Siberia, and Superior cratons produces equilibration temperatures and pressures that lie along a conductive geotherm that intersects a mantle adiabat at about $200 \mathrm{~km}$ depth [e.g., Finnerty and Boyd, 1987; Rudnick et al., 1998; Rudnick and Nyblade, 1999]. This result is similar to a $40 \mathrm{~mW} / \mathrm{m}^{2}$ conductive geotherm and to PT estimates for the low-temperature Kaapvaal xenoliths (Figure 4), suggesting that the conductively cooled cratonic thermal boundary layer beneath Kaapvaal was in a thermal steady state prior to the time the kimberlites were erupted. The ages of Kaapvaal kimberlites that host the xenoliths imply that a steady state geotherm in the $\sim 200 \mathrm{~km}$ thick lithospheric mantle section beneath Kaapvaal must have been established earlier than 1200 $\mathrm{Ma}$ and been sustained until after $100 \mathrm{Ma}$ [e.g., Richardson, 1986; Smith et al., 1994].

[27] Along the $40 \mathrm{~mW} / \mathrm{m}^{2}$ conductive geotherm, the calculated equilibration temperatures of the spinel peridotites fall within the garnet peridotite stability field, yet these xenoliths do not contain garnet. Spinel is not stabilized to unusually high pressures by high Cr-contents; among Kaapvaal 

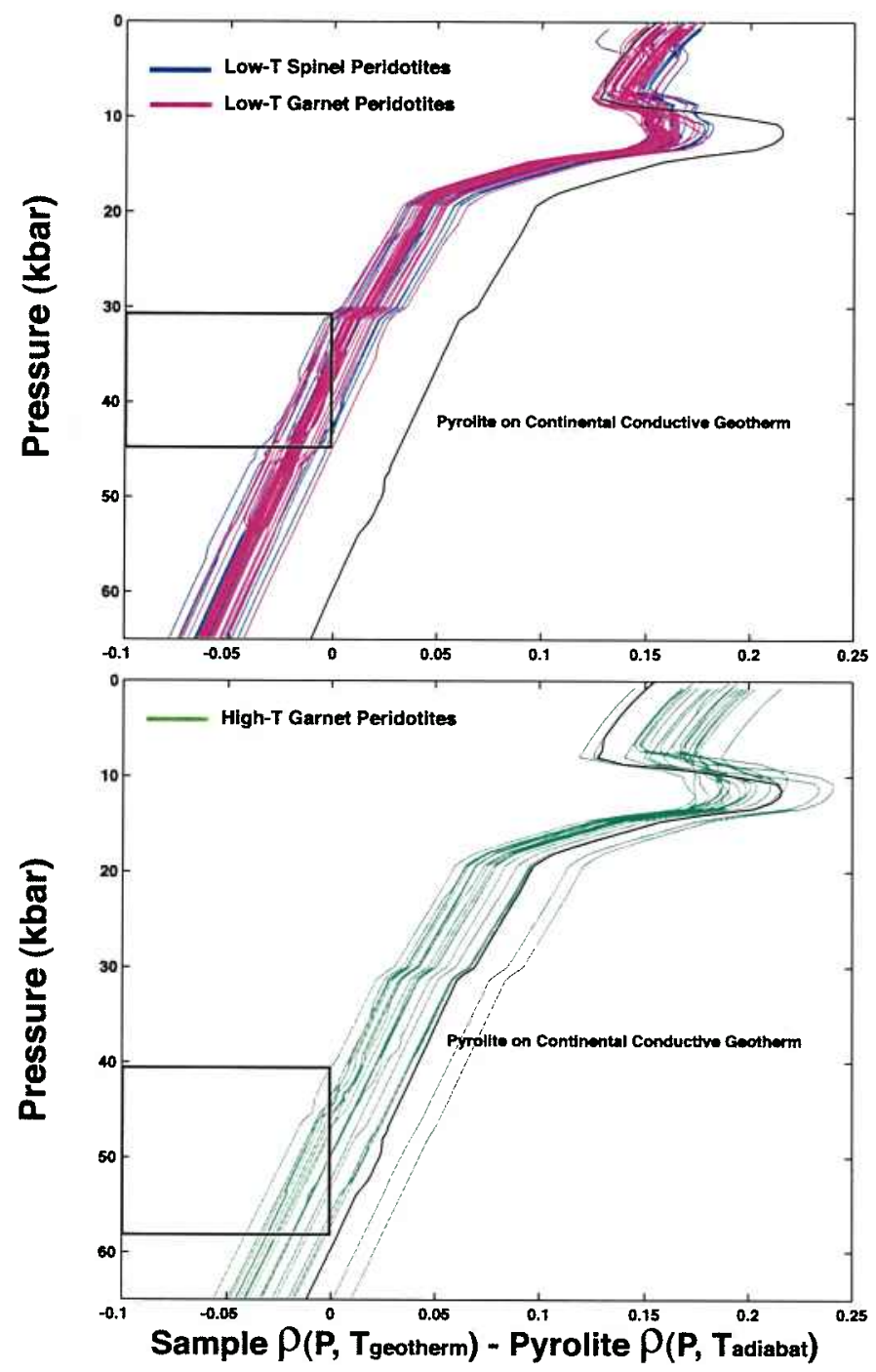

Figure 12. (top) Calculated $\Delta \rho$ for the suite of Kaapvaal spinel and low-temperature, garnet-bearing peridotites along a $40 \mathrm{~mW} / \mathrm{m}^{2}$ conductive geotherm ( $\rho$ sample on geotherm - $\rho$ pyrolite on an adiabat at the same pressure and a mantle potential temperature of $1300^{\circ} \mathrm{C}$ ), plotted against pressure. The spinel peridotites are in blue, and the garnetbearing peridotites are in red. The solid black line represents $\Delta \rho$ for pyrolite on the conductive geotherm. The open black box indicates the range of pressures for which this suite of samples is neutrally buoyant relative to pyrolite on the adiabat. (bottom) Green lines illustrate $\Delta \rho$ for high-temperature Kaapvaal garnet peridotites. Note that the crossover pressures for the high-temperature garnet peridotites (open black box) are higher than those for the lowtemperature peridotites, and that two samples are not positively buoyant relative to pyrolite on the adiabat at any pressure between 0 and $65 \mathrm{kbar}$.

xenoliths, spinel peridotites are not systematically more Cr-rich than garnet peridotites. However, there are several possible explanations for the absence of garnet in spinel peridotites that are consistent with available data. One viable hypothesis is that the equilibration pressures for the spinel peridotites inferred from their temperatures along a $40 \mathrm{~mW} / \mathrm{m}^{2}$ geotherm are incorrect. A hotter geo- 


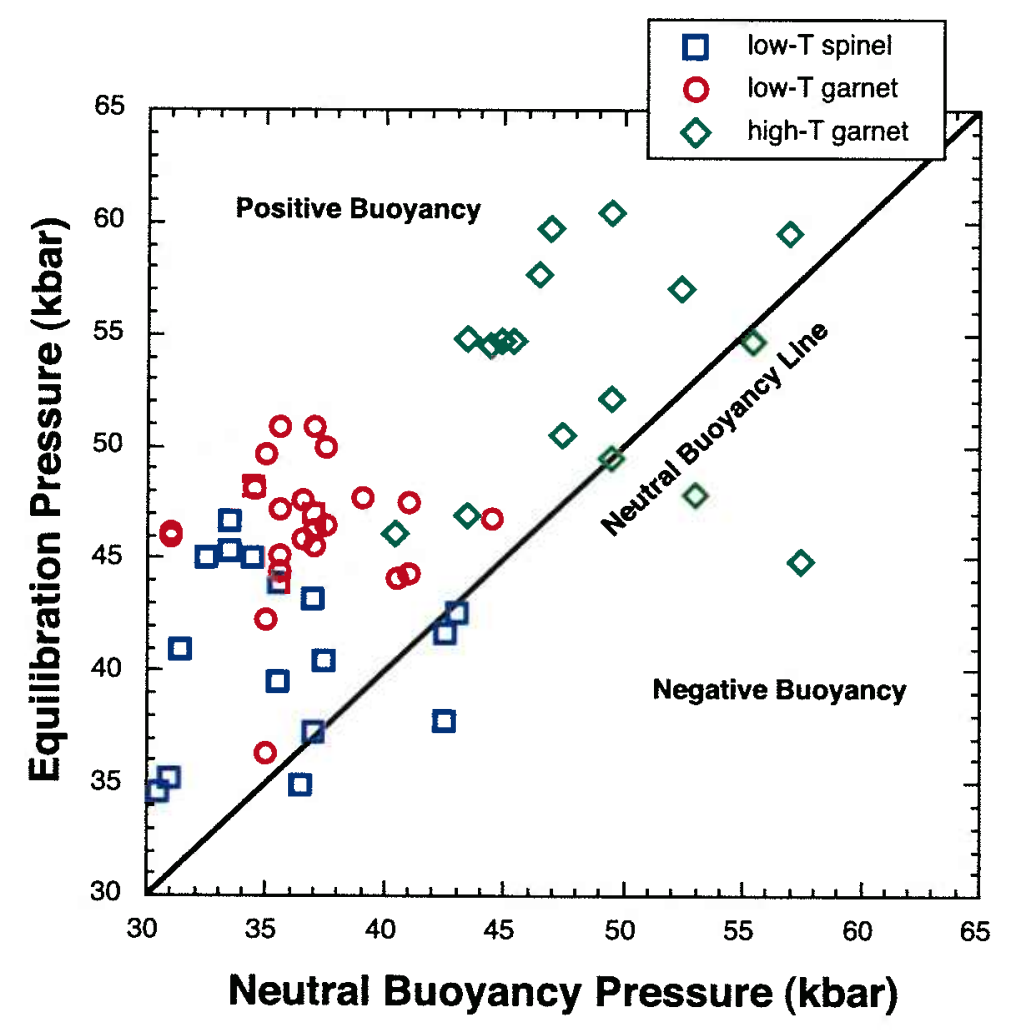

Figure 13. Comparison of sample equilibration pressure to the crossover pressure, at which a given sample becomes neutrally buoyant along a $40 \mathrm{~mW} / \mathrm{m}^{2}$ conductive geotherm relative to pyrolite on an adiabat with a mantle potential temperature of $1300^{\circ} \mathrm{C}$. Most of the calculated equilibration pressures for the suite of analyzed Kaapvaal peridotites are higher than the pressure at which each sample would be neutrally buoyant. These samples are positively buoyant.

therm, as suggested by some of the garnet-bearing xenoliths, would result in lower projected equilibration pressures for the spinel-bearing xenoliths. However, inferred pressures would still be greater than $25 \mathrm{kbar}$, which is within the garnet lherzolite stability field at $\sim 800^{\circ} \mathrm{C}$, and inferred pressure/ temperature conditions would still overlap with those of garnet peridotite xenoliths. A second possibility is that the spinel-bearing xenoliths were recently reheated, for example by a magmatic process, so that they do not record temperatures along the steady state conductive geotherm. In this case, their depths of equilibration are unknown and could be within the spinel lherzolite stability field. Third, $\mathrm{Al} / \mathrm{Cr}$ exchange within phases, used to calculate the temperature, may be more rapid than garnet nucle- ation and growth; isobaric cooling into the garnet Iherzolite stability field is recorded by the thermometer, but the phase assemblage is "stuck" at a higher temperature. And fourth, the closure temperature for the Al-Cr orthopyroxene/spinel exchange thermometer might have been high when the spinel peridotites initially cooled; in this case, the steady state temperature for the spinel peridotites is lower than we calculate using the $\mathrm{Al}-\mathrm{Cr}$ thermometer.

[28] The program Perplex [Connolly, 1990] uses bulk rock compositions to determine the solid phase proportions and solid solution compositions at different pressures and temperatures by free energy minimization. From the predicted mineral phase assemblages at each pressure and temper-

18 of 24 

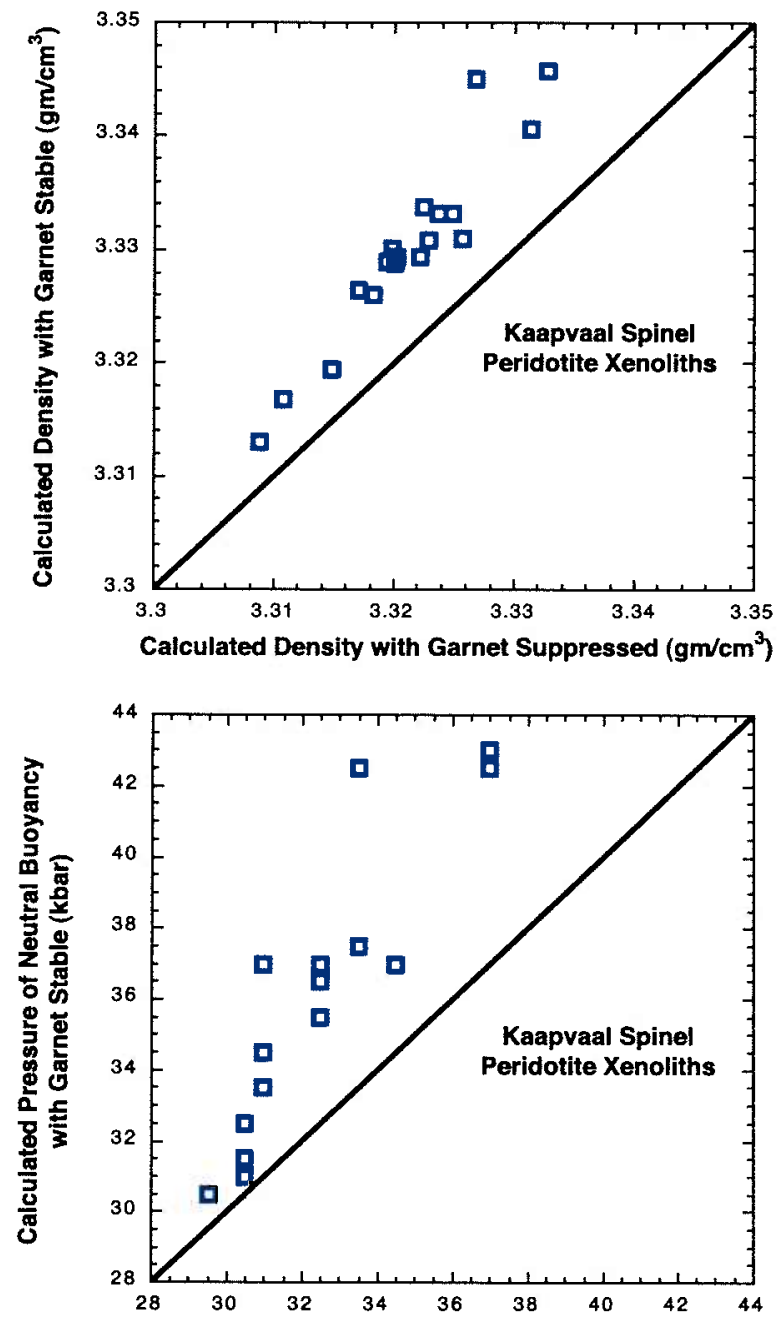

Calculated Pressure of Neutral Buoyancy with Garnet Suppressed (kbar)

Figure 14. Calculated densities and pressures of neutral buoyancy for Kaapvaal spinel peridotite xenolith compositions. The top panel compares densities at the equilibration temperature and the corresponding pressure along a $40 \mathrm{~mW} / \mathrm{m}^{2}$ conductive geotherm, with and without garnet in the calculated phase assemblage. The bottom panel compares the crossover pressure at which each composition along a $40 \mathrm{~mW} / \mathrm{m}^{2}$ conductive geotherm becomes neutrally buoyant with respect to pyrolite on an adiabat with a potential temperature of $1300^{\circ} \mathrm{C}$, again with and without gamet in the phase assemblage. Garnet-free densities for spinel peridotite xenoliths, calculated using Perplex, are also shown as a diagonally ruled rectangle in Figure $10 \mathrm{~b}$. Predicted gamet in the Perplex phase assemblages for the spinel peridotites leads to an overprediction of equilibrium densities, as seen in the top panel. The pressures at which the spinel peridotites become neutrally buoyant relative to pyrolite are shallower when garnet formation is suppressed in the Perplex calculations, as seen in the bottom panel.

ature, the density of the material can be calculated. As already discussed in the first two paragraphs of section 3.2, one of the main drawbacks to using Perplex for the Kaapvaal mantle peridotite xeno- liths is that the model does not incorporate $\mathrm{Cr}_{2} \mathrm{O}_{3}$ into any phases. In natural assemblages, the presence of Cr-bearing spinel suppresses the onset of garnet formation during cooling or compression. 
The end-member garnet-bearing phase assemblage is denser than the $\mathrm{Cr}$-spinel end-member assemblage, so excess garnet in the $\mathrm{Cr}$-free peridotite compositions used for Perplex might lead to an overestimate of density at a given pressure and temperature. In order to determine the magnitude of this effect, we ran test cases for the spinel xenolith compositions in which garnet formation was suppressed. The equilibrium densities of the garnet-free assemblages were lower than when garnet was allowed to form (Figure 14). These differences are less than $0.5 \%$ and are insignificant compared to the variation in density observed in the entire data set. However, we note that the pressures at which peridotites are neutrally buoyant relative to pyrolite are shallower for the garnet-free assemblages (Figure 14).

\subsection{Positively Buoyant Cratonic Mantle Peridotites}

[29] The bulk rock $\mathrm{Mg} \#$ s combined with calculated equilibration pressures allow a comparison of the normative densities of the Kaapvaal low-temperature garnet and spinel peridotite xenoliths to isopycnic densities. As seen in Figure 10a, for all of the low-temperature peridotites and the majority of the high-temperature peridotites, the normative densities are lower than isopycnic densities for a $200 \mathrm{~km}$ thick thermal boundary layer. This implies that these mantle xenoliths have compositions that are positively buoyant along a conductive geotherm when compared to the adiabatically convecting mantle at the same depth. This supports the Kelemen et al. [1998] hypothesis that the cratonic upper mantle may be positively buoyant, rather than neutrally buoyant as suggested by Jordan [1988]. However, normative density estimates are open to question.

[30] For the garnet and spinel peridotite bulk rock compositions provided by F.R. Boyd, predicted equilibrium phase assemblages can be used to calculate equilibrium densities at a range of pressures and temperatures, as in the example in Figure 8. These densities can then be compared to those of pyrolite (Figure 9) along an adiabatic geotherm with a potential temperature of $1300^{\circ} \mathrm{C}$ (example in Figure 11).
[31] The difference between calculated equilibrium densities for all xenolith compositions on a $40 \mathrm{~mW} / \mathrm{m}^{2}$ conductive geotherm and pyrolite along an adiabat with a potential temperature of $1300^{\circ} \mathrm{C}$ has been plotted against pressure in Figure 12. All of the low-temperature peridotites and all but two of the high-temperature xenoliths have bulk rock compositions that will become neutrally buoyant relative to adiabatic pyrolite in the range of $0-65 \mathrm{kbar}$ given sufficiently high pressure. Figure 13 demonstrates that, for the majority of these xenoliths, the pressure at which each sample equilibrated is greater than the pressure at which it would become neutrally buoyant relative to pyrolite on an adiabat. Thus, most of these peridotites are estimated to be positively buoyant relative to the convecting mantle at their respective equilibration pressures.

[32] These results agree with the Griffin et al. [1998, 1999] and Poudjom Djomani et al. [2001] studies of Kaapvaal mantle buoyancy. However, these authors emphasized that the entire craton might be positively buoyant, whereas we prefer the hypothesis that the craton is neutrally buoyant, because we are persuaded by the long-term retention of a thin but ancient sedimentary cover, and the result that topography in southern Africa may be dynamically supported [e.g., Lithgow-Bertelloni and Gurnis, 1997; Lithgow-Bertelloni and Silver, 1998].

[33] As the compositions of the Kaapvaal peridotites yield equilibration pressures no lower than 30 kbar, the composition, and therefore the buoyancy, of the upper part of the mantle thermal boundary layer is poorly known. Peridotite compositions analogous to the Kaapvaal garnet and spinel peridotite xenoliths would be neutrally or negatively buoyant at shallower pressures due to the lower temperatures along a cratonic geotherm. Therefore there could be a negatively buoyant layer of spinel peridotite between the base of the crust at about $40 \mathrm{~km}$ depth and about $75 \mathrm{~km}$ depth (see diagonally nuled area in Figure 10b). This might be sufficient to offset the positive buoyancy of compositionally similar, hotter peridotites at greater depth.

[34] The presence of high-density eclogite layers in the lower crust or upper mantle could also compensate for the positively buoyant spinel and garnet 
peridotites, resulting in a neutrally buoyant thermal boundary layer. Schulze [1989] calculated 3-15\% eclogite by volume from the Roberts Victor, Bobbejaan, and Zagadochnaya kimberlites in southern Africa and Siberia. This is sufficient to balance the positive buoyancy of depleted cratonic peridotite. For example, 93\% Kaapvaal peridotite $(\rho \sim 3.335$ $\left.\mathrm{gm} / \mathrm{cm}^{3}\right)$ and $7 \%$ eclogite $\left(\rho \sim 3.600 \mathrm{gm} / \mathrm{cm}^{3}\right)$ could be neutrally buoyant with respect to pyrolite on an adiabat $\left(\rho \sim 3.353 \mathrm{gm} / \mathrm{cm}^{3}\right)$ at an average pressure of $\sim 45 \mathrm{kbar}$ within the pressure range from 30 to $65 \mathrm{kbar}$ (e.g., Figure 10b).

\subsection{Effect of Hotter Archean Geotherm}

[35] As cratons began to form, the thermal boundary layer would have been thinner than at present. If the thermal boundary layer were $100 \mathrm{~km}$ thick, rather than $200 \mathrm{~km}$ thick, the conductive geotherm would have been steeper. Also, the mantle potential temperature may have been higher in the Archean. As can be observed from the example in Figure 11, compositions of the Kaapvaal garnet and spinel peridotite xenoliths are neutrally or positively buoyant with respect to the convecting mantle at low pressures, provided the temperatures are high enough. Thus, peridotites with the composition of the Kaapvaal xenoliths would have been neutrally to positively buoyant at shallow depth when they originally began to accumulate. As the cratons thickened and the conductive geotherm relaxed through time, the peridotites toward the base of the thermal boundary layer remained positively or neutrally buoyant in comparison to the underlying convecting asthenospheric mantle, while those at cooler temperatures and shallower depths may have become neutrally or negatively buoyant.

\section{Conclusions}

[36] Thermobarometry of Kaapvaal garnet and spinel peridotites yields estimated equilibration pressures greater than $30 \mathrm{kbar}$ for all samples, with some originating as deep as $60 \mathrm{kbar}$. The garnet peridotites fall along a conductive geotherm with a surface heat flux of $\sim 40 \mathrm{~mW} / \mathrm{m}^{2}$, or slightly higher, similar to that proposed for the continents by Pollack and Chapman [1977]. This geotherm intersects a mantle adiabat with a potential temperature of $1300^{\circ} \mathrm{C}$ at about $200 \mathrm{~km}$ depth.

[37] Using the relationship between whole rock $\mathrm{Mg \#}$ and normative density described by Jordan [1988], the majority of the Kaapvaal xenoliths in a $200 \mathrm{~km}$ thick thermal boundary layer are estimated to be positively buoyant compared to the asthenosphere. Using bulk rock compositions of these xenoliths and calculations of the equilibrium subsolidus phase assemblage (Perplex [Connolly, 1990]), we calculated the densities of the xenolith compositions for a range of pressures and temperatures. As for the normative densities, calculated equilibrium densities for most Kaapvaal xenolith compositions are positively buoyant compared to pyrolite on an adiabat with a mantle potential temperature of $1300^{\circ} \mathrm{C}$. At pressures less than their equilibration pressures, the xenolith compositions are negatively buoyant along a $40 \mathrm{~mW} / \mathrm{m}^{2}$ conductive geotherm. However, they would have been positively or neutrally buoyant at low pressure at high temperature during craton formation, given a thinner thermal boundary layer and/or higher mantle potential temperatures in the Archean.

[38] These results suggest that much of the depleted peridotite component of the cratonic upper mantle is positively buoyant with respect to the surrounding, convecting mantle. The absence of either uplift or substantial departures from isostasy suggests that the cratons as a whole are neutrally buoyant. Therefore some other component of the cratons, perhaps a shallow layer of dense spinel peridotite, eclogite layers within the mantle, or garnet granulites at the base of the crust, is negatively buoyant and offsets the positive buoyancy of the depleted peridotites (Figure 3 ). A region of positively buoyant peridotite near the base of the lithospheric mantle could help explain the longterm stability of continental cratons.

\section{Acknowledgments}

[39] We would like to thank F.R. Boyd for generously providing us with Kaapvaal peridotite xenolith bulk rock and mineral composition data. We also thank Cin-Ty Lee for his assistance in adding to the mineral composition data, Jamie 
Connolly for his help with the thermodynamic calculations, Claude Jaupart for encouragement, and Neal Driscoll for his advice on isostasy. Cin-Ty Lee, Bill Griffin, and Roberta Rudnick provided their insightful and helpful reviews. This research was supported by NSF grants EAR-9814632 and EAR-9910899 (P. B. Kelemen), and EAR-0087706 (M. Jull and P. B. Kelemen)

\section{References}

Bass, J. D., Elasticity of minerals, glasses, and molts, in Mineral Physics and Crystallography: A Handbook of Physical Constants, edited by T. J. Ahrens, pp. 45-63, AGU, Washington, D. C., 1995.

Bernstein, S., P. B. Kelemen, and C. K. Brooks, Depleted spinel harzburgite xenoliths in Tertiary dykes from East Greenland: Restites from high degree melting, Earth Planet. Sci. Lett., 154, 221-235, 1998.

Bird, P., Continental delamination and the Colorado plateau, J. Geophys. Res., 84, 7561-7571, 1979.

Boyd, F. R., Compositional distinction between oceanic and cratonic lithosphere, Earth Planet. Sci. Lett., 96, 15-26, 1989.

Boyd, F. R., and R. H. McCallister, Densities of fertile and sterile garnet peridotites, Geophys. Res. Lett., 3, 509-512, 1976.

Boyd, F. R., N. P. Pokhilenko, D. G. Pearson, S. A. Mertzman, N. V. Sobolev, and L. W. Finger, Composition of the Siberian cratonic mantle: Evidence from Udachnaya periodotite xenoliths, Contrib. Mineral. Petrol., 128, 228-246, 1997.

Boyd, F. R., D. G. Pearson, and S. A. Mertzman, Spinel-facies peridotites from the Kaapvaal Root, in Proceedings of the VIIth International Kimberlite Conference, vol. 1, edited by J. J. Gurney et al., pp. 40-48, Red Roof Design, Cape Town, South Africa, 1999.

Brey, G. P., and T. Kohler, Geothermobarometry in four-phase lherzolites, II, New thermobarometers, and practical assessment of existing thermobarometers, J. Petrol., 31, 1353$1378,1990$.

Connolly, J. A. D., Multivariable phase diagrams: An algorithm based on generalized thermodynamics, Am. J. Sci., 290, 666-718, 1990.

Dzicwonski, A. M., Mapping the lower mantle: Determination of lateral heterogencity in $\mathrm{P}$ velocity up to degree and order 6, J. Geophys. Res., 89, 5929-5952, 1984.

Eggler, D. H., M. E. McCallum, and M. B. Kirkley, Kimberlite-transported nodules from Colorado-Wyoming: A record of enrichment of shallow portions of an infertile lithosphere, Spec. Pap. Geol. Soc. Am., 215, 77-90, 1987.

Finnerty, A. A., and F. R. Boyd, Thermobarometry for garnet peridotites: Basis for the determination of thermal and compositional structure of the upper mantle, in Mantle Xenoliths, edited by P. H. Nixon, pp. 381-402, Wiley-Interscience, New York, 1987.

Forsyth, D. W., Subsurface loading and cstimate of flexural rigidity of continental lithosphere, J. Geophys. Res., 90, $12,623-12,632,1985$.
Gaul, O. F., W. L. Griffin, S. Y. O'Reilly, and N. J. Pearson, Mapping olivine composition in the lithospheric mantle, Earth Planet. Sci. Lett., 182, 223-235, 2000.

Goes, S., and S. van der Lee, Thermal structure of the North American uppermost mantle inferred from seismic tomography, J. Geophys. Res., I07(B3), 2050, doi:10.1029/ 2000JB000049, 2002.

Grand, S. P., R. D. van der Hilst, and S. Widiyantoro, Global seismic tomography: A snapshot of convection in the Earth, GSA Today, 7, 1-7, 1997.

Grecn, D. H., and R. C. Licberman, Phase equilibria and elastic properties of a pyrolite model for the oceanic upper mantle, Tectonophysics, 32, 61-92, 1976.

Griffin, W. L., S. Y. O'Reilly, C. G. Ryan, O. Gaul, and D. A. Ionov, Secular variation in the composition of subcontinental lithospheric mantle: Geophysical and geodynamic implications, in Structure and Evolution of the Australian Continent, Geodyn. Ser, vol. 26, edited by J. Braun et al., pp. 1-25, AGU, Washington, D. C., 1998.

Griffin, W. L., S. Y. O'Reilly, and C. G. Ryan, The composition and origin of subcontinental lithospheric mantle, in Mantle Petrology: Field Observations and High-Pressure Experimentation, A Tribute to Francis $R$. (Joe) Boyd, edited by Y. Fei, C. M. Bertka, and B. O. Mysen, Spec. Publ. Geochem. Soc., 6, 13-45, 1999.

Hacker, B. R., Eclogite formation and the rheology, buoyancy, seismicity and $\mathrm{H}_{2} \mathrm{O}$ content of oceanic crust, in Subduction Top to Bottom, Geophys. Monogr. Ser., vol. 96, edited by G. E. Bebout et al., pp. 337-346. AGU, Washington, D. C., 1996.

Hager, B. H., R. W. Clayton, M. A. Richards, R. P. Comer, and A. M. Dziewonski, Lower mantle heterogeneity, dynamic topography, and the geoid, Nature, 313, 541-545, 1985.

Haxby, W. F., and D. L. Turcotte, On isostatic geoid anomalics, J. Geophys. Res., 83, 5473-5478, 1978.

Holland, T. J. B., and R. Powell, An internally consistent thermodynamic data set for phases of petrological interest, J. Metamorph. Geol., 16, 309-343, 1998.

Houseman, G. A., D. P. McKenzie, and P. Molnar, Convective instability of a thickening boundary layer and its relevance for the thermal evolution of continental convergent belts, J. Geophys. Res., 86, 6115-6132, 1981.

Jordan, T. H., The continental tectosphcre, Rev. Geophys., 13, $1-12,1975 \mathrm{a}$

Jordan, T. H., Lateral heterogeneity and mantle dynamics, Nature, 257, 745-750, 1975b.

Jordan, T. H., Mineralogies, densities, and seismic velocitics of garnct lherzolites and their geophysical implications, in The Mantle Sample: Inclusions in Kimberlites and Other Volcanics, edited by F. R. Boyd and H. O. A. Meyer, pp. 1-14, AGU, Washington, D. C., 1979.

Jordan, T. H., Structure and formation of the continental tectosphere, J. Petrol. (Special Lithosphere Issue), II-37, 1988.

Kamer, G. D., and A. B. Watts, Gravity anomalies and flexure of the lithosphere at mountain ranges, J. Geophys. Res., 88, $10,449-10,477,1983$. 
Karner, G. D., M. S. Steckler, and J. A. Thorne, Long-term thermo-mechanical properties of the continental lithosphere, Nature, 304, 250-253, 1983.

Kelemen, P. B., S. R. Hart, and S. Bemstein, Silica entrenchment in the continental upper mantle via meltrock reaction, Earth Planet. Sci. Lett., I64, 387-406, 1998.

Kopylova, M. G., J. K. Russell, and H. Cookenboo, Uppermantlc stratigraphy of the Slave craton, Canada: Insights into a new kimbcrlite province, Geology, 26, 315-318, 1998.

Kopylova, M. G., J. K. Russell, and H. Cookenboo, Petrology of peridotite and pyroxenite xenoliths from the Jericho kimberlite: Implications for the thermal state of the mantle beneath the Slave Craton, Northern Canada, J. Petrol, 40, 79104, 1999.

Kusznir, N., and G. Karner, Dependence of the flexural rigidity of the continental lithosphere on rheology and temperature, Nature, 316, 138-142, 1985.

Larsen, J. G., Mantle-driven dunite and lherzolite nodules from Ubekendt Ejland, west Greenland Tertiary province, Mineral. Mag., 46, 329-336, 1982.

Lee, C.-T., and R. L. Rudnick, Compositionally stratificd cratonic lithosphere: Petrology and geochemistry of peridotite xenoliths from the Labait Volcano, Tanzania, in Proceedings of the VIth International Kimberlite Conference, edited by J. J. Gurney ct al., pp. 503-521, Red Roof Design, Cape Town, South Africa, 1999

Lec, C.-T., Q. Yin, R. L. Rudnick, and S. B. Jacobsen, Preservation of ancient and fertile lithospheric mantle beneath the southwestem United Statcs, Nature, 411, 69-73, 2001

$\mathrm{Li}, \mathrm{X}$. D., and B. Romanowicz, Global shear-velocity model developed using nonlinear asymptotic coupling theory, J. Geophys. Res., 101, 22,245 -22,272, 1996.

Lithgow-Bertelloni, C., and M. Gurnis, Cenozoic subsidence and uplift of continents from time-varying dynamic topography, Geology, 25, 735-738, 1997

Lithgow-Bertelloni, C., and P. G. Silver, Dynamic topography, plate driving forces and the African superswell, Nature, 395, 269-272, 1998.

Lowry, A. R., and R. B. Smith, Flexural rigidity of the Basin and Rangc-Colorado Platcau-Rocky Mountain transition from coherence analysis of gravity and topography, $J$. Geophys. Res., 99, 20,123-20,140, 1994.

Menzics, M. A., Geochemistry: Effects of small volume melts, Nature, 343, 312-313, 1990.

Mitchell, R. H., Ultramafic xenoliths from the Elwin Bay kimberlite: The first Canadian paleogeotherm, Can. J. Earth Sci., 14, 1202-1210, 1977

Mitchell, R. H., Gamet lherzolites from Somerset Island, Canada, and aspects of the nature of perturbed geotherms, Contrib. Mineral. Petrol., 67, 341-347, 1978.

Nyblade, A. A., and S. W. Robinson, The African superswell, Geophys. Res. Lett., 21, 765-768, 1994

O'Hara, M. J., Is there an Icelandic mantlc plume?, Nature, 253, 708-710, 1975.

O'Reilly, S. Y., W. L. Griffin, Y. H. Poudjom Djomani, and P. Morgan, Are lithosphercs forever? Tracking changes in subcontinental lithosperic mantle through time, GSA Today, 11 , $4-9,2001$
Oxburgh, E. R., and E. M. Parmentier, Thermal processes in the formation of continental lithosphere, Philos. Trans. R. Soc. London, Ser. A, 288, 415-429, 1978.

Parsons, B., and D. McKenzic, Mantle convection and the thermal structure of the plates, J. Geophys. Res., 83, 4485-4496, 1978.

Parsons, B., and F. M. Richter, A relation between the driving force and geoid anomaly associated with mid-ocean ridges, Earth Planet. Sci. Lett., S1, 445-450, 1980.

Parsons, B., and J. G. Sclater, A analysis of the variation of ocean bathymetry and heat flow with age, J. Geophys. Res., $82,803-827,1977$

Pollack, H. N., and D. S. Chapman, On the regional variation of heat flow, geotherms, and lithospheric thickness, Tectonophysics, 38, 279-296, 1977.

Poudjom Djomani, Y. H., J. M. Nnange, M. Diament, C. J. Ebinger, and J. D. Fairhead, Effective elastic thickness and crustal thickness variations in West-Central Africa inferred from gravity data, J. Geophys. Res., 100, 22,047-22,070, 1995.

Poudjom Djomani, Y. H., J. D. Fairhead, and W. L. Griffin, The flexural rigidity of Fennoscandia: Reflection of the tectonothermal age of the lithospheric mantle, Earth Planet. Sci. Lett., 174, 139-154, 1999.

Poudjom Djomani, Y. H., S. Y. O'Rcilly, W. L. Griffin, and P. Morgan, The density structure of subcontinental lithosphere through time, Earth Planet. Sci. Lett., 184, 605$621,2001$.

Poupinet, G., and B. de Voogd, Some consequences of the differences in seismic properties in old and young continental plates for isostatic compensation, Earth Planet. Sci. Lett., 56, 278-286, 1981.

Richards, M. A., and B. H. Hager, Geoid anomalies in a dynamic carth, J. Geophys. Res., 89, 5987-6002, 1984.

Richardson, S. H., Latter-day origin of diamonds of eclogitic paragenesis, Nature, 322, 623-626, 1986.

Ringwood, A. E., Mincralogy of the mantle, in Advances in Earth Science: International Conference on the Earth Sciences, edited by P. M. Hurley, pp. 357-399, MIT Press, Cambridge, Mass., 1966.

Rudnick, R. L., and A. A. Nyblade, The thickness and heat production of Archean lithosphere: Constraints from xenolith themobarometry and surface heat flow, in Mantle Petrology: Field Observations and High-Pressure Experimentation, $A$ Tribute to Francis R. (Joe) Boyd, edited by Y. Fei, C. M. Bertka, and B. O. Mysen, Spec. Publ. Geochem. Soc., 6, 312, 1999.

Rudnick, R. L., W. F. McDonough, and R. J. O'Connell, Thermal structure, thickness and composition of continental lithosphere, in Geochemical Earth Reference Model (GERM), edited by F. Albarede et al., Chem. Geol., 145, 395-4l1, 1998.

Ryan, C. G., W. L. Griffin, and N. J. Pearson, Garnet geotherms: Pressure-temperature data from $\mathrm{Cr}$-pyrope garnet $\mathrm{xc}$ nocrysts in volcanic rocks, J. Geophys. Res., 101, 5611$5625,1996$.

Schulze, D. J., Constraints on the abundance of eclogite in the upper mantle, J. Geophys. Res., 94, 4205-4212, 1989. 
Smith, C. B., T. C. Clark, E. S. Barton, and J. W. Bristow, Emplacement ages of kimberlite occurrences in the Pricska region, southwest border of the Kaapvaal Craton, South Africa, Chem. Geol, 113, 149-169, 1994.

Su, W.-J., R. L. Woodward, and A. M. Dziewonski, Degree 12 model of shear velocity heterogeneity in the mantle, J. Geophys. Res., 99, 6945-6980, 1994. van der Hilst, R., S. Widiyantoro, and R. Engdahl, Evidence for deep mantle circulation from global tomography, Nature, 386, 578-584, 1997.

Witt-Eickschen, G., and $\mathrm{H}$. A. Seck, Solubility of $\mathrm{Ca}$ and $\mathrm{Al}$ in orthopyroxene from spinel peridotite: An improved version of an empirical geothermometer, Contrib. Mineral. Petrol., $106,431-439,1991$. 